\title{
In vitro toxicogenomics : unravelling the mechanisms underlying drug-induced hepatotoxicity
}

Citation for published version (APA):

van den Hof, W. F. P. M. (2014). In vitro toxicogenomics : unravelling the mechanisms underlying druginduced hepatotoxicity. [Doctoral Thesis, Maastricht University]. Maastricht University. https://doi.org/10.26481/dis.20141119wh

Document status and date:

Published: 01/01/2014

DOI:

10.26481/dis.20141119wh

Document Version:

Publisher's PDF, also known as Version of record

\section{Please check the document version of this publication:}

- A submitted manuscript is the version of the article upon submission and before peer-review. There can be important differences between the submitted version and the official published version of record.

People interested in the research are advised to contact the author for the final version of the publication, or visit the DOI to the publisher's website.

- The final author version and the galley proof are versions of the publication after peer review.

- The final published version features the final layout of the paper including the volume, issue and page numbers.

Link to publication

\footnotetext{
General rights rights.

- You may freely distribute the URL identifying the publication in the public portal. please follow below link for the End User Agreement:

www.umlib.nl/taverne-license

Take down policy

If you believe that this document breaches copyright please contact us at:

repository@maastrichtuniversity.nl

providing details and we will investigate your claim.
}

Copyright and moral rights for the publications made accessible in the public portal are retained by the authors and/or other copyright owners and it is a condition of accessing publications that users recognise and abide by the legal requirements associated with these

- Users may download and print one copy of any publication from the public portal for the purpose of private study or research.

- You may not further distribute the material or use it for any profit-making activity or commercial gain

If the publication is distributed under the terms of Article $25 \mathrm{fa}$ of the Dutch Copyright Act, indicated by the "Taverne" license above, 


\section{IN VitRo TOXICOGENOMICS}

UNRAVELLING THE MECHANISMS

UNDERLYING DRUG-INDUCED HEPATOTOXICITY

\section{PROEFSCHRIFT}

Ter verkrijging van de graad docto

aan de Universiteit Maastricht,

op gezag van Rector Magnificus, prof. dr. L.L.G. Soete,

volgens het besluit van het College van Decanen

in het openbaar te verdedigen

op woensdag 19 November 2014 om 12:00 uur

door

Wilhelmus Franciscus Petrus Maria Van den Hof

Geboren te Heerlen op 21 September 1984

\section{() W.F.P.M. Van den Hof, Maastricht 2014}

ISBN 978-90-8891-996-1

\section{Cover design and layout}

Pieter Van den Hof, VandenHof\&Soons, Schin op Geul, The Netherlands

\section{Printed by}

Proefschriftmaken.nl || Uitgeverij BOXPress 


\section{Promotor}

Prof. dr. J.C.S. Kleinjans

\section{Copromotor}

\section{Dr.W.K.W.H. Wodzig}

\section{Beoordelingscommissie}

Prof. dr. E.C.M. Mariman (voorzitter)

Prof. dr. G.T.J. van der Horst (Erasmus MC)

Prof. dr. H. van Loveren

Dr. S.W.M. Olde Damink

Prof. dr. B. van de Water (Universiteit Leiden)

\section{Contents}

Chapter 1 General introduction

Chapter 2 Classification of hepatotoxicants using HepG2 cells A proof of principle study

Chapter 3 Validation of gene expression profiles from cholestatic hepatotoxicants in vitro against human in vivo cholestasis

Chapter 4 Integrating multiple omics to unravel mechanisms of cyclosporine A induced hepatotoxicity in vitro

Chapter 5 Integrative analysis of multiple omics in primary mouse hepatocytes to unravel mechanisms of cyclosporin A induced hepatotoxicity

Chapter 6 MicroRNA involvement in drug-induced hepatotoxicity: A multi-omics approach

Chapter 7 Summary and general discussion

Chapter 8 Nederlandse samenvatting

Valorisation

Curriculum Vitae

List of publications

Dankwoord 
Chapter 1

GENGRA2

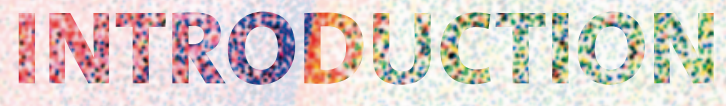




\section{Drug-induced hepatotoxicity}

Drug development is a time-, and money-consuming business; it may take several years and up to US $\$ 800$ million before a single new drug is approved and released onto the market. Before a new compound can enter the market, it is extensively tested in preclinical and clinical trials. Preclinical testing mostly consists of long-term animal treatments. When no adverse effects are seen in laboratory animals, the compounds advance towards clinical human trials, which proceed through three phases. In the first phase, safe dosages, kinetics and toxicity of the compound are assessed in a small number of volunteers. The second phase is conducted in a larger number of people, who are diagnosed with the targeted disease. In this phase, the safety and efficacy is tested. In the last phase, the efficacy is further tested and patients are monitored for side-effects. Overall, on average $20 \%$ of all new drugs tested in clinical trials are successful after phase III and are approved for marketing. ${ }^{2}$

In a review of causes for project termination during clinical trials, toxicity is the second most indicated reason after lack of efficacy. ${ }^{3}$ In approximately one third of these cases, hepatotoxicity is indicated as cause for project termination, rating drug-induced hepatotoxicity one of the major reasons for drug withdrawal. ${ }^{4-6}$ The liver metabolizes and excretes drugs, making it vulnerable for adverse drug effects. Accumulation of drugs or the formation of toxic drug metabolites by hepatic enzymes can induce liver injury. Only a low percentage of drug-induced liver injuries is predictable and dose-dependent. Most druginduced liver injuries occur infrequently and are considered to be idiosyncratic. Idiosyncratic drug-induced liver injury occurs at an incidence level of 1 in every 1000 to 1 in every 100,000 patients receiving therapeutic doses, which is another reason why these adverse drug reactions are often missed during clinical trials. ${ }^{5}$ Different classes of drug-induced liver injury are considered, including necrosis, steatosis, cholestasis, inflammation or a combination of these.

Necrosis has been defined as an uncontrolled form of cell death in comparison to programmed cell death, named apoptosis. However, increasing evidence indicates that programmed cell death can occur with non-apoptotic features and that necrosis may be regulated by signal transduction pathways and catabolic mechanisms. ${ }^{7}$ Necrosis is usually involved in acute drug-induced hepatotoxicity and is characterized by cellular and organelles swelling and rupture of the plasma membrane. ${ }^{8}$

Steatosis is characterized by the intracellular formation of lipid droplets in the cytoplasm, which is believed to be the result of inhibition of ß-oxidation of fatty acids or inhibited secretion of fatty acids by very-low-density-lipoprotein particles. ${ }^{\circ}$

Cholestasis is one of the most severe manifestations of drug-induced liver injury because of a high mortality rate and may account for $16 \%$ or up to $50 \%$ of all cases of drug-induced hepatotoxicity ${ }^{10}$ Cholestasis is characterized by the intracellular accumulation of substance normally excreted via the bile, such as bile acids, cholesterol, bilirubin, and drug metabolites. This intracellular accumulation may be the result of drug-induced inhibition of transport proteins. One of the most important transport proteins for bile acids is the bile salt export pump (BSEP). Several cholestasis inducing drugs were shown to inhibit the function of the 
Stem cells

When using primary hepatocytes, one depends on donors and even though cells can be frozen and used later, the number of cells is limited. Another option for generating hepatocytes may be the use of stem cells. In this relatively new field, two models are mostly investigated, namely embryonic stem cells and induced pluripotent stem cells. Metabolic active hepatocyte-like cells can be produced using both models. ${ }^{6-27}$ However, different differentiation protocols result in major differences between the hepatocyte-like cells and the final culture will contain stem cells next to differentiated liver cells. Furthermore, the use of embryonic stem cells is subject to an ethical debate. Moreover, the metabolic functionality of the hepatocyte-like cells will decrease over time, comparable to cultures of primary hepatocytes. ${ }^{28}$ Optimization of differentiation protocols may further improve the functionality of hepatocyte-like cells produced from stem cells, which may lead to the use of these cells in high-throughput toxicity screenings.

\section{Immortalized cell lines}

The human hepatocellular carcinoma cell line $\mathrm{HepG}_{2}$ and the commercially available HepaRC cell model are thought to present acceptable alternatives, since both represent a human cell model and are easy and cheap to culture. Research has shown that HepG 2 cells show less metabolization of compounds compared to $\mathrm{PHH}$, in association with low levels of specific enzymes involved in phase I and II metabolism. ${ }^{29-30}$ However, several studies demonstrated

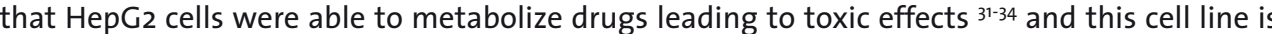
still used in many toxicological studies. ${ }^{35-46}$ Furthermore, HepG 2 cells and PHH showed similarly modulated gene sets after treatment with a toxic compound, suggesting similar drug-induced effects between these two cell types. ${ }^{47}$ HepaRG cells show higher baseline levels of phase and phase II enzymes in comparison to HepG 2 cells; however, when exposed to toxicants, the responses of both cell lines are comparable. ${ }^{48-49}$

\section{Primary hepatocytes from rodents}

Since animal-based toxicity screenings are most often performed with rodents, it is suggested that primary hepatocytes from rodents present a relevant alternative in vitro liver model. Primary hepatocytes from rodents cultured in a collagen sandwich configuration have the same advantages as $\mathrm{PHH}$, including good metabolic competence. Furthermore, primary hepatocytes from rodents are easily available, have a low interindividual variation and knockout models can be used to investigate specific genotypes and mechanisms. Mathijs et al. showed that primary mouse hepatocytes (PMH) are metabolic more stable than primary rat hepatocytes and maintain their metabolic competence for up to go hours, making PMH more useful as an in vitro liver model. ${ }^{50}$ Toxicity screening using PMH facilitates the screening of multiple compounds using one single mouse, resulting in reduced numbers of laboratory animals needed for these screenings. However, extrapolating mouse in vitro results to human in vivo mechanisms might be complicated and should be done with care. is bound to limitations. Fresh human liver samples are not always available and culturing procedures are laborious. Furthermore, the use of $\mathrm{PHH}$ is costly and comparing multiple experiments is difficult due to inter-individual differences between liver donors. ${ }^{25}$ 
Table 1. Advantages and disadvantages of in vitro liver models.

Model

Advantages

Three dimensional structure

All liver cell types

Maintain hepatocyte-specific functions Comparable to in vivo liver

Unlimited production of hepatocytes

Expression of phase I

and phase Il enzymes

Easy and cheap to culture Human cell model

Easy available and low variability

Primary hepatocytes

from rodents
Disadvantages

Preparation and

culturing laborious

Only short term exposures

Interindividual differences

Low availability

\section{Many protocols results}

in differences in cells

Cultures contain mix of

stem cells and hepatocytes

Embryonic stem cells:

ethical debate

\section{Lower expression of phase I}

and phase ll enzymes

Hepatocytes from rodents

and phase II enzymes

\section{Toxicogenomics}

Traditionally, drug-induced liver injury in preclinical studies and clinical trials is assessed using several parameters, e.g. clinical chemistry and pathology. ${ }^{51}$ However, identification of hepatotoxicity relies on the integration of all study data and a correct interpretation. ${ }_{52}$ Traditional biomarkers for in vivo liver injury are alanine aminotransferase, aspartate aminotransferase, alkaline phosphatase, $\gamma$-glutamyltransferase, bilirubin, ammonia and prolonged prothrombin time. Although these biomarkers can give valuable information about liver damage, their specificity and sensitivity are far from ideal and differentiation between different liver injury phenotypes is difficult. 53-54 Furthermore, these traditional parameter mostly reflect late responses and endpoints when irreversible cell damage has already occurred. Moreover, traditional biomarkers may not be sensitive enough to detect cell damage in vitro due to the low number of cells used in in vitro models. Drug-induced toxicity is the result of altered biological processes by a compound or its metabolites, resulting in adverse effects. Therefore, the investigation of drug-induced alteration of biological processes will further improve the identification of hepatotoxic compounds. For this, toxicogenomics which refers to the combination of toxicology with genomics, involving transcriptomics, proteomics, and metabonomics, is considered promising. ${ }^{55}$

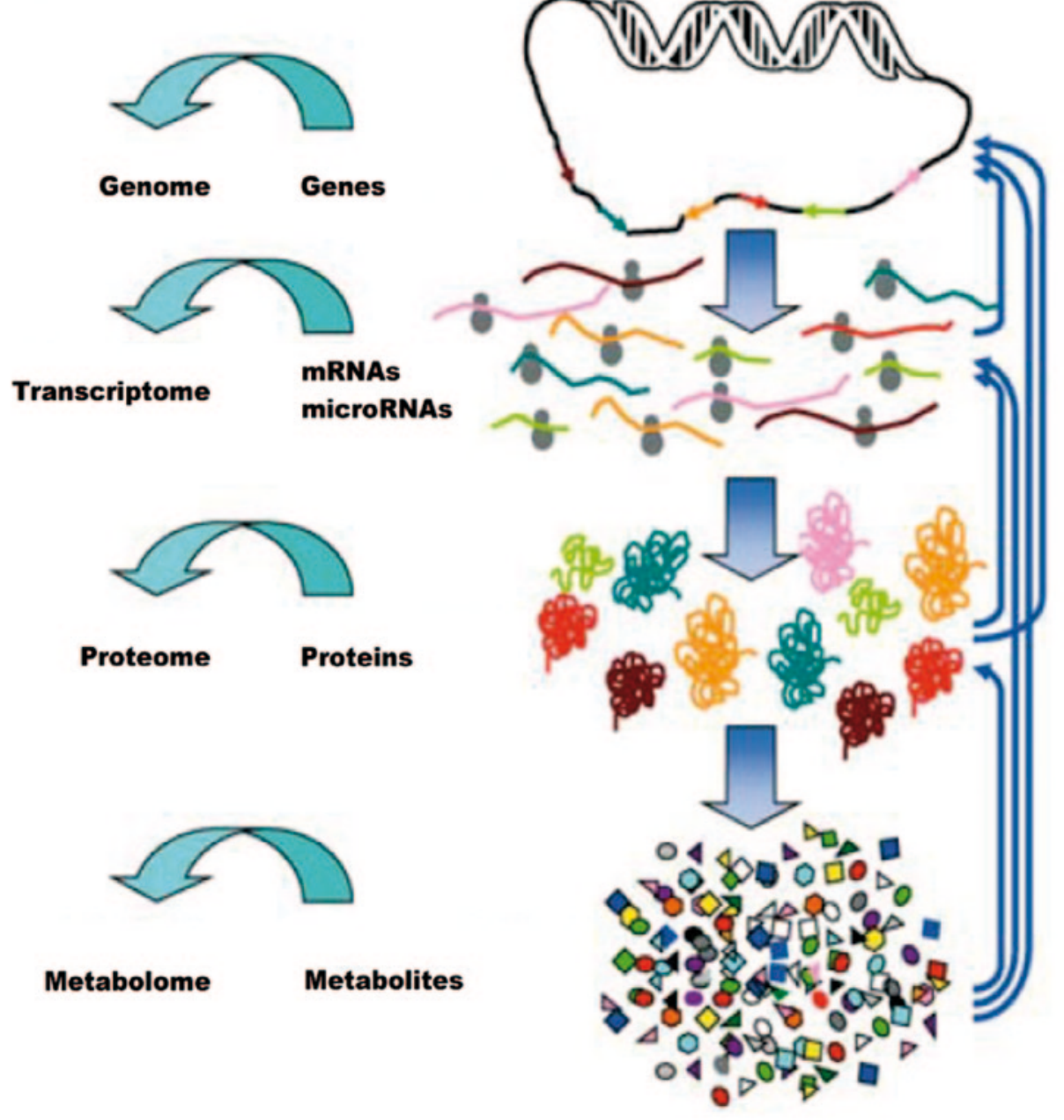

Figure 1. In Toxicogenomics, toxicology is combined with genomics, transcriptomics, proteomics and metabolomics. Since all these molecules interact with each other, it is believed that integrated data analysis of all omics platforms is needed to fully elucidate the mechanisms underlying drug-induced liver injury. Figure is adapted from Goodacre. 56

\section{Transcriptomics}

Transcriptomics is defined as the profiling of DNA transcripts or RNA molecules. Profiling of messenger RNA (mRNA) levels also known as gene expression profiling, is most common. Gene expression profiling using microarrays is still the most used technological platform in toxicogenomic research. ${ }^{57} \mathrm{It}$ is a robust technique ${ }^{58}$ and has frequently been used to investigate drug-induced liver toxicity. ${ }^{59-61}$ Transcriptomic research is still expanding and also includes 
profiling of other RNA molecules, such as microRNAs. MicroRNAs can regulate mRNA levels and mRNA translation to proteins and therefore may play an important role in cellular mechanisms, including drug-induced toxicity. ${ }^{62}$ The recent introduction and advances of next generation sequencing of RNA molecules has the potential to further improve the transcriptomic field, where sequencing can lead to the discovery of new transcripts involved in drug-induced toxicity. ${ }^{63}$

Proteomics

Transcriptomic profiles can give an indication of protein expression; however, true protein levels as well as post-translational modifications need to be measured by means of proteomic technologies. Proteomics is applied to toxicology and has been proposed as technique to give valuable information about the mode of action of compounds and to discover biomarkers of drug-induced hepatotoxicity. ${ }^{64-65} \mathrm{In}$ order to find new biomarkers using untargeted analysis of drug-induced changes on protein expression, cellular proteins need to be separated, quantified and identified, which can be done using multiple techniques (e.g. Liquid Chromatography coupled to (Tandem) Mass Spectrometry or Difference Gel Electrophoresis). ${ }^{66}$ Targeted proteomics can be used to validate potential biomarkers or investigate a specific subset of proteins. ${ }^{67}$

\section{Metabonomics}

Metabonomics is defined as 'the quantitative measurement of the time-related multiparametric metabolic response of living systems to pathophysiological stimuli or genetic modification' 68 and is applied to toxicology to investigate drug-induced metabolite changes. Metabonomics has to potential to be used in high-throughput toxicity screening, identification of biomarkers of toxicity and further elucidation of mechanisms of action. ${ }^{69}$ Mass spectrometry and Nuclear Magnetic Resonance spectroscopy are the most applied techniques in targeted and untargeted metabonomics and each technique has its own advantages and disadvantages. $7^{\circ}$

Integrative analyses

Although every omic technology individually provides valuable information about drug induced changes, it is believed that their true value lies within an integrative analyses of multiple omics, ultimately evolving into a complete systems biology approach. ${ }^{51,71}$ Several publications showed that integrative analyses of multiple omics data of in vivo drug-induced liver injury in rodents resulted in a better understanding of the underlying mechanisms. ${ }^{22-74}$ Analysis of transcriptomics and metabonomics data in HepG2 experiments confirmed the added value of integration in vitro. 75 Overall, integrated data analysis has the potential to fully elucidate mechanisms underlying drug-induced hepatotoxicity and improve the preclinical screening of new drugs.

\section{Model compounds}

In order to further elucidate mechanisms underlying specific hepatotoxic phenotypes, the use of prototypical drugs that induce these phenotypes in vivo is essential. Model compound known to induce necrosis, steatosis or cholestasis in humans and negative controls were selected based on information from the National Toxicology Program (http://ntp.niehs.nih gov/) and literature. ${ }^{6-77}$ To introduce these prototypical drugs, we will describe a number of hepatotoxicants.

\section{Necrosis-inducing compounds}

Acetaminophen

Acetaminophen (APAP) is an over-the-counter available non-steroidal anti-inflammatory drug (NSAID) and analgesic which is not toxic at a therapeutic dose. However, at high doses APAP can induce sever liver damage and APAP overdose is one of the most common causes of acute liver failure in the US and Europe. ${ }^{78-79}$ The mechanism underlying APAP-induced necrosis is thought to be the result of glutathione depletion by reactive metabolites formed in the metabolism of APAP by CYP enzymes. Depleted glutathione levels lead to increased oxidative stress, which results in ATP loss and eventually necrosis. ${ }^{80}$

Diclofenac

Diclofenac (DIC) is an analgesic and NSAID frequently prescribed for the treatment of rheumatoid disorders and known to induce hepatic necrosis. Although mechanisms underlying DIC-induced liver injury are not fully understood, reactive metabolites, oxidative stress and mitochondrial failure are thought to be involved. ${ }^{81}$

Isoniazid

soniazid (ISO) is used in the prevention and treatment of tuberculosis and is metabolized in the liver. The metabolite hydrazine is believed to be responsible for the ISO-induced hepatic necrosis. ${ }^{82}$

Paraquat

Paraquat (PAO) is a widely used herbicide and high dose and prolonged exposure can induce hepatic necrosis is humans and rodents. ${ }^{83-84}$ Liver injury is believed to be the result of oxidative stress by free radical formation and glutathione depletion. ${ }^{85}$

\section{Steatosis-inducing compounds}

\section{Amiodarone}

Amiodarone (AM) is an antiarrhythmic drug effective in several cardiac tachyarrhythmias's and thus regularly prescribed. AM accumulates in fat tissue and due to the high fat content of the liver, this is one of the prominent organs where AM accumulates and induces steatosis which may evolve in liver cirrhosis. ${ }^{86}$

Tetracycline

Tetracycline (TET) is an antibacterial drug which by itself or through one of its metabolites inhibits mitochondrial fatty acid oxidation resulting in microvesicular steatosis. ${ }^{8}$ 
The HepG2 cell model is frequently used in hepatotoxicity studies, is easy to culture and has previously been used to predict the genotoxic properties of compounds based on the omics approach. Therefore, transcriptomic profiling of HepG2 cells exposed to hepatotoxic and nonhepatotoxic compounds was used to predict hepatotoxic potential of compounds, which is described in Chapter 2.

Where the metabolic capacity of primary mouse hepatocytes is better than the metabolic capacity of HepG2 cells, Chapter 3 compares gene expression analyses of three cholestatic compounds in HepGz cells and primary mouse hepatocytes to further unravel the mechanisms underlying drug-induced cholestasis in two in vitro liver cell models.

In Chapter 4 transcriptomic and metabonomic analyses of HepG2 cells exposed to the cholestatic compound cyclosporin A were integrated to investigate the added value of multiomics analysis.

In Chapter 5, we exposed primary mouse hepatocytes to cyclosporin A and used an integrated transcriptomics, proteomics and metabonomics approach to further unravel the mechanism underlying cyclosporin A induced hepatotoxicity.

The three hepatotoxic phenotypes necrosis, steatosis and cholestasis were further investigated using integrated multi-omics analyses in order to elucidate different and comparable mechanisms induced by drugs. Two in vitro cell models, HepG2 cells and primary mouse hepatocytes, were exposed to three prototypic drugs and transcriptomic and proteomic results were integrated as described in Chapter 6.

Finally, the work presented in the previous chapters is summarized in Chapter 7 and the results are discussed in view of previous work and future research directions are suggested.

Drug discovery and development are time-consuming and expensive processes, which involve the design and production of the drug and its testing for efficacy and safety in pre-clinical research and in subsequent clinical trials. Drug-induced hepatotoxicity appears one of the most indicated reasons for drug withdrawal during clinical trials or even after admittance onto the market. Discovery of hepatotoxic potential of new drugs at an early time point may therefore save considerable time and resources. Animal toxicity testing based upon traditional endpoints remains to be the standard in pre-clinical toxicity testing, in despite of large number of drug missed as hepatotoxic. Relatively new technologies such as transcriptomics, proteomics and metabolomics providing a large amount of new endpoints are expected to generate better predictors for human toxicity and are being used more and more in preclinical safety research. This PhD project is based on the hypothesis that the combination of transcriptomics, proteomics and metabonomics in an integrative in vitro toxicogenomics approach will improve the knowledge of mechanisms underlying drug-induced hepatotoxicity. This may lead to better in vitro hepatotoxicity prediction and classification of hepatotoxicants. 


\section{References}

1. DiMasi, J. A., Hansen, R. W., Grabowski, H. G. (2003) The price of innovation: new estimates of drug development costs. Journal of Health Economics 22, 151-185.

2. Bradbard, L., From Test Tube to Patient: Improving Health Through Human Drugs. Diane Publishing Company: 1999

3. Schuster, D., Laggner, C., Langer, T. (2005) Why drugs fail--a study on side effects in new chemical entities. Curr. Pharm. Design 11, 3545-3559.

4. Russmann, S., Kullak-Ublick, G.A., Grattagliano, I. (2009) Current concepts of mechanisms in drug-induced hepatotoxicity. Curr. Med. Chem. 16, 3041-3053.

5. Lee, W. M. (2003) Drug-Induced Hepatotoxicity. N Engl J Med 349, 474-485.

6. MacDonald, J. S., Robertson, R. T. (2009) Toxicity Testing in the 21st Century: A View from the Pharmaceutical Industry. Toxicol. Sci. 110, 40-46

7. Kroemer, G., Galluzzi, L., Vandenabeele, P., Abrams, J., Alnemri, E. S., Baehrecke, E. H., Blagosklonny, M. V., El-Deiry, W. S., Golstein, P., Green, D. R., Hengartner, M., Knight, R. A., Kumar, S., Lipton, S. A., Malorni, W., Nunez, G., Peter, M. E. Tschopp, J., Yuan, J., Piacentini, M., Zhivotovsky, B., Melino, G. (2008) Classification of cell death: recommendations of the Nomenclature Committee on Cell Death 2009. Cell Death Differ 16, 3-11.

8. Malhi, H., Gores, G. J., Lemasters, J. J. (2006) Apoptosis and necrosis in the liver: A tale of two deaths? Hepatology 43 S31-S44.

9. Labbe, G., Dominique, P., Bernard, F. (2008) Drug-induced liver injury through mitochondrial dysfunction: mechanism and detection during preclinical safety studies. Fundamental \& Clinical Pharmacology 22, 335-353.

10. Björnsson, E., Olsson, R. (2005) Outcome and prognostic markers in severe drug-induced liver disease. Hepatology 42 481-489.

11. Byrne, J. A., Strautnieks, S. S., Mieli-Vergani, G., Higgins, C. F., Linton, K. J., Thompson, R. J. (2002) The human bile salt export pump: Characterization of substrate specificity and identification of inhibitors. Gastroenterology 123, 1649-1658.

12. Vinken, M., Landesmann, B., Goumenou, M., Vinken, S., Shah, I., Jaeschke, H., Willett, C., Whelan, M., Rogiers, V. (2013) Development of an Adverse Outcome Pathway From Drug-Mediated Bile Salt Export Pump Inhibition to Cholestatic Liver Injury. Toxicol. Sci.

13. Adams, D. H., Ju, C., Ramaiah, S. K., Uetrecht, J., Jaeschke, H. (2010) Mechanisms of Immune-Mediated Liver Injury. Toxicol. Sci. 115, 307-321.

14. Olson, H., Betton, G., Robinson, D., Thomas, K., Monro, A., Kolaja, G., Lilly, P., Sanders, J., Sipes, G., Bracken, W., Dorato, M. Van Deun, K., Smith, P., Berger, B., Heller, A. (2000) Concordance of the Toxicity of Pharmaceuticals in Humans and in Animals. Regul. Toxicol. Pharm. 32, 56-67.

15. Shanks, N., Greek, R., Greek, J. (2009) Are animal models predictive for humans? Philos. Ethics Humanit. Med. 4, 1-20.

16. Lerche-Langrand, C., Toutain, H. J. (2000) Precision-cut liver slices: characteristics and use for in vitro pharmacotoxicology. Toxicology 153, 221-253

17. Boess, F., Kamber, M., Romer, S., Gasser, R., Muller, D., Albertini, S., Suter, L. (2003) Gene Expression in Two Hepatic Cell Lines, Cultured Primary Hepatocytes, and Liver Slices Compared to the in Vivo Liver Gene Expression in Rats: Possible Implications for Toxicogenomics Use of in Vitro Systems. Toxicol. Sci. 73, 386-402.

18. Olinga, P., Groen, K., Hof, I. H., De Kanter, R., Koster, H. J, Leeman, W. R., Rutten, A. A. J.J.L., Van Twillert, K., Groothuis, G. M. M. (1997) Comparison of five incubation systems for rat liver slices using functional and viability parameters. Journal of Pharmacological and Toxicological Methods 38, 59-69.

19. Wright, M. C., Paine, A. J. (1992) Evidence that the loss of rat liver cytochrome P450 in vitro is not solely associated with the use of collagenase, the loss of cell-cell contacts and/or the absence of an extracellular matrix. Biochem. Pharmacol. $43,237-243$

20. Soldatow, V. Y., Lecluyse, E. L., Griffith, L. G., Rusyn, I. (2013) In vitro models for liver toxicity testing. Toxicol Res (Camb) 2 , 23-39.

21. Hewitt, N. J., Gómez Lechón, M. J., Houston, J. B., Hallifax, D., Brown, H. S., Maurel, P., Kenna, J. G., Gustavsson, L Lohmann, C., Skonberg, C., Guillouzo, A., Tuschl, G., Li, A. P., LeCluyse, E., Groothuis, G. M. M., Hengstler, J. G. (2007) Primary Hepatocytes: Current Understanding of the Regulation of Metabolic Enzymes and Transporter Proteins, and Pharmaceutical Practice for the Use of Hepatocytes in Metabolism, Enzyme Induction, Transporter, Clearance, and Hepatotoxicity Studies. Drug Metab. Rev. 39, 159-234.

22. Gomez-Lechon, M. J., Donato, M. T., Castell, J. V., Jover, R. (2004) Human hepatocytes in primary culture: the choice to investigate drug metabolism in man. Curr Drug Metab 5, 443-462.

23. Olsavsky, K. M., Page, J. L., Johnson, M. C., Zarbl, H., Strom, S. C., Omiecinski, C. J. (2007) Gene expression profiling an differentiation assessment in primary human hepatocyte cultures, established hepatoma cell lines, and human liver tissues. Toxicol Appl Pharmacol 222, 42-56.

24. Ponsoda, X., Donato, M. T., Perez-Cataldo, G., Gomez-Lechon, M. J., Castell, J. V. (2004) Drug metabolism by cultured human hepatocytes: how far are we from the in vivo reality? Altern Lab Anim 32, 101-110.

25. Madan, A., Graham, R. A., Carroll, K. M., Mudra, D. R., Burton, L. A., Krueger, L. A., Downey, A. D., Czerwinski, M. Forste, J., Ribadeneira, M. D., Gan, L.-S., LeCluyse, E. L., Zech, K., Robertson, P., Koch, P., Antonian, L., Wagner, G., Yu, L., Parkinson, A. (2003) Effects of Prototypical Microsomal Enzyme Inducers on Cytochrome P450 Expression in Cultured Human Hepatocytes. Drug Metab. Dispos. 31, 421-431.

26. Roelandt, P., Vanhove, J., Verfaillie, C.. Directed Differentiation of Pluripotent Stem Cells to Functional Hepatocytes. In Pluripotent Stem Cells, Lakshmipathy, U.; Vemuri, M. C., Eds. Humana Press: 2013; Vol. 997, pp 141-147.

27. Cai, J., Zhao, Y., Liu, Y., Ye, F., Song, Z., Q Qin, H., Meng, S., Chen, Y., Zhou, R., Song, X., Guo, Y., Ding, M., Deng, H. (2007) Directed differentiation of human embryonic stem cells into functional hepatic cells. Hepatology 45, 1229-1239.

28. Ulvestad, M., Nordell, P., Asplund, A., Rehnström, M., Jacobsson, S., Holmgren, G., Davidson, L., Brolén, G., Edsbagge, J. Björquist, P., Küppers-Munther, B., Andersson, T. B. (2013) Drug metabolizing enzyme and transporter protein profiles of hepatocytes derived from human embryonic and induced pluripotent stem cells. Biochem. Pharmacol. 86, 691-702.

29. Westerink, W. M. A., Schoonen, W. G. E. J. (2007) Cytochrome P450 enzyme levels in HepG2 cells and cryopreserved primary human hepatocytes and their induction in HepG2 cells. Toxicol. In Vitro 21, 1581-1591.

30. Westerink, W. M. A., Schoonen, W. G. E.J. (2007) Phase Il enzyme levels in HepG2 cells and cryopreserved primary human hepatocytes and their induction in HepGz cells. Toxicol. In Vitro 21, 1592-1602.

31. Hewitt, N. J., Hewitt, P. (2004) Phase I and II enzyme characterization of two sources of HepG2 cell lines. Xenobiotica 34 243-256.

32. Knasmüller, S., Mersch-Sundermann, V., Kevekordes, S., Darroudi, F., Huber, W. W., Hoelzl, C., Bichler, J., Majer, B. J. (2004) Use of human-derived liver cell lines for the detection of environmental and dietary genotoxicants; current state of knowledge. Toxicology 198, 315-328.

33. O'Brien, P., Haskins, J., In Vitro Cytotoxicity Assessment. In High Content Screening, Taylor, D. L.; Haskins, J.; Giuliano, K. Eds. Humana Press: 2006; Vol. 356, pp 415-425.

34. Schoonen, W. G. E. J., Westerink, W. M. A., Horbach, G. J., High-throughput screening for analysis of in vitro toxicity. In Molecular, Clinical and Environmental Toxicology, Luch, A., Ed. Birkhäuser Basel: 2009; Vol. 99, pp 401-452.

35. Dias da Silva, D., Carmo, H., Lynch, A., Silva, E. (2013) An insight into the hepatocellular death induced by amphetamines, 
individually and in combination: the involvement of necrosis and apoptosis. Arch. Toxicol., 1-21.

36. Schoonen, W. G. E. J., Westerink, W. M. A., de Roos, J. A. D. M., Débiton, E. (2005) Cytotoxic effects of 100 reference compounds on Hep $\mathrm{G}_{2}$ and HeLa cells and of 60 compounds on ECC-1 and $\mathrm{CHO}$ cells. I Mechanistic assays on ROS, glutathione depletion and calcein uptake. Toxicol. In Vitro 19, 505-516.

37. Menezes, C., Alverca, E., Dias, E., Sam-Bento, F., Pereira, P. (2013) Involvement of endoplasmic reticulum and autophagy in microcystin-LR toxicity in Vero-E6 and HepG2 cell lines. Toxicol. In Vitro 27, 138-148.

38. Sahu, S. C., O'Donnell, M. W., Sprando, R. L. (2012) Interactive toxicity of usnic acid and lipopolysaccharides in human liver HepG2 cells. J. Appl. Toxicol. 32, 739-749.

9. O'Brien, P., Irwin, W., Diaz, D., Howard-Cofield, E., Krejsa, C., Slaughter, M., Gao, B., Kaludercic, N., Angeline, A., Bernard, P., Brain, P., Hougham, C. (2006) High concordance of drug-induced human hepatotoxicity with in vitro cytotoxicity measured in a novel cell-based model using high content screening. Arch. Toxicol. 80, 580-604.

40. Burczynski, M. E., McMillian, M., Ciervo, J., Li, L., Parker, J. B., Dunn, R. T., Hicken, S., Farr, S., Johnson, M. D. (2000) Toxicogenomics-Based Discrimination of Toxic Mechanism in HepG2 Human Hepatoma Cells. Toxicol. Sci. 58, 399-415.

41. Choi, S., Park, S.-Y., Jeong, J., Cho, E., Phark, S., Lee, M., Kwak, D., Lim, J.-Y., Jung, W.-W., Sul, D. (2010) Identification of toxicological biomarkers of di(2-ethylhexyl) phthalate in proteins secreted by HepG2 cells using proteomic analysis. Proteomics 10, 1831-1846.

42. Cosgrove, B. D., King, B. M., Hasan, M. A., Alexopoulos, L. G., Farazi, P. A., Hendriks, B. S., Griffith, L. G., Sorger, P. K., Tidor, B, $\mathrm{Xu}$, J. J., Lauffenburger, D. A. (2009) Synergistic drug-cytokine induction of hepatocellular death as an in vitro approach for the study of inflammation-associated idiosyncratic drug hepatotoxicity. Toxicol. Appl. Pharm. 237, 317-330.

43. Hockley, S. L., Mathijs, K., Staal, Y. C., Brewer, D., Giddings, I., van Delft, J. H., Phillips, D. H. (2009) Interlaboratory and interplatform comparison of microarray gene expression analysis of $\mathrm{HepG}_{2}$ cells exposed to benzo(a)pyrene. OMICS 13 , $115-125$

44. Hong, Y., Müller, U. R., Lai, F. (2003) Discriminating two classes of toxicants through expression analysis of HepG2 cells with DNA arrays. Toxicol. In Vitro 17, 85-92.

45. van Delft, J. H. M., van Agen, E., van Breda, S. G. J., Herwijnen, M. H., Staal, Y. C. M., Kleinjans, J. C. S. (2004) Discrimination of genotoxic from non-genotoxic carcinogens by gene expression profiling. Carcinogenesis 25, 1265-1276.

46. Westerink, W. M. A., Stevenson, J. C. R., Horbach, G. J., Schoonen, W. G. E. J. (2010) The development of RAD51C, Cystatin A, p53 and Nrfz luciferase-reporter assays in metabolically competent $\mathrm{HepG}_{2}$ cells for the assessment of mechanismbased genotoxicity and of oxidative stress in the early research phase of drug development. Mutat. Res.-Gen. Tox. En $696,21-40$.

47. Liguori, M. J., Blomme, E. A. G., Waring, J. F. (2008) Trovafloxacin-Induced Gene Expression Changes in Liver-Derived in Vitro Systems: Comparison of Primary Human Hepatocytes to HepG2 Cells. Drug Metab. Dispos. 36, 223-233.

48. Gerets, H., Tilmant, K., Gerin, B., Chanteux, H., Depelchin, B., Dhalluin, S., Atienzar, F. (2012) Characterization of primary human hepatocytes, HepG2 cells, and HepaRG cells at the mRNA level and CYP activity in response to inducers and their predictivity for the detection of human hepatotoxins. Cell Biol. Toxicol. 28, 69-87.

49. Jetten, M. J. A., Kleinjans, J. C. S., Claessen, S. M., Chesné, C., van Delft, J. H. M. (2013) Baseline and genotoxic compound induced gene expression profiles in HepG2 and HepaRG compared to primary human hepatocytes. Toxicol. In Vitro.

50. Mathijs, K., Kienhuis, A. S., Brauers, K. J. J., Jennen, D. G. J., Lahoz, A., Kleinjans, J. C. S., van Delft, J. H. M. (2009) Assessing the Metabolic Competence of Sandwich-Cultured Mouse Primary Hepatocytes. Drug Metab. Dispos. 37, 1305-1311.

51. Heijne, W. H. M., Kienhuis, A. S., van Ommen, B., Stierum, R. H., Groten, J. P. (2005) Systems toxicology: applications of toxicogenomics, transcriptomics, proteomics and metabolomics in toxicology. Expert Review of Proteomics 2, 767-780.
52. Boone, L., Meyer, D., Cusick, P., Ennulat, D., Bolliger, A. P., Everds, N., Meador, V., Elliott, G., Honor, D., Bounous, D., Jordan, H. (2005) Selection and interpretation of clinical pathology indicators of hepatic injury in preclinical studies. Vet Clin Pathol 34, 182-188.

53. Dufour, D. R., Lott, J. A., Nolte, F. S., Gretch, D. R., Koff, R. S., Seeff, L. B. (2000) Diagnosis and Monitoring of Hepatic Injury. 1. Performance Characteristics of Laboratory Tests. Clinical Chemistry 46, 2027-2049.

54. Dufour, D. R., Lott, J. A., Nolte, F. S., Gretch, D. R., Koff, R. S., Seeff, L. B. (2000) Diagnosis and Monitoring of Hepatic Injury. II. Recommendations for Use of Laboratory Tests in Screening, Diagnosis, and Monitoring. Clinical Chemistry 46, 20502068.

55. Cui, Y., Paules, R. S. (2010) Use of transcriptomics in understanding mechanisms of drug-induced toxicity Pharmacogenomics $11,573-585$

56. Goodacre, R. (2005) Metabolomics - the way forward. Metabolomics 1, 1-2.

57. Chen, M., Zhang, M., Borlak, J., Tong, W. (2012) A Decade of Toxicogenomic Research and Its Contribution to Toxicological Science. Toxicol. Sci.

58. Shi, L., Reid, L. H., Jones, W. D., Shippy, R., Warrington, J. A., Baker, S. C., Collins, P. J, de Longueville, F., Kawasaki, E. S., Lee, K. Y., Luo, Y., Sun, Y. A., Willey, J. C., Setterquist, R. A., Fischer, G. M., Tong, W., Dragan, Y. P., Dix, D. J., Frueh, F. W., Goodsaid, F.M. Herman, D., Jensen, R. V., Johnson, C. D., Lobenhofer, E. K., Puri, R. K., Schrf, U., Thierry-Mieg, J., Wang, C., Wilson, M, Wolber, P. K. Zhang, L., Amur, S., Bao, W. Barbacioru, C. C., Lucas, A. B. Bertholet V. Boysen, C., Bromley, B., Brown, D, Brunner, A., Canales, R., Cao, X. M., Cebula, T. A., Chen, J. J., Cheng, J., Chu, T. M., Chudin, E., Corson, J., Corton, J. C., Croner, L. J., Davies, C., Davison, T. S., Delenstarr, G., Deng, X., Dorris, D., Eklund, A. C., Fan, X. H., Fang, H., Fulmer-Smentek, S., Fuscoe, J. C., Gallagher, K., Ge, W., Guo, L., Guo, X., Hager, J., Haje, P. .., Han, J., Han, T., Harbottle, H. C., Harris, S. C., Hatchwell, E, Hauser, C. A., Hester, S., Hong, H., Hurban, P., Jackson, S. A., Ji, H., Knight, C. R., Kuo, W. P., LeClerc, J. E., Levy, S., Li, O. Z., Liu, C. Liu, Y., Lombardi, M. J., Ma, Y., Magnuson, S. R., Maqsodi, B., McDaniel, T., Mei, N., Myklebost, O., Ning, B., Novoradovskaya N., Orr, M. S., Osborn, T. W., Papallo, A., Patterson, T. A., Perkins, R. G., Peters, E. H., Peterson, R., Philips, K. L., Pine, P. S, Pusztai, L., Oian, F., Ren, H., Rosen, M., Rosenzweig, B. A., Samaha, R. R., Schena, M., Schroth, G. P., Shchegrova, S., Smith, D. D., Staedtler, F., Su, Z., Sun, H., Szallasi, Z., Tezak, Z., Thierry-Mieg, D., Thompson, K. L., Tikhonova, I., Turpaz, Y., Vallanat, B. Van, C., Walker, S. J., Wang, S. J., Wang, Y., Wolfinger, R., Wong, A., Wu, J., Xiao, C., Xie, O., Xu, J., Yang, W., Zhong, S., Zong, Y. Slikker, W., Jr. (2006) The MicroArray Quality Control (MAQC) project shows inter- and intraplatform reproducibility of gene expression measurements. Nat Biotechnol 24, 1151-1161.

59. Nuwaysir, E. F., Bittner, M., Trent, J., Barrett, J. C., Afshari, C. A. (1999) Microarrays and toxicology: The advent of toxicogenomics. Mol. Carcinogen. 24, 153-159.

60. Cheng, F., Theodorescu, D., Schulman, I. G., Lee, J. K. (2011) In vitro transcriptomic prediction of hepatotoxicity for early drug discovery. J. Theor. Biol. 290, 27-36.

61. Guo, L., Lobenhofer, E. K., Wang, C., Shippy, R., Harris, S. C., Zhang, L., Mei, N., Chen, T., Herman, D., Goodsaid, F. M., Hurban, P., Phillips, K. L., Xu, J., Deng, X., Sun, Y. A., Tong, W., Dragan, Y. P., Shi, L. (2006) Rat toxicogenomic study reveals analyticad consistency across microarray platforms. Nat Biotechnol 24, 1162-1169.

62. Lema, C., Cunningham, M. J. (2010) MicroRNAs and their implications in toxicological research. Toxicol. Lett. 198, 100-105. 63. Merrick, B. A., Phadke, D. P., Auerbach, S. S., Mav, D., Stiegelmeyer, S. M., Shah, R. R., Tice, R. R. (2013) RNA-Seq profiling reveals novel hepatic gene expression pattern in aflatoxin B1 treated rats. PLOS ONE 8, e61768

64. Wetmore, B. A., Merrick, B. A. (2004) Invited Review: Toxicoproteomics: Proteomics Applied to Toxicology and Pathology. Toxicol. Pathol. 32, 619-642.

65. Amacher, D. E. (2010) The discovery and development of proteomic safety biomarkers for the detection of drug-induced 
diquat administration. Effect of selenium deficiency. J Clin Invest 65, 1024-1031.

Van Summeren, A. Renes, J, van Delft, J.H. M., Kleinjans, J. C. S., Mariman, E. C. M. (2012) Proteomics in the search for mechanisms and biomarkers of drug-induced hepatotoxicity. Toxicol. In Vitro 26, 373-385.

67. Meng, Z., Veenstra, T. D. (2011) Targeted mass spectrometry approaches for protein biomarker verification. J Proteomics $74,2650-2659$.

68. Nicholson, J. K., Lindon, J. C., Holmes, E. (1999) 'Metabonomics': understanding the metabolic responses of living systems to pathophysiological stimuli via multivariate statistical analysis of biological NMR spectroscopic data. Xenobiotica 29 $1181-1189$.

69. Robertson, D. G. (2005) Metabonomics in Toxicology: A Review. Toxicol. Sci. 85, 809-822.

70. Dunn, W. B., Ellis, D. I. (2005) Metabolomics: Current analytical platforms and methodologies. TrAC Trends in Analytical Chemistry 24, 285-294

71. Harrill, A. H., Rusyn, I. (2008) Systems biology and functional genomics approaches for the identification of cellular responses to drug toxicity. Expert Opin Drug Metab Toxicol 4, 1379-1389.

72. Coen, M., Ruepp, S. U., Lindon, J. C., Nicholson, J. K., Pognan, F. o., Lenz, E. M., Wilson, I. D. (2004) Integrated application of transcriptomics and metabonomics yields new insight into the toxicity due to paracetamol in the mouse. Pharmaceut. Biomed. 35, 93-105.

73. Heijne, W. H. M., Lamers, R.-J. A. N., van Bladeren, P. J., Groten, J. P., van Nesselrooij, J. H. J., van Ommen, B. (2005) Profiles of Metabolites and Gene Expression in Rats with Chemically Induced Hepatic Necrosis. Toxicol Pathol 33, 425-433.

74. Schnackenberg, L. K., Jones, R. C., Thyparambil, S., Taylor, J. T., Han, T., Tong, W., Hansen, D. K., Fuscoe, J. C., Edmondson, R. D, Beger, R. D., Dragan, Y. P. (2006) An Integrated Study of Acute Effects of Valproic Acid in the Liver Using Metabonomics, Proteomics, and Transcriptomics Platforms. OMICS 10, 1-14

75. Jennen, D., Ruiz-Aracama, A., Magkoufopoulou, C., Peijnenburg, A., Lommen, A., van Delft, J., Kleinjans, J. (2011) Integrating transcriptomics and metabonomics to unravel modes-of-action of 2,3,7,8-tetrachlorodibenzo-p-dioxin (TCDD) in HepG cells. BMC Syst. Biol. 5, 139.

76. Zimmerman, H. J., Hepatotoxicity: The Adverse Effects of Drugs and Other Chemicals on the Liver. Lippincott Williams \& Wilkins: 1999

77. Chen, M., Vijay, V., Shi, Q., Liu, Z., Fang, H., Tong, W. (2011) FDA-approved drug labeling for the study of drug-induced liver injury. Drug Discovery Today 16, 697-703.

78. Lee, W. M. (2007) Acetaminophen toxicity: changing perceptions on a social/medical issue. Hepatology 46, 966-970.

79. Kuehn, B. M. (2009) FDA focuses on drugs and liver damage: labeling and other changes for acetaminophen. JAMA 302 369-371.

80. Hinson, J. A., Roberts, D. W., James, L. P. (2010) Mechanisms of acetaminophen-induced liver necrosis. Handb Exp Pharmacol, $369-405$

81. Boelsterli, U. A. (2003) Diclofenac-induced liver injury: a paradigm of idiosyncratic drug toxicity. Toxicol. Appl. Pharm. 192, 307-322.

82. Woo, J., Chan, C. H., Walubo, A., Chan, K. K. (1992) Hydrazine--a possible cause of isoniazid--induced hepatic necrosis. Med 23, 51-59.

83. Baharuddin, M. R. B., Sahid, I. B., Noor, M. A. B. M., Sulaiman, N., Othman, F. (2011) Pesticide risk assessment: A study on inhalation and dermal exposure to 2,4-D and paraquat among Malaysian paddy farmers. Journal of Environmental Science and Health, Part B 46, 600-607

84. Burk, R. F., Lawrence, R. A., Lane, J. M. (1980) Liver necrosis and lipid peroxidation in the rat as the result of paraquat and
85. Ahmad, I., Shukla, S., Kumar, A., Singh, B. K., Kumar, V., Chauhan, A. K., Singh, D., Pandey, H. P., Singh, C. (2013) Biochemical and molecular mechanisms of $\mathrm{N}$-acetyl cysteine and silymarin-mediated protection against maneb- and paraquatinduced hepatotoxicity in rats. Chemico-Biological Interactions 201, 9-18.

86. Santangeli, P., Di Biase, L., Burkhardt, J. D., Bai, R., Mohanty, P., Pump, A., Natale, A. (2012) Examining the safety of amiodarone. Expert Opinion on Drug Safety 11, 191-214.

87. Leitner, J. M., Graninger, W., Thalhammer, F. (2010) Hepatotoxicity of Antibacterials: Pathomechanisms and Clinical Data Infection 38, 3-11.

88. Silva, M. F. B., Aires, C. C. P., Luis, P. B. M., Ruiter, J. P. N., lilst, L., Duran, M., Wanders, R. J. A., Tavares de Almeida, I. (2008) Valproic acid metabolism and its effects on mitochondrial fatty acid oxidation: A review. Journal of Inherited Metabolic Disease 31, 205-216

99. Soresi, M., Sparacino, V., Pisciotta, G., Bonfissuto, G., Caputo, F., Carroccio, A., Calabrese, S., Montalto, G. (1995) Effects of cyclosporin A on various indices of cholestasis in kidney transplant recipients. Minerva Urol Nefrol $47,65-69$.

go. Galán, A. I., Román, I. D., Muñoz, M. E., Cava, F., Gonzalez-Buitrago, J. M., Esteller, A., Jlmenez, R. (1992) Inhibition of biliary lipid and protein secretion by cyclosporine a in the rat. Biochem. Pharmacol. 44, 1105-1113.

91. Böhme, M., Jedlitschky, G., Leier, I., Büchler, M., Keppler, D. (1994) ATP-dependent export pumps and their inhibition by cyclosporins. Adv. Enzyme Regul. 34, 371-380.

92. Kis, E., loja, E., Nagy, T., Szente, L., Herédi-Szabó, K., Krajesi, P. (2009) Effect of Membrane Cholesterol on BSEP/Bsep Activity: Species Specificity Studies for Substrates and Inhibitors. Drug Metab. Dispos. 37, 1878-1886.

93. Padda, M. S., Sanchez, M., Akhtar, A. J., Boyer, J. L. (2011) Drug-induced cholestasis. Hepatology 53, 1377-1387.

94. Adams, C. E., Awad, G. A., Rathbone, J., Thornley, B., Soares-Weiser, K. (2014) Chlorpromazine versus placebo for schizophrenia. Cochrane Database Syst Rev 1, CDooo28

95. Velayudham, L. S., Farrell, G. C. (2003) Drug-induced cholestasis. Expert Opin Drug Saf 2, 287-304.

9. Crocenzi, F. A., Sánchez Pozzi, E. J, Pellegrino, J. M., Favre, C. O. Rodríguez Garay, E. A. Mottino A. D. Coleman, R. Roma, M. G. (2001) Beneficial effects of silymarin on estrogen-induced cholestasis in the rat: A study in vivo and in isolated hepatocyte couplets. Hepatology 34, 329-339. 


\section{Chapter 2}

\section{CLASSTRAISS}

OF HEPATOTOXICANTS USING HEPG2 CELLS:

A PROOF OF PRINCIPLE STUDY

Van den Hof, W.F.P.M

Coonen, M.L.J.

van Herwijnen, $M$

Brauers, $K$.

Wodzig, W.K.W.H.

van Delft, J.H.M

and Kleinjans, J.C.S. 


\section{Abstract}

With the number of new drug candidates increasing every year, there is a need for highthroughput human toxicity screenings. As the liver is the most important organ in drug metabolism and thus capable of generating relatively high levels of toxic metabolites, it is important to find a reliable strategy to screen for drug-induced hepatotoxicity. Microarraybased transcriptomics is a well-established technique in toxicogenomics research and is an ideal approach to screen for drug-induced injury at an early stage. The aim of this study was to prove the principle of classifying known hepatotoxicants and non-hepatotoxicants using thei distinctive gene expression profiles in vitro in HepG2 cells. Furthermore, we undertook to subclassify the hepatotoxic compounds by investigating the subclass of cholestatic compounds. Prediction Analysis for Microarrays was used for classification of hepatotoxicants and nonhepatotoxicants, which resulted in an accuracy of $92 \%$ on the training set and $91 \%$ on the validation set, using 36 genes. A second model was set up with the goal of finding classifiers for cholestasis, resulting in 12 genes that appeared capable of correctly classifying 8 of the 9 cholestatic compounds, resulting in an accuracy of $93 \%$. We were able to prove the principle that transcriptomic analyses of HepG2 cells can indeed be used to classify chemical entities for hepatotoxicity. Genes selected for classification of hepatotoxicity and cholestasis indicate that endoplasmic reticulum stress and the unfolded protein response may be important cellular effects of drug-induced liver injury. However, the number of compounds in both the training set and the validation set should be increased to improve the reliability of the prediction. 
an in vitro screening test for phospholipidosis using gene expression analyses of HepG2 cells exposed to toxic compounds. ${ }^{18}$ All in all, we considered it worthwhile to investigate the HepG2 liver model for its relevance for assessing hepatotoxicants based on the toxicogenomics approach.

Therefore, the aim of this study was to prove the principle of classifying known hepatotoxicants and non-hepatotoxicants in vitro using their distinctive gene expression profile in HepG2 cells after 24 hours of incubation. Furthermore, we aim to evaluate the classification of the important subclass cholestasis. Prediction Analysis for Microarrays (PAM) was used for classification of hepatotoxicants and non-hepatotoxicants. PAM uses the nearest shrunken centroid method and was used by Tibshirani et al. to diagnose multiple cancer types. ${ }^{19}$

\section{Materials and methods}

\section{Chemicals}

Modified Eagle's medium (MEM) plus glutamax, sodium pyruvate, fetal calf serum (FCS), nonessential amino acids, penicillin/streptomycin, Hanks' calcium- and magnesium-free buffe were obtained from Invitrogen (Breda, The Netherlands), dimethylsulfoxide (DMSO), Trypan blue, 3-(4,5-dimethylthiazol-2-yl)-2,5-diphenyltetrazolium bromide (MTT), Acetaminophen, Amiodarone, Chlorpromazine, Cyclosporin A, Diclofenac, D-Mannitol, Ethinyl Estradiol, Isoniazid, Lithium Carbonate, Paraquat, Tetracycline and Valproic Acid were purchased from Sigma-Aldrich (Zwijndrecht, The Netherlands). Adefovir was a gift from Leiden University.

Training set

HepG2 cells were cultured in MEM plus glutamax containing $10 \% \mathrm{v} / \mathrm{v}$ FCS, $1 \% \mathrm{v} / \mathrm{v}$ Sodium Pyruvate, $1 \% \mathrm{v} / \mathrm{v}$ non-essential amino acids, $2 \% \mathrm{v} / \mathrm{v}$ penicillin and streptomycin at $37^{\circ} \mathrm{C}$ in an atmosphere containing $5 \% \mathrm{CO}$

Compound concentrations were derived from cytotoxicity tests based on the MTT method as described in an earlier study ${ }^{20}$ and results for the 24 hours incubation can be found in Table 1. HepG 2 cells were seeded in 6 well plates and were treated for 24 hours with the IC 20 concentrations measured after 24 hours. Compounds were dissolved in DMSO or PBS and added to the medium with a final concentration of $0.5 \% \mathrm{v} / \mathrm{v}$ DMSO or PBS. Cells incubated in the presence of $0.5 \% \mathrm{v} / \mathrm{v}$ DMSO or PBS served as solvent controls. These experiments were performed with three replicates which were from independent cultures, with $\mathrm{HepG}_{2}$ passage numbers between 8 and 14. HepG2 cells were treated with 10 hepatotoxic compound Acetaminophen, Amiodarone, Chlorpromazine, Cyclosporin A, Diclofenac, Ethinyl Estradiol, Isoniazid, Paraquat, Tetracycline, Valproic Acid) and 3 non-hepatotoxic compounds (Adefovir, D-Mannitol, Lithium Carbonate).

Total RNA isolation, target preparation and microarray hybridization on the Affymetrix Human Genome U133 Plus 2.0 GeneChip arrays and scanning on an Affymetrix GeneArray scanner, were performed according to standard procedures. Quality control was performed using the ArrayAnalysis.org web service ${ }^{21}$ including Robust Multi-array Average (RMA) normalization and analyses of the default parameters indicated that all microarrays were livers. ${ }^{16}$ Previous work from our department showed that also in vitro transcriptomic analysis of HepG 2 cells combined with results from the Ames mutagenicity test is capable of successfully predicting the genotoxic hazard of compounds in vivo. ${ }^{17}$ Furthermore, Sawada et al. developed 
annotation and normalization resulted in 18,926 genes.

\section{Validation set}

CEL-files of HepG2 cells exposed to 6 hepatotoxic compounds (17-beta Estradiol, Azathioprine, Cisplatin, Cyclophosphamide, Cyclosporin A and Phenobarbital) and 2 non-hepatotoxic compounds (D-Mannitol and Mitomycin C) were obtained from the study of Magkoufopoulou et al. ${ }^{7}$ From in-house studies, two additional data sets on hepatotoxic compounds (Nifedipine and Tolbutamide) and one non-hepatotoxic compound (Clonidine) were added. For this set of compounds $\mathrm{HepG}_{2}$ cells were exposed for 24 hours to the $\mathrm{IC}_{20}$ concentrations measured after 72 hours (see Table 2).

\section{Classification}

All pre-processing analyses were performed using R version 2.15 .3 for Windows (64-bit). ${ }^{22}$ Several packages were used for this analysis (Affy v1.36.1, SimpleAffy v2.34.0, Affycomp v1.34.0) and were all acquired from Bioconductor, version $2.11 .{ }^{23} \mathrm{~A}$ total of 105 Affymetrix CEL-files were obtained and were reannotated to EntrezGene IDs using Brainarray's custom CDF version 15.1.0, as described by Dai et al. ${ }^{24}$ and normalized using the RMA method combined with MAS5PMA-calling. ${ }^{25}$ Only present and marginal probes were selected for further analysis and their intensities were transformed into LogRatios compared to matching controls.

\section{Preselection of feature}

To rule out compound-specific effects contributing to gene expression changes, a leave-1compound-out $\mathrm{t}$-test $(\mathrm{p}<0.01)$ was performed as described previously. ${ }^{17}$ Therefore, the set was divided in 2 groups: hepatotoxic and non-hepatotoxic compounds. To validate the results of the leave-1-compound-out t-test, we compared the results with an additional approach using a moderated t-test. The amount of significant features was lower in the moderated t-test, however, more than $80 \%$ of the features were overlapping with the list of the leave1-compound-out $t$-test, which indicates the robustness of this approach. Genes that were significant in all of the leave-1-compound-out t-tests were selected for classification.

\section{Class prediction}

The preselected set of features was loaded into PAM (Prediction Analysis for Microarrays, version 2.21) for class prediction. ${ }^{19}$ The data were trained and the model was chosen based on the best threshold matching our criteria of A) a low misclassification error and B) a strong reduction in amount of features. Hepatotoxic versus non-hepatotoxic classification threshold was 2.273 resulting in a reduction of features from 740 to 36 . Cholestasis classification threshold was 3.126, resulting in a reduction of features from 853 to 12 . The validation set was predicted using the features in this model. Final compound-class was assigned by at least 2 out of 3 biological replicate experiments. The distribution of the performance estimates could not be assessed, since an external validation set from a different experiment was used and no multiple splits of

\section{Biological interpretation}

Pearson/Ward hierarchical clusters were generated within GenePattern ${ }^{26}$ based on the log 2 fold changes (Additional file 1-2). For the biological interpretation of the selected genes for the classification of hepatotoxic compounds, a network was created using the MiMI-plugin ${ }^{27}$ in Cytoscape (version 2.8.3). ${ }^{28}$ The selected features were uploaded into the MiMI-plugin and a network was created based on known biological interactions including nearest neighbors shared by more than one gene. For visualization of the different effects of hepatotoxic and nonhepatotoxic compounds, the ExprEssence-plugin ${ }^{29}$ was used to add gene expression data to the network based on the fold changes between exposed cells and the solvent controls.

For further biological interpretation of the features selected for the classification of hepatotoxicity and for the features selected for the classification of cholestasis, Gene ontology terms ${ }^{30}$ associated with the selected genes were explored.

\section{Results}

PAM was applied to select gene signatures for prediction of drug-induced hepatotoxicity. The accuracy, sensitivity, false negative rate, specificity, false positive rate, positive predictive value, and negative predictive value are presented in Table 3 . This prediction model has an accuracy of $92 \%$ for the training set and $91 \%$ for the validation set for the prediction of hepatotoxicity A specificity of $100 \%$ was found because there were no false positive predictions. Sensitivity is also high, only one false negative in the training set, isoniazid, and one in the validation set, cisplatin, which results in a sensitivity of $90 \%$ and $88 \%$ for the training set and validation set, respectively. A total of 36 genes were selected and these are summarized in Table 4.

Hierarchical cluster analyses of the genes in the training set and validation set show different gene expression patterns for hepatotoxic and non-hepatotoxic compounds (Figure 1). In the training set, the hepatotoxic compounds paraquat and isoniazid cluster together with the non-hepatotoxic compounds. This may be explained by the fact that the overall LogRatios of these two hepatotoxic compounds for the selected classifiers are low compared to the other hepatotoxic compounds.

For biological interpretation a network was built by means of Cytoscape using the MiM plugin. All classifiers were uploaded and were supplemented with their nearest neighbors shared by more than one gene. The created network comprises 21 of the 36 genes, supplemented with 33 neighbors (Figure 2). The other 15 genes did not show interactions with the 21 genes and 33 added neighbors and did therefore not appear in this network. For the visualization of the different effects of hepatotoxic and non-hepatotoxic compounds on the selected features, two representative compounds were selected based on their high fold changes after treatment. For the non-hepatotoxic compounds, adefovir was chosen, and tetracycline was used as a representative for the hepatotoxic compounds, visualized on the left and right side of the colored nodes, respectively. There is an opposite effect between these two compound on most of the genes in this network. The genes up-regulated after treatment with adefovir 
and down-regulated after tetracycline treatment are mostly involved in cell cycle processes. Genes up-regulated after treatment with tetracycline and down-regulated after adefovir treatment were involved in several processes, including cell cycle processes. Furthermore, genes up-regulated after treatment with the hepatotoxic compound tetracycline were involved in the endoplasmic reticulum (ER) overload response, amino acid metabolism and transport.

For further biological interpretation, the Gene Ontology (GO) terms associated with the selected features were analyzed and the most relevant terms are summarized in Table 5 . For four of the features selected for the classification of hepatotoxic compounds versus non hepatotoxic compounds, INHBE, NEAT1, LOC100505650 and USP6NL-IT1, no GO terms were found. The other 32 features were associated with GO terms involved in cell cycle processes, cellular and ER stress, protein processing and lipid metabolism.

For exploring the feasibility of classifying cholestasis, a new model was trained and validated with PAM without the steatotic and necrotic compounds. The accuracy, sensitivity, false negative rate, specificity, false positive rate, positive predictive value, and negative predictive value are presented in Table 6. An accuracy of $100 \%$ was found for the training set and $78 \%$ for the validation set for this prediction model containing 16 genes. No false positives wer identified, resulting in a specificity of $100 \%$ in both the training and validation set. Sensitivity was $100 \%$ in the training set and $67 \%$ in the validation set, due to 2 false negative compounds, namely 17-beta estradiol and phenobarbital. However, these results were based on a training set containing only three cholestatic and three non-hepatotoxic compounds. To reduce the risk of overtraining the model and focusing on compound-specific changes, all cholestatic and nonhepatotoxic compounds from the training set and validation set were combined. Leave-oneout t-tests and PAM were performed to see if cholestatic specific genes could be found which could be used to classify cholestatic and non-hepatotoxic compounds (results are summarized in Table 7). 12 genes were selected (Table 8) which were able to correctly predict the cholestatic properties of 8 of the 9 cholestatic compounds in the combined set; only 17-beta estradio was incorrectly predicted as non-hepatotoxic. All non-hepatotoxic compounds were correctly predicted.

Most of the cholestatic compounds show the same gene expression pattern of the gene in the hierarchical cluster analysis (Figure 3). However, the cholestatic compound 17-bet estradiol shows low LogRatios for the selected genes and does not cluster together with the other cholestatic compounds. For the cholestatic compounds azathioprine and phenobarbital respectively one and two of the three replicates do not cluster with the replicates of the cholestatic compounds. The non-hepatotoxic compounds show an opposite gene pattern for the selected genes when compared to the cholestatic compounds or show low LogRatios indicative of a low response of these genes to the specific compounds.

GO terms associated with the 12 selected genes were explored for the biological interpretation (see Table 9). Five of the selected genes for classification of cholestasis were directly associated with GO terms involved in the unfolded protein response (UPR). No GO terms were found for the INHBE gene. GO terms associated with the other 6 genes were involved in cellula metabolism, response to drugs and cell cycle processes.

\section{Discussion}

In this study, we aimed to classify hepatotoxic and non-hepatotoxic compounds using transcriptomic profiles of exposed HepG2 cells. Compounds were selected based on information from databases from the National Toxicology Program (http://ntp.niehs.nih.gov/) and literature. ${ }^{3}$ Finding the appropriate representative candidates for non-hepatotoxic compounds and the different hepatotoxic classes is not trivial. Some negative controls for hepatotoxicity are not toxic for the liver but may be toxic for other organs. This toxicity may include comparable modes of action and differential gene expression, which may interfere with the classification of hepatotoxicants from non-hepatotoxicants. Furthermore, D-mannitol is an inert compound, where Mitomycin C can induce chromosomal damage, which shows that there are also major differences between the selected non-toxicants. Building microarray based databases that consist of gene-expression data from hepatocytes exposed to well-known hepatotoxicants and non-hepatotoxicants could therefore further improve the prediction of newly developed compounds as has been done by some groups for rat livers. ${ }^{32-34}$

Predicting hepatotoxicity resulted in an accuracy of $92 \%$ in the training set, where only one hepatotoxic compound, isoniazid, was predicted as non-hepatotoxic. The metabolites of isoniazid formed by $\mathrm{CYP}_{3} \mathrm{~A}_{4}$ are more toxic than the compound itself. CYP $3 \mathrm{~A}_{4}$ activity is low in HepG2 cells ${ }^{35}$, which could possibly result in lower levels of metabolites and lower LogRatios of the selected genes after isoniazid treatment which could consequently be responsible for the wrong prediction. Amiodarone was correctly predicted as hepatotoxic, but LogRatios of the selected genes are low compared to the other hepatotoxic compounds, which also could be due to the low activity of $\mathrm{CYP}_{3} \mathrm{~A}_{4}$ in $\mathrm{HepG}_{2}$ cells. ${ }^{36}$

In the validation set, an accuracy of $91 \%$ was found for the prediction of hepatotoxicity. The hepatotoxic compound Cisplatin was incorrectly predicted as non-hepatotoxic. In contrast to the training set where the $\mathrm{IC}_{20}$ after 24 hours was used as the incubation concentration, in the validation set $\mathrm{HepG}_{2}$ cells were treated for 24 hours with the $\mathrm{IC}_{20}$ established after 72 hours of exposure, which may be lower than the $\mathrm{IC}_{20}$ after 24 hours. As can be seen in the hierarchical cluster analyses, some compounds, including Cisplatin, show only minor changes of the genes used for the classification of hepatotoxicity. Preferably, a comparable concentration selection should be used, however, no such data set was available at this time.

For biological interpretation a network was created to assess the interactions between the 36 selected genes. 21 of the 36 genes could be added to the network including 33 neighbors, suggesting possible indirect interactions between these 21 genes. The down-regulation of genes involved in cell cycle processes after exposure to hepatotoxic compounds may indicate cell cycle arrest, which is an indication of induced toxicity. Furthermore, genes involved in ER stress were up-regulated after treatment with hepatotoxic compounds also indicative of a stress response to the hepatotoxic compounds. ER stress could result in an accumulation of unfolded proteins and subsequently to an unfolded protein response. General protein translation is down-regulated by the UPR, which results in lower expression of proteins with short half-lives. Many of these proteins are involved in the cell cycle and a reduction of these cell cycle proteins will result in cell cycle arrest. ${ }^{37-38}$ 
For 32 of the selected features of the first classification step associated GO terms were investigated which revealed mechanisms indicative for hepatotoxicity like cellular and ER stress, UPR and lipid metabolism. The GO terms associated with ER stress and the UPR signify the UPR as an important event in drug-induced hepatotoxicity. It is suggested that the UPR is also capable of modulating lipid metabolism ${ }^{39}$, further emphasizing an important role for the UPR in drug-induced toxicity. For four features, INHBE, NEAT1, LOC100505650 and USP6NL-IT1, no $\mathrm{GO}$ terms were found and literature was searched to identify possible associated mechanisms. Bruning et al. showed that INHBE was up-regulated by drug-induced ER stress $4^{\circ}$ and INHBE was also up-regulated in HepG2 cells exposed to hepatotoxicants. NEAT1 is in Mus Musculus associated with the GO term paraspeckles. Fox et al. suggest that paraspeckles have a role in the regulation of translation ${ }^{41}$, but the exact mechanisms are not clear. Nissim et al. showed up-regulation of LOC100505650 in hepatitis B virus associated acute liver failure ${ }^{42}$, however this gene was down-regulated after treatment with hepatotoxicants. The function of USP6NLIT 1 is not yet understood. Further research should investigate the function of this gene and the possible relationship between up-regulation of this gene and hepatotoxicity.

The used validation set mostly consisted of cholestatic compounds. A second model was set up focusing only on predicting cholestasis or non-hepatotoxicity of all cholestatic and non-hepatotoxic compounds in the training and validation set. In an attempt to train and validate with two independent sets, the PAM model was trained using the cholestatic and nonhepatotoxic compounds of the original training set and validated using the cholestatic and non-hepatotoxic compounds of the initial validation set (Table 6). This resulted in an accuracy of $78 \%$ in this validation set based on 16 genes. However, it has to be noted that training of this PAM model was only done using 3 cholestatic and 3 non-hepatotoxic compounds. To reduce the risk of overtraining the model and only find compound-specific changes, a new PAM model was setup with a combined dataset of the cholestatic and non-hepatotoxic compounds of the training and validation set. Cholestasis could be classified with an accuracy of $93 \%$ based on 12 genes. These results are based on a validation using the same data that was used to train the PAM model, thus in follow up studies, validation of these classifiers for cholestasis with an independent data set is needed. 6 of the found genes, AARS, ASNS, CTH, DDIT3, DNAJBg and INHBE, are associated with ER stress and the UPR. The MTHFD2 gene was also found as classifier for hepatotoxicity and is associated with folate-mediated one-carbon metabolism and disruption hereof is associated with many pathologies. ${ }^{43}$ The other 5 genes are associated with several GO terms indicative of a toxicological response, such as DNA damage response.

One of the hallmarks of cholestasis is the accumulation of bile acids in serum and hepatocytes. Bernstein et al. showed that the bile salt deoxycholate activates promoters of genes associated with DNA damage and protein malfolding 44 and accumulation of bile acids in hepatocytes may thus induce oxidative stress and the UPR. Recently, Vinken et al. developed an Adverse Outcome Pathway (AOP) for cholestasis and proposed that this AOP serves as the basis for new in vitro tests and biomarkers of drug-induced cholestasis. ${ }^{45}$ Although important cellular effects such as mitochondrial permeability pore (MPP) and oxidative stress are included in this AOP, no information on ER stress or UPR is added. ER stress and UPR can lead to $\mathrm{Ca}^{2}$ release into the cytosol and this $\mathrm{Ca}^{2+}$ can be taken up by mitochondria leading to opening of the MPP, triggering oxidative stress and ultimately apoptosis. ${ }^{8}$ The results from this manuscript suggest that ER stress and the UPR may be important early cellular effects in drug-induced hepatotoxicity and cholestasis and should therefore be further investigated in the search for new in vitro tests and biomarkers.

\section{Conclusions}

We were able to prove the principle that transcriptomic analyses of HepG2 cells can be used to classify hepatotoxicity. Classifiers selected for classification of hepatotoxicity and cholestasis indicate that endoplasmic reticulum stress and the unfolded protein response may be important cellular effects of drug-induced liver injury. However, the number of compounds in both the training and validation sets should be increased to further validate the prediction.

\section{Supporting information}

The data sets supporting the results of this article are included within the article and additiona files or are available in the NCBI's gene expression omnibus. ${ }^{46}$ The transcriptomics data are accessible through GEO series accession number GSE51952. Additional file 1 and 2 consist of the log2 fold change values of the 36 genes selected for classification of hepatotoxicity and the 12 genes selected for classification of cholestasis, respectively. This information is available free of charge via the Internet at http://pubs.acs.org/.

\section{Acknowledgments}

We are grateful to Rachel Cavill for her advice regarding the quality of English. 
Table 1. Compounds of the training set with their corresponding class, subclass and the $I_{20}$ concentrations measured after 24 hours.

\begin{tabular}{|c|c|c|c|c|c|c|}
\hline $\begin{array}{l}\text { Training set } \\
\text { Compound }\end{array}$ & Abbreviation & CAS no & Solvent & Class & Subclass & Dose $(\mu M)$ \\
\hline Acetaminophen & APAP & $103-90-2$ & DMSO & Hepatotoxic & Necrosis & 10000 \\
\hline Adefovir & $A D F$ & $106941-25-7$ & DMSO & Non-hepatotoxic & Non-hepatotoxic & 50 \\
\hline Amiodarone & $A M$ & $1951-25-3$ & DMSO & Hepatotoxic & Steatosis & 15 \\
\hline Chlorpromazine & CLP & $50-53-3$ & DMSO & Hepatotoxic & Cholestasis & 25 \\
\hline Cyclosporin A & CsA & $59865-13-3$ & DMSO & Hepatotoxic & Cholestasis & 20 \\
\hline Diclofenac & DIC & $15307-86-5$ & PBS & Hepatotoxic & Necrosis & 500 \\
\hline D-mannitol & Dman & $69-65-8$ & PBS & Non-hepatotoxic & Non-hepatotoxic & 2000 \\
\hline Ethinyl Estradiol & $E E$ & $57-63-6$ & DMSO & Hepatotoxic & Cholestasis & 90 \\
\hline Isoniazid & 150 & $54-85-3$ & DMSO & Hepatotoxic & Necrosis & 2000 \\
\hline Lithium Carbonate & LiC & $554-13-2$ & PBS & Non-hepatotoxic & Non-hepatotoxic & 2000 \\
\hline Paraquat & $P A Q$ & $1910-42-5$ & PBS & Hepatotoxic & Necrosis & 120 \\
\hline Tetracycline & TET & $60-54-8$ & DMSO & Hepatotoxic & Steatosis & 2000 \\
\hline Valproic Acid & VPA & $99-66-1$ & PBS & Hepatotoxic & Steatosis & 2000 \\
\hline
\end{tabular}

Table 2. Compounds of the validation set with their corresponding class, subclass and the $I_{20}$ concentrations measured after 72 hours.

\begin{tabular}{|c|c|c|c|c|c|c|}
\hline $\begin{array}{l}\text { Validation set } \\
\text { Compound }\end{array}$ & Abbreviation & CAS no & Solvent & Class & Subclass & Dose $(\mu M)$ \\
\hline 17-beta Estradiol & $E_{2}$ & $50-28-2$ & DMSO & Hepatotoxic & Cholestasis & 30 \\
\hline Azathioprine & $A Z A$ & $446-86-6$ & DMSO & Hepatotoxic & Cholestasis & 250 \\
\hline Cisplatin & cisPt & $15663-27-1$ & PBS & Hepatotoxic & Necrosis & 20 \\
\hline Clonidine & $\mathrm{Clo}$ & $4205-90-7$ & DMSO & Non-hepatotoxic & Non-hepatotoxic & 500 \\
\hline Cyclophosphamide & $C P$ & 50-18-0 & PBS & Hepatotoxic & Cholestasis & 2000 \\
\hline Cyclosporin A & $\operatorname{Cs} A$ & $59865-13-3$ & DMSO & Hepatotoxic & Cholestasis & 3 \\
\hline D-mannitol & Dman & $69-65-8$ & PBS & Non-hepatotoxic & Non-hepatotoxic & 250 \\
\hline Mitomycin C & $M M C$ & $50-07-7$ & DMSO & Non-hepatotoxic & Non-hepatotoxic & 0.2 \\
\hline Nifedipine & Nfe & $21829-25-4$ & DMSO & Hepatotoxic & Cholestasis & 106.25 \\
\hline Phenobarbital & Phb & $50-06-6$ & DMSO & Hepatotoxic & Cholestasis & 1000 \\
\hline Tolbutamide & $T b$ & $64-77-7$ & DMSO & Hepatotoxic & Cholestasis & 2000 \\
\hline
\end{tabular}

Table 3. Results of the prediction of hepatotoxicity for the compounds in the training set and validation set.

Training set as validation

\begin{tabular}{|l|l|}
\hline Accuracy & $92 \%$ \\
\hline Sensitivity & $90 \%$ \\
\hline False negative rate & $10 \%$ \\
\hline Specificity & $100 \%$ \\
\hline False positive rate & $0 \%$ \\
\hline Positive predictive value & $100 \%$ \\
\hline Negative predictive value & $75 \%$ \\
\hline
\end{tabular}

Validation set as validation

Sensitivity

False positive rate $\quad \% \%$

Positive predictive value $\quad 100 \%$ Negative predictive value $75 \%$ 
Table 5. Relevant Gene Ontology terms associated with the selected features for classification of hepatotoxic compounds versus non-hepatotoxic compounds.

Gene Symbol Gene Ontology Terms (Biological processes)

Entrez Gene ID Gene Symbol Description

\begin{tabular}{l|l|l|}
\hline 16 & AARS & Aminoacyl tRNA synthetase \\
\hline 113 & ADCY7 & Adenylate cyclase type 7 \\
\hline 1646 & AKR1C2 & Aldo-keto reductase family 1 member C 2 \\
440 & ASNS & Asparagine synthetase \\
\hline 875 & CBS & Cystathionine beta synthase \\
9236 & CCPG1 & Cell cycle progression 1 \\
\hline 1491 & CTH & Cystathionine gamma-lyase \\
\hline 57834 & CYP4F11 & Cytochrome P450, family 4, subfamily F, polypeptide 11 \\
\hline 1649 & DDIT3 & DNA damage-inducible transcript 3 \\
\hline 1978 & EIF4EBP1 & Eukaryotic translation initiation factor 4E-binding protein 1 \\
\hline 9569 & GTF2IRD1 & General transcription factor II-I repeat domain-containing protein 1 \\
\hline 83729 & INHBE & Inhibin, beta E \\
\hline 9388 & LIPG & Endothelial lipase \\
\hline 10797 & MTHFD2 & Bifunctional methylenetetrahydrofolate dehydrogenase/cyclohydrolase \\
\hline 283131 & NEAT1 & Nuclear paraspeckle assembly transcript 1 \\
\hline 4758 & NEU1 & Sialidase 1 (lysosomal sialidase) \\
\hline 29095 & ORMDL2 & ORM1 like protein 2 \\
\hline 80336 & PABPC1L & Poly(A) binding protein, cytoplasmic 1-like \\
\hline 140809 & SRXN1 & Sulfiredoxin 1 \\
\hline 51175 & TUBE1 & Tubulin, epsilon 1 \\
\hline 100507213 & USP6NL-IT1 & USP6NL intronic transcript 1 \\
\hline 11260 & XPOT & Exportin- $T$ \\
\hline
\end{tabular}

\begin{tabular}{|l|l|l|}
\hline 57291 & DANCR & Differentiation antagonizing non-protein coding RNA \\
\hline 1906 & EDN1 & Endothelin 1 \\
\hline 9837 & GINS1 & DNA replication complex GINS protein PSF1 \\
\hline 220296 & HEPACAM & Hepatic and glial cell adhesion molecule \\
\hline 3183 & HNRNPC & Heterogeneous nuclear ribonucleoproteins C1/C2 \\
\hline 100505650 & LOC100505650 & Uncharacterized LOC100505650 \\
\hline 4153 & MBL2 & Mannose-binding lectin \\
\hline 5019 & OXCT1 & Succinyl-CoA:3-ketoacid-coenzyme A transferase 1 \\
5422 & POLA1 & DNA polymerase alpha catalytic subunit \\
6157 & RPL27A & 60S Ribosomal protein L27a \\
\hline 10590 & SCGN & Secretagogin \\
\hline 8436 & SDPR & Serum deprivation-response protein \\
\hline 10772 & SRSF10 & Serine/arginine-rich splicing factor 10 \\
\hline 57473 & ZNF512B & Zinc finger protein 512B \\
\hline
\end{tabular}

AARS Protein folding; Unfolded protein response

$\mathrm{ADCY}_{7} \quad$ Intracellular signal transduction; Transmembrane transport

AKR1C2 Positive regulation of cell proliferation; Bile acid binding

ASNS Activation of signaling protein activity involved in unfolded protein response

CBS Negative regulation of apoptotic process

CCPG1 Cell cycle

CTH Transsulfuration; Endoplasmic reticulum unfolded protein respons

CYP4F11 Xenobiotic metabolic process; Arachidonic acid or fatty acid metabolism

DDIT3 Activation of signaling protein activity involved in unfolded protein response

EIF4EBP1 G G1/S transition of mitotic cell cycle; Positive regulation of mitotic cell cycle

GTF2IRD1 Regulation of transcription, DNA-dependent

INHBE No Gene Ontology terms were found

LIPG Lipid metabolic process; Cholesterol homeostasis; Cell proliferation

MTHFD2 One-carbon metabolic process; Folic acid-containing compound biosynthetic process

NEAT1 No Gene Ontology terms were found

NEU1 $\quad$ Sphingolipid metabolic process

ORMDL2 Ceramide metabolic process; Endoplasmic reticulum

PABPC1L RNA binding

TUBE1 Centrosome cycle; Structural constituent of cytoskeleton

USP6NL-IT1 No Gene Ontology terms were found

XPOT Intracellular protein transport; tRNA binding

DANCR Differentiation

GINS1

Differentiatio

Cell cycle arrest

HNRNPC MRNA binding

LOC100505650 No Gene Ontology terms were found

MBL2 Response to oxidative stress; Complement activation; Calcium-dependent protein binding

OXCT1 Cellular lipid metabolic process; Response to drug

POLA1 DNA replication; Cell proliferation

RPL27A Translation

SCGN Calcium ion binding

SDPR Phosphatidylserine binding

SRSF10 Unfolded protein binding; Regulation of transcription, DNA-dependent

ZNF512B Regulation of transcription, DNA-dependent
$S_{S R X N 1} \quad$ Response to oxidative stress 
Table 6. Results of the prediction of cholestasis and non-hepatotoxicity Table 7. Results of the prediction of for the cholestatic and non-hepatotoxic compounds in the training cholestasis and non-hepatotoxicity and validation set.

for the combined set of cholestatic and non-hepatotoxic compounds of the training and validation set.

\section{Training set Validation set Combination set}

\begin{tabular}{|l|l|l|l}
\hline Accuracy & $100 \%$ & $78 \%$ & $93 \%$ \\
\hline Sensitivity & $100 \%$ & $67 \%$ & $89 \%$ \\
\hline False negative rate & $0 \%$ & $33 \%$ & $11 \%$ \\
\hline Specificity & $100 \%$ & $100 \%$ & $100 \%$ \\
\hline False positive rate & $0 \%$ & $0 \%$ & $0 \%$ \\
\hline Positive predictive value & $100 \%$ & $100 \%$ & $100 \%$ \\
\hline Negative predictive value & $100 \%$ & $60 \%$ & $86 \%$
\end{tabular}

Table 8. Genes selected by PAM for prediction of cholestasis versus non-hepatotoxicity.

Entrez Gene ID Gene Symbol Description

\begin{tabular}{|l|l|l|}
\hline 16 & AARS & Aminoacyl tRNA synthetase \\
\hline 440 & ASNS & Asparagine synthetase \\
\hline 1491 & CTH & Cystathionase \\
\hline 1649 & DDIT3 & DNA-damage-inducible transcript 3 \\
\hline 4189 & DNAJB9 & DnaJ (Hsp40) homolog, subfamily B, member 9 \\
5106 & PCK2 & Phosphoenolpyruvate carboxykinase 2 \\
\hline 5450 & POU2AF1 & POU class 2 associating factor 1 \\
\hline 6286 & S10oP & S10o calcium binding protein P \\
\hline 7298 & TYMS & Thymidylate synthetase \\
\hline 10797 & MTHFD2 & Methylenetetrahydrofolate dehydrogenase (NADP+ dependent) 2 \\
\hline 83729 & INHBE & Inhibin, beta E \\
\hline 144455 & E2F7 & E2F transcription factor 7 \\
\hline
\end{tabular}

Table 9. Relevant Gene Ontology terms associated with the selected features for classification of cholestatic compounds versus non-hepatotoxic compounds.

Gene Symbol Gene Ontology Terms (Biological processes)

AARS Protein folding; Unfolded protein response

ASNS Activation of signaling protein activity involved in unfolded protein response

CTH Transsulfuration; Endoplasmic reticulum unfolded protein response

DDIT3 Activation of signaling protein activity involved in unfolded protein response

DNAJB9 Endoplasmic reticulum unfolded protein response

Carbohydrate metabolic process; Gluconeogenesis

POU2AF1 Humoral immune response; Regulation of transcription, DNA-dependent

S10OP Calcium-dependent protein binding; Response to organic substance

TYMS Response to drug; DNA replication and repair

One-carbon metabolic process; Folic acid-containing compound biosynthetic process

INHBE No Gene Ontology terms were found

$\mathrm{E}_{2} \mathrm{F7} \quad$ Hepatocyte differentiation; DNA damage response 
A

B

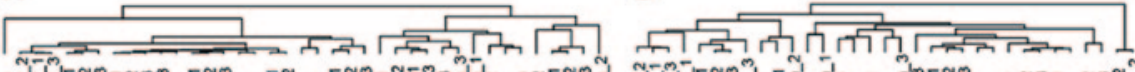

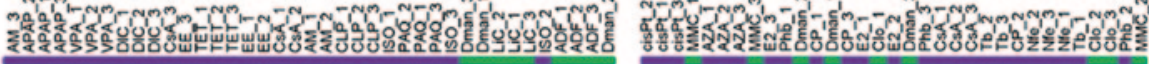
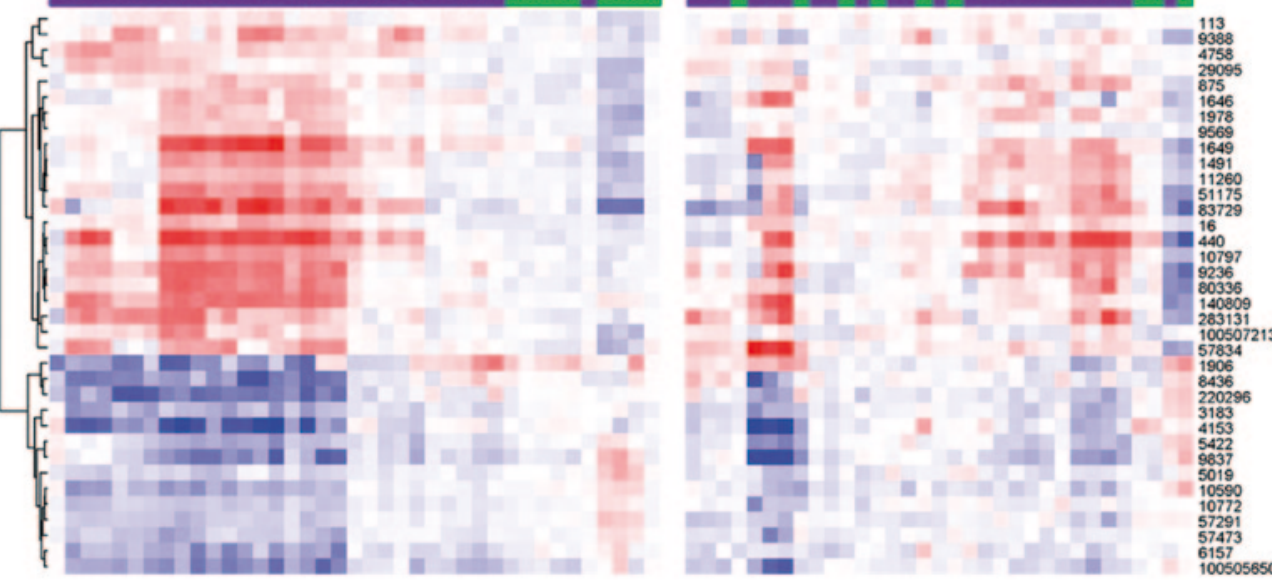

- Hepatotoxic

Non-hepatotoxic

Figure 1. Visualization of gene expression patterns by hierarchical cluster analyses of the 36 genes for the training set (A) and validation set (B) based on the Log2 fold changes between compound and solvent control.

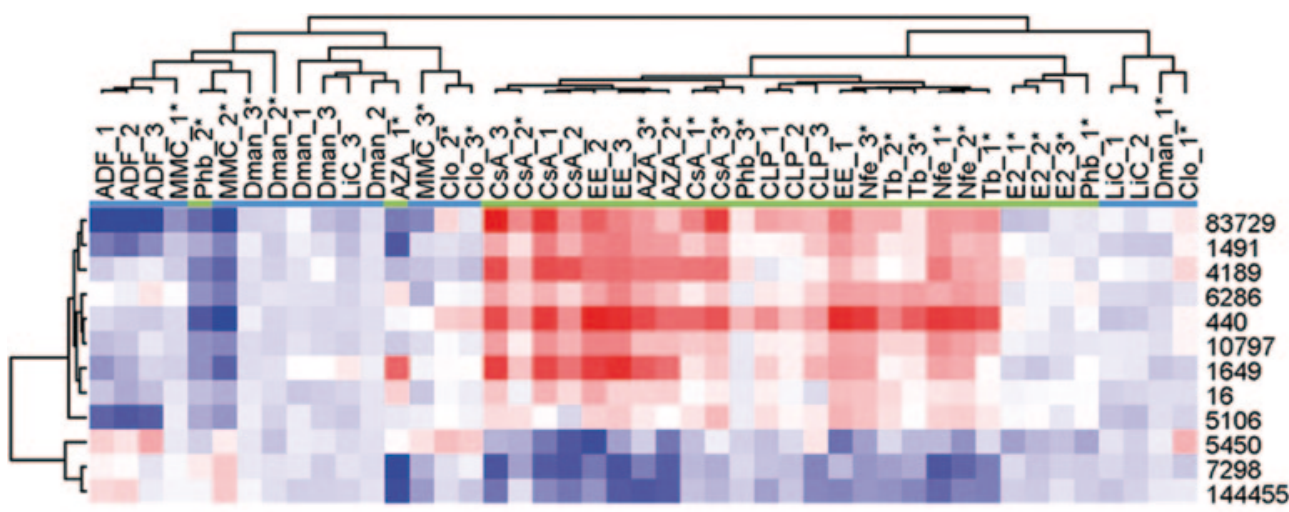

= Cholestatic

- Non-hepatotoxic

Figure 3. Visualization of gene expression patterns by hierarchical cluster analysis of the 12 genes for the cholestatic and non-hepatotoxic compounds based on the Log2 fold changes between compound and solvent control (" compounds from the validation set).

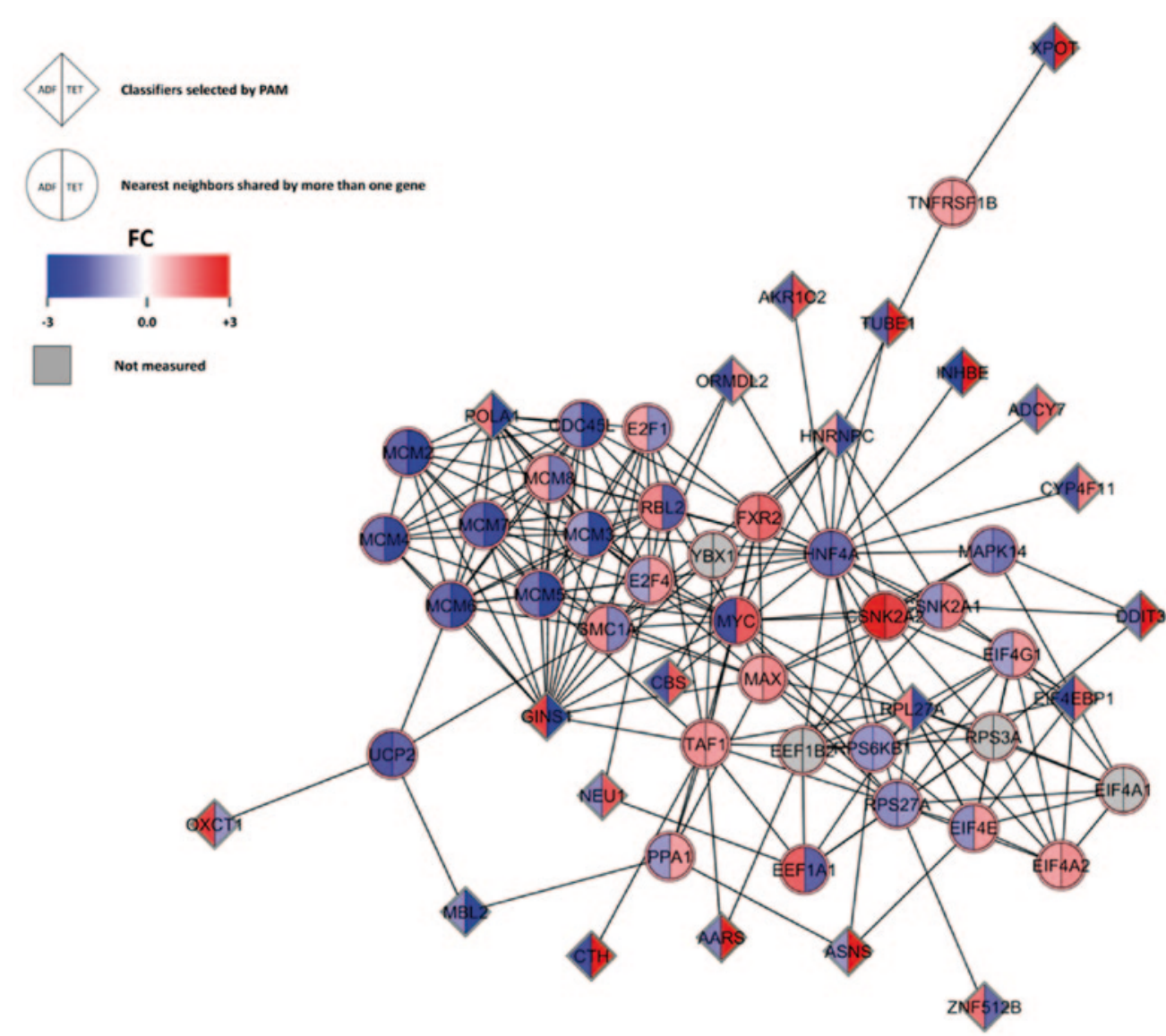

Figure 2. Network created with Cytoscape based on interactions of the genes selected by PAM (diamonds) and their nearest neighbors shared by more than one gene (circles) and visualized using the fold changes after treatment with the hepatotoxic compound Tetaracycline (TET) and non-hepatotoxic compound Adefovir (ADF). 


\section{References}

1. Russmann, S., Kullak-Ublick, G. A., Grattagliano, I. (2009) Current concepts of mechanisms in drug-induced hepatotoxicity. Curr. Med. Chem. 16, 3041-3053.

2. Schuster, D., Laggner, C., Langer, T. (2005) Why drugs fail--a study on side effects in new chemical entities. Curr. Pharm Design 11, 3545-3559.

3. Westerink, W. M. A., Schoonen, W. G. E. J. (2007) Cytochrome P450 enzyme levels in HepG2 cells and cryopreserved primary human hepatocytes and their induction in HepG2 cells. Toxicol. In Vitro 21, 1581-1591.

4. Westerink, W. M. A., Schoonen, W. G. E.J. (2007) Phase Il enzyme levels in HepG2 cells and cryopreserved primary human hepatocytes and their induction in HepG2 cells. Toxicol. In Vitro 21, 1592-1602.

5. Dias da Silva, D., Carmo, H., Lynch, A., Silva, E. (2013) An insight into the hepatocellular death induced by amphetamines, individually and in combination: the involvement of necrosis and apoptosis. Arch. Toxicol., 1-21.

6. Schoonen, W. G. E. J., Westerink, W. M. A., de Roos, J. A. D. M., Débiton, E. (2005) Cytotoxic effects of 100 reference compounds on Hep $\mathrm{G}_{2}$ and HeLa cells and of 60 compounds on ECC-1 and CHO cells. I Mechanistic assays on ROS, glutathione depletion and calcein uptake. Toxicol. In Vitro 19, 505-516.

7. Menezes, C., Alverca, E., Dias, E., Sam-Bento, F., Pereira, P. (2013) Involvement of endoplasmic reticulum and autophagy in microcystin-LR toxicity in Vero-E6 and HepG2 cell lines. Toxicol. In Vitro 27, 138-148.

8. Sahu, S.C., O'Donnell, M. W., Sprando, R. L. (2012) Interactive toxicity of usnic acid and lipopolysaccharides in human liver HepG2 cells. J. Appl. Toxicol. 32, 739-749.

9. Kaplowitz, N. (2004) Drug-Induced Liver Injury. Clin. Infect. Dis. 38, 544-548.

10. Liguori, M. J., Blomme, E. A. G., Waring, J. . . (2008) Trovafloxacin-Induced Gene Expression Changes in Liver-Derived in vitro Systems: Comparison of Primary Human Hepatocytes to HepG2 Cells. Drug Metab. Dispos. 36, 223-233.

11. Cui, Y., Paules, R. S. (2010) Use of transcriptomics in understanding mechanisms of drug-induced toxicity. Pharmacogenomics 11, 573-585.

12. Uehara, T., Kiyosawa, N., Hirode, M., Omura, K., Shimizu, T., Ono, A., Mizukawa, Y., Miyagishima, T., Nagao, T., Urushidani T. (2008) Gene expression profiling of methapyrilene-induced hepatotoxicity in rat. J. Toxicol. Sci. 33, 37-50.

13. Heijne, W. H. M., Jonker, D., Stierum, R. H., Ommen, B. v., Groten, J. P. (2005) Toxicogenomic analysis of gene expression changes in rat liver after a 28-day oral benzene exposure. Mutat. Res.-Fund. Mol. M. 575, 85-101.

14. Minami, K., Saito, T., Narahara, M., Tomita, H., Kato, H., Sugiyama, H., Katoh, M., Nakajima, M., Yokoi, T. (2005) Relationship between Hepatic Gene Expression Profiles and Hepatotoxicity in Five Typical Hepatotoxicant-Administered Rat. Toxicol. Sci. 87, 296-305.

15. Zidek, N., Hellmann, J., Kramer, P.-.., Hewitt, P. G. (2007) Acute Hepatotoxicity: A Predictive Model Based on Focused Illumina Microarrays. Toxicol. Sci. 99, 289-302.

16. Steiner, G., Suter, L, Boess, F., Gasser, R., de Vera, M. C., Albertini, S., Ruepp, S. (2004) Discriminating different classes of toxicants by transcript profiling. Environ. Health Persp. 112, 1236-1248.

17. Magkoufopoulou, C., Claessen, S. M. H., Tsamou, M., Jennen, D. G. J., Kleinjans, J. C. S., van Delft, J. H. M. (2012) A transcriptomics-based in vitro assay for predicting chemical genotoxicity in vivo. Carcinogenesis $33,1421-1429$.

18. Sawada, H., Takami, K., Asahi, S. (2005) A Toxicogenomic Approach to Drug-Induced Phospholipidosis: Analysis of Its Induction Mechanism and Establishment of a Novel in vitro Screening System. Toxicol. Sci. 83, 282-292.

19. Tibshirani, R., Hastie, T., Narasimhan, B., Chu, G. (2002) Diagnosis of multiple cancer types by shrunken centroids of gene expression. P. Natl. Acad. Sci. USA 99, 6567-6572.

20. Van Summeren, A., Renes, J., Bouwman, F. G., Noben, J.P., van Delft, J. H. M., Kleinjans, J. C. S., Mariman, E. C. M. (2011)
Proteomics Investigations of Drug-Induced Hepatotoxicity in HepG2 Cells. Toxicol. Sci. 120, 109-122.

21. Eijssen, L. M. T. Jaillard, M., Adriaens, M. E., Gaj, S., de Groot, P. J., Müller, M. Evelo, C. T. (2013) User-friendly solutions for microarray quality control and pre-processing on ArrayAnalysis.org. Nucleic Acids Res. 41, W71-W76.

22. R-Core-Team R: A language and environment for statistical computing. R Foundation for Statistical Computing, Vienna, Austria. ISBN 3-900051-07-0. URL http://www.R-project.org/

23. R. Gentleman, V. J. Carey, D. M. Bates, B.Bolstad, M. Dettling, S. Dudoit, B. Ellis, L. Gautier, Y. Ge, others, a. (2004) Bioconductor: Open software development for computational biology and bioinformatics. Genome Biology Vol. 5 .

24. Dai, M., Wang, P., Boyd, A. D., Kostov, G., Athey, B., Jones, E. G., Bunney, W. E., Myers, R. M., Speed, T. P., Akil, H., Watson, S. J., Meng, F. (2005) Evolving gene/transcript definitions significantly alter the interpretation of GeneChip data. Nucleic Acids Res. 33, e175

25. Irizarry, R. A., Hobbs, B., Collin, F., BeazerâfBarclay, Y. D., Antonellis, K. J., Scherf, U., Speed, T. P. (2003) Exploration, normalization, and summaries of high density oligonucleotide array probe level data. Biostatistics 4, 249-264.

26. Reich, M. Liefeld, T. Gould, J. Lerner, J. Tamayo, P., Mesirov, J. P. (2006) GenePattern 2.0. Nat. Genet. 38 , 500-501.

27. Gao, J., Ade, A. S., Tarcea, V. G., Weymouth, T. E., Mirel, B. R., Jagadish, H. V., States, D. J. (2009) Integrating and annotating the interactome using the MiMl plugin for cytoscape. Bioinformatics 25, 137-138.

28. Smoot, M. E., Ono, K., Ruscheinski, J., Wang, P.-L, Ideker, T. (2011) Cytoscape 2.8: new features for data integration and network visualization. Bioinformatics 27, 431-432.

29. Warsow, G., Greber, B., Falk, S., Harder, C., Siatkowski, M., Schordan, S., Som, A., Endlich, N., Scholer, H., Repsilber, D. Endlich, K., Fuellen, G. (2010) ExprEssence - Revealing the essence of differential experimental data in the context of an interaction/regulation net-work. BMC Syst. Biol. 4. 164.

30. Ashburner, M., Ball, C. A., Blake, J. A., Botstein, D., Butler, H., Cherry, J. M., Davis, A. P., Dolinski, K., Dwight, S. S., Eppig, T., Harris, M. A., Hill, D. P., Issel-Tarver, L., Kasarskis, A., Lewis, S., Matese, J. C., Richardson, J. E., Ringwald, M., Rubin, G. M. Sherlock, G. (2000) Gene ontology: tool for the unification of biology. The Gene Ontology Consortium. Nat. Genet. 25 25-29.

Zimmerman, H. J., Hepatotoxicity: The Adverse Effects of Drugs and Other Chemicals on the Liver. Lippincott William \& Wilkins: 1999.

32. Karpinets, T. V., Foy, B. D., Frazier, J. M. (2004) Tailored gene array databases: applications in mechanistic toxicology. Bioinformatics 20, 507-517.

33. Kiyosawa, N., Shiwaku, K., Hirode, M., Omura, K., Uehara, T., Shimizu, T., Mizukawa, Y., Miyagishima, T., Ono, A., Nagao, T., Urushidani, T. (2006) Utilization of a one-dimensional score for surveying chemical-induced changes in expressio levels of multiple biomarker gene sets using a large-scale toxicogenomics database. Toxicol. Sci. 31, 433-448.

34. Dai, X., He, Y. D., Dai, H., Lum, P. Y., Roberts, C. J., Waring, J. F., Ulrich, R. G. (2006) Development of an approach for ab initio estimation of compound-induced liver injury based on global gene transcriptional profiles. Cenome Inform 17, 17-88.

35. Vignati, L., Turlizzi, E., Monaci, S., Grossi, P., Kanter, R. d., Monshouwer, M. (2005) An in vitro approach to detect metabolite toxicity due to CYP3A4-dependent bioactivation of xenobiotics. Toxicology 216, 154-167.

36. Zahno, A., Brecht, K., Morand, R., Maseneni, S., Török, M., Lindinger, P. W., Krähenbühl, S. (2011) The role of $\mathrm{CYP}_{3} \mathrm{~A}_{4}$ in amiodarone-associated toxicity on HepG2 cells. Biochem. Pharmacol. 81, 432-441.

37. Brewer, J. W., Hendershot, L. M., Sherr, C. J., Diehl, J. A. (1999) Mammalian unfolded protein response inhibits cyclin D1 translation and cell-cycle progression. P. Natl. Acad. Sci. USA 96, 8505-8510.

38. Lafleur, M. A., Stevens, J. L., Lawrence, J. W. (2013) Xenobiotic Perturbation of ER Stress and the Unfolded Protein Response. Toxicol. Pathol. 41, 235-262, 
39. Basseri, S., Austin, R. C. (2012) Endoplasmic Reticulum Stress and Lipid Metabolism: Mechanisms and Therapeutic Potential. Biochem. Res. Int. 2012, 13

40. Brüning, A., Matsingou, C., Brem, G. J., Rahmeh, M., Mylonas, I. (2012) Inhibin beta E is upregulated by drug-induced endoplasmic reticulum stress as a transcriptional target gene of ATF4. Toxicol. Appl. Pharm. 264, 300-304.

41. Fox, A. H., Lam, Y. W., Leung, A. K. L., Lyon, C. E., Andersen, J., Mann, M., Lamond, A. I. (2002) Paraspeckles: A Novel Nuclear Domain. Curr. Biol. 12, 13-25.

42. Nissim, O., Melis, M., Diaz, G., Kleiner, D. E., Tice, A., Fantola, G., Zamboni, F., Mishra, L., Farci, P. (2012) Liver Regeneration Signature in Hepatitis B Virus (HBV)-Associated Acute Liver Failure Identified by Gene Expression Profiling. PLOS ONE 7 e49611.

43. Fox, J. T., Stover, P. J., Chapter 1 Folate - Mediated One - Carbon Metabolism. In Vitamins \& Hormones, Gerald, L., Ed. Academic Press: 2008; Vol. Volume 79, pp 1-44

44. Bernstein, H., Payne, C. M., Bernstein, C., Schneider, J., Beard, S. E., Crowley, C. L. (1999) Activation of the promoters of genes associated with DNA damage, oxidative stress, ER stress and protein malfolding by the bile salt deoxycholate. Toxicol. Lett. 108, 37-46.

45. Vinken, M., Landesmann, B., Goumenou, M., Vinken, S., Shah, I., Jaeschke, H., Willett, C., Whelan, M., Rogiers, V. (2013) Development of an Adverse Outcome Pathway From Drug-Mediated Bile Salt Export Pump Inhibition to Cholestatic Liver Injury. Toxicol. Sci.

46. Edgar, R., Domrachev, M., Lash, A. E. (2002) Gene Expression Omnibus: NCBI gene expression and hybridization array data repository. Nucleic Acids Res. 30, 207-210. 


\section{Chapter 3}

\section{VAMDATOM:}

OF GENE EXPRESSION PROFILES FROM CHOLESTATIC HEPATOTOXICANTS IN VITRO AGAINST HUMAN IN VIVO CHOLESTASIS

Van den Hof, W.F.P.M.

Coonen, M.L.J.,

van Herwijnen, $M$.

Brauers, K.,

Wodzig, W.K.W.H.,

Olde Damink, S.W.M.

Schaap, F.G.,

and Kleinjans, J.C.S. 
Abstract

Drug-induced liver injury remains the most common cause of acute liver failure and a frequently indicated reason for withdrawal of drugs. Cholestasis is one of the most severe manifestations of drug-induced hepatotoxicity. Intracellular bile accumulation via the inhibition of transport proteins has been suggested to be the main underlying mechanism of drug-induced cholestasis. There is an increasing demand for liver models better capable of predicting drug-induced cholestasis in humans. We here aimed to benchmark 'omics-derived mechanistic data from three in vitro models for parenchymal liver function, for the investigation of drug-induced cholestasis against omics data from cholestatic patients.

Transcriptomic changes in $\mathrm{HepG}_{2}$ cells, primary mouse hepatocytes and primary human hepatocytes exposed to Cyclosporin A, Chlorpromazine and Ethinyl Estradiol were analyzed using microarrays. In order to find an in vitro fingerprint of drug-induced cholestasis, the overlapping differentially expressed genes were selected in each model. 151 genes were differentially expressed in all treatments in $\mathrm{HepG}_{2}$ cells of which 13 were also differentially expressed in human cholestasis. The overlap between drug-induced transcriptomic responses in primary mouse hepatocytes and primary human hepatocytes appeared limited and no overlapping genes with in vivo cholestasis were found. Gene ontology terms associated with the 13 overlapping gene expressions in in vivo cholestasis and in drug-induced cholestasis in HepG2 cells indicated the involvement of the unfolded protein response in cholestasis. The limited overlap between expression profiles of the different compounds however suggests different mechanisms. Thereupon, a previously published pathway for drug-induced cholestasis was used to map the drug-induced transcriptomic modifications involved in bile homeostasis, and compare those to gene expression changes in human cholestasis.

Indications of an adaptive response to prevent and reduce intracellular bile accumulation were observed in vivo as well as in vitro. Furthermore, drug-specific changes on the transcription of several important bile salt secreting and conjugating genes were found. These drug-induced changes may result in intracellular accumulation of bile constituents and may be indicative of their cholestatic properties. 
In this study, we thus validated the transcriptomic changes in $\mathrm{PHH}, \mathrm{PMH}$ and $\mathrm{HepG} 2$ cells induced by cholestatic compounds, against the transcriptomic fingerprint derived from liver samples from patients suffering from extrahepatic cholestasis (manuscript in preparation). For this purpose, we analyzed cellular responses to treatment with three prototypical compounds, which are known to induce cholestasis in humans, namely Cyclosporin A (CsA), Chlorpromazine (CPZ) and Ethinyl Estradiol (EE).

\section{Materials and methods}

Chemicals

Modified Eagle's medium (MEM) plus glutamax, fetal calf serum (FCS), non-essential amino acids, sodium pyruvate, penicillin/streptomycin, insulin and Hanks' calcium- and magnesium-free buffer were purchased from Invitrogen (Breda, The Netherlands). Glucagon, hydrocortisone (water soluble), collagenase type IV, dimethylsulfoxide (DMSO), Trypan blue, 3-(4,5-dimethylthiazol-2-yl)-2,5-diphenyltetrazolium bromide (MTT), Cyclosporin A Chlorpromazine, Ethinyl Estradiol, $\mathrm{NaCl}, \mathrm{NaHCO}_{3^{\prime}} \mathrm{KCl} \mathrm{KH}_{2} \mathrm{PO}_{4^{\prime}}, \mathrm{MgSO}_{4^{\prime}}$ glucose, and $\mathrm{CaCl}_{2}$ were obtained from Sigma-Aldrich (Zwijndrecht, The Netherlands). Collagen type I Rat Tail was obtained from BD Biosciences (Bedford, MA, USA). The Trizol reagent and the RNeasy mini kit were from Qiagen Westburg (Leusden, The Netherlands)

\section{Human in vivo data}

Microarray data of cholestatic liver samples and control liver samples were obtained from different study (manuscript in preparation) using samples from previous published research. ${ }^{10}$ In short, the respective protocols of the studies were approved by the local Medical Ethica Committee and the patients gave their informed consent. Samples were derived from 9 perioperative liver biopsies from patients with a pancreatic or periampullary malignancy and subsequent obstructive jaundice (cholestatic group) and from 9 nonjaundiced patients with a pancreatic malignancy or undergoing liver resection (control group). Liver samples were collected in RNAlater and stored at $-80^{\circ} \mathrm{C}$ until RNA isolation. Isolated RNA was hybridized to Agilent SurePrint $G_{3}$ Human Gene Expression 8x6oK v2 Microarrays and scanned using an Affymetrix GeneArray scanner.

Primary human hepatocytes data

Data of primary human hepatocytes exposed to CSA, CPZ and EE were retrieved from the Open TG-GATEs database (http://toxico.nibio.go.jp). In total 22 Affymetrix CEL-files were collected. Hepatocytes were exposed for 24 hours in duplo to the compounds and 0.5\% DMSO as solvent control. The used concentrations to compare to exposures in the other cell lines were: $20 \mu \mathrm{M}$ for $\mathrm{CPZ}, 6 \mu \mathrm{M}$ for CsA and $15 \mu \mathrm{M}$ for EE.

HepG2 data

In total 72 Affymetrix CEL-files of HepG2 cells exposed to CSA, CPZ and EE and matching controls were collected from previously published data. ${ }^{9} \mathrm{HepG} 2$ cells were exposed for 24 hours to the 


\section{Results}

Primary mouse hepatocytes data
The animal studies were approved by the Animal Ethical Committee of the Maastricht University, The Netherlands (approval number: 2011-108). Adult male C57BL/6 mice, weighing 20-25 grams, were obtained from Charles River $\mathrm{GmbH}$, Sulzfeld, Germany. Animals were housed in macrolon cages with sawdust bedding at $22^{\circ} \mathrm{C}$ and $50-60 \%$ humidity. Food and tap water were available ad libitum, and the light cycle was 12 hours light/12 hours dark. Isolation and culture of primary mouse hepatocytes were performed as described before. ${ }^{8} \mathrm{After}$ the recovery period, cells were exposed to culture medium containing Chlorpromazine, Ethinyl Estradiol or $0.5 \% \mathrm{v} / \mathrm{v}$ DMSO as a vehicle control. Based on the $\mathrm{IC}_{20}$ values for 24 and 48 hours exposure, which were determined by the MTT reduction method ", the hepatocytes were exposed as follows: $0.5 \% \mathrm{v} / \mathrm{v}$ DMSO as a vehicle control, $20 \mu \mathrm{M} \mathrm{CPZ}$ and $100 \mu \mathrm{M}$ EE for 24 hours. Isolated RNA was labeled and hybridized to Affymetrix Mouse Genome 4302.0 arrays and scanned using an Affymetrix GeneArray scanner.

Data of primary mouse hepatocytes exposed to CsA were derived from a previous study. ${ }^{12} \mathrm{PMH}$ were exposed for 24 to $50 \mu \mathrm{M}$ CsA, which is the $\mathrm{IC}_{20}$ value for 24 hours. In total, the primary mouse hepatocytes set comprised 42 arrays.

\section{Data normalization and preprocessing}

Ouality of Agilent arrays was being determined applying an in-house developed pipeline in $R$ version 3.0.2 R Development Core. ${ }^{13}$ Probes that were flagged by this pipeline were left out for further processing. Arrays were quantile normalized and replicate probes were summarized by taking the median. Probes that were present in $75 \%$ of all arrays were included for further processing. Remaining probes were reannotated to EntrezGenelDs using Agilent annotation file (date: 2012-06-28).

Quality of Affymetrix CEL-files was assessed by the arrayanalysis.org webservice. ${ }^{14}$ All arrays were determined of high quality. Probesets were reannotated to EntrezGene IDs using Brainarray's custom CDF version 17.1.0, as described by Dai et al. ${ }^{15}$ and normalized using the RMA method combined with MAS5-PMA-calling. ${ }^{16}$ Only probes that were present or marginal in at least 2 out of 3 replicates in all experimental groups were selected for further analysis, and their intensities were transformed to LogRatios relative to their matching controls.

\section{Statistical analyses}

Features that passed the Agilent OC (Human in vivo: 17581) and the Affymetrix PMA-criteria (HepG2: 11381; PMH: 10436; PHH: 10800) were used as input for analysis of differentially expressed genes (DEGs) using the BioConductor package LIMMA version 3.18.3. ${ }^{17}$ First, per cell line a linear model was fitted to the expression data, whereby replicate information (pairing) was treated as random effect. Subsequently, contrasts were defined that estimated the compound effect over DMSO controls. A moderated $t$-test was executed to find DEGs based on a combination of the following criteria: I) a P-value $<0.05$, II) an average absolute fold change

\section{Comparison of transcriptomic effects}

In order to find a transcriptomic fingerprint of cholestasis in vivo, differences in mRNA expression of liver biopsies from patients with and without cholestasis were analyzed and compared (Table 1). In total, 1245 genes appeared significantly up-regulated and 1097 genes were down-regulated in the cholestasis samples compared to the healthy controls.

The transcriptomic responses of three in vitro models, HepG2 cells, $\mathrm{PMH}$ and $\mathrm{PHH}$, to three cholestasis-inducing compounds, CSA, CPZ and EE, were analyzed. Exposure for 24 hours to these cholestatic compounds was analyzed in all in vitro models and this time point was therefore used to compare the drug-induced transcriptomic changes. Table 1 summarizes the number of differentially expressed genes (DEGs) for the three treatments in all three in vitro models. Of the three compounds, CsA treatment induced the largest number of transcriptional changes in all in vitro models. Overall, the highest number of DEGs was found in HepGr cells. The PMH model demonstrated a similar number of DEGs as the HepG2 cells after CsA treatment; however, the transcriptomic response after treatment with $\mathrm{CPZ}$ and $\mathrm{EE}$ was much lower. In general, the $\mathrm{PHH}$ model showed the lowest number of DEGs after treatment with the cholestatic compounds.

In order to find cholestasis-specific changes rather than compound-specific changes, the overlap of DEGs between the three compounds was analyzed using Venn Diagrams. In HepG2 cells, 68 genes were differentially up-regulated and 83 genes were differentially down-regulated in all three treatments (Figure $1 \mathrm{~A}$ and B). Two DEGs were up-regulated and two down-regulated in all three treatments in the PMH model (Figure $1 C$ and $D$ ) and only one gene was differentially up-regulated in all treatments in the PHH model, where no overlapping down-regulated genes were found (Figure $1 \mathrm{E}$ and F). The genes found to have a significantly changed expression into the same direction in all three treatments in the PMH and PHH models, were not differentially expressed, nor differentially expressed in the opposite direction, in the human in vivo samples. By contrast, HepG2 data did demonstrate overlap with the human in vivo data. Figure 2 shows the overlap of up-regulated DEGs (Figure $2 \mathrm{~A}$ ) and down-regulated DEGs (Figure $2 \mathrm{~B}$ ) between in vivo cholestasis samples and $\mathrm{HepG}_{2}$ cells exposed to the three cholestatic compounds. 12 genes were found to be differentially up-regulated both in in vivo cholestasis and in HepG2 cells exposed to cholestatic compounds. The SNRNP25 gene was found differentially down-regulated in both groups (Table 2), which is involved in mRNA processing. The 12 up-regulated genes are involved in several processes including lysosomal processes and the Endoplasmic Reticulum (ER) stress response.

Overall, the overlap between DEGs in in vivo cholestasis and DEGs after treatment with the three cholestatic compounds in vitro is limited and only DEGs in HepG2 cells showed the same directionality as DEGs in in vivo samples.

\section{Pathway mapping}

A previously published drug-induced cholestasis pathway was used to map significant 
transcriptomic changes in in vivo cholestasis and after in vitro treatment of $\mathrm{HepG} 2$ cells, $\mathrm{PMH}$ and PHH with the three cholestatic compounds (Table 3). The mRNA level of the SLCO1B gene, which is involved in the uptake of unconjugated bile salts, appeared significantly downregulated in the human cholestasis samples which thus may prevent further intracellula accumulation of bile salts. However, no significant changes in mRNA levels of this gene were detected in HepG2 cells and PHH. In PMH, no homologue for this gene was found and could therefore not be assessed. The SLC10A1 gene coding for NTCP is involved in the uptake of conjugated bile salts but appeared not significantly affected in in vivo cholestasis, where CsA treatment in PMH and CPZ treatment in PHH significantly down-regulate SLC10A1 mRNA level which may thus decrease the uptake of bile salts. Expression of this gene could not be demonstrated in HepG2 cells.

CYP7A 1 and $C Y P_{27} A_{1}$ are the rate-limiting enzymes in the synthesis of bile salts and $m R N A$ levels of CYP7A1 were drastically down-regulated in in vivo cholestasis. CYP $27 \mathrm{~A}_{1}$ expression was down-regulated in PMH after treatment with CsA. CYP7A1 expression was not measured in $\mathrm{PHH}$

$\mathrm{CYP}_{3} \mathrm{~A}_{4}, \mathrm{BAAT}$ and $\mathrm{SULT}_{2} \mathrm{~A}_{1}$ are involved in the hydroxylation and conjugation of bile salts and toxic compounds. BAAT and CYP3A4 are down-regulated in in vivo cholestasis. SULT2A1 is down regulated in HepG2 cells after treatment with CSA and EE, but up-regulated after CPZ treatment. In PMH, BAAT is differentially expressed after treatment with CSA and EE, however, after CSA treatment expression is down-regulated and after EE treatment expression is up-regulated. In PHH, SULT2A1 is significantly up-regulated after CsA treatment and CYP3 $\mathrm{A}_{4}$ is significantly up-regulated after treatment with $\mathrm{CPZ}$ and $\mathrm{EE}^{\mathrm{C}} \mathrm{CYP}_{3} \mathrm{~A}_{4}$ was not measured in $\mathrm{HepG}_{2}$ cells and no homologue was found in PMH and SULT2A1 was not assessed in PMH.

7 genes involved in the basolateral or canalicular secretion of bile salts are included in the drug-induced cholestasis pathway and three of these are significantly up-regulated in in vivo cholestasis, namely OST $\alpha$, OST $\beta$ and $A B C B 11$ (BSEP). ABCC4 expression was not measured in the in vivo cholestasis samples. In HepG2 cells, treatment with CSA and EE resulted in a down-regulation of OST $\alpha$ and an up-regulation of $A B C C_{2}, A B C C_{3}$ and $A B C B 1$. Furthermore, $E E$ treatment of HepG 2 cells up-regulated the expression of OST $\beta$ and ABCC 4 . ABCB11 expression was not assessed in $\mathrm{HePG}_{2}$ cells. In $\mathrm{PMH} A B C B 11, A B C B_{1}$ and $A B C C_{3}$ were up-regulated after treatment with $\mathrm{EE}$. However, an opposite effect on these genes was found after treatment with CsA. Expression levels of OST $\alpha$ and OST $\beta$ were not assessed in PMH. In PHH, only one of the genes involved in secretion was differentially expressed, namely OST $\alpha$, which was downregulated after treatment with CsA.

The drug-induced cholestasis pathway includes four nuclear receptors, $\mathrm{NR}_{1} \mathrm{H}_{4}$ (FXR), VDR, NR112 (PXR) and NR113 (CAR). PXR and CAR are down-regulated in in vivo cholestasis. In HepG2 cells, FXR is up-regulated after treatment with CSA and CPZ. CAR expression was not assessed in HepG 2 cells. CsA treatment resulted in a down-regulation of FXR and PXR in PMH. Expression levels of VDR and CAR were not measured in PMH. No nuclear receptors were differentially expressed in $\mathrm{PHH}$ after treatment with cholestatic compounds.

The DEGs of the established drug-induced cholestasis pathway in vivo suggest an adaptive response to cholestasis, where the uptake and synthesis of bile salts is down-regulated and their secretion up-regulated. However, not all genes in the drug-induced cholestasis pathway were differentially expressed in the patient samples. Although the in vitro data shows some similarities to the in vivo data, overall no clear response of these pathway-specific genes is observed in any of the in vitro models.

\section{Discussion}

In this study we aimed to investigate the transcriptomics fingerprint of cholestasis and we compared in vitro cholestasis induced by drugs to human cholestasis. Since samples of in vivo drug-induced cholestasis were not available, we evaluated data derived from liver biopsies from patients suffering from non-drug-induced cholestasis, in this case extra-hepatic cholestasis caused by a pancreatic tumor. In these patients, the pancreatic tumor obstructs the flow of bile through the common bile ducts towards the duodenum, causing accumulation of bile in the bile ducts, the liver and plasma. ${ }^{10}$ Cholestasis in vivo will activate an adaptive response in which the uptake and synthesis of bile salts in hepatocytes is down-regulated and the hepatocellular secretion is up-regulated in order to prevent further accumulation of bile salts. ${ }^{18}$ This adaptive response is to some degree also present in the in vivo samples of extra-hepatic cholestasis and is visualized in Table 3 presenting the drug-induced cholestasis pathway. The uptake of bile salts is down-regulated in cholestatic patients via the down-regulation of the solute carrier organic anion transporter family member ${ }^{\mathrm{B} 1} 1$. CYP7A 1 is the rate-limiting enzyme in the classic pathway of bile salt synthesis. ${ }^{19}$ The CYP7A1 gene appears differentially down-regulated in cholestatic patients in this study, which implies a down-regulation of bile salt synthesis. Furthermore, the transcription of the hepatocellular export proteins OST- $\alpha$, OST $\beta$ and the BSEP was significantly up-regulated in these in vivo samples, which may be an indication of up-regulated bile salt secretion. However, the nuclear receptors that are thought to control the adaptive response after activation by bile salts are not differentially up-regulated in the studied human cholestatic samples, PXR and CAR even being down-regulated. Furthermore, BAAT and $\mathrm{CYP}_{3} \mathrm{~A}_{4}$, which are involved in preventive conjugation of bile salts, are also down regulated. Schaap et al. suggested that FGF19, normally produced by the small intestine but ectopically overexpressed in the human cholestatic liver, may be involved in the adaptive response, including the down-regulation of CYP7A1 expression. ${ }^{10}$ Overall, an adaptive response is observed in the patient samples using the drug-induced cholestasis pathway, which confirms the involvement of the genes in this pathway in in vivo cholestasis. However, not all genes of the drug-induced cholestasis pathway are significantly changed in the patient samples. Therefore, further validation of this pathway, using in vivo data on drug-induced cholestasis, is necessary.

In order to create a transcriptomic fingerprint of drug-induced cholestasis, three liver cell models were exposed to three cholestasis-inducing compounds. In an attempt to select cholestasis-specific DEGs, the overlap between DEGs in all three treatments was selected. 15 genes were differentially expressed into the same direction in all three treatments in $\mathrm{HepG}_{2}$ cells, of which 13 were also significantly changed in in vivo cholestasis. These overlapping genes are involved in several processes, including cell proliferation and metabolism. Furthermore, genes involved in ER stress and in the unfolded protein response, were differentially expressed. 
In vitro classification of cholestatic compounds previously indicated that the UPR may be an important cellular effect in drug-induced hepatotoxicity. ${ }^{9}$ However, in the other two cell models, only low numbers of overlapping DEGs were found, which were not differentially expressed in vivo. Overall, these low numbers of overlapping DEGs suggest different mechanisms for the three cholestatic drugs.

Cyclosporin A is a known inhibitor of the BSEP and several other ATP-dependent export carriers, which is suggested to be the mechanism behind CSA-induced cholestasis. ${ }^{20-21}$ The inhibition of the BSEP could not be assessed in HepG2 cells since expression of the BSEP is low in these cells and the expression values of the $A B C B 11$ gene did not pass the PMA criteria. ${ }^{22-23}$ The $A B C B 11$ gene was significantly down-regulated in $\mathrm{PMH}$, but no significant change was found in PHH. In HepG2 cells and PHH, CsA treatment down-regulated OST- $\alpha$, which may point to CsA-induced accumulation of bile constituents. Three other proteins involved in secretion were differentially up-regulated in $\mathrm{HepG}_{2}$ cells after $\mathrm{CsA}_{\mathrm{A}}$ treatment, $\mathrm{ABCC} 2, \mathrm{ABCC} 3$ and $\mathrm{ABCB}$. In combination with the observed up-regulation of the FXR, this may indicate an adaptive response of $\mathrm{HepG}_{2}$ cells to $\mathrm{CSA}_{\mathrm{A}}$-induced toxicity. However, $\mathrm{ABCC} 3$ and $A B C B 1$ were significantly down-regulated after CsA-treatment in PMH, suggesting differences in CsA-induced toxicity between human and mouse cells. CsA exposure in PHH resulted in an up-regulation of SULT2A which catalyzes the sulfate conjugation of many substrates, including bile salts, which increases their solubility and excretion. ${ }^{24}$ Although the three cell models show differences in differentially expressed genes after CsA treatment, indications for significant changes of expression of CsAspecific genes and genes involved in the cholestasis-related adaptive response were observed in all cell models.

CPZ treatment only resulted in changes in PHH and HepG2 cells when evaluating its impact on the a priori defined cholestasis pathway. SLC1OA1 involved in the uptake of bile salts, was down-regulated in $\mathrm{PHH}$, which may indicate an adaptive response to $\mathrm{CPZ}$-induced cholestasis in $\mathrm{PHH}$. Furthermore, $\mathrm{CYP}_{3} \mathrm{~A}_{4}$ was up-regulated in $\mathrm{PHH}$ after $\mathrm{CPZ}$ treatment. $\mathrm{CYP}_{3} \mathrm{~A}_{4}$ is involved in the metabolism of CPZ and up-regulation of this enzyme suggests that the PHH up-regulate the breakdown of CPZ and accumulated bile salts. ${ }^{25}$ Down-regulation of SLC10A1 and up-regulation of $\mathrm{CYP}_{3} \mathrm{~A} 4$ was also observed in HepaRG cells after CPZ treatment. ${ }^{26}$ Anthérieu et al. report CPZ-induced ROS formation which resulted in taurocholic acid accumulation as an early response and an adaptive response to cholestasis after 24 hours exposure to CPZ. CPZ exposure of $\mathrm{HepG}_{2}$ cells resulted in an up-regulation of FXR and SULT2A1. FXR is up-regulated as a response to accumulating bile salts and activates the adaptive response including increased bile salt sulfation by up-regulation of SULT2A1. ${ }^{27}$ Overall CPZ treatment resulted in a relative low number of DEGs in all three cell models, however gene expression changes indicative of an adaptive response in hepatocytes after treatment with CPZ were observed in HepG2 cells and $\mathrm{PHH}$.

Investigation of changes in the drug-induced cholestasis pathway after treatment with $\mathrm{EE}$ identified most gene expression changes in $\mathrm{HepG}_{2}$ cells, followed by $\mathrm{PMH}$ and $\mathrm{PHH}$ with only one gene expression significantly changed. In $\mathrm{PHH}$, the expression of $\mathrm{CYP}_{3} \mathrm{~A}_{4}$ was

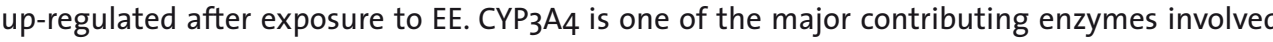

in the metabolism of EE and thus, up-regulation of this enzyme may be a direct response to EE treatment. ${ }^{28}$ Four genes were differentially expressed after EE treatment in $\mathrm{PMH}$, namely $B A A T, A B C B 11, A B C C_{3}$ and $A B C B 1$. $B A A T$ is involved in the conjugation of bile salts and $A B C B 11$ $A B A B 1$ and $A B C C_{3}$ are involved in the secretion of bile salts. Up-regulation of these enzyme may therefore be part of the adaptive response to EE-induced bile salt accumulation. Genes involved in the export of bile salts were also differentially up-regulated in $\mathrm{HepG} 2$ cells, namely OST $-\beta, A B C C_{2}, A B C C_{3}, A B C C_{4}$ and $A B C B 1$, indicative of an adaptive response. However, OST- $\alpha$ was down-regulated and the sulfation of bile salts via SULT2A1 was down-regulated. EE was shown to down-regulate mRNA levels of OST- $\alpha$ in the ileum of rats in vivo ${ }^{29}$ and SULT2A1 is involved in the sulfation of EE. ${ }^{30}$ The down-regulation of OST- $\alpha$ and SULT $2 A 1$ is not in line with an adaptive response to EE-induced bile salt accumulation. However, down-regulation of these genes may be EE-specific and may play a role in the induction of EE-induced cholestasis.

Overall, investigation of gene expression changes induced by prototypical cholestatic drugs in HepG2 cells, PMH and PHH showed little overlap with gene expression profiles of cholestasis in patients, the HepG2 model performing best. However, investigation of drug induced expression levels of genes involved in the a priori defined cholestasis pathway revealed some indications for an adaptive response in vivo as well as in the in vitro liver cell models. Considerable differences in induced gene expressions were observed between compounds and between different cell models. In the present study, only one time point and one concentration were investigated. Extensive dose-dependency studies and time-series analyses may further improve our understanding of drug-induced cholestasis. Furthermore, the development and improvement of new in vitro models, e.g. three dimensional cell cultures and the simultaneous culturing of multiple cell types, may better resemble the in vivo liver and improve the investigation of drug-induced liver injury.

Table 1. Numbers of differentially expressed genes (moderate t-test with $p$-value $<0.05$ and absolute $F C$ 1.5) in in vivo cholestasis and in three in vitro models (HepG cells, primary mouse hepatocytes and primary human hepatocytes) after treatment for 24 hours with three cholestasis-inducing compounds (cyclosporin $A$, chlorpromazine and ethinyl estradiol).

\begin{tabular}{|l|l|l|l|l|l|l|l|l|l|l|} 
& Human & HepG2 Cells & PMH & \multicolumn{4}{c|}{ PHH } \\
& In Vivo & CSA & CPZ & EE & CSA & CPZ & EE & CSA & CPZ & EE \\
\hline Up-regulated DEGs & 1245 & 1216 & 201 & 776 & 1756 & 97 & 362 & 325 & 59 & 8 \\
\hline Down-regulated DEGs & 1097 & 2017 & 327 & 1053 & 1708 & 173 & 174 & 452 & 70 & 13 \\
\hline
\end{tabular}


Table 2. Differentially expressed genes both in in vivo cholestasis samples and in HepG2 cells exposed to cyclosporin A, chlorpromazine and ethinyl estradiol.

\begin{tabular}{|c|c|c|c|}
\hline \multicolumn{4}{|c|}{ Up-regulated genes } \\
\hline Entrez Gene ID & Gene Symbol & Gene description & GO term \\
\hline 440 & ASNS & $\begin{array}{l}\text { Asparagine synthetase } \\
\text { (glutamine-hydrolyzing) }\end{array}$ & Response to amino acid \\
\hline 586 & BCAT1 & $\begin{array}{l}\text { Branched chain amino-acid } \\
\text { transaminase 1, cytosolic }\end{array}$ & Cell proliferation \\
\hline 4131 & $M A P_{1} B$ & $\begin{array}{l}\text { Microtubule-associated } \\
\text { protein } 1 B\end{array}$ & $\begin{array}{l}\text { Negative regulation of } \\
\text { intracellular transport }\end{array}$ \\
\hline 6286 & S10oP & $\begin{array}{l}\text { S10o calcium binding } \\
\text { protein P }\end{array}$ & Calcium-dependent protein binding \\
\hline 6809 & $S T X_{3}$ & Syntaxin 3 & $\begin{array}{l}\text { Intracellular protein transport; } \\
\text { Vesicle-mediated transport }\end{array}$ \\
\hline 10797 & MTHFD2 & $\begin{array}{l}\text { Methylenetetrahydrofolate } \\
\text { dehydrogenase } \\
\text { (NADP+ dependent) } 2, \\
\text { methenyltetrahydrofolate } \\
\text { cyclohydrolase }\end{array}$ & $\begin{array}{l}\text { Folic acid-containing compound } \\
\text { biosynthetic process }\end{array}$ \\
\hline 23433 & RHOQ & $\begin{array}{l}\text { Ras homolog family } \\
\text { member } Q\end{array}$ & $\begin{array}{l}\text { Negative regulation of establishment } \\
\text { of protein localization to } \\
\text { plasma membrane }\end{array}$ \\
\hline 23643 & LYg6 & Lymphocyte antigen 96 & $\begin{array}{l}\text { Cell surface receptor signaling } \\
\text { pathway; Endosome membrane }\end{array}$ \\
\hline 55062 & WIPI1 & $\begin{array}{l}\text { WD repeat domain, } \\
\text { phosphoinositide interacting } 1\end{array}$ & $\begin{array}{l}\text { Endoplasmic reticulum unfolded } \\
\text { protein response }\end{array}$ \\
\hline 57016 & $A K R \backslash B 10$ & $\begin{array}{l}\text { Aldo-keto reductase family } 1 \text {, } \\
\text { member B10 (aldose reductase) }\end{array}$ & Steroid metabolic process; Lysosome \\
\hline 57761 & $T_{R I B}$ & Tribbles pseudokinase 3 & $\begin{array}{l}\text { Negative regulation of fatty acid } \\
\text { biosynthetic process; Positive } \\
\text { regulation of ubiquitin-protein ligase } \\
\text { activity; Response to endoplasmic } \\
\text { reticulum stress }\end{array}$ \\
\hline 84662 & GLIS2 & GLIS family zinc finger 2 & $\begin{array}{l}\text { Negative regulation of transcription, } \\
\text { DNA-templated; Cell differentiation }\end{array}$ \\
\hline Down-regulate & ed genes & & \\
\hline 79622 & SNRNP25 & $\begin{array}{l}\text { Small nuclear ribonucleo- } \\
\text { protein } 25 \mathrm{kDa}\left(\mathrm{U}_{11} / \mathrm{U}_{12}\right)\end{array}$ & mRNA processing \\
\hline
\end{tabular}

Table 3. Differentially expressed genes ( $F C>1,5 ; F D R<0,05$ or $p$-value $<0,05)$ of the drug-induced cholestasis pathway published by Yuryev et al. in in vivo cholestasis and after in vitro treatment of HepGz cells, primary mouse hepatocytes and primary human hepatocytes for 24 hours with cholestatic compounds.

\begin{tabular}{|c|c|c|c|c|c|c|c|c|c|c|c|}
\hline & & & Hepc & cells & & $\begin{array}{l}\text { Prima } \\
\text { Hepa }\end{array}$ & $\begin{array}{l}\text { y Mo } \\
\text { ocyte }\end{array}$ & & $\begin{array}{l}\text { Prin } \\
\text { Hep }\end{array}$ & $\begin{array}{l}\text { y Hur } \\
\text { ocyte }\end{array}$ & \\
\hline Entrez & & & & & & & & & & & \\
\hline $\begin{array}{l}\text { Gene ID } \\
\text { Uptake }\end{array}$ & Symbol & In Vivo & CSA & $C P Z$ & $E E$ & $\operatorname{Cs} A$ & $C P Z$ & $E E$ & CSA & $C P Z$ & $E E$ \\
\hline 10599 & $S L C_{1} B_{1}$ & $-1,9^{* *}$ & & & & $n h$ & $n h$ & $n h$ & & & \\
\hline 6554 & SLC1OA1 & & $n m$ & $n m$ & $n m$ & $-32,32^{*}$ & & & & $-1,77^{*}$ & \\
\hline
\end{tabular}

Synthesis

\begin{tabular}{|l|l|l|l|l|l|l|l|}
\hline 1593 & CYP27A1 & & & & \\
\hline 1581 & CYP7A1 & $-18,77^{* *}$ & & & & & \\
\hline
\end{tabular}

\section{Conjugation}

\begin{tabular}{|l|l|l|l|l|l|l|l|l|l|l|l|}
\hline 570 & BAAT & $-1.9^{*}$ & & & \multicolumn{1}{c}{$-21,68^{* *}$} & $9.84^{*}$ & & \\
\hline 6822 & SULT2A1 & & $-1,66^{* *}$ & $2,42^{* *}$ & $-2,86^{* *}$ & $n m$ & $n m$ & $n m$ & $2,24^{* *}$ & & \\
\hline 1576 & CYP3A4 & $-1.63^{*}$ & $n m$ & $n m$ & $n m$ & $n h$ & $n h$ & $n h$ & & $2,26^{* *}$ & $1,85^{* *}$ \\
\hline
\end{tabular}

\section{Secretion}

\begin{tabular}{|l|l|l|l|l|l|l|l|l|l|l|l|}
\hline 200931 & OSTalpha & $2,79^{* *}$ & $-2,49^{* *}$ & & $-3,03^{* *}$ & $n m$ & $n m$ & $n m$ & $-2,16^{* *}$ & & \\
\hline 123264 & OSTBETA & $10,57^{* *}$ & & & $2,37^{* *}$ & $n m$ & $n m$ & $n m$ & & & \\
\hline 10257 & ABCC4 & $n m$ & & & $1,66^{* *}$ & & & & & \\
\hline 8647 & $A B C B 11$ & $1.73^{*}$ & $n m$ & $n m$ & $n m$ & $-4,94^{* *}$ & & $3.03^{*}$ & & \\
\hline 1244 & $A B C C 2$ & & $1,59^{* *}$ & & $2,09^{* *}$ & & & & & \\
\hline 8714 & $A B C C 3$ & & $2,05^{* *}$ & & $1,79^{* *}$ & $-2,67^{* *}$ & & $1,68^{* *}$ & & \\
\hline 5243 & $A B C B 1$ & & $1,53^{* *}$ & & $2,44^{* *}$ & $-2,21^{* *}$ & & $2,07^{* *}$ & & \\
\hline
\end{tabular}

\section{Nuclear receptors}

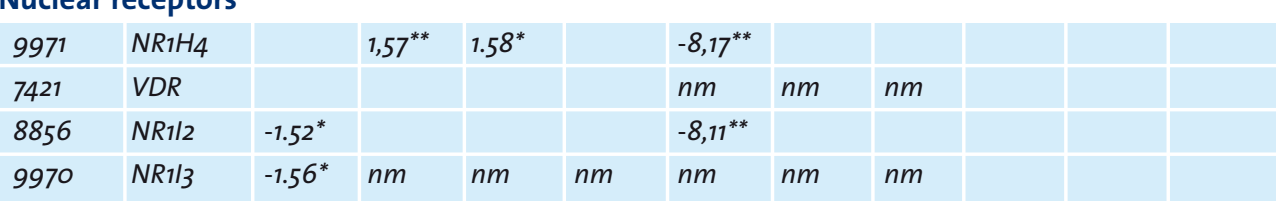

* p-value $<0.05$ (FDR > 0.05); ** FDR < $0.05 ; n m$, Not measured; $n h$, No homologue 
HepG2
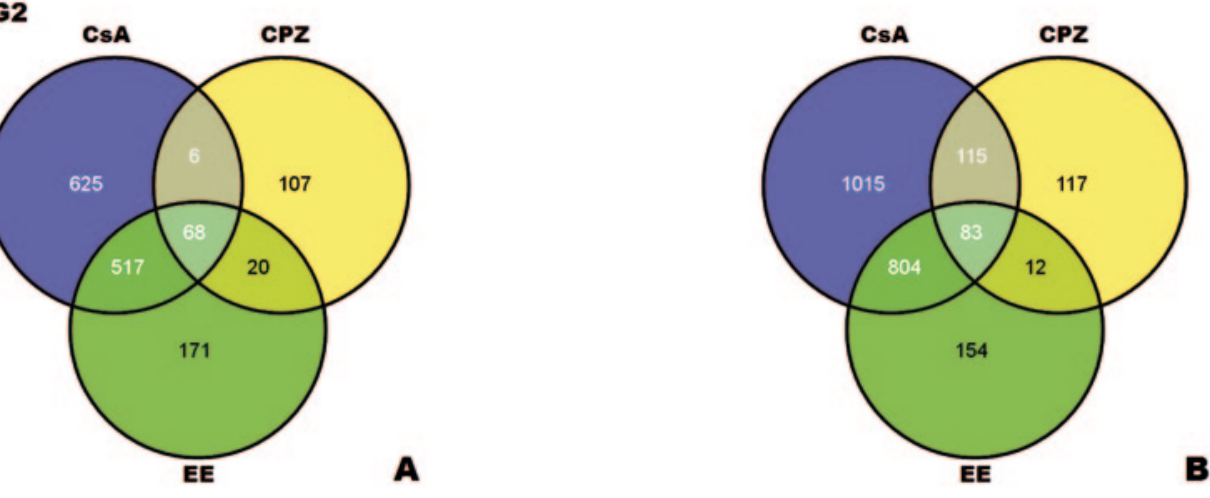

A
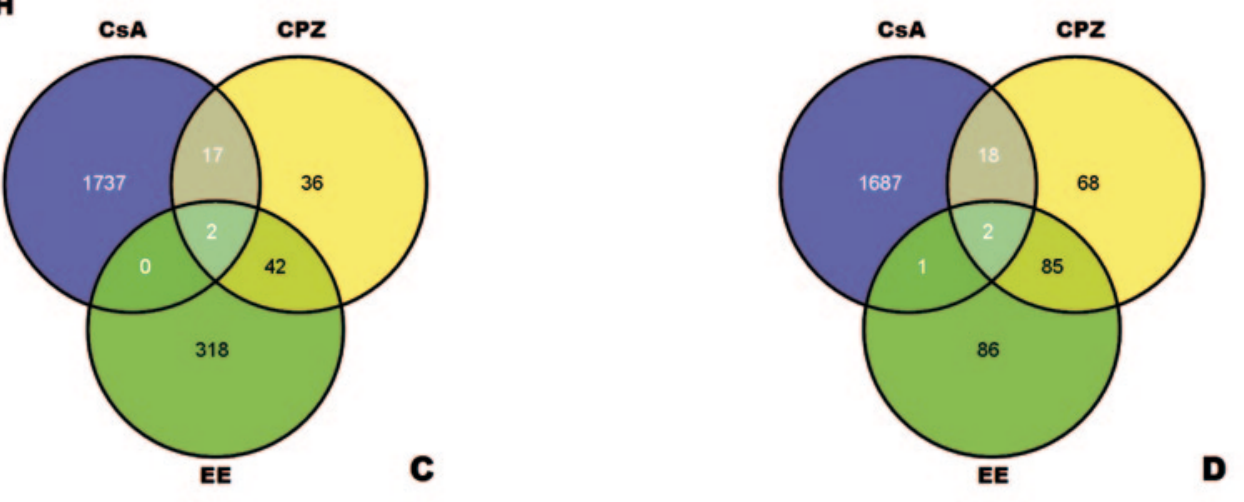

c

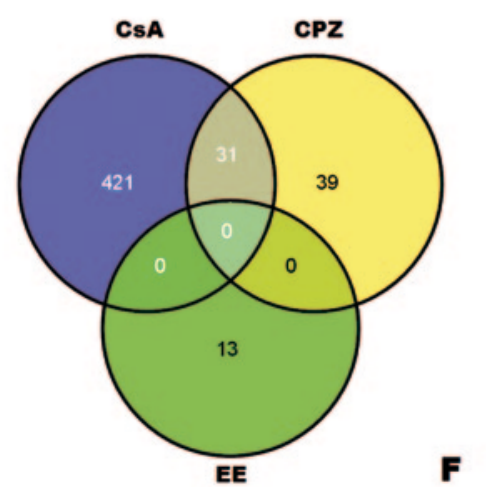

Up-regulated

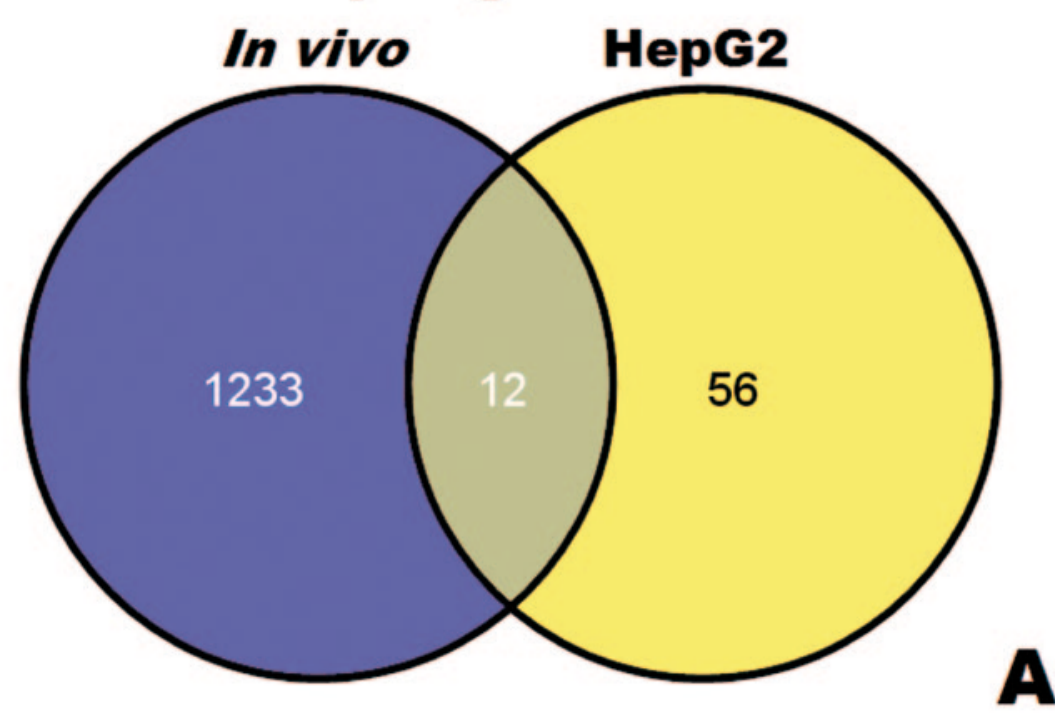

Down-regulated

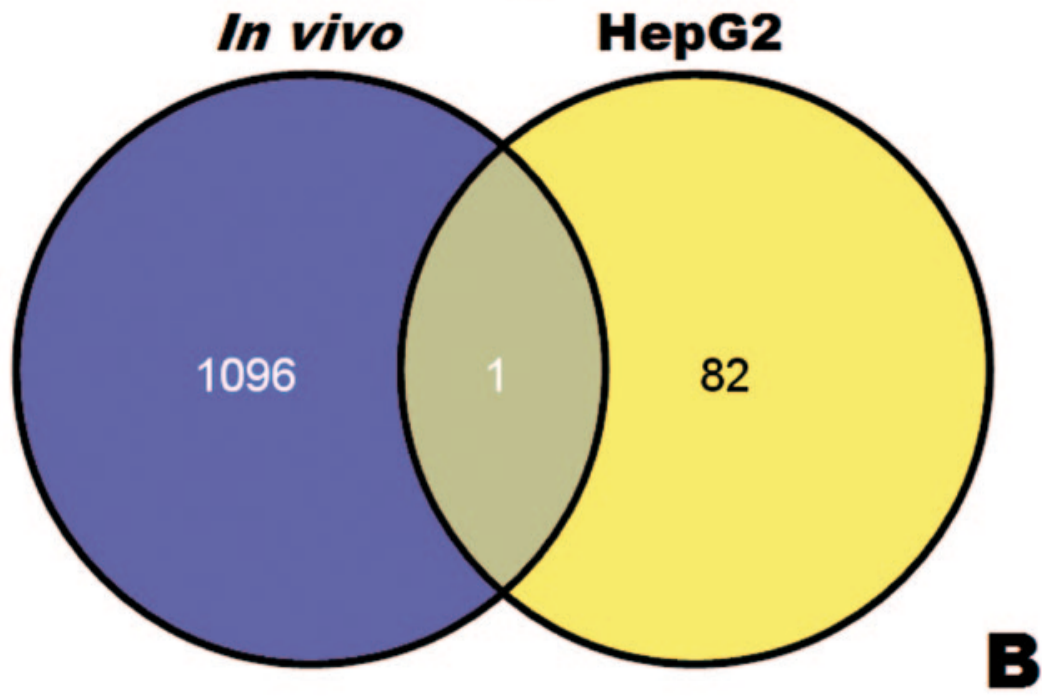

Figure 2. Venn diagrams showing the overlap in up-regulated (A) and down-regulated (B) differentially expressed genes (moderate t-test with $p$-value $<0.05$ and absolute $F C>1.5$ ) in in vivo cholestasis and in $\mathrm{HepG}_{2}$ cells after treatment with cyclosporin A, chlorpromazine and ethinyl estradiol.

Figure 1. Venn diagrams showing the overlap in up-, and down-regulated differentially expressed genes (moderate t-test with $p$-value $<0.05$ and absolute $F C>1.5$ ) after treatment with cyclosporin A, chlorpromazine and ethinyl estradiol in HepG2 cells ( $A$ and $B$ ), primary mouse hepatocytes (C and D) and primary human hepatocytes (E and F). 


\section{References}

Björnsson, E., Olsson, R. (2005) Outcome and prognostic markers in severe drug-induced liver disease. Hepatology 42 , $481-489$.

2. Vinken, M., Landesmann, B., Goumenou, M., Vinken, S., Shah, I., Jaeschke, H., Willett, C., Whelan, M., Rogiers, V. (2013) Development of an Adverse Outcome Pathway From Drug-Mediated Bile Salt Export Pump Inhibition to Cholestatic Liver Injury. Toxicol. Sci.

3. Yuryev, A., Kotelnikova, E., Daraselia, N. (2009) Ariadne's ChemEffect and Pathway Studio knowledge base. Expert Opin Drug Dis. 4, 1307-1318.

4. Hartung, T. (2009) Toxicology for the twenty-first century. Nature 460, 208-212

5. Caiment, F., Tsamou, M., Jennen, D., Kleinjans, J. (2014) Assessing compound carcinogenicity in vitro using connectivity mapping. Carcinogenesis 35, 201-207.

6. Hebels, D. G., Jetten, M. J., Aerts, H. J., Herwig, R., Theunissen, D. H., Gaj, S., van Delft, J. H., Kleinjans, J. C. (2014) Evaluation of database-derived pathway development for enabling biomarker discovery for hepatotoxicity. Biomark Med 8, 185

7. Gomez-Lechon, M. J., Donato, M. T., Castell, J. V., Jover, R. (2004) Human hepatocytes in primary culture: the choice to investigate drug metabolism in man. Curr Drug Metab 5, 443-462.

8. Mathijs, K., Kienhuis, A. S., Brauers, K. J. J., Jennen, D. G. J., Lahoz, A., Kleinjans, J. C. S., van Delft, J. H. M. (200g) Assessing the Metabolic Competence of Sandwich-Cultured Mouse Primary Hepatocytes. Drug Metab. Dispos. 37, 1305-1311.

9. Van den Hof, W. F. P. M., Coonen, M. L. J., van Herwijnen, M., Brauers, K., Wodzig, W. K. W. H., van Delft, J. H. M., Kleinjans, J. C. S. (2014) Classification of Hepatotoxicants Using HepG2 Cells: A Proof of Principle Study. Chem. Res. Toxicol. 27, 433-

10. Schaap, F. G., van der Gaag, N. A., Gouma, D. J., Jansen, P. L. M. (2009) High expression of the bile salt-homeostatic hormone fibroblast growth factor 19 in the liver of patients with extrahepatic cholestasis. Hepatology 49, 1228-1235.

11. Mosmann, T. (1983) Rapid colorimetric assay for cellular growth and survival: Application to proliferation and cytotoxicity assays. Journal of Immunological Methods 65, 55-63.

12. Van den Hof, W. F. P. M., Van Summeren, A., Lommen, A., Coonen, M. L. J., Brauers, K., Herwijnen, M. v., Wodzig, W. K. W. H., Kleinjans, J. C. S. (2014) Integrative Cross-Omics Analysis in Primary Mouse Hepatocytes unravels Mechanisms of Cyclosporin A-Induced Hepatotoxicity. Toxicology Accepted.

13. Team, R. D. C., R: A Language and Environment for Statistical Computing. R Foundation for Statistical Computing: 2013.

14. Eijssen, L. M. T., Jaillard, M., Adriaens, M. E., Gaj, S., de Groot, P. J., Müller, M., Evelo, C. T. (2013) User-friendly solutions for microarray quality control and pre-processing on ArrayAnalysis.org. Nucleic Acids Res. 41, W71-W76.

15. Dai, M., Wang, P., Boyd, A. D., Kostov, G., Athey, B., Jones, E. G., Bunney, W. E., Myers, R. M., Speed, T. P., Akil, H., Watson, S. J., Meng, F. (2005) Evolving gene/transcript definitions significantly alter the interpretation of GeneChip data. Nucleic Acids Res. 33, 1775

16. Irizarry, R. A., Hobbs, B., Collin, F., Beazer-Barclay, Y. D., Antonellis, K. J., Scherf, U., Speed, T. P. (2003) Exploration, normalization, and summaries of high density oligonucleotide array probe level data. Biostatistics 4, 249-264.

17. Smyth, G. K., limma: Linear Models for Microarray Data. In Bioinformatics and Computational Biology Solutions Using R and Bioconductor, Gentleman, R.; Carey, V. Huber, W. Irizarry, R. Dudoit, S., Eds. Springer New York: 2005. pp 397-420.

18. Wagner, M., Zollner, G., Trauner, M. (2010) Nuclear receptor regulation of the adaptive response of bile acid transporters in cholestasis. Semin Liver Dis 30, 160-177.

19. Chiang, J. Y. L. (2009) Bile acids: regulation of synthesis. J. Lipid Res. 50, 1955-1966.
20. Böhme, M., Jedlitschky, G., Leier, I., Büchler, M., Keppler, D. (1994) ATP-dependent export pumps and their inhibition by cyclosporins. Adv. Enzyme Regul. 34, 371-380.

21. Kis, E., loja, E., Rajnai, Z., Jani, M., Méhn, D., Herédi-Szabó, K. Krajicsi, P. (2012) BSEP inhibition - In vitro screens to assess cholestatic potential of drugs. Toxicol. In Vitro 26, 1294-1299.

22. Yu, J., Lo, J.-L., Huang, L., Zhao, A., Metzger, E., Adams, A., Meinke, P. T., Wright, S. D., Cui, J. (2002) Lithocholic Acid Decreases Expression of Bile Salt Export Pump through Farnesoid X Receptor Antagonist Activity J . Biol. Chem. 277, 31441-31447.

23. Weerachayaphorn, J., Cai, S.-Y., Soroka, C. J., Boyer, J. L. (2009) Nuclear factor erythroid 2-related factor 2 is a positive regulator of human bile salt export pump expression. Hepatology 50, 1588-1596.

24. Alnouti, Y. (2009) Bile Acid Sulfation: A Pathway of Bile Acid Elimination and Detoxification. Toxicol. Sci. 108, 225-246.

25. Wójcikowski, J., Boksa, J., Daniel, W. A. (2010) Main contribution of the cytochrome P450 isoenzyme 1A2 (CYP1A2) to $\mathrm{N}$-demethylation and 5 -sulfoxidation of the phenothiazine neuroleptic chlorpromazine in human liver-A compariso with other phenothiazines. Biochem. Pharmacol. 80, 1252-1259.

26. Anthérieu, S., Azzi, P. B.-E., Dumont, J., Abdel-Razzak, Z., Guguen-Guillouzo, C., Fromenty, B., Robin, M.-A. Guillouzo, A. (2013) Oxidative stress plays a major role in chlorpromazine-induced cholestasis in human HepaRG cells. Hepatology 57, 1518-1529.

27. Zollner, G., Trauner, M. (2006) Molecular mechanisms of cholestasis. Wien Med Wochenschr 156, 380-385.

28. Wang, B., Sanchez, R. I., Franklin, R. B. Evans, D. C., Huskey, S. E. (2004) The involvement of CYP3 44 and CYP2C9 in the metabolism of 17 alpha-ethinylestradiol. Drug Metab Dispos 32, 1209-1212.

29. Hirsova, P., Karlasova, G., Dolezelova, E., Cermanova, J., Zagorova, M., Kadova, Z., Hroch, M., Sispera, L., Tomsik, P., Lenicek, M., Vitek, L., Pavek, P., Kucera, O., Cervinkova, Z., Micuda, S. (2013) Cholestatic effect of epigallocatechin gallate in rats is mediated via decreased expression of Mrp2. Toxicology 303, 9-15.

3o. Cui, D., Booth-Genthe, C. L., Carlini, E., Carr, B., Schrag, M. L. (2004) Heterotropic modulation of sulfotransferase $2 \mathrm{~A}$ activity by celecoxib: product ratio switching of ethynylestradiol sulfation. Drug Metab. Dispos. 32, 1260-1264. 


\section{Chapter 4}

\section{MTEGRTME}

MULTIPLE OMICS TO UNRAVEL MECHANISMS OF CYCLOSPORIN A INDUCED HEPATOTOXICITY IN VITRO

Van den Hof, W.F.P.M

Ruiz-Aracama, A.

Van Summeren, A.

Jennen, D.G.J.

$$
\text { Gaj, } S \text {. }
$$

Coonen, M.L.J.

Brauers, K.

Wodzig, W.K.W.H.

$$
\text { van Delft }
$$

and Kleinjans, J.C.S 
Abstract

In order to improve attrition rates of candidate-drugs there is a need for a better understanding of the mechanisms underlying drug-induced hepatotoxicity. We aim to further unravel the toxicological response of hepatocytes to a prototypical cholestatic compound by integrating transcriptomic and metabonomic profiling of HepG 2 cells exposed to Cyclosporin A. Cyclosporin A exposure induced intracellular cholesterol accumulation and diminished intracellular bile acid levels. Performing pathway analyses of significant mRNAs and metabolites separately and integrated, resulted in more relevant pathways for the latter. Integrated analyses showed pathways involved in cell cycle and cellular metabolism to be significantly changed. Moreover, pathways involved in protein processing of the endoplasmic reticulum, bile acid biosynthesis and cholesterol metabolism were significantly affected. Our findings indicate that an integrated approach combining metabonomics and transcriptomics data derived from representative in vitro models, with bioinformatics can improve our understanding of the mechanisms of action underlying drug-induced hepatotoxicity. Furthermore, we showed that integrating multiple omics and thereby analyzing genes, microRNAs and metabolites of the opposed model for drug-induced cholestasis can give valuable information about mechanisms of drug-induced cholestasis in vitro and therefore could be used in toxicity screening of new drug candidates at an early stage of drug discovery. 


\section{Introduction}

New drugs are being developed continuously. Before they can be released for use by the genera public their safety needs to be tested extensively in animal studies and clinical trials. The liver metabolizes many drugs which makes it a vulnerable target for drug-induced toxicity. Despite all the preclinical tests, many drugs are found to be hepatotoxic in phase I to III clinical trials or later ', indicating that the preclinical tests are not sensitive enough to correctly predict hepatotoxicity.

Hepatotoxicity is one of the most important causes of drug failure, accountable for up to $29 \%$ of all drug withdrawals. ${ }^{2}$ Drug-induced hepatotoxicity can roughly be divided into three major pathological classes, necrosis, steatosis and cholestasis, and the modes-ofaction underlying these pathologies have been investigated extensively. Although multiple mechanisms are identified, some toxicological responses still remain to be clarified. Before clinical testing, drugs are tested in animal toxicity studies, but these studies are timeconsuming and are subject to an ongoing ethical debate. Although animal toxicity studies can give valuable information about human toxicity ${ }^{3}$, the predictability of animal tests for human toxicity should be improved. ${ }^{4}$ Therefore, a major effort is put in finding new, and better, non-animal-based in vitro tests for toxicity screening and investigation of toxicological mechanisms.

Toxicogenomics combines toxicology with omics technologies to investigate the mechanisms underlying a toxicological response. ${ }^{5}$ Microarray-based gene expression profiling still remain the core technological platform in toxicogenomic research. ${ }^{6}$ It is a well-established technique and provides genome-wide information on transcriptomic changes 7 and is used to obtain bette insight in the molecular mechanisms underlying drug-induced liver toxicity. ${ }^{8-10}$ During the las decade, toxicogenomics research has expanded and also includes transcriptomics of microRNAs, proteomics, metabonomics and epigenomics. MicroRNAs are regulators of mRNA and protein levels and therefore may play an important role in the mechanisms of toxicity. "Protein levels as well as post-translational modifications can be measured by proteomic technologies and therewith give valuable information about the mode of action. ${ }^{12}$ Metabonomics is defined as the quantitative measurement of the time-related multi-parametric metabolic response of living systems to pathophysiological stimuli or genetic modification' ${ }^{13}$ and provides information on the dynamic metabolic status after exposure to a toxicant.

All these 'omics'-technologies individually can generate valuable information about the mechanism underlying drug-induced liver injury. ${ }^{14-16}$ It has been shown that integrating transcriptomics with metabonomics data, gives new insights in the molecular mechanisms underlying drug-induced hepatotoxicity in vivo. ${ }^{77-18}$ Furthermore, Jennen et al. showed that an integrated analysis of transcriptomics and metabonomics data in an in vitro experiment with 2,3,7,8-Tetrachlorodibenzo-p-dioxin also resulted in novel insights into response pathways. Although their study also integrated transcriptomics and metabonomics, microRNA profiling was not included. We therefore hypothesize that an integrated transcriptomics and metabonomics approach combined with microRNA profiling will result in an improved understanding of the mechanisms underlying drug-induced hepatotoxicity.
To test this hypothesis HepG2 cells were exposed to the hepatotoxicant Cyclosporin A (CsA) CsA is a calcineurin inhibitor and is widely used as an immunosuppressant in transplant patients. A toxic side effect of CsA is that it could cause cholestasis in transplant patients. ${ }^{20}$ This has been confirmed in animal experiments. ${ }^{21}$ Additionally, CsA inhibits several ATPdependent export carriers, including the Bile Salt Export Pump (BSEP, ABCB11). ${ }^{22-23}$ The BSEP is responsible for the secretion of bile into the bile canaliculus and inhibition of these transport proteins by CsA will slow down or block the flow of bile, leading to either an intrahepatocellular build-up of bile-acids or to an increase of serum bile acid levels. Eventually, this will cause hepatocellular damage and induce cholestasis. ${ }^{24}$ We consequently decided to exploit this a priori knowledge on CsA-induced hepatotoxicity for evaluating the added value of our integrated omics approach.

Primary human hepatocytes $(\mathrm{PHH})$ are considered to represent the best in vitro cell system for liver studies ${ }^{25}$, although their use in toxicity screening is bound to limitations. Low availability of fresh human liver samples, difficult culturing procedures and interindividual differences between liver donors hinder the use of PHH for large screening purposes. ${ }^{26}$ Therefore, immortalized liver-derived cell lines are thought to present an acceptable alternative and have consequently been used in many toxicity studies. One of these alternatives is the human hepatocellular carcinoma cell line HepG2. Although HepG2 cells have a lower metabolizing capacity compared to $\mathrm{PHH}^{27}$, several studies demonstrate that $\mathrm{HepG}_{2}$ cells are able to metabolize drugs leading to toxic effects. ${ }^{28-31}$ Therefore, HepG2 cells are still frequently used for toxicogenomics and high-throughput toxicity screening studies. ${ }^{2-40}$

HepG2 cells were exposed to different concentrations of CsA for several treatment periods. Bile acid analysis and investigation of the apolar cell extracts was performed for the phenotypic anchoring of cholestatic events. Individual and integrated pathway analyses of transcriptomics and metabonomics data were compared. Mechanisms of CsA-induced hepatotoxicity were further unraveled by investigating the significantly affected pathways and the possible impact of deregulated microRNAs on these pathways.

\section{Materials and methods}

Chemicals

Modified Eagle's medium (MEM) plus glutamax, sodium pyruvate, fetal calf serum (FCS), non-essential amino acids, penicillin/streptomycin, Hanks' calcium- and magnesium-free buffer were obtained from Invitrogen (Breda, The Netherlands), dimethylsulfoxide (DMSO), Trypan blue, 3-(4,5-dimethylthiazol-2-yl)-2,5-diphenyltetrazolium bromide (MTT), Cyclosporin A (BioChemika), Cholic Acid, Chenodeoxycholic Acid, Deoxycholic Acid, Dehydrocholic Acid and $\mathrm{N}, \mathrm{N}$-dimethylformamide (anhydrous, 99.8\%) were purchased from Sigma-Aldrich (Zwijndrecht, The Netherlands), deuterated chloroform $\left(\mathrm{CDCl}_{3}\right)$, deuterium oxide $\left(\mathrm{D}_{2} \mathrm{O}\right)$ and deuterated methanol (CD OD) were obtained from VWR International (Amsterdam, The Netherlands) and Ammonium acetate $\left(\mathrm{NH}_{4} \mathrm{Ac}\right)$, sodium chloride $(\mathrm{NaCl})$, dipotassium hydrogenphosphate $\left(\mathrm{K}_{2} \mathrm{HPO}_{4}\right)$, monopotassium hydrogenphosphate $\left(\mathrm{KH}_{2} \mathrm{PO}_{4}\right)$ were obtained from Merck (Darmstadt, Germany). 
Cell culture

HepG2 cells were cultured in MEM plus glutamax containing 10\% v/v FCS, 1\% v/v Sodium Pyruvate, $1 \% \mathrm{v} / \mathrm{v}$ non-essential amino acids, $2 \% \mathrm{w} / \mathrm{v}$ penicillin and streptomycin at $37^{\circ} \mathrm{C}$ in an atmosphere containing $5 \% \mathrm{CO}_{2}$

\section{Cell treatment}

CsA concentrations were derived from cytotoxicity tests based on the MTT method as described in an earlier study. ${ }^{41}$ In short, HepG2 cells were treated with $3 \mu \mathrm{M}$ or $20 \mu \mathrm{M}$, which are the $\mathrm{IC}_{20}$ concentrations for 72 and 24 hours, respectively. While MTT assays were performed using $2 \%$ FCS, different culture conditions requiring different FCS concentrations had to be used in the experiments. $10 \%$ FCS was used in the experiments described in this paper, which induced approximately $8 \%$ less cytotoxicity (Supplemental file 40 ). For transcriptomics (mRNA and microRNA) HepG2 cells were seeded in 6 well plates and were exposed for 12, 24, 48 and 72 hours. For metabonomics HepG 2 cells were seeded in $T 75 \mathrm{~cm}^{2}$ flasks and exposed for 24 and 72 hours. CsA was dissolved in DMSO and added to the medium with a final concentration of $0.5 \% \mathrm{v} / \mathrm{v}$ DMSO. Cells incubated in the presence of $0.5 \% \mathrm{v} / \mathrm{v}$ DMSO served as control. These experiments were performed with three replicates for transcriptomics and five replicates for metabonomics. Replicates were from independent cultures, with passage numbers between 8 and 14 .

Phenotypic analyses

Extraction of the apolar metabolites from exposed cells and analysis with $1 \mathrm{H}-\mathrm{NMR}$ was executed as extensively described by Ruiz Aracama et al. ${ }^{42} \mathrm{H}-\mathrm{H}$-NR analysis of apolar extracts were used to investigate fatty acid and cholesterol levels in HepG2 cells, with and without exposure to CsA. Identification of peaks from the apolar extracts was done by using a combination of commercial standards, literature and databases like the Human Metabolome Database. ${ }^{4}$

The bile acids cholic acid, chenodeoxycholic acid, deoxycholic acid and dehydrocholic acid were measured using LC-MS. LC-MS analysis was carried out using a 6410 Triple Ouad LC/MS (Agilent Technologies, Santa Clara, USA), equipped with a Agilent 1100 HPLC system with auto sampler and column-oven equipped with an ESI source in negative mode. $10 \mu \mathrm{L}$ of the cellular extract was injected onto a C18 column (Alltima HP C18-HL $3 \mu \mathrm{m}$ particle size, $2.1 \mathrm{~mm} \times 150 \mathrm{~mm}$ equipped with an Alltima HP guard column C18-HL $5 \mu \mathrm{m}, 2.1 \mathrm{~mm} \times 7.5 \mathrm{~mm}$, Grace Discovery Sciences, Deerfield, USA). Compounds were separated at a flow rate of $200 \mu \mathrm{L} / \mathrm{min}$ using an acetonitrile gradient. Mobile phase A (A) was Acetonitrile $+0.1 \%$ formic acid, mobile phase B (B) was demineralized water +0.1 formic acid. The gradient started at $A-B, 5: 95 \mathrm{v} / \mathrm{v}$ for 4 minutes and increased to 20:80 in 4 minutes and further increased to 95:5 in 5 minutes, which was kept for 3 minutes. The column was then washed with 5:95 for 2 minutes. The column was stabilized at the initial gradient for 13 minutes before injecting the next sample. The total separation time was 27 minutes including stabilization of the column, this was sufficient to achieve baseline separation of several bile acids. The column temperature was maintained at $23^{\circ} \mathrm{C}$. After separation, eluting compounds were ionized in ESI in the negative ion mode and detected in full scan. Operating conditions of the MS were optimized using the initial setting as followed spray voltage of $4 \mathrm{kV}$, and the heated capillary temperature of $300^{\circ} \mathrm{C}$. Nitrogen was used for the sheath and auxiliary gas, set at $10 \mathrm{~L} / \mathrm{min}$ and $15 \mathrm{psi}$ respectively. The data was processed using the Masshunter Workstation software (Agilent technologies).

\section{Transcriptomics}

mRNA expression profiling

Total RNA isolation, target preparation and microarray hybridization on the Affymetrix Human Genome U133 Plus 2.0 GeneChip arrays and scanning on an Affymetrix GeneArray scanner, were performed according to standard procedures. Ouality control was performed using the Arrayanalysis.org web service and all microarrays were of high quality. A total of 24 CEL files were obtained, which were re-annotated to EntrezGene IDs using the MBNI BrainArray Custom CDF-files V14 ${ }^{44}$, RMA normalized 45 and the intensities were log2 transformed. Correction for False Discovery Rate (FDR) resulted in no significant changes in the low concentration treatments. In order to select biologically relevant changes in all treatments and use identical procedures for all omics analyses, different cutoffs were applied. It was previously reported that combining fold change ranking with a nonstringent $p$-value cutoff was successful in identifying reproducible gene lists. ${ }^{7}$ Therefore, differentially expressed genes (DEGs) for each condition were selected using the following criteria: I) $\log 2$ value $>6$ for at least two replicates, II) for the three replicates an average absolute fold change (FC) of 1.5 (i.e. average log2 ratio of $<$ -0.58 or $>0.58$ ), III) same direction of the log 2 ratio for all three replicates and IV) a $p$ value $<0.05$ determined by a paired Student's T-test.

\section{microRNA expression profiling}

MicroRNA expression profiling was performed using sixth generation miRCURY LNA microRNA arrays (Exiqon, Vedbaek, Denmark). Reporters on the microarray cover all mature human (1.223), mouse (1.055), rat (680) and related viral (human 146, mouse 57) microRNA sequences as annotated in miRBase v16.0. Each microRNA reporter was present four times on the array. The hybridization was performed following standard protocols. After hybridization, the microarray slides were washed and scanned with a DNA microarray scanner (Agilent Technologies). Feature Extraction Software v10.7.3.1 from Agilent Technologies was used to convert the scanned images into TXT files, which were imported in R 2.14.1 (http://www.r-project.org) for quality control and further downstream analysis. In a first filter step only the viral and human microRNA reporter intensities were retained. Next, these intensities were log2-transformed and quantile normalized. In a final step, the technical replicates of each microRNA were averaged into a single value per microRNA. During this summarization step several criteria had to be met: I) at least 3 out of 4 reporters needed to have a measurable intensity ( [foreground] $>1.5 x$ [background] ); II) The minimum background-corrected intensity per reporter had to be 10 (unlogged); III) the mean/median ratio of the replicates should not deviate more than $10 \%$. The selection of differentially expressed microRNAs was identical to the last three criteria for mRNAs. 
The transcriptomics data discussed in this publication have been deposited in NCBI's gene expression omnibus ${ }^{46}$ and are accessible through GEO series accession number GSE45802.

\section{Metabonomics}

Extraction of the polar metabolites from exposed cells and analysis with 'H-NMR was done as described by Ruiz-Aracama et al. ${ }^{42}$ The NMR data were pre-processed and aligned using an in-house developed program. ${ }^{47}$ The aligned fingerprint data in the form of generated spreadsheets were normalized using Probalistic Quotient Normalization ${ }^{8}$ combined with log transformation. Metabolites were considered to be differentially expressed when the studen $t$ test $p$-value was $<0.05$ and the absolute $F C$ was $>1.5$ for all five biological replicates. Polar metabolites were identified by using a combination of commercial standards, literature and databases like the Human Metabolome Database. ${ }^{43}$ The results were further used for pathway analyses. Raw data are accessible through Additional file 38.

\section{Pathway analysis}

Integrated pathway analyses of transcriptomics and metabonomics dato

Lists of differentially expressed genes and metabolites were uploaded into the web-tool 'IMPaLA' ${ }^{49}$ for pathway over-representation analysis. Analyses were performed for data generated by the various 'omics' platforms individually as well as combined. Pathways were considered significantly affected if the False Discovery Rate (FDR) was $<0.05$ and pathways with less than three genes or metabolites were filtered out. Venn diagrams created with VENNY ${ }^{50}$ were used to investigate the overlap between the different conditions and Pearson/Ward hierarchical clusters were generated within GenePattern. ${ }^{51}$

Pathway visualization

PathVisio 2.0.11 ${ }^{52}$ was used for integrated visualization of the differentially expressed genes, metabolites and microRNAs. Gene database release date 2011-06-01 and metabolite database release date 2011-12-03 was used. The KEGG converted pathway 'Primary bile acid biosynthesis Homo sapiens (human)' (hsaoo120; 2011-05-18) was downloaded from PathVisio and microRNAs were added (see next paragraph). The 'Drug-induced cholestasis pathway' from Ariadne Genomics ${ }^{53}$ was adapted by us and microRNAs were included.

\section{Selection of highly conserved microRNA/mRNA targets}

For the integration of microRNAs and their mRNA targets custom Perl scripts were used to combine two flat-text files derived from miRanda 54 (release data: Aug 2010) and TargetScan 55 Human (release 60). For miRanda the human 'good mirSVR score, Conserved miRNA' text file was used. For TargetScan this was the 'Predicted Conserved Targets Info' file. As such, both text files only contained highly conserved microRNA targets. The content of both databases was merged based on the stable MIMAT identifier and can be downloaded at http://web.tgx. unimaas.nl/svn/public/miRNA/.

\section{Results}

Phenotypic analyses

The focus in bile acids and cholesterol analyses was on four different bile acid standards, namely Cholic Acid, Chenodeoxycholic Acid, Deoxycholic Acid and Dehydrocholic acid, but only Chenodeoxycholic Acid could be detected in intracellular extracts. Chenodeoxycholic Acid was present in the solvent controls with a concentration of $36.50 \mu \mathrm{g} / \mathrm{L}( \pm 4.95)$, but absent after treatment with $20 \mu \mathrm{M}$ CsA for 24 hours (Additional file 1) when Chenodeoxycholic Acid levels were diminished and could no longer be detected intracellular.

Intracellular cholesterol levels were measured using $\mathrm{H} \mathrm{H}-\mathrm{NMR}$ analysis of the apolar extracts. Three different cholesterol pools were identified, namely Esterified Cholesterol, Free Cholestero and Total Cholesterol. Esterified Cholesterol was significantly lowered after treatment with $3 \mu \mathrm{M}$ CsA for 72 hours and $20 \mu \mathrm{M}$ CsA for 24 and 72 hours. The FCs were $-1.36,-1.65$ and -2.01 respectively. Free Cholesterol and Total Cholesterol increased after treatment with $20 \mu \mathrm{M}$ CsA for 24 and 72 hours. After 24 hours fold changes were 1.42 and 1.25 and after 72 hours 1.34 and 1.21 for Free Cholesterol and Total Cholesterol respectively.

Cholestasis is defined as a condition in which substances normally excreted into bile, like bile acids, bilirubin and cholesterol, are retained. ${ }^{56}$ Accumulation of bile acids due to impaired secretion by hepatocytes or obstruction of bile ducts is the most common condition, but cholesterol accumulation can also be defined as cholestasis. In these experiments cholesterol accumulation was detected and as such is an indication of CsA-induced cholestasis in $\mathrm{HepG}_{2}$ cells.

Transcriptomics and metabonomics

Total numbers of differentially expressed mRNAs, microRNAs and metabolites are summarized in Table 1 and lists are available in the additional files (Additional files 2-20). There is pronounced dose-related effect, at all time-points more transcripts and metabolites are changed at $20 \mu \mathrm{M}$ CsA compared to $3 \mu \mathrm{M}$. Although less pronounced as the dose-related effect, also a time-dependent effect is observed. Incubating the HepG2 cells with $20 \mu \mathrm{M}$ of CsA for 72 hours increases the number of differentially expressed mRNAs and microRNAs compared to 12 hours of incubation. At the other time points and for microRNAs and metabolites with the lower concentration the same time-dependent effect is visible.

Venn diagrams showing the overlap of significant genes, microRNAs and metabolites over time and concentration can be found in the additional files (Additional file 21-23). When incubated with $3 \mu \mathrm{M}$ CsA there were no significant genes overlapping in all time-points, but 737 genes were significantly expressed at all time-points after exposure to $20 \mu \mathrm{M}$. Combining all time-points resulted in a total of 150 unique genes differentially expressed during $3 \mu \mathrm{M}$ CsA exposure of which 137 genes were also differentially expressed during $20 \mu \mathrm{M}$ CsA treatment. In total 18 unique microRNAs were significantly changed when combining all time-points after $3 \mu \mathrm{M}$ CsA exposure; seven of these were also found after $20 \mu \mathrm{M}$ CsA treatment. In total 91 unique microRNAs were significantly affected when combining all time-points after $20 \mu \mathrm{M}$ CsA exposure. No microRNAs were found which were significantly affected at all time-points 
Pattern analysis of significant pathways

In order to gain insight in the time- and dose-related patterns of the affected pathways and possible associations between or grouping of pathways, a hierarchical clustering analysis was performed. Pathways which were significant in at least one of the treatments were selected and hierarchical cluster analysis was performed using the -log p-values (Figure 2). The first cluster consists of five pathways which are mainly affected at 24 hours and $3 \mu \mathrm{M}$ and are involved in amino acid metabolism and protein processing of the ER (Additional file 28A and 29). The second cluster with main effects at 24 hours and $20 \mu \mathrm{M}$, mostly included pathways involved in cell cycle, DNA damage repair and amino acid metabolism covering $73 \%$ of all significant pathways in this cluster (Additional file 28B and 30). The third cluster with pathways affected after 72 hours and $20 \mu \mathrm{M}$ mostly included pathways involved in amino acid and energy metabolism covering up to $55 \%$ of all pathways in this cluster (Additional file $28 \mathrm{C}$ and 31 ). Moreover, the percentage of pathways involved in cholesterol and bile metabolism and pathways involved in blood clotting and transport were increased when comparing the second and third cluster, where the percentage of pathways involved in cell cycle were decreased.

\section{MicroRNA transcriptomics}

In order to further unravel the mechanisms underlying CsA-induced hepatotoxicity, microRNA expression levels were investigated. Since microRNAs can negatively regulate targeted mRNA levels, we explored whether such correlating effects occurred within our data set. For all the differentially expressed microRNAs, the differentially expressed mRNAs were searched for their targets and checked if (anti-)correlating combinations were significantly enriched. Despite that many of those combinations were found, no significant enrichment was observed, meaning that in this study the effects on mRNAs cannot be explained by direct regulation through microRNAs.

In order to gain insight in the time- and dose-related patterns of the differentially expressed microRNAs and possible associations between or grouping of these, a clustering analysis was performed (Figure 3). To understand in which biological pathways, thus possible mechanisms, the microRNAs are involved, for each cluster the predicted target genes were retrieved and enrichment analyses were performed on these target mRNAs in IMPaLA.

The first cluster (Figure 3; cluster 1) consists of only one microRNA, hsa-miR-27a. This microRNA is slightly elevated after exposure to $3 \mu \mathrm{M}$ and $20 \mu \mathrm{M}$ CsA for 12 hours, with a FC of 1.06 and 1.20 respectively. Over time the FC increases and after 72 hours exposure to $3 \mu M$ and $20 \mu \mathrm{M}$ CsA a FC of 1.40 and 1.69 is reached, respectively. In total this microRNA has 886 target genes of which 293 genes were differentially expressed within the mRNA experiment, although no significant enrichment of correlation or anti-correlation occurs. Pathway analysis indicates that the target genes of this microRNA are involved in 99 significant pathways (Additional file 32), which are mostly related to cell cycle, immune response and energy metabolism. Furthermore, the significant pathways included the SREBP signaling pathway, an important pathway in the cellular lipid homeostasis.

Thirteen microRNAs were found in the second cluster (Figure 3; cluster 2) which are significantly affected pathways and included all pathways which are found with the pathway analyses of the separate omics. Furthermore, the extra pathways found by integrating multiple omics give more information about the cellular response to drug-induced toxicity. 
was used (Figure 4). Nine of the 17 genes and three of the 47 metabolites, including cholestero and Chenodeoxycholic acid, were significantly altered in at least one of the experimental conditions. The second pathway was the 'Drug-induced cholestasis pathway' from Ariadne Genomics 53 which was setup as a model for drug-induced cholestasis and was adapted by us to visualize the data (Figure 5). Eleven out of the 18 genes were significantly affected in at least one of the treatments.

Since these pathways lacked any information on microRNAs, we added these based on predicted microRNA-mRNA pairs based on TargetScan and miRanda. Three of the 18 genes in the 'Drug-induced cholestasis pathway' may be regulated by microRNAs and eight of the 17 genes of the 'Primary bile acid biosynthesis'. In total 23 and 46 microRNAs may be involved in the 'Primary bile acid biosynthesis' pathway and the 'Drug-induced cholestasis' pathway, respectively. In both pathways six microRNAs were differentially expressed. The effects of CsA on mRNAs, microRNAs, metabolites, cholesterol and bile acids were visualized in Figure 4 and 5 .

The 'Primary bile acid biosynthesis' pathway is overall down-regulated, which is in accordance with the phenotypic data, namely that the input of the pathway, cholesterol, is up-regulated and the output, Chenodeoxycholic acid, is down-regulated.

Most of the genes of the 'Drug-induced cholestasis' pathway were also down regulated, especially the genes involved in the synthesis and conjugation of bile acids which is consistent with the expression of genes in the 'Primary bile acid biosynthesis' pathway. Although no significant enrichment of correlation and anti-correlation of mRNA-microRNA pairs was found, these data suggests that microRNAs may play a role in the bile acid biosynthesis and druginduced cholestasis.

\section{Discussion}

In this study, we aimed to unravel the mechanisms underlying CsA-induced hepatotoxicity by integrating transcriptomics and metabonomics with microRNAs. HepG2 cells were used to study the CsA-induced effects in vitro. In order to check endpoints of the CsA-induced toxicity in $\mathrm{HepG} 2$ cells, phenotypic analyses of cholesterol and bile acids were performed. We showed an increase of total cholesterol and free cholesterol and a decrease of esterified cholesterol. Intracellular cholesterol accumulation can lead to reduced cholesterol uptake by hepatocytes and increased cholesterol secretion, which corresponds to in vivo cholestasis where an increased serum cholesterol level is an important marker for cholestasis. ${ }^{57}$ Up to a certain concentration level, free cholesterol is an important part of the cellular membrane, but a rise in free cholesterol levels can change the ratio of free cholesterol and phospholipids and impair the function of membrane proteins. Furthermore, high levels of free cholesterol can induce mitochondrial and ER-stress. ${ }^{58}$ Free cholesterol is therefore esterified to be stored or secreted as free and esterified cholesterol via lipoproteins. ${ }^{59}$ ACAT 2 is the most important enzyme involved in cholesterol esterification in hepatocytes. ${ }^{60}$ It is significantly down-regulated after $3 \mu \mathrm{M}$ CsA exposure for 24 hours with a $\mathrm{FC}$ of -1.36 and after $20 \mu \mathrm{M}$ CsA exposure for 24 and 72 hours with a FC of -2.19 and -4.51, respectively. This may explain the decrease of esterified cholesterol levels. Moreover, free cholesterol can be broken down towards bile acids and secreted into bile. There retrieved and visualized with PathVisio. The first pathway, bile acid biosynthesis, was found multiple times; for visualization the KEGG converted pathway 'Primary bile acid biosynthesis' 
B. Cyclophilin B is a protein in the ER which is important for proper protein folding ${ }^{66}$ and previous studies showed that CSA can impair the function of this protein resulting in an accumulation of misfolded proteins in the ER and ER stress. ${ }^{67}$ Furthermore, ER stress and subsequent changes in calcium homeostasis and mitochondrial function have been related to several liver diseases, including cholestasis ${ }^{68}$, and CsA-induced hepatotoxicity. ${ }^{69}$ Future research, using multiple cholestatic compounds, should asses if the changes induced by CSA are truly specific for cholestasis or are compound specific.

Cytochrome P450 enzymes are the major enzymes involved in drug metabolism and are involved in steroid, cholesterol and bile acid metabolism. Bile acid biosynthesis is an important part of the opposed model for drug-induced cholestasis (Figure 5). Besides down regulation of the transcription of the key enzymes in the classic and alternative pathways also the downstream genes in these pathways were down regulated, especially at the high CsA concentration, as can be seen in Figure 4. Figure 5 shows a proposed model of drug-induced cholestasis in which four processes of bile acid metabolism are incorporated, namely the uptake, synthesis, conjugation and secretion of bile acids. The uptake of bile acids is downregulated when bile acids accumulate in hepatocytes. ${ }^{70}$ However, it has been shown that the functionality of uptake-transporters for bile acids in HepG2 cells is limited. Kullak-Ublick et al. showed that the $\mathrm{Na}^{+}$-taurocholate co-transporting polypeptide (NTCP/SLC1OA1) is not active in $\mathrm{HepG}_{2}$ cells, but there was uptake of taurochate via the organic anion transporting polypeptide (OATP) which had an expression of $40 \%$ in comparison with normal liver. ${ }^{71}$ In our study the expression level of both $\mathrm{SLCO}_{1 \mathrm{~B}}$ (OATP1B1) and $\mathrm{SLC}_{10 \mathrm{~A}}$ (NTCP) did not pass our detection filter and thus deregulation thereof could not be investigated. Bile acid synthesis was significantly down-regulated after CsA treatment. Conjugation of bile acids and xenobiotics is necessary to increase the secretion. BAAT is responsible for conjugation of bile acids with taurine and glycine, but both BAAT and glycine are significantly affected after $20 \mu \mathrm{M}$ CsA treatment for 72 hours. BAAT gene expression is down-regulated with a FC of -3.03 and glycine is up-regulated with a FC of 1.97 suggesting a down-regulation of glycine conjugation of bile acids. Sulfation is also an important pathway for detoxification and secretion of bile acids and is regulated in hepatocytes by SULT $2 A_{1} 7^{72}$, which was significantly down-regulated after $20 \mu \mathrm{M}$ CsA treatment for 48 and 72 hours with a $\mathrm{FC}$ of -3.16 and -6.54 , respectively. $\mathrm{CYP}_{3} \mathrm{~A}_{4}$ is one of the most important enzymes involved in the metabolism of xenobiotics, including CsA, but is only significantly up-regulated after $20 \mu \mathrm{M}$ CsA treatment for 12 hours with a FC of 1.24. The last important step in this mode for drug-induced cholestasis is the secretion from hepatocytes. Inhibition of bile acid secretion via the BSEP has been related to cholestasis and CSA is a known inhibitor. However, expression levels are low in HepG2 cells ${ }^{73-74}$ and no effect of CsA was found. Several other proteins that can secrete bile acids and xenobiotics, OSTalpha, OSTbeta, $A B C C_{2}, A B C C_{3}, A B C C_{4}$ and $A B C B 1$, are expressed 7576 and functional in HepG 2 cells although in lower levels than in human liver. ${ }^{77}$ In ou study OSTalpha and OSTbeta were down-regulated after $20 \mu \mathrm{M}$ CsA treatment, where ABCC2, $A B C C_{3}, A B C C_{4}$ and $A B C B 1$ were up-regulated.

To complete the model, several important nuclear receptors involved in bile acid metabolism ${ }^{78}$ are added in Figure 5 . The farnesoid $\mathrm{X}$ receptor $\left(\mathrm{FXR} ; \mathrm{NR}_{1} \mathrm{H}_{4}\right)$ is a nuclear receptor for which and ER membranes by the accumulation of free cholesterol ${ }^{8}$ and could therefore be a genera cholestasis effect. Furthermore, ER stress could be a result of a direct effect of CSA on cyclophilin 
Chenodeoxycholic acid and other bile acids are natural ligands, and regulates genes involved in the bile acid biosynthesis. The FXR is significantly down-regulated after $20 \mu \mathrm{M}$ CsA treatment for 72 hours compared to the solvent control, which could be the result of the diminished levels of Chenodeoxycholic acid after CsA exposure. The pregnane X receptor (PXR; NR112) is a nuclear receptor which up-regulates proteins involved in detoxification and is significantly up-regulated after $20 \mu \mathrm{M}$ CsA treatment for 72 hours. The vitamin D receptor (VDR; NR111) and constitutive androstane receptor ( $\left.C A R ; N_{1} 13\right)$ were also shown to be activated by bile acids or bile acid metabolites.

Analysis of microRNAs and mRNAs did not result in significant enrichment of correlating or anti-correlating combinations, although many microRNA-mRNA combinations were found. Comparing the pathway analyses of the target genes of microRNAs with the same time- and dose-related patterns to the integrated pathway analyses of mRNAs and metabolites resulted in pathways involved in similar processes, indicating a possible role for microRNAs in the cellular reaction on CsA exposure. Furthermore, several microRNAs were found to have target genes located in the bile acid biosynthesis and 'drug-induced cholestasis' pathways which were affected in CsA treated HepGz cells. Involvement of microRNAs in drug-induced toxicity has not been studied extensively, but microRNA expression levels could be important to elucidate all mechanisms underlying a cellular reaction to a compound, because microRNAs are able to post-transcriptionally alter protein expressions. Further research is needed to investigate the reaction of microRNAs to CsA and their ability to regulate the target genes and corresponding protein levels in drug-induced cholestasis.

\section{Conclusions}

We could unravel mechanisms of CsA-induced hepatotoxicity using an integrated-omics approach, both by combining transcriptomics and metabonomics and by including microRNAs. Data analysis using the proposed model for drug-induced cholestasis gives valuable information about important genes, microRNAs and metabolites involved in bile acid metabolism in hepatocytes. This model could therefore be used to screen new compounds for their ability to influence bile acid metabolism, which could be an indication of cholestatic properties. However, validation of this model using multiple compounds, including non-cholestatic drugs, should be performed. Several differentially expressed genes were related to ER stress and mitochondrial impairment after CsA exposure. Cytochrome $\mathrm{P} 450$ enzymes were also affected which resulted in intracellular cholesterol accumulation due to impairment of cholesterol metabolism and bile acid synthesis. We showed that integrating multiple omics and thereby analyzing genes, microRNAs and metabolites of the opposed model for drug-induced cholestasis can give valuable information about mechanisms of drug-induced cholestasis in vitro and therefore could be used as addition in toxicity screening of new drug candidates at an early stage of drug discovery. Further research is needed to validate our results in different models. Furthermore, multiple cholestatic compounds should be used to separate the compound specific changes from the true cholestatic mechanisms.

\section{Availability of supporting data}

The data sets supporting the results of this article are included within the article (and its additional files) or are available in the NCBl's gene expression omnibus. The transcriptomics data are accessible through GEO series accession number GSE45802. Additional files are available upon request.

\section{Acknowledgements}

The authors acknowledge Rianne Fijten for her help with adapting the 'Drug-induced cholestasis' pathway for visualization with PathVisio.

Table 1. Numbers of differentially expressed mRNAs, microRNAs and metabolites induced in HepG2 cells after cyclosporin A exposure across time and concentration.

\section{$3 \mu \mathrm{M}$}

\begin{tabular}{|l|r|r|r|r|}
\hline & \multicolumn{4}{|c|}{$3 \mu \mathrm{M}$} \\
\hline MRNA & $12 h$ & $24 h$ & $48 h$ & $72 h$ \\
\hline Up-regulated & 89 & 72 & 20 & 29 \\
\hline Down-regulated & 82 & 61 & 17 & 20 \\
\hline
\end{tabular}

MICRORNA

Up-regulated

Down-regulated

Metabolites

Up-regulated

Down-regulated

$-3$

\begin{tabular}{|l|l|l|}
\hline 0 & 7 & 11 \\
\hline 0 & 3 & 9 \\
\hline & 4 & 2 \\
\hline
\end{tabular}

NA, not analyzed
$20 \mu \mathrm{M}$

\begin{tabular}{|r|r|r|r|}
\hline $12 h$ & $24 h$ & $48 h$ & $72 h$ \\
\hline 2189 & 2130 & 3004 & 3095 \\
\hline 1001 & 838 & 1431 & 1494 \\
\hline 1188 & 1292 & 1573 & 1601 \\
\hline
\end{tabular}

\begin{tabular}{l|l|l|l|}
8 & 8 & 62 & 43 \\
\hline & 7 & 30 & 30
\end{tabular}

\begin{tabular}{|l|l|l|l|}
\hline 0 & 1 & 32 & 13 \\
\hline
\end{tabular}

NA $16 \quad$ NA 16

8 - 10



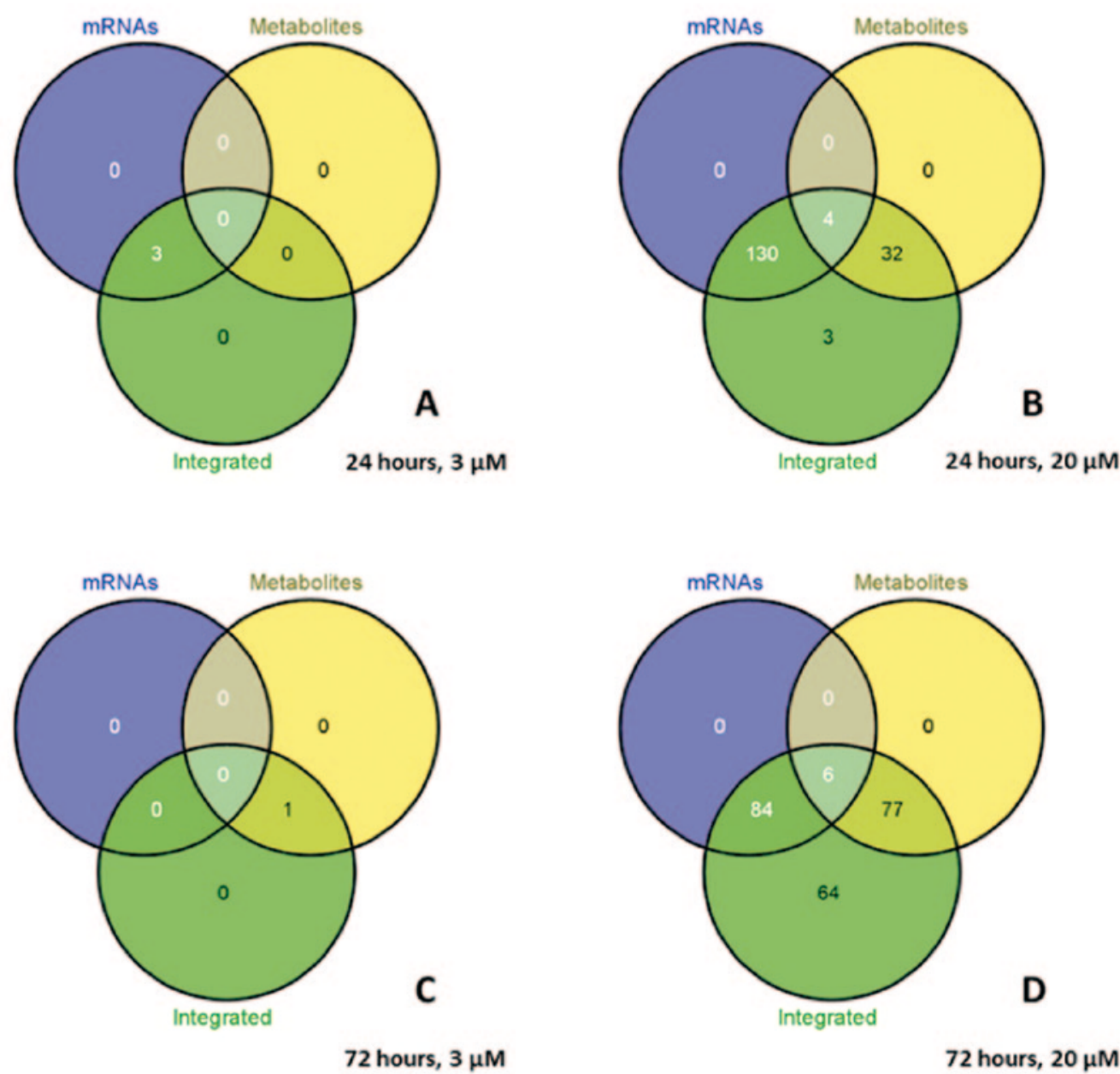

Figure 1. Venn diagrams showing the overlap of significantly changed pathways (FDR $<0.05$; IMPaLA) between transcriptomics and metabonomics separately and integrated.
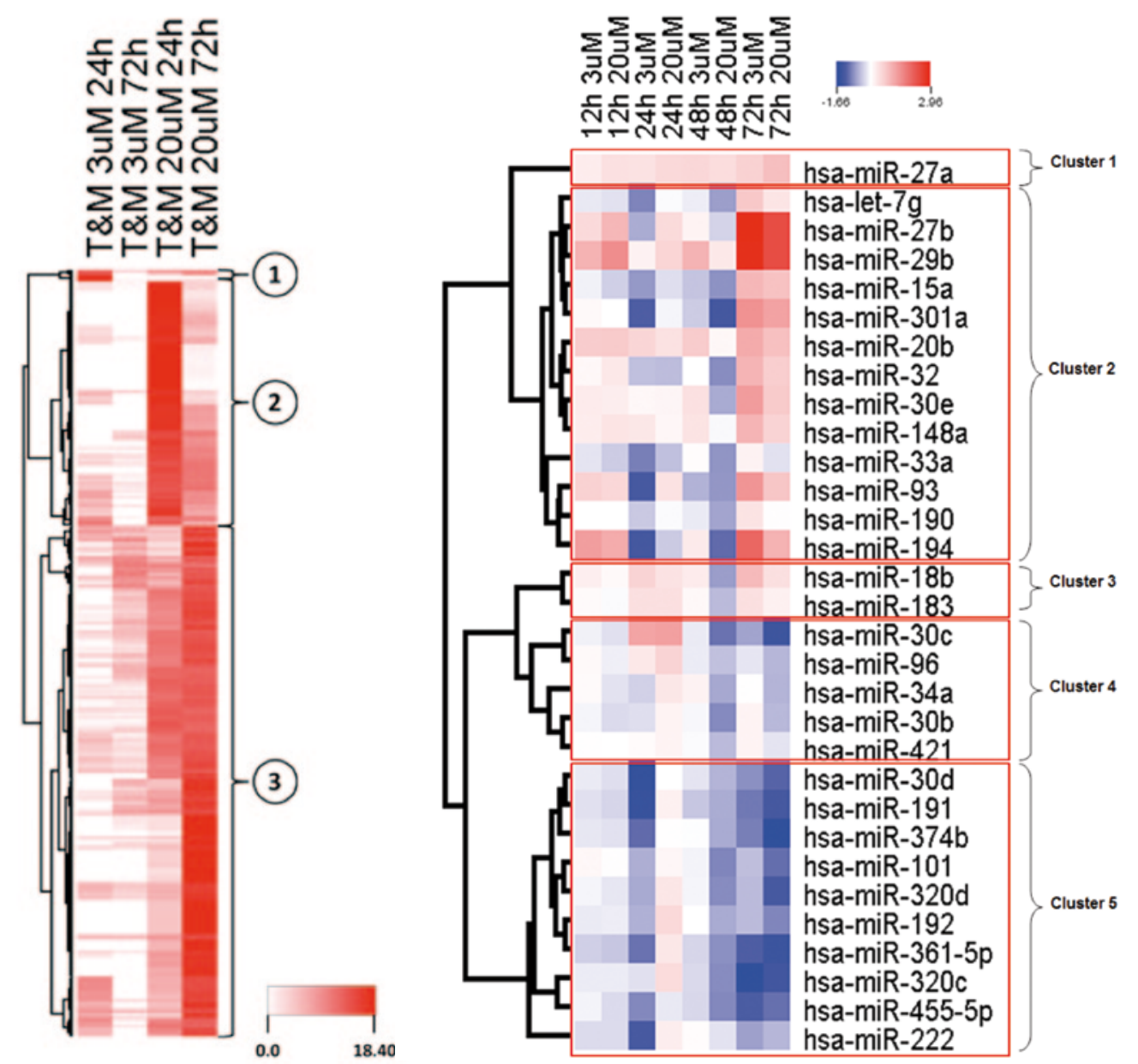

Figure 2. Hierarchical clustering of pathways which were significantly affected in at least one of the treatments based on their -log p-values.
Figure 3. Hierarchical cluster analysis of microRNAs, which were significant in at least one of the treatments and are known to have target genes, based on the log2 of their FC. 


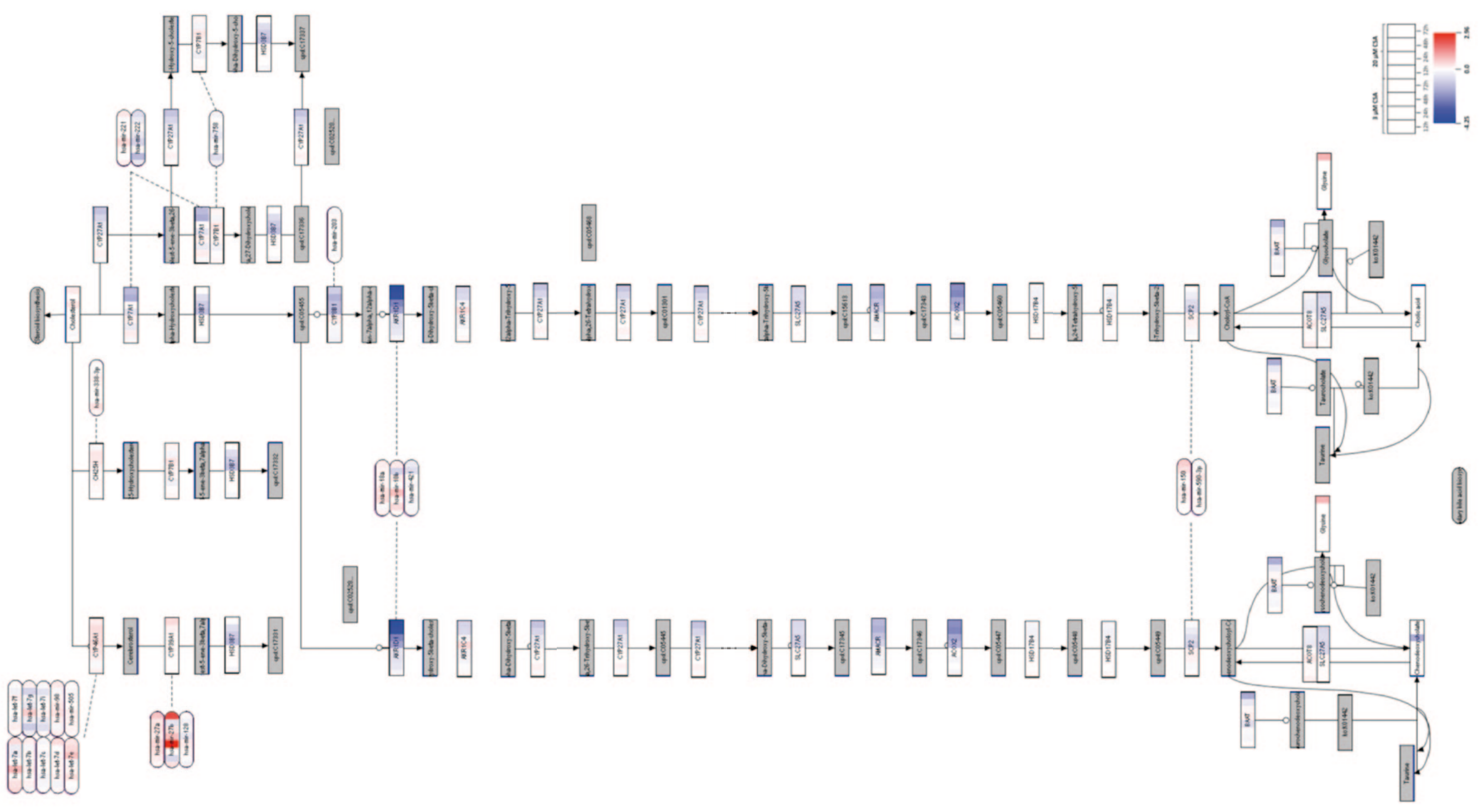

Figure 4. Visualization of expression levels (log2 FC) of all measured transcriptomics, metabonomics and phenotypic data in the Kegg pathway 'Primary bile acid biosynthesis'. 


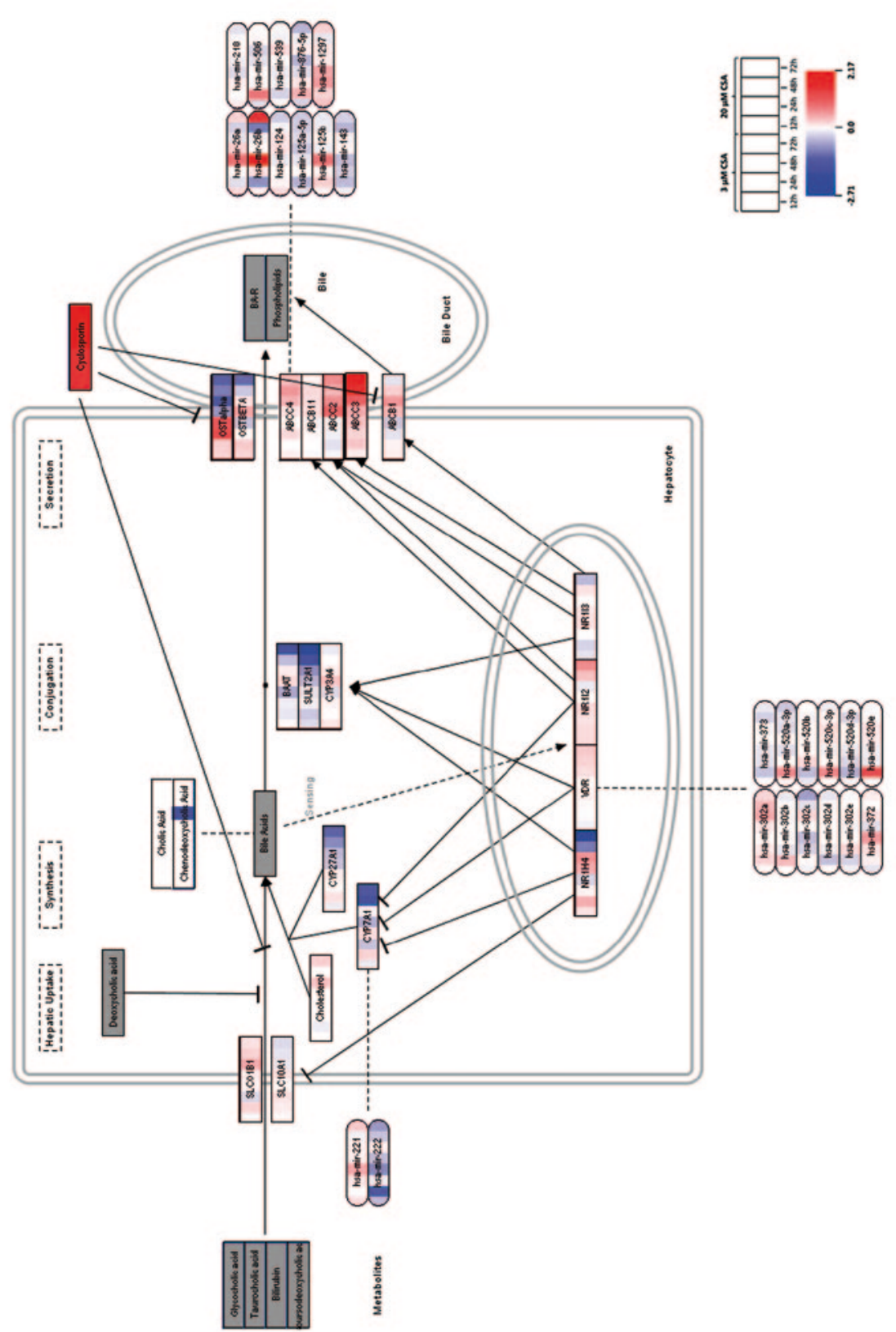

Figure 5. Visualization of expression levels (log2 $F C$ ) of all measured transcriptomics, metabonomics and phenotypic data in the 'Drug-induced cholestasis' pathway, which is suggested to be a model for drug-induced cholestasis.

\section{References}

1. Lee, W. M. (2003) Drug-Induced Hepatotoxicity. N Engl J Med 349, 474-485.

2. MacDonald, J. S., Robertson, R. T. (2009) Toxicity Testing in the 215t Century: A View from the Pharmaceutical Industry. Toxicol. Sci. 110, 40-46.

3. Olson, H., Betton, G., Robinson, D., Thomas, K., Monro, A., Kolaja, G., Lilly, P., Sanders, J., Sipes, G., Bracken, W., Dorato, M., Van Deun, K., Smith, P., Berger, B., Heller, A. (2000) Concordance of the Toxicity of Pharmaceuticals in Humans and in Animals. Regul. Toxicol. Pharm. 32, 56-67.

4. Shanks, N., Greek, R., Greek, J. (2009) Are animal models predictive for humans? Philos. Ethics Humanit. Med. 4, 1-20.

5. Waters, M. D., Fostel, J. M. (2004) Toxicogenomics and systems toxicology: aims and prospects. Nat Rev Genet 5, 936-948.

6. Chen, M., Zhang, M., Borlak, J., Tong, W. (2012) A Decade of Toxicogenomic Research and Its Contribution to Toxicological Science. Toxicol. Sci.

7. Shi, L., Reid, L. H., Jones, W. D., Shippy, R., Warrington, J. A., Baker, S. C., Collins, P. J., de Longueville, F., Kawasaki, E. S., Lee, K. Y. Luo, Y. Sun, Y. A. Willey, J. C. Setterquist, R. A., Fischer, G. M. Tong. W. Dragan, Y. P., Dix, D. J., Frueh, F. W. Goodsaid, F. M., Herman, D., Jensen, R. V., Johnson, C. D., Lobenhofer, E. K., Puri, R. K., Schrf, U., Thierry-Mieg, J., Wang, C., Wilson, M., Wolber, P. K., Zhang, L., Amur, S., Bao, W., Barbacioru, C. C., Lucas, A. B., Bertholet, V., Boysen, C., Bromley, B., Brown, D. Brunner, A. Canales, R., Cao, X. M., Cebula, T. A. Chen, J. J., Cheng J., Chu, T. M. Chudin, E., Corson, J., Corton, J. C.., Croner, L. J., Davies, C., Davison, T. S., Delenstarr, G., Deng, X., Dorris, D., Eklund, A. C., Fan, X. H., Fang, H., Fulmer-Smentek, S. Fuscoe, J. C., Gallagher, K., Ge, W., Guo, L., Guo, X., Hager, J., Haje, P. K., Han, J., Han, T., Harbottle, H. C., Harris, S. C., Hatchwell, E., Hauser, C. A., Hester, S., Hong, H., Hurban, P., Jackson, S. A., Ji, H., Knight, C. R., Kuo, W. P., LeClerc, J. E., Levy, S., Li, O. Z., Liu, C., Liu, Y., Lombardi, M. J., Ma, Y., Magnuson, S. R., Magsodi, B., McDaniel, T., Mei, N., Myklebost, O., Ning, B., Novoradovskaya, N., Orr, M. S., Osborn, T. W., Papallo, A., Patterson, T. A., Perkins, R. G., Peters, E. H., Peterson, R., Philips, K. L., Pine, P. S. Pusztai, L., Oian, F., Ren, H., Rosen, M., Rosenzweig, B. A., Samaha, R. R., Schena, M., Schroth, G. P., Shchegrova, S., Smith, D. D., Staedtler, F., Su, Z., Sun, H., Szallasi, Z., Tezak, Z., Thierry-Mieg, D., Thompson, K. L., Tikhonova, I., Turpaz, Y., Vallanat, B., Van, C., Walker, S. J., Wang, S. J., Wang, Y., Wolfinger, R., Wong, A., Wu, J., Xiao, C., Xie, O., Xu, J., Yang, W., Zhong, S., Zong, Y. Slikker, W., Jr. (2006) The MicroArray Quality Control (MAOC) project shows inter- and intraplatform reproducibility of gene expression measurements. Nat Biotechnol 24, 1151-1161.

8. Cui, Y., Paules, R. S. (2010) Use of transcriptomics in understanding mechanisms of drug-induced toxicity Pharmacogenomics $11,573-585$.

9. Nuwaysir, E. F., Bittner, M., Trent, J., Barrett, J. C., Afshari, C. A. (1999) Microarrays and toxicology: The advent of toxicogenomics. Mol. Carcinogen. 24, 153-159.

10. Cheng, F., Theodorescu, D., Schulman, I. G., Lee, J. K. (2011) In vitro transcriptomic prediction of hepatotoxicity for early drug discovery. J. Theor. Biol. 290, 27-36.

11. Lema, C., Cunningham, M. J. (2010) MicroRNAs and their implications in toxicological research. Toxicol. Lett. 198, 100-105.

12. Wetmore, B. A., Merrick, B. A. (2004) Invited Review: Toxicoproteomics: Proteomics Applied to Toxicology and Pathology Toxicol. Pathol. 32, 619-642.

13. Nicholson, J. K., Lindon, J. C., Holmes, E. (1999) 'Metabonomics': understanding the metabolic responses of living systems to pathophysiological stimuli via multivariate statistical analysis of biological NMR spectroscopic data. Xenobiotica 29

14. De Backer, M. D., Thurmond, R. L., Carmen, A. A., Luyten, W. H. (2002) Gene-Expression - Based Responses to Drug Treatment. Drug News Perspect 15, $155-165$

15. Tyers, M., Mann, M. (2003) From genomics to proteomics. Nature 422, 193-197. 
16. Nicholson, J. K., Connelly, J., Lindon, J. C., Holmes, E. (2002) Metabonomics: a platform for studying drug toxicity and gene function. Nat Rev Drug Discov 1, 153-161.

17. Coen, M., Ruepp, S. U., Lindon, J. C., Nicholson, J. K., Pognan, F. o., Lenz, E. M., Wilson, I. D. (2004) Integrated application of transcriptomics and metabonomics yields new insight into the toxicity due to paracetamol in the mouse. Pharmaceut. Biomed. 35, 93-105.

18. Heijne, W. H. M., Lamers, R.-J. A. N., van Bladeren, P. J., Groten, J. P., van Nesselrooij, J. H. J., van Ommen, B. (2005) Profiles of Metabolites and Gene Expression in Rats with Chemically Induced Hepatic Necrosis. Toxicol Pathol 33, 425-43.

19. Jennen, D., Ruiz-Aracama, A., Magkoufopoulou, C., Peijnenburg, A., Lommen, A., van Delft, J., Kleinjans, J. (2011) Integrating transcriptomics and metabonomics to unravel modes-of-action of 2,3,7,8-tetrachlorodibenzo-p-dioxin (TCDD) in HepG cells. BMC Syst. Biol. 5, 139 .

20. Soresi, M., Sparacino, V., Pisciotta, G., Bonfissuto, G., Caputo, F., Carroccio, A., Calabrese, S., Montalto, G. (1995) Effects of cyclosporin A on various indices of cholestasis in kidney transplant recipients. Minerva Urol Nefrol 47, 65-69.

21. Galán, A. I., Román, I. D., Muñoz, M. E., Cava, F., Gonzalez-Buitrago, J. M., Esteller, A., Jlmenez, R. (1992) Inhibition of biliary lipid and protein secretion by cyclosporine a in the rat. Biochem. Pharmacol. 44, 1105-1113.

22. Böhme, M., Jedlitschky, G., Leier, I., Büchler, M., Keppler, D. (1994) ATP-dependent export pumps and their inhibition by cyclosporins. Adv. Enzyme Regul. 34, 371-380.

23. Kis, E., loja, E., Nagy, T., Szente, L., Herédi-Szabó, K., Krajcsi, P. (2009) Effect of Membrane Cholesterol on BSEP/Bsep Activity: Species Specificity Studies for Substrates and Inhibitors. Drug Metab. Dispos. 37, 1878-1886.

24. Padda, M. S., Sanchez, M., Akhtar, A. J., Boyer, J. L. (2011) Drug-induced cholestasis. Hepatology 53, 1377-1387.

25. Hewitt, N. J., Gómez Lechón, M. J., Houston, J. B., Hallifax, D., Brown, H. S., Maurel, P., Kenna, J. G., Gustavsson, L, Lohmann, C., Skonberg, C., Guillouzo, A., Tuschl, G., Li, A. P., LeCluyse, E., Groothuis, G. M. M., Hengstler, J. G. (2007) Primary Hepatocytes: Current Understanding of the Regulation of Metabolic Enzymes and Transporter Proteins, and Pharmaceutical Practice for the Use of Hepatocytes in Metabolism, Enzyme Induction, Transporter, Clearance, and Hepatotoxicity Studies. Drug Metab. Rev. 39, 159-234.

26. Madan, A., Graham, R. A., Carroll, K. M., Mudra, D. R., Burton, L. A., Krueger, L. A., Downey, A. D., Czerwinski, M., Forster, J., Ribadeneira, M. D., Gan, L.-S., LeCluyse, E. L., Zech, K., Robertson, P., Koch, P., Antonian, L., Wagner, G., Yu, L., Parkinson A. (2003) Effects of Prototypical Microsomal Enzyme Inducers on Cytochrome P450 Expression in Cultured Human Hepatocytes. Drug Metab. Dispos. 31, 421-431.

27. Gerets, H., Tilmant, K., Gerin, B., Chanteux, H., Depelchin, B., Dhalluin, S., Atienzar, F. (2012) Characterization of primary human hepatocytes, HepG2 cells, and HepaRG cells at the mRNA level and CYP activity in response to inducers and their predictivity for the detection of human hepatotoxins. Cell Biol. Toxicol. 28, 69-87.

28. Hewitt, N. J., Hewitt, P. (2004) Phase I and II enzyme characterization of two sources of $\mathrm{HepG}_{2}$ cell lines. Xenobiotica 34 $243-256$.

29. Knasmüller, S., Mersch-Sundermann, V., Kevekordes, S., Darroudi, F., Huber, W. W., Hoelzl, C., Bichler, J., Majer, B. J. (2004) Use of human-derived liver cell lines for the detection of environmental and dietary genotoxicants; current state of knowledge. Toxicology 198, 315-328.

30. O'Brien, P., Haskins, J., In vitro Cytotoxicity Assessment. In High Content Screening, Taylor, D. L.; Haskins, J.; Giuliano, K. Eds. Humana Press: 2006; Vol. 356, pp 415-425.

31. Schoonen, W. G. E. J., Westerink, W. M. A., Horbach, G. J., High-throughput screening for analysis of in vitro toxicity. In Molecular, Clinical and Environmental Toxicology, Luch, A., Ed. Birkhäuser Basel: 2009; Vol. 99, pp 401-452

32. O'Brien, P., Irwin, W., Diaz, D., Howard-Cofield, E., Krejsa, C., Slaughter, M., Gao, B., Kaludercic, N., Angeline, A., Bernardi,
P., Brain, P., Hougham, C. (2006) High concordance of drug-induced human hepatotoxicity with in vitro cytotoxicity measured in a novel cell-based model using high content screening. Arch. Toxicol. 80, 580-604.

33. Burczynski, M. E., McMillian, M., Ciervo, J., Li, L., Parker, J. B., Dunn, R. T., Hicken, S., Farr, S., Johnson, M. D. (2000) Toxicogenomics-Based Discrimination of Toxic Mechanism in HepG2 Human Hepatoma Cells. Toxicol. Sci. 58, 399-415.

34. Choi, S., Park, S.Y., Jeong, J., Cho, E., Phark, S., Lee, M., Kwak, D., Lim, J.Y., Jung, W.-W., Sul, D. (2010) Identification of toxicological biomarkers of di(2-ethylhexyl) phthalate in proteins secreted by HepG2 cells using proteomic analysis. Proteomics 10, 1831-1846.

35. Cosgrove, B. D., King, B. M., Hasan, M. A., Alexopoulos, L. G., Farazi, P. A., Hendriks, B. S., Griffith, L. G., Sorger, P. K., Tidor, B., $\mathrm{Xu}, \mathrm{J}$. J., Lauffenburger, D. A. (2009) Synergistic drug-cytokine induction of hepatocellular death as an in vitro approach for the study of inflammation-associated idiosyncratic drug hepatotoxicity. Toxicol. Appl. Pharm. 237, 317-330.

36. Hockley, S. L., Mathijs, K., Staal, Y. C., Brewer, D., Giddings, I., van Delft, J. H., Phillips, D. H. (2009) Interlaboratory and interplatform comparison of microarray gene expression analysis of $\mathrm{HepG}_{2}$ cells exposed to benzo(a)pyrene. OMICS 13 , $115-125$

37. Hong, Y., Müller, U. R., Lai, F. (2003) Discriminating two classes of toxicants through expression analysis of HepG2 cells with DNA arrays. Toxicol. In Vitro $17,85-92$

8. van Delft, J. H. M., van Agen, E., van Breda, S. G. J., Herwijnen, M. H., Staal, Y. C. M., Kleinjans, J. C. S. (2004) Discrimination of genotoxic from non-genotoxic carcinogens by gene expression profiling. Carcinogenesis 25, 1265-1276.

39. Westerink, W. M. A., Stevenson, J. C. R., Horbach, G. J., Schoonen, W. G. E. J. (2010) The development of RAD51C, Cystati A, P53 and Nrf2 luciferase-reporter assays in metabolically competent HepG2 cells for the assessment of mechanismbased genotoxicity and of oxidative stress in the early research phase of drug development. Mutat. Res.-Gen. Tox. En $696,21-40$

40. Jetten, M. J. A., Kleinjans, J. C. S., Claessen, S. M., Chesné, C., van Delft, J. H. M. (2013) Baseline and genotoxic compoun induced gene expression profiles in HepGz and HepaRG compared to primary human hepatocytes. Toxicol. In Vitro.

41. Van Summeren, A., Renes, J., Bouwman, F. G., Noben, J.P., van Delft, J. H. M., Kleinjans, J. C. S., Mariman, E. C. M. (2011) Proteomics Investigations of Drug-Induced Hepatotoxicity in HepG2 Cells. Toxicol. Sci. 120, 109-122.

42. Ruiz-Aracama, A., Peijnenburg, A., Kleinjans, J., Jennen, D., van Delft, J., Hellfrisch, C., Lommen, A. (2011) An untargeted multi-technique metabolomics approach to studying intracellular metabolites of HepG2 cells exposed to 2,3,7,8-tetrachlorodibenzo-p-dioxin. BMC Genomics 12, 251.

43. Wishart, D. S., Tzur, D., Knox, C., Eisner, R., Guo, A. C., Young, N., Cheng, D., Jewell, K., Arndt, D., Sawhney, S., Fung, C., Nikolai, L., Lewis, M., Coutouly, M.-A., Forsythe, I., Tang, P., Shrivastava, S., Jeroncic, K., Stothard, P., Amegbey, G., Block, D., Hau, D. D., Wagner, J., Miniaci, J., Clements, M., Gebremedhin, M., Guo, N., Zhang, Y., Duggan, G. E., Maclnnis, G. D., Weljie, A. M. Dowlatabadi, R., Bamforth, F., Clive, D., Greiner, R., Li, L., Marrie, T., Sykes, B. D., Vogel, H. J., Querengesser, L. (2007) HMDB. the Human Metabolome Database. Nucleic Acids Res. 35, D521-D526.

44. Dai, M., Wang, P., Boyd, A. D., Kostov, G., Athey, B., Jones, E. G., Bunney, W. E., Myers, R. M., Speed, T. P., Akil, H., Watson, S. J., Meng, F. (2005) Evolving gene/transcript definitions significantly alter the interpretation of GeneChip data. Nucleic Acids Res. 33, e175

45. Irizarry, R. A., Hobbs, B., Collin, F., Beazerât Barclay, Y. D., Antonellis, K. J., Scherf, U., Speed, T. P. (2003) Exploration, normalization, and summaries of high density oligonucleotide array probe level data. Biostatistics 4, 249-264.

46. Edgar, R., Domrachev, M., Lash, A. E. (2002) Gene Expression Omnibus: NCBI gene expression and hybridization array data repository. Nucleic Acids Res. 30, 207-210.

47. Lommen, A., Weseman, J. M., Smith, G. O., Noteborn, H. P. J. M. (1998) On the detection of environmental effects on 
complex matrices combining off-line liquid chromatography and $1 \mathrm{H}-\mathrm{NMR}$. Biodegradation 9, 513-525.

48. Dieterle, F., Ross, A., Schlotterbeck, G. t., Senn, H. (2006) Probabilistic Quotient Normalization as Robust Method to Account for Dilution of Complex Biological Mixtures. Application in 1 H NMR Metabonomics. Anal. Chem. 78, 4281-4290

49. Kamburov, A., Cavill, R., Ebbels, T. M. D., Herwig, R., Keun, H. C. (2011) Integrated pathway-level analysis of transcriptomic and metabolomics data with IMPaLA. Bioinformatics 27, 2917-2918.

50. Oliveros, J. C. VENNY. An interactive tool for comparing lists with Venn Diagrams. http://bioinfogp.cnb.csic.es/tools/ venny/index.html.

51. Reich, M., Liefeld, T., Gould, J., Lerner, J., Tamayo, P., Mesirov, J. P. (2006) GenePattern 2.0. Nat. Genet. 38, 500-501.

52. van lersel, M., Kelder, T., Pico, A., Hanspers, K., Coort, S., Conklin, B., Evelo, C. (2008) Presenting and exploring biological pathways with PathVisio. BMC Bioinformatics 9,399 .

53. Yuryev, A., Kotelnikova, E., Daraselia, N. (2009) Ariadne's ChemEffect and Pathway Studio knowledge base. Expert Opin Drug Dis. 4, 1307-1318.

54. Betel, D., Wilson, M., Gabow, A., Marks, D. S., Sander, C. (2008) The microRNA.org resource: targets and expression. Nucleic Acids Res. 36, D149-D153.

55. Friedman, R. C., Farh, K. K.-H., Burge, C. B., Bartel, D. P. (2009) Most mammalian mRNAs are conserved targets of microRNAs. Genome Res. 19, 92-105.

56. Stedman, C. A. M., Liddle, C., Coulter, S. A., Sonoda, J., Alvarez, J. G. A., Moore, D. D., Evans, R. M., Downes, M. (2005) Nuclear receptors constitutive androstane receptor and pregnane $X$ receptor ameliorate cholestatic liver injury. P. Natl. Acad. Sci. USA 102, 2063-2068.

57. Soros, P., Bottcher, J., Maschek, H., Selberg, O., Muller, M. J. (1998) Lipoprotein-X in patients with cirrhosis: its relationship to cholestasis and hypercholesterolemia. Hepatology 28, 1199-1205.

58. Musso, G., Gambino, R., Cassader, M. (2013) Cholesterol metabolism and the pathogenesis of non-alcoholic steatohepatitis. Prog. Lipid. Res. 52, 175-191.

59. Stone, B. G., Schreiber, D., Alleman, L. D., Ho, C. Y. (1987) Hepatic metabolism and secretion of a cholesterol-enriched lipoprotein fraction. J. Lipid Res. 28, 162-172.

6o. Parini, P., Davis, M., Lada, A. T., Erickson, S. K., Wright, T. L., Gustafsson, U., Sahlin, S., Einarsson, C., Eriksson, M., Angelin B., Tomoda, H. Ōmura, S., Willingham, M. C., Rudel, L. L. (2004) ACAT2 Is Localized to Hepatocytes and Is the Major Cholesterol-Esterifying Enzyme in Human Liver. Circulation 110, 2017-2023.

61. Chiang, J. Y. L. (2009) Bile acids: regulation of synthesis. J. Lipid Res. 50, $1955-1966$.

62. Andreou, E. R., Prokipcak, R. D. (1998) Analysis of Human CYP7A1 mRNA Decay in HepG2 Cells by Reverse TranscriptionPolymerase Chain Reaction. Arch. Biochem. Biophys. 357, 137-146.

63. Levy, J., Budai, K., Javitt, N. B. (1994) Bile acid synthesis in HepG2 cells: effect of cyclosporin. J. Lipid Res. 35, 1795-1800

64. Winegar, D. A., Salisbury, J. A., Sundseth, S. S., Hawke, R. L. (1996) Effects of cyclosporin on cholesterol 27-hydroxylation and LDL receptor activity in HepG2 cells. J. Lipid Res. 37, 179-191.

65. Anderson, P. O., Knoben, J. E., Troutman, W. G., In Handbook of Clinical Drug Data, Tenth ed.; McGraw-Hill Medical Publishing Division: 2002; pp 275-279.

66. Kim, J., Choi, T. G., Ding, Y., Kim, Y., Ha, K. S., Lee, K. H., Kang, I., Ha, J., Kaufman, R. J., Lee, J., Choe, W., Kim, S. S. (2008) Overexpressed cyclophilin B suppresses apoptosis associated with ROS and Ca2+ homeostasis after ER stress.J. Cell S 121, 3636-3648.

67. Bernasconi, R., Soldà, T., Galli, C., Pertel, T., Luban, J., Molinari, M. (2010) Cyclosporine A-Sensitive, Cyclophilin B-Dependen Endoplasmic Reticulum-Associated Degradation. PLOS ONE 5, e13008.
68. Malhi, H., Kaufman, R. J. (2011) Endoplasmic reticulum stress in liver disease. J. Hepatol. 54, 795-809.

6. Van Summeren, A., Renes, J. Lizarraga, D., Bouwman, F. G. Noben, J. P. van Delft, J. H., Kleinjans, J. C., Mariman, E. C. (2013) Screening for Drug-Induced Hepatotoxicity in Primary Mouse Hepatocytes Using Acetaminophen, Amiodarone, and Cyclosporin A as Model Compounds: An Omics-Guided Approach. OMICS.

70. Zollner, G., Wagner, M., Fickert, P., Geier, A., Fuchsbichler, A., Silbert, D., Gumhold, J., Zatloukal, K., Kaser, A., Tilg, H., Denk, H., Trauner, M. (2005) Role of nuclear receptors and hepatocyte-enriched transcription factors for Ntcp repression in biliary obstruction in mouse liver. Am. J. Physiol.-Gastr. L. 289, G798-805.

71. Kullak-Ublick, G. A., Beuers, U., Paumgartner, G. (1996) Molecular and functional characterization of bile acid transport in human hepatoblastoma HepG2 cells. Hepatology 23, 1053-1060.

72. Alnouti, Y. (2009) Bile Acid Sulfation: A Pathway of Bile Acid Elimination and Detoxification. Toxicol. Sci. 108, 225-246.

73. Yu, J., Lo, J.-L., Huang, L., Zhao, A., Metzger, E., Adams, A., Meinke, P. T., Wright, S. D., Cui, J. (2002) Lithocholic Acid Decreases Expression of Bile Salt Export Pump through Farnesoid X Receptor Antagonist Activity. J. Biol. Chem. 277, 31441-31447.

74. Weerachayaphorn, J., Cai, S.Y., Soroka, C. J., Boyer, J. L. (2009) Nuclear factor erythroid 2-related factor 2 is a positive regulator of human bile salt export pump expression. Hepatology 50, 1588-1596.

75. Hilgendorf, C., Ahlin, G., Seithel, A., Artursson, P., Ungell, A.L., Karlsson, J. (2007) Expression of Thirty-six Drug Transporter Genes in Human Intestine, Liver, Kidney, and Organotypic Cell Lines. Drug Metab. Dispos. 35, 1333-1340.

76. Rosales, R. Romero, M. R., Vaquero, J., Monte, M. J., Requena, P., Martinez-Augustin, O., Sanchez de Medina, F., Marin, J.J. G. (2013) FXR-dependent and -independent interaction of glucocorticoids with the regulatory pathways involved in the control of bile acid handling by the liver. Biochem. Pharmacol. 85, 829-838.

77. Le Vee, M., Jigorel, E., Glaise, D., Gripon, P., Guguen-Guillouzo, C., Fardel, O. (2006) Functional expression of sinusoida and canalicular hepatic drug transporters in the differentiated human hepatoma HepaRG cell line. Eur. J. Pharm. Sci. 28 , $109-117$

78. Li, T., Chiang, J. Y. L. (2013) Nuclear receptors in bile acid metabolism. Drug Metab. Rev. 45, 145-155. 


\section{Chapter 5}

\section{TRTELATHE}

CROSS-OMICS ANALYSIS IN PRIMARY MOUSE

HEPATOCYTES UNRAVELS MECHANISMS

OF CYCLOSPORIN A-INDUCED HEPATOTOXICITY

Van den Hof, W.F.P.M.

Van Summeren, A.

Lommen, A.

Coonen, M.L.J.

Brauers, K.

van Herwijnen, $M$

Wodzig, W.K.W.H.

and Kleinjans, J.C.S. 


\section{Abstract}

The liver is responsible for drug metabolism and drug-induced hepatotoxicity is the most frequent reason for drug withdrawal, indicating that better pre-clinical toxicity tests are needed. In order to bypass animal models for toxicity screening, we exposed primary mouse hepatocytes for exploring the prototypical hepatotoxicant cyclosporin A. To elucidate the mechanisms underlying cyclos porin A-induced hepatotoxicity, we analyzed expression levels of proteins, mRNAs, microRNAs and metabolites.

Integrative analysis of transcriptomics and proteomics showed that protein disulfide isomerase family A, member 4 was up-regulated on both the protein level and mRNA level. This protein is involved in protein folding and secretion in the endoplasmic reticulum. Furthermore, the microRNA mmu-miR-182-5p which is predicted to interact with the mRNA of this protein was also differentially expressed, further emphasizing endoplasmic reticulum stress as important event in drug-induced toxicity. To further investigate the interaction between the significantly expressed proteins, a network was created including genes and microRNAs known to interact with these proteins and this network was used to visualize the experimental data. In total 6 clusters could be distinguished which appeared to be involved in several toxicity related processes, including alteration of protein folding and secretion in the endoplasmic reticulum. Metabonomic analyses resulted in 5 differentially expressed metabolites, indicative of an altered glucose, lipid and cholesterol homeostasis which can be related to cholestasis.

Single and integrative analyses of transcriptomics, proteomics and metabonomics revea mechanisms underlying cyclosporin A-induced cholestasis demonstrating that endoplasmic reticulum stress and the unfolded protein response are important processes in drug-induced liver toxicity. 


\section{Materials and methods}

\section{Chemicals}

Modified Eagle's medium (MEM) plus glutamax, sodium pyruvate, fetal calf serum (FCS), non-essential amino acids, penicillin/streptomycin, Hanks' calcium- and magnesium-free buffer and insulin were obtained from Invitrogen (Breda, The Netherlands). Glucagon, hydrocortisone (water soluble), collagenase type IV, dimethylsulfoxide (DMSO), Trypan blue, 3-(4,5-dimethylthiazol-2-yl)-2,5-diphenyltetrazolium bromide (MTT), Cyclosporin A (BioChemika) and $\mathrm{N}, \mathrm{N}$-dimethylformamide (anhydrous, 99.8\%), $\mathrm{NaCl}, \mathrm{NaHCO}_{3}, \mathrm{KCl}_{2} \mathrm{KH}_{2} \mathrm{PO}_{4}, \mathrm{MgSO}_{4}$, glucose and $\mathrm{CaCl}_{2}$ were purchased from Sigma-Aldrich (Zwijndrecht, The Netherlands). Collagen type I Rat Tail was obtained from BD Biosciences (Bedford, MA, USA). Deuterated chloroform $\left(C D C I_{3}\right)$, deuterium oxide $\left(D_{2} O\right)$ and deuterated methanol $\left(C D_{3} O D\right)$ were obtained from VWR International (Amsterdam, The Netherlands) and Ammonium acetate $\left(\mathrm{NH}_{4} \mathrm{Ac}\right)$, sodium chloride $(\mathrm{NaCl})$, dipotassium hydrogenphosphate $\left(\mathrm{K}_{2} \mathrm{HPO}_{4}\right)$, monopotassium hydrogenphosphate $\left(\mathrm{KH}_{2} \mathrm{PO}_{4}\right)$ were obtained from Merck (Darmstadt, Germany). The Trizol reagent and the RNeasy mini kit were from Qiagen Westburg (Leusden, The Netherlands).

Animals

The animal studies were approved by the Animal Ethical Committee of Maastricht University, The Netherlands (approval number: 2011-108). Adult male C57BL/6 mice, weighing 20-25 grams, were obtained from Charles River $\mathrm{GmbH}$, Sulzfeld, Germany. Animals were housed in macrolon cages with sawdust bedding at $22^{\circ} \mathrm{C}$ and $50-60 \%$ humidity. Food and tap water were available ad libitum, and the light cycle was 12 hours light/12 hours dark.

\section{solation and culturing of primary mouse hepatocytes}

A two-step collagenase perfusion method according to Seglen ${ }^{9}$, with modifications as described before ${ }^{3}$ was used to isolate hepatocytes. In short, cell suspensions with cell viability $\geq 80 \%$ were brought into culture in a collagen-collagen sandwich. The primary mouse hepatocytes were allowed to recover for $40-42$ hours at $37^{\circ} \mathrm{C}$ in a humidified chamber with $95 \% / 5 \%$ air/ $\mathrm{CO}_{2}$ in serum-free culture medium supplemented with glucagon $(7 \mathrm{ng} / \mathrm{mL})$, insulin $(0.5 \mathrm{U} /$ $\mathrm{mL}$ ), $2 \%$ penicillin/streptomycin ( $5000 \mathrm{U} / \mathrm{mL}$ penicillin and $5000 \mu \mathrm{g} / \mathrm{mL}$ streptomycin), and hydrocortisone $(7.5 \mu \mathrm{g} / \mathrm{mL})$. Culture medium was refreshed every 24 hours. After the recovery period, cells were exposed to culture medium containing CsA or $0.5 \%$ DMSO as a vehicle control. Based on $\mathrm{IC}_{20}$ values, which were determined by the MTT reduction method ${ }^{\circ}$, hepatocytes were exposed as follows: $0.5 \%$ DMSO as a vehicle control and $10 \mu \mathrm{M}$ CsA for $\mathrm{IC}_{20}$ at 48 hours. For transcriptomics analyses, three independent biological experiments, each with cells from a different animal, were performed. For metabolome analysis, five experiments were performed.

\section{Transcriptomics}

MRNA expression profiling

Standard procedures were used to perform total RNA isolation, target preparation and microarray hybridization on the Affymetrix Mouse Genome 4302.0 arrays and scanning on an
By analyzing expression levels of proteins, mRNAs, microRNAs and metabolites, we aim to further elucidate the mechanisms behind CSA-induced hepatotoxicity and to investigate the processes leading to CsA-induced cholestasis. 
was done as described previously. ${ }^{19}$ The data were pre-processed and aligned using an in-house developed program. ${ }^{20}$ The aligned fingerprint data were normalized using Probabilistic Ouotient Normalization ${ }^{21}$ combined with log2 transformation. Differentially expressed metabolites were selected using the combination of the following criteria: I) the Student's T-test p-value was $<0.05$, II) the absolute FC was $>1.5$ for all five biological replicates. Metabolites were identified by using a combination of commercial standards, literature and databases like the Human Metabolome Database. ${ }^{22}$ Raw data of the polar and apolar peaks are accessible through Additional file 6 and 7, respectively.

\section{Integrative data analysis}

Selection of microRNA/mRNA targets

For the integration of microRNAs and their mRNA targets, first the database miRTarBase ${ }^{23}$ was used to get a list of experimentally validated microRNA-target interactions (Mus Musculus, Release 4.4). Additionally, also predicted mRNA targets were of interest. For that purpose, custom Perl scripts were used to combine two flat-text files derived from miRanda ${ }^{24}$ (release date: Aug 2010) and TargetScan ${ }^{25}$ (release 6.0). The mouse 'good mirSVR score, Conserved miRNA' text file from miRanda and the 'Predicted Conserved Targets Info' file from TargetScan were merged based on the stable MIMAT identifier and can be downloaded at http://web. tgx.unimaas.nl/svn/public/miRNA/. As such, the merged file only contains highly conserved microRNA targets.

\section{Network visualization of integrated data}

For the biological interpretation of the significant proteins, a network was created using the MiMI-plugin ${ }^{26}$ in Cytoscape (version 2.8.3). ${ }^{27}$ The selected significant proteins were uploaded into the MiMI-plugin and a network was created based on known biological interactions including nearest neighbors. CyTargetLinker was used to add microRNAs to this network based on information from miRTarBase (version 4.4).

The transcriptomics data discussed in this publication have been deposited in NCBI's gene expression omnibus ${ }^{17}$ and are accessible through GEO series accession number GSE55883.

\section{Proteomics}

Proteomics results from primary mouse hepatocytes exposed to CsA were derived from published experiments by Van Summeren et al..$^{18}$ In short, after exposure to CsA, amiodarone or acetaminophen, cells were washed and proteins were isolated. Labeling and differential in ge electrophoresis (DIGE) was performed and a one-way ANOVA test ( $p<0.05$ ) was used to selec the significant differential spots between the experimental groups. Differentially expressed proteins were identified using mass spectrometry. A post-hoc test was performed to find differentially changed proteins between CsA-treated cells and solvent controls.

\section{Metabonomics}

The polar and apolar metabolites were extracted from exposed cells and analysis with $1 \mathrm{H}-\mathrm{NMR}$

\section{Results}

Omics analyses

After exposure to CsA the gene, microRNA, protein and metabolite expressions of primary mouse hepatocytes were analyzed. Microarray-based transcriptomic analyses of primary mouse hepatocytes revealed 1836 differentially expressed genes for mRNA analysis of which 813 were up-regulated and 1023 were down-regulated (Additional file 1). Pathway analysis was performed for biological interpretation of differentially expressed genes, resulting in 223 significantly changed pathways which were allocated to general cellular processes (Table 1). 68 pathways, approximately $30 \%$ of the total number, were related to processes involved in lipid metabolism. Amino acid metabolism and drug metabolism were also significantly affected, representing approximately $14 \%$ and $9 \%$ of the significantly affected pathways, respectively. A complete overview of the significantly changed pathways, the general cellular processes and the differentially expressed genes involved can be found in Additional file 2. 
7 differentially expressed microRNAs were found for microRNA analysis of which five were up-regulated and 2 down-regulated (Table 2). The five up-regulated microRNAs were mmumiR-20a, mmu-miR-182, mmu-miR-183, mmu-miR-767, mmu-miR-3096b and the two downregulated microRNAs were mmu-miR-212 and mmu-miR-221.

For the creation of molecular networks, the significantly changed proteins after CsA treatment were used, which were found with a post-hoc test between CsA-treated cells and the corresponding controls. This resulted in 21 differential protein-spots belonging to 19 unique proteins (Table 3 ).

Metabonomics analysis revealed 5 differentially expressed metabolites (Table 4). Analysis of polar metabolites showed significant up-regulation of glucose. Analysis of the apolar cell extracts revealed a decreased level of fatty acyl chains and an increase of free fatty acids, glycerol backbone and glycerophospholipid backbone.

\section{Integrative data analysis}

To investigate protein-mRNA-microRNA interactions after CsA exposure, proteomic and transcriptomic data were analyzed to find sets of differentially expressed proteins, genes and microRNAs. 19 differentially expressed proteins were found and 9 of these 19 genes were also found to be differentially expressed in the gene expression analysis after treatment with 10 $\mu M$ CsA for 48 hours (Table 3). MicroRNA-mRNA-targets for these 9 genes were evaluated using experimentally validated data from miRTarBase, as well as the overlap of predicted data from TargetScan and MiRanda. However, no associated microRNAs were found using miRTarBase.

After integration, one set was found of which protein, gene and associated microRNA indeed appeared significantly expressed after the treatment with $10 \mu \mathrm{M}$ CsA for 48 hours. The corresponding protein, member 4 from protein disulfide isomerase family $A$, was significantly up-regulated with a FC of 1.40. The PDIA4 gene coding for this protein was also significantly up-regulated with a FC of 1.84. Based on the merged list of MiRanda and TargetScan, mmumiR-182 is predicted to target the PDIA4 mRNA. This microRNA was up-regulated with a FC of 2.04. Exploring the related Gene Ontology processes for this protein revealed a role in folding and secretion of proteins in the endoplasmic reticulum (ER).

\section{Network visualization of integrated data}

To further investigate the interaction between the significantly changed proteins and the associated genes and microRNAs, networks were created using Cytoscape. Firstly, the 19 significantly modulated proteins were up-loaded into the MiMl-plugin of Cytoscape and interactions were investigated including genes directly interacting with these proteins. Interactions were found for 8 of the 19 proteins including nearest neighboring genes (Figure 1). In total, 88 genes were added to the network; expression levels of 36 genes appeared significantly changed after treatment with CsA ( $p<0.05)$ and 23 of these significantly changed gene expressions had absolute FCs higher than 1.5. Six clusters could be distinguished, which were associated with transport (Cluster 1), cell cycle processes (Cluster 2), lipid homeostasis (Cluster 4), glycolysis (Cluster 5) and protein folding and catabolism (Cluster 3, 4 and 6). Secondly, experimentally validated microRNA/mRNA interactions were added using the CyTargeLinkerplugin of Cytoscape based on the miRTarBase database. 13 microRNAs were added to the network of which one, mmu-miR-221, appeared significantly expressed after CsA treatment with a FC of -1.55 (Figure 2). All significant proteins, genes and microRNAs were visualized in this network and all nodes included in this network are listed in Additional file 4.

\section{Discussion}

In this study we present an integrative cross-omics analysis of CsA-induced toxicity in primary mouse hepatocytes. Expression of proteins, genes, microRNAs and metabolites were analyzed after treatment with $10 \mu \mathrm{M}$ CsA for 48 hours. The present study reveals that in total 1836 genes were significantly expressed after CsA treatment. Pathway analysis of mRNA results indicated changes in lipid, amino acid, drug, glucose and bile metabolism on transcription level, which can be related to drug-induced cholestasis. However, to elucidate the complete cellular response to CsA treatment, these transcriptomic changes need to be confirmed by measuring the protein and metabolite levels.

Protein results have previously been published by Van Summeren et al. and the authors concluded that the deregulated proteins were involved in ER stress and ER-Golgi transport. ${ }^{18}$ In addition to mRNA results, proteomics investigation of CSA-induced toxicity reveals that processes like vesicle-mediated transport and protein secretion may be affected. MicroRNA expression profiling resulted in 7 differentially expressed microRNAs after CsA treatment. MiR182 and miR-183 were differentially up-regulated and belong to the same microRNA-cluster. MiR-96 is also part of this microRNA-cluster and although this microRNA was also up-regulated, the change was not significant due to high inter-sample variation. The microRNAs in this cluster interact with genes involved in the insulin signaling pathway ${ }^{28}$, which was shown to be linked to ER stress and the UPR. ${ }^{29-30}$ Mir-212 was shown to target CYP2E1 and miR-212 expression was shown to be regulated by insulin ${ }^{31}$, further emphasizing a link between insulin signaling and drug-induced ER stress. MiR-2Oa was shown to negatively regulate E2F1 expression, which is an important transcription factor involved in cell cycle progression. ${ }^{32}$ MiR-221 was also shown to target mRNAs involved in pathways related to cell cycle progression and apoptosis. ${ }^{33} \mathrm{No}$ literature was found describing possible roles for miR-767. Furthermore, miR-3096b has been shown to be independent of Dicer and is believed to be a misannotation. ${ }^{34}$ Additional to the insights gained from mRNA and protein analysis, microRNA analysis indicates that microRNAs involved in cell cycle progression and insulin signaling are differentially expressed, which both can be linked to drug-induced toxicity.

The differentially expressed proteins, genes and microRNAs were investigated to find sets of which the protein, gene and interacting microRNA(s) were all significantly affected. The protein disulfide isomerase family A, member 4 (Pdia4) coding gene and protein were differentially expressed after CsA treatment. Furthermore, the microRNA mmu-miR-182-5p, which is predicted to interact with the Pdia4 mRNA by both TargetScan and MiRanda, was also differentially expressed. Most studied are the mechanisms underlying microRNA-induced mRNA decay and repression of mRNA translation resulting in repressed protein synthesis. 35-37 
homeostasis and transport. Furthermore, three of these clusters were involved in important processes involved in the UPR, namely protein folding and protein catabolism. The network was further expanded with interacting microRNAs. Overall, all proteins, genes and microRNAs in the expanded network are involved in processes known to be affected after CsA treatment suggesting a possible role in drug-induced toxicity.

Metabolites were analyzed to further elucidate the mechanisms underlying CsA-induced hepatotoxicity. Investigation of the polar metabolites after treatment with $10 \mu \mathrm{M}$ resulted in 1 significantly up-regulated metabolite, glucose. This higher expression of glucose after CsA treatment could possibly be explained by down-regulation of glycolysis, while one of the significantly down-regulated proteins was $\alpha$-enolase. No significantly expressed microRNAs were predicted to interact with the mRNA of $\alpha$-enolase and no mRNA levels were assessed with the used arrays, so regulation of this protein could not be further investigated in our experiments. However, in cluster 5 of the expanded network more genes involved in glucose homeostasis and microRNAs interacting with the mRNA of these genes are visible and could be involved in the down-regulation of glycolysis. One of these genes is pyruvate kinase and the mRNA coding for this enzyme was significantly down-regulated after CsA treatment. It has been shown that fatty acids are capable of down-regulating pyruvate kinase; investigation of the apolar metabolites indeed shows a significant increase of the fatty acids level afte CsA treatment. The level of glycerol is also increased after CsA treatment. However, the leve of fatty acyl chain is decreased. A possible explanation is that the long chain fatty acids are still broken down by beta-oxidation in the peroxisomes, resulting in a decreased level of fatty acyl chain, but the short chain fatty acids are not further oxidized in the mitochondria due to mitochondrial stress, thus resulting in increased levels of free fatty acids and glycerol.

When investigating apolar metabolites of the samples treated with $50 \mu \mathrm{M}$ CsA, tota cholesterol levels were decreased after 48 hours, where the level of esterified cholesterol was increased. Furthermore, after treatment with the high dose, levels of sphingomyelin, choline and multiple cholesterol protons were decreased. The detection of several other apola metabolites was impossible because of interference from CsA. Protons belonging to CsA were detected after treatment with the high dose, suggesting an intracellular accumulation of CsA. Sphingomyelin is synthesized by the ER and the sphingomyelin level was lower after CsA treatment which could therefore be a result of the CsA-induced ER stress. Kockx et al. showed that cholesterol accumulation can inhibit ER to Golgi transport and protein secretion. ${ }^{40}$ Total cholesterol levels and peaks belonging to multiple cholesterol protons are decreased after CsA treatment; however, the level of esterified cholesterol is increased after treatment with the high dose for 48 hours. Unfortunately, levels of free cholesterol could not be investigated because of interference by the protons belonging to CsA. A relative increase of the esterified fraction of cholesterol could be an indication that the cells are trying to secrete the intracellula cholesterol via lipoproteins as a reaction to reduced bile acid flow. This would explain the tota amount of cholesterol decreasing, while the esterified fraction increases. Overall, additiona to mRNA, microRNA and protein analyses, metabonomic investigation of CsA-induced toxicity reveals impairment of the lipid and cholesterol homeostasis. These processes can be related changed proteins and their neighboring genes. This resulted in five clusters which are involved in several cellular processes like cell cycle, amino acid homeostasis, glucose homeostasis, lipid 
to cholestatic mechanisms, which would indicate CsA-induced cholestasis in primary mouse hepatocytes.

Although single omics analysis can indicate which cellular processes are affected after exposure to toxic compounds, integrating multiple omics reveals the implications of thes compound-induced changes and further elucidates the mechanisms underlying compoundinduced toxicity.

The AOP for cholestasis recently published by Vinken et al. summarizes the literature on the deteriorative and adaptive cellular response induced by bile acid accumulation as a result of BSEP inhibition. Many of the cellular responses described in this AOP were also found to be affected in our study on PMH after exposure to CSA, which is a known inhibitor of the BSEP. However, integrating multiple omics additionally identified the involvement of ER stress and the UPR in CsA-induced hepatotoxicity. Activation of several nuclear receptors is indicated to be a key event in the AOP for cholestasis, which in turn results in altered gene expression of target genes. Since the ER is important in the translation and folding of proteins, induced transcriptomic changes by nuclear receptors are dependent on a correct functioning of the ER. This novel finding resulting from an innovative multi-omics integration effort, thus indicates that $E R$ stress represents an important process in the induction of cholestasis and should be included in an AOP for cholestasis.

\section{Conclusions}

This integrative omics analysis of the transcriptome and the proteome in primary mouse hepatocytes further emphasizes the induction of ER-stress and the unfolded protein response by cyclosporin A. microRNA analysis indicates that cell cycle progression and insulin signaling are involved in CsA-induced toxicity. Furthermore, the metabonomics and transcriptomics analysis revealed impairment of the lipid and cholesterol homeostasis which may be a result of mechanisms involved in drug-induced cholestasis. We conclude that cross-omics analysis confirms and strengthens the results found with the single omics approach and has the potential of substantially deepening our insights in Adverse Outcome Pathways.

\section{Availability of supporting data}

The data sets supporting the results of this article are included within the article (and its additional files) or are available in the NCBl's gene expression omnibus. The transcriptomics data are accessible through GEO series accession number GSE55883.

\section{Acknowledgements}

We are grateful to Gerard van Bruchen for his help with the 'H-NMR measurements of the primary mouse hepatocyte samples.
Table 1. Cellular processes affected after treatment with $10 \mu \mathrm{M}$ cyclosporin $\mathrm{A}$ for 48 hours based on differentially expressed genes. ConsensusPathDB pathways that were significantly affected were allocated to general cellular processes.

\begin{tabular}{|l|c|}
\hline Cellular Process & \# of Pathways \\
\hline Lipid Metabolism & 68 \\
\hline Amino Acid Metabolism & 32 \\
\hline Drug Metabolism & 20 \\
\hline Glucose Metabolism & 13 \\
\hline Complement System & 11 \\
\hline Hemostasis & 10 \\
\hline Protein processing & 9 \\
\hline Bile Metabolism & 8 \\
\hline Cell Surface Interactions & 2 \\
\hline Apoptosis & 2 \\
\hline Peroxisome & 2 \\
\hline Other Cellular Processes & 46 \\
\hline Total & 223 \\
\hline
\end{tabular}

Table 2. Differentially expressed microRNAs (absolute FC > 1.5 and $p$-value $<0.05$ ) of primary mouse hepatocytes after treatment with $10 \mu M$ cyclosporin A for 48 hours with their FC and p-value.

\begin{tabular}{|l|l|l|}
\hline microRNA & FC & p-value \\
\hline mmu-miR-182-5p & 2.04 & 0.04 \\
\hline mmu-miR-183-5p & 2.07 & 0.00 \\
\hline mmu-miR-20a-5p & 1.63 & 0.05 \\
\hline mmu-miR-212-3p & -1.55 & 0.01 \\
\hline mmu-miR-221-3p & -1.55 & 0.03 \\
\hline mmu-miR-3096b-3p & 1.53 & 0.02 \\
\hline mmu-miR-767 & 3.5 & 0.01 \\
\hline
\end{tabular}


Table 3. Protein and gene expression results after treatment with $10 \mu \mathrm{M}$ cyclosporin A for 48 hours for the significantly changed proteins.

FC p-value Gene FC p-value

Protein name

protein name gene gene

$\begin{array}{lllllll}\text { Protein disulfide-isomerase } & 1.89 & 0.01 & \text { P4hb } & 1.64 & 0.00\end{array}$

\begin{tabular}{|l|l|l|l|l|l}
78 kDa glucose-regulated protein & 1.69 & 0.01 & Hspa5 & 2.08 & 0.00
\end{tabular}

$\begin{array}{llllllll}\text { Hydroxyacylglutathione hydrolase, mitochondrial } & 1.24 & 0.03 & \text { Hagh } & 1.40 & 0.00\end{array}$

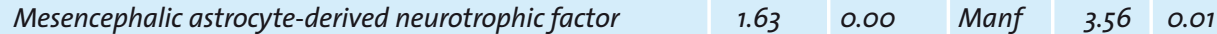

$\begin{array}{lllllll}\text { Peptidyl-prolyl cis-trans isomerase B / Cyclophilin B } & -1.68 & 0.00 & \text { Ppib } & 1.19 & 0.02\end{array}$

\begin{tabular}{|l|l|l|l|l|l|l|l|l|l|l|l|l|l|l|l|}
\hline Peptidyl-prolyl cis-trans isomerase B / Cyclophilin B & -1.90 & 0.00 & Ppib & 1.19 & 0.02 \\
\hline
\end{tabular}

Protein disulfide isomerase A4

$\begin{array}{lllll}1.40 & 0.01 & \text { Pdia4 } & 1.84 & 0.02\end{array}$

Keratin, type l cytoskeletal 10

\begin{tabular}{l|r|r|r|} 
Krt10 & 1.61 & 0.03
\end{tabular}

$\begin{array}{lllllll}\text { Ornithine carbamoy/transferase, mitochondrial } & & 2.12 & 0.01 & \text { Otc } & -6.60 & 0.03\end{array}$

\begin{tabular}{|l|c|c|c|c|c|}
\hline Liver carboxylesterase 1 & -1.46 & 0.04 & Ces1 & -6.26 & 0.04
\end{tabular}

$\begin{array}{lllllll}\text { Proteasome subunit beta type-7 } & 1.22 & 0.02 & \text { Psmb7 } & 1.12 & 0.06\end{array}$

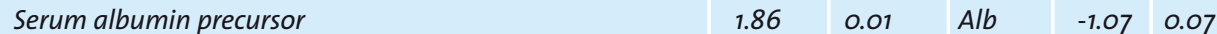

$\begin{array}{lllllll}\text { Protein disulfide-isomerase } A_{3} & -1.46 & 0.04 & P_{\text {dia }} & 1.46 & 0.07\end{array}$

\begin{tabular}{|l|l|l|l|l|l|l|} 
Isoform 1 of Peroxisomal coenzyme A diphosphatase NUDT7 & 1.22 & 0.02 & Nudt7 & -1.38 & 0.12
\end{tabular}

$\begin{array}{lllll}1.54 & 0.04 & \text { Inmt } & -1.26 & 0.18\end{array}$

\begin{tabular}{|l|l|l|l|l|l|l|} 
Perilipin-2 / Adipophilin & -2.01 & 0.00 & Plin2 & -1.15 & 0.18
\end{tabular}

$\begin{array}{lllllll}\text { Perilipin-2 / Adipophilin } & -2.25 & 0.00 & \text { Plin2 } & -1.15 & 0.18\end{array}$

\begin{tabular}{|l|l|l|l|l|l|l|}
\hline Voltage-dependent anion-selective channel protein 2 & 1.24 & 0.01 & Vdac2 & 1.04 & 0.51
\end{tabular}

$\begin{array}{lllllll}\text { Proline-rich protein } 15 & 1.63 & 0.00 & \text { Prr15 } & -1.03 & 0.70\end{array}$

\begin{tabular}{|l|l|l|l|l|l|}
\hline Arfaptin-1 protein & -2.25 & 0.00 & Arfip1 & -1.01 & 0.81 \\
\hline
\end{tabular}

LOC100044223 Alpha-enolase $\quad-2.25$ o.00 Eno1 NA NA

Table 4. Differentially expressed metabolites in primary mouse hepatocytes after exposure to $10 \mu \mathrm{M}$ CsA for 48 hours with their FCs.

\section{Polar Metabolites}

Glucose FC

Apolar Metabolites

Fatty acyl chain

Free fatty acids

$-1.62$

Glycerol Backbone

4.87

Glycerol/Glycerophospholipid Backbone

4.87

3.79

NA, Not Analyzed; Adapted from Van Summeren, A., et al. ${ }^{18}$

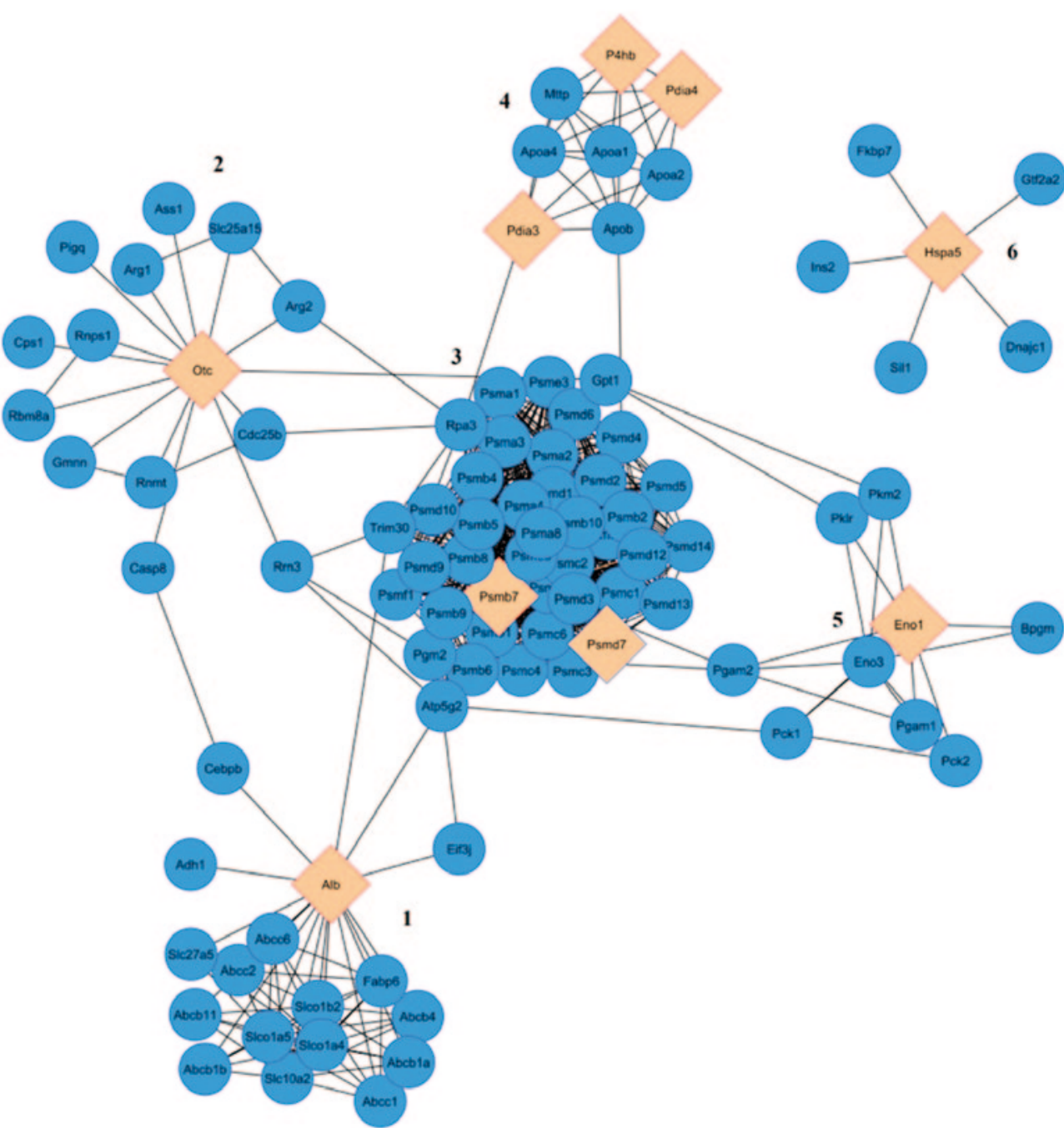

Figure 1. Network created with Cytoscape to visualize the interaction between the significantly changed proteins (diamonds) and their interactions with neighboring genes (circles) resulting in 6 clusters. 


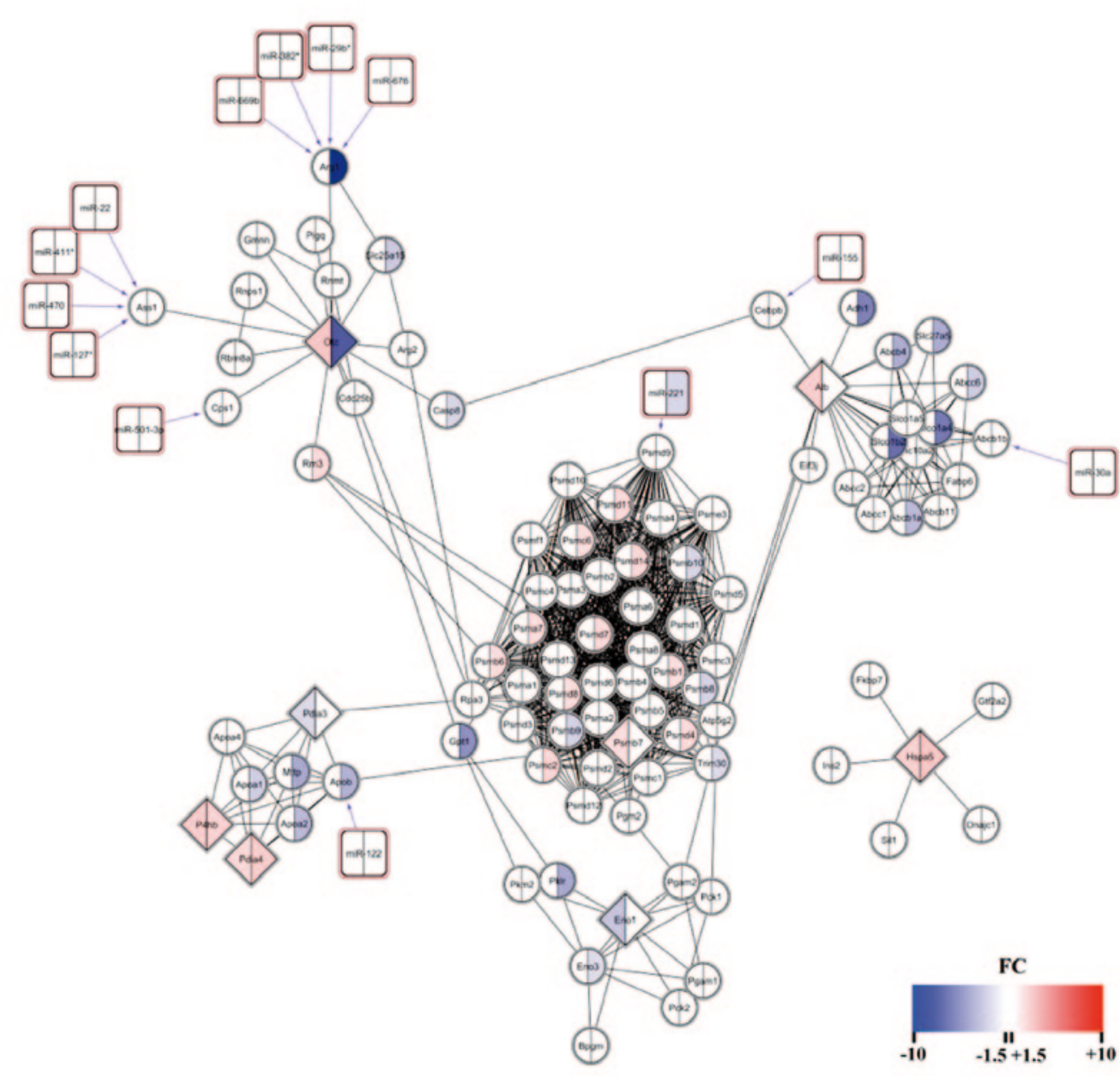

Figure 2. Network created with Cytoscape to visualize the interaction between the significantly changed proteins (diamonds) and their interactions with neighboring genes (circles) and validated interacting microRNAs based on miRTarBase database (squares). Significant proteomics data is visualized on the left side of the nodes and significant gene and microRNA data on the right side of the nodes, based on the fold changes after treatment with $10 \mu \mathrm{M}$ cyclosporin A for 48 hours.

\section{References}

1. Lee, W. M. (2003) Drug-Induced Hepatotoxicity. N Engl J Med 349, 474-485.

2. Hewitt, N. J., Gómez Lechón, M. J., Houston, J. B., Hallifax, D., Brown, H. S., Maurel, P., Kenna, J. G., Gustavsson, L., Lohmann, C, Skonberg, C., Guillouzo, A., Tuschl, G., Li, A. P., LeCluyse, E., Groothuis, G. M. M., Hengstler, J. G. (2007) Primary Hepatocytes Current Understanding of the Regulation of Metabolic Enzymes and Transporter Proteins, and Pharmaceutical Practice for the Use of Hepatocytes in Metabolism, Enzyme Induction, Transporter, Clearance, and Hepatotoxicity Studies. Drug Metab. Rev. 39, $159-234$.

3. Mathijs, K., Kienhuis, A. S., Brauers, K. J. J., Jennen, D. G. J., Lahoz, A., Kleinjans, J. C. S., van Delft, J. H. M. (2009) Assessing the Metabolic Competence of Sandwich-Cultured Mouse Primary Hepatocytes. Drug Metab. Dispos. 37, 1305-1311.

4. Ozer, J., Ratner, M., Shaw, M., Bailey, W., Schomaker, S. (2008) The current state of serum biomarkers of hepatotoxicity Toxicology 245, 194-205.

5. Blomme, E. A. G., Yang, Y., Waring, J. F. (2009) Use of toxicogenomics to understand mechanisms of drug-induced hepatotoxicity during drug discovery and development. Toxicol. Lett. 186, 22-31.

6. Van Summeren, A., Renes, J., van Delft, J. H. M., Kleinjans, J. C. S., Mariman, E. C. M. (2012) Proteomics in the search for mechanisms and biomarkers of drug-induced hepatotoxicity. Toxicol. In Vitro 26, 373-385.

Robertson, D. G. (2005) Metabonomics in Toxicology: A Review. Toxicol. Sci. 85, 809-822.

8. Vinken, M., Landesmann, B., Goumenou, M., Vinken, S., Shah, I., Jaeschke, H., Willett, C., Whelan, M., Rogiers, V. (2013) Development of an adverse outcome pathway from drug-mediated bile salt export pump inhibition to cholestatic liver injury. Toxicol Sci 136, 97-106.

9. Seglen, P. O. (1976) Preparation of isolated rat liver cells. Methods Cell Biol 13, 29-83.

10. Mosmann, T. (1983) Rapid colorimetric assay for cellular growth and survival: Application to proliferation and cytotoxicity assays. Journal of Immunological Methods 65, 55-63.

11. Eijssen, L. M. T., Jaillard, M., Adriaens, M. E., Gaj, S., de Groot, P. J, Müller, M., Evelo, C. T. (2013) User-friendly solutions for microarray quality control and pre-processing on ArrayAnalysis.org. Nucleic Acids Res. 41, W71-W76.

12. Dai, M., Wang, P., Boyd, A. D., Kostov, G., Athey, B., Jones, E. G., Bunney, W. E., Myers, R. M., Speed, T. P., Akil, H., Watson, S. J., Meng, F. (2005) Evolving gene/transcript definitions significantly alter the interpretation of GeneChip data. Nucleic Acids Res. $33, \mathrm{e} 175$

13. Irizarry, R. A., Hobbs, B., Collin, F., Beazer-Barclay, Y. D., Antonellis, K. J., Scherf, U., Speed, T. P. (2003) Exploration, normalization, and summaries of high density oligonucleotide array probe level data. Biostatistics 4, 249-264.

14. Kamburov, A., Wierling, C., Lehrach, H., Herwig, R. (2009) ConsensusPathDB-a database for integrating human functional interaction networks. Nucleic Acids Res. 37. D623-D628.

15. Benjamini, Y., Hochberg, Y. (1995) Controlling the False Discovery Rate: A Practical and Powerful Approach to Multiple Testing. Journal of the Royal Statistical Society. Series B (Methodological) 57, 289-300.

16. Lopez-Romero, P. (2011) Pre-processing and differential expression analysis of Agilent microRNA arrays using the AgiMicroRna Bioconductor library. BMC Genomics 12, 64

17. Edgar, R., Domrachev, M., Lash, A. E. (2002) Gene Expression Omnibus: NCBI gene expression and hybridization array data repository. Nucleic Acids Res. 30, 207-210.

8. Van Summeren, A. Renes, J., Lizarraga, D. Bouwman, F. G., Noben, J. P. van Delft, J. H. Kleinjans, J. C., Mariman, E. C. (2013) Screening for drug-induced hepatotoxicity in primary mouse hepatocytes using acetaminophen, amiodarone, and cyclosporin a as model compounds: an omics-guided approach. OMICS 17, 71-83.

9. Ruiz-Aracama, A., Peijnenburg, A., Kleinjans, J., Jennen, D., van Delft, J., Hellfrisch, C., Lommen, A. (2011) An untargeted 
multi-technique metabolomics approach to studying intracellular metabolites of HepG2 cells exposed to 2,3,7,8-tetrachlorodibenzo-p-dioxin. BMC Genomics 12, 251 .

20. Lommen, A., Weseman, J. M., Smith, G. O., Noteborn, H. P. J. M. (1998) On the detection of environmental effects on complex matrices combining off-line liquid chromatography and $1 \mathrm{H}-\mathrm{NMR}$. Biodegradation 9, 513-525.

21. Dieterle, F., Ross, A., Schlotterbeck, G. t., Senn, H. (2006) Probabilistic Quotient Normalization as Robust Method to Account for Dilution of Complex Biological Mixtures. Application in 1 H NMR Metabonomics. Anal. Chem. 78, 4281-4290.

22. Wishart, D. S., Tzur, D., Knox, C., Eisner, R., Guo, A. C., Young, N., Cheng, D., Jewell, K., Arndt, D., Sawhney, S., Fung, C., Nikolai, L., Lewis, M., Coutouly, M.-A., Forsythe, I., Tang, P., Shrivastava, S., Jeroncic, K., Stothard, P., Amegbey, C., Block, D., Hau, D. D., Wagner, J., Miniaci, J., Clements, M., Gebremedhin, M., Guo, N., Zhang, Y., Duggan, G. E., Maclnnis, G. D., Weljie, A. M. Dowlatabadi, R., Bamforth, F., Clive, D., Greiner, R., Li, L., Marrie, T., Sykes, B. D., Vogel, H. J., Ouerengesser, L. (2007) HMDB the Human Metabolome Database. Nucleic Acids Res. 35, D521-D526.

23. Hsu, S.-D., Lin, F.-M., Wu, W.-Y., Liang, C., Huang, W.-C., Chan, W.-L., Tsai, W.-T., Chen, C.-Z., Lee, C.-J., Chiu, C.-M., Chien, C.-H., Wu, M.-C., Huang, C.-Y., Tsou, A.P., Huang, H.-D. (2011) miRTarBase: a database curates experimentally validated microRNA-target interactions. Nucleic Acids Res. 39, D163-D169.

24. Betel, D., Wilson, M., Gabow, A., Marks, D. S., Sander, C. (2008) The microRNA.org resource: targets and expression. Nucleic Acids Res. 36, D149-D153.

25. Friedman, R. C., Farh, K. K.-H., Burge, C. B., Bartel, D. P. (2009) Most mammalian mRNAs are conserved targets of microRNAs. Genome Res. 19, 92-105.

26. Gao, J., Ade, A. S., Tarcea, V. G., Weymouth, T. E., Mirel, B. R., Jagadish, H. V., States, D. J. (2009) Integrating and annotating the interactome using the MiMl plugin for cytoscape. Bioinformatics 25, 137-138.

27. Smoot, M. E., Ono, K., Ruscheinski, J., Wang, P.-L., Ideker, T. (2011) Cytoscape 2.8: new features for data integration and network visualization. Bioinformatics 27, 431-432

28. Xu, J., Wong, C. (2008) A computational screen for mouse signaling pathways targeted by microRNA clusters. RNA 14 1276-1283.

29. Park, S. W., Zhou, Y., Lee, J., Lu, A., Sun, C., Chung, J., Ueki, K., Ozcan, U. (2010) The regulatory subunits of Pl3K, p85[alpha] and $\mathrm{p} 8$ [ [beta], interact with XBP-1 and increase its nuclear translocation. Nat Med 16, 429-437.

3o. Winnay, J. N., Boucher, J., Mori, M. A., Ueki, K., Kahn, C. R. (2010) A regulatory subunit of phosphoinositide 3-kinase increases the nuclear accumulation of $\mathrm{X}$-box-binding protein-1 to modulate the unfolded protein response. Nat Med 16 $438-445$.

31. Shukla, U., Tumma, N., Gratsch, T., Dombkowski, A., Novak, R. F. (2013) Insights into Insulin-Mediated Regulation of CYP2E1: miR-132/-212 Targeting of CYP2E1 and Role of Phosphatidylinositol 3-Kinase, Akt (Protein Kinase B), Mammalian Target of Rapamycin Signaling in Regulating miR-132/-212 and miR-122/-181a Expression in Primary Cultured Rat Hepatocytes. Drug Metab. Dispos. 41, 1769-1777.

32. O'Donnell, K. A., Wentzel, E. A., Zeller, K. I., Dang, C. V., Mendell, J. T. (2005) c-Myc-regulated microRNAs modulate E2 expression. Nature 435, 839-843.

33. Lupini, L., Bassi, C., Ferracin, M., Bartonicek, N., D’Abundo, L., Zagatti, B., Callegari, E., Musa, G., Moshiri, F., Gramantieri, L, Corrales, F. J., Enright, A. J., Sabbioni, S., Negrini, M. (2013) miR-221 affects multiple cancer pathways by modulating the level of hundreds messenger RNAs. Front Genet 4, 64

34. Castellano, L., Stebbing, J. (2013) Deep sequencing of small RNAs identifies canonical and non-canonical miRNA and endogenous siRNAs in mammalian somatic tissues. Nucleic Acids Res. 41, 3339-335.

35. Fabian, M. R., Sonenberg, N., Filipowicz, W. (2010) Regulation of mRNA Translation and Stability by microRNAs. Annual
Review of Biochemistry 79, 351-379.

36. Pillai, R. S., Bhattacharyya, S. N., Filipowicz,W. (2007) Repression of protein synthesis by miRNAs: how many mechanisms? Trends in Cell Biology 17, 118-126.

37. Huntzinger, E., Izaurralde, E. (2011) Gene silencing by microRNAs: contributions of translational repression and mRNA decay. Nat Rev Genet 12, 99-110.

38. Vasudevan, S., Tong, Y., Steitz, J. A. (2007) Switching from Repression to Activation: MicroRNAs Can Up-Regulate Translation. Science 318, 1931-1934

39. Mortensen, R. D., Serra, M., Steitz, J. A., Vasudevan, S. (2011) Posttranscriptional activation of gene expression in Xenopus laevis oocytes by microRNA-protein complexes (microRNPs). Proceedings of the National Academy of Sciences 108, 82818286.

40. Kockx, M., Dinnes, D. L., Huang, K. Y., Sharpe, L. J., Jessup, W., Brown, A. J., Kritharides, L. (2012) Cholesterol accumulation inhibits ER to Golgi transport and protein secretion: studies of apolipoprotein E and VSVGt. Biochem. J. 447, 51-60. 


\section{Chapter 6}

\section{MEROSHE}

INVOLVEMENT IN

DRUG-INDUCED HEPATOTOXICITY:

A MULTI-OMICS APPROACH

Van den Hof, W.F.P.M

Coonen, M.L.J.

Van Summeren, $A$.

van Herwijnen, $M$.

Brauers, K.

Wodzig, W.K.W.H.

and Kleinjans, J.C.S. 
Abstract

Drug-induced liver injury is a frequently reported reason for project termination during drug development and withdrawal of drugs already available on the market. Therefore, early detection of drug-induced toxicity is important. Liver specific microRNAs have been proposed as early biomarkers of hepatotoxicity; however their role in drug-induced toxicity is largely unknown. We investigated the microRNA and mRNA expression changes induced in vitro by three well known hepatotoxicants. HepG2 cells and primary mouse hepatocytes were treated with acetaminophen, amiodarone and cyclosporin A and RNA was isolated. Microarrays were performed to investigate the hepatotoxicant-induced changes. Different significantly expressed microRNAs are observed in HepG2 cells and primary mouse hepatocytes. MiR2110 and miR-3152 are differentially expressed in HepG2 cells after treatment with all three compounds for 24 hours. In primary mouse hepatocytes miR-212 and miR-3470a are overlapping after treatment for 24 hours with these three compounds. Investigation of these microRNAs and their targets indicates a possible role in regeneration and proliferation, which may induce cell repair and inhibit apoptosis. Furthermore, drug-specific changes in microRNA expression levels are observed in both cell models. Investigation of these drug-specific differentially expressed microRNAs suggests a possible role in the processes involved in liver injury. MicroRNAs targeting genes involved in lipid metabolism are differentially expressed in multiple treatments. Furthermore, changed microRNAs in in vivo cholestasis are differentially expressed after CsA treatment in primary mouse hepatocytes. Targeted research of these drug-specific microRNAs including their target genes and the proteins they code for may further unravel the mechanisms underlying drug-induced hepatotoxicity. 
Acetaminophen, Amiodarone, and Cyclosporin A were purchased from Sigma-Aldrich (Zwijndrecht, The Netherlands). Collagen type I Rat Tail was obtained from BD Biosciences (Bedford, MA, USA). The Trizol reagent and the RNeasy mini kit were from Qiagen Westburg (Leusden, The Netherlands).

\section{HepG2 data}

HepG2 cells were cultured in MEM plus glutamax containing $10 \% \mathrm{v} / \mathrm{v} \mathrm{FCS}, 1 \% \mathrm{v} / \mathrm{v}$ Sodium Pyruvate, $1 \% \mathrm{v} / \mathrm{v}$ non-essential amino acids, $2 \% \mathrm{w} / \mathrm{v}$ penicillin and streptomycin at $37^{\circ} \mathrm{C}$ in an atmosphere containing $5 \% \mathrm{CO}$.

Cells were seeded in 6 well plates and exposed to Cyclosporin A, Amiodarone, Acetaminophen and matching controls ( $0.5 \% \mathrm{v} / \mathrm{v}$ DMSO) for 24 hours. The $\mathrm{IC}_{20}$ of 24 hours was used to treat the cells. Concentrations were as follows: Cyclosporin A (CsA), $20 \mu \mathrm{M}$; Amiodarone (AM), $15 \mu \mathrm{M}$; Acetaminophen (APAP), $10 \mathrm{mM}$.

MRNA microarray analysis

Total RNA isolation, target preparation and microarray hybridization on the Affymetrix Human Genome U133 Plus 2.0 GeneChip arrays and scanning on an Affymetrix GeneArray scanner, were performed according to standard procedures. Quality control was performed using the Arrayanalysis.org web service and all microarrays were of high quality. ${ }^{12} \mathrm{CEL}$ files were re-annotated to EntrezGene IDs using the MBNI BrainArray Custom CDF-files v17.1.0 ${ }^{13}$, RMA normalized combined with MAS5-PMA-calling ${ }^{14}$ and the intensities were log2 transformed.

\section{microRNA microarray analysis}

MicroRNA expression profiling was performed using sixth generation miRCURY LNA microRNA arrays (Exiqon, Vedbaek, Denmark). Hybridization and scanning with a DNA microarray scanne (Agilent Technologies) were performed following standard protocols. Feature Extraction Software v10.7.3.1 from Agilent Technologies was used to convert the scanned images into TXT files, which were imported in R 2.15.2 (http://www.r-project.org) for quality control and intensities were log2-transformed and quantile normalized.

\section{Primary mouse hepatocytes data}

The animal studies were approved by the Animal Ethical Committee of the Maastricht University, The Netherlands (approval number: 2011-108). Adult male C57BL/6 mice, weighing 20-25 grams, were obtained from Charles River $\mathrm{GmbH}$, Sulzfeld, Germany. Animals were housed in macrolon cages with sawdust bedding at $22^{\circ} \mathrm{C}$ and $50-60 \%$ humidity. Food and tap water were available ad libitum, and the light cycle was 12 hours light/12 hours dark. Isolation and culture of primary mouse hepatocytes were performed as described before. "After a recovery period, cells were exposed to culture medium containing Cyclosporin A, Amiodarone, Acetaminophen or $0.5 \% \mathrm{v} / \mathrm{v}$ DMSO as a vehicle control. Based on the $\mathrm{IC}_{20}$ value for 24 hours, the hepatocytes were exposed as follows: 0.5\% v/v DMSO as a vehicle control; CsA: $50 \mu \mathrm{M}$; AM: $25 \mu \mathrm{M}$; APAP: $10 \mathrm{mM}$.

\section{Materials and methods}

Modified Eagle's medium (MEM) plus glutamax, fetal calf serum (FCS), non-essentia amino acids, sodium pyruvate, penicillin/streptomycin, insulin and Hanks' calcium- and magnesium-free buffer were purchased from Invitrogen (Breda, The Netherlands). Glucagon, hydrocortisone (water soluble), collagenase type IV, dimethylsulfoxide (DMSO), N,N dimethylformamide (anhydrous, 99.8\%), $\mathrm{NaCl}, \mathrm{NaHCO}_{3}, \mathrm{KCl}_{2} \mathrm{KH}_{2} \mathrm{PO}_{4^{\prime}}, \mathrm{MgSO}_{4^{\prime}}$ glucose, $\mathrm{CaCl}_{2}$ 


\section{Results}

Transcriptomic changes induced by cyclosporin $\mathrm{A}$, amiodarone and acetaminophen mRNA and microRNA expression profiling was performed of $\mathrm{HepG}_{2}$ cells and PMH exposed to CsA, AM and APAP. A moderated T-test was performed to minimalize the chance of finding false discoveries; however this stringent approach resulted in low number of significant genes and microRNAs in several exposures (Table 1). HepG2 cells exposed to CsA, AM and APAP, revealed 3217 differentially expressed genes (DEGs) for CSA and 2273 DEGS for APAP, where only 5 DEGs were found after AM treatment. CsA also induced the most significant changes at the microRNA level. Where APAP induced many significant changes at the mRNA level, only 4 microRNAs were significantly changed. AM treatment only induced 5 DEGs, but did result in 19 differentially expressed microRNAs. PMH treated with CSA, AM and APAP resulted in over 1000 DEGs for al three treatments, with up to 3972 DEGs for CsA treatment. Interestingly, AM induced the lowest number of DEGs but the second highest number of differentially expressed microRNAs.

Pathway analysis of the differentially expressed genes revealed overlapping processes between all three compounds (Additional files). AM treatment of HepG2 cells only induced 5 significantly changed genes and no differential pathways. CsA and APAP exposure in HepG2 cells both showed significant pathways involved in lipid, bile and glucose metabolism. CsA treatment also induced significant changes of the glutathione metabolism. Furthermore, most significant pathways were involved in cell cycle processes. In PMH, all three compounds induced changes in the lipid, bile and glutathione metabolism and significant pathways involved in glucose metabolism were found after CsA treatment. Moreover, one pathway involved in p53 signaling was significant after CsA and APAP treatment and no pathways involved in cell cycle processes were found for the three treatments in $\mathrm{PMH}$.

Figure $1 A$ and $B$ show respectively the overlap of up-regulated and down-regulated DEGs in HepG2 cells after treatment with CsA, AM, and APAP for 24 hours. In HepG2 cells only 1 gene, coding for sialidase 1 , was significantly up-regulated in all three treatments, which was mainly due to the low response on gene expression level after AM treatment. In PMH the overlap between the different treatments was much higher (Figure $1 \mathrm{C}$ and D). Moreover, treatmentspecific genes were found for all treatments. Figure 2 shows the overlap of up-regulated and down-regulated differentially expressed microRNAs in HepG2 cells and PMH. Although some overlap was found in both HepG2 cells and PMH, most differentially expressed microRNAs were only significantly affected in one of the treatments. Table 2 shows the significantly downregulated and up-regulated microRNAs in HepG2 cells (Table 2.1) and PMH (Table 2.2) after treatment with CSA, AM and APAP for 24 hours. Overall, the number of DEGs and differentially expressed microRNAs after treatment with CsA, AM and APAP did not appear to correspond and large differences between compounds were observed.

Interactions between significant microRNAs and their target genes after treatment for 24 hours in HepG2 cells

Several drug-specific microRNAs were differentially expressed and two microRNAs were significantly down-regulated in all three treatments, namely miR-2110 and miR-3152.

if the False Discovery Rate (FDR) was $<0.05$ and the percentage of input genes of the total number of genes in a pathway was $\geq 10 \%$. Pathways with less than three genes were filtered out. 
Experimentally validated interactions were investigated using lists from miRTarBase en revealed 4 target genes for miR-2110 and no interactions for miR-3152. The four target genes of miR-2110 are genes coding for chromosome 10 open reading frame 118 (C10orf118), bromodomain containing 4 (BRD4), nuclear receptor corepressor 2 (NCOR2) and fatty acid synthase (FASN). The genes C10orf118 and BRD4 were significantly up-regulated after treatment with CsA, but not with the other compounds. NCOR2 was not differentially expressed in any of the treatments and the expression of FASN was not assessed with the used microarrays.

CsA treatment in HepG2 cells for 24 hours resulted in 19 differentially expressed microRNAs which were investigated for target genes, based on the experimentally validate interaction list from miRTarBase. For 12 microRNAs no interactions were identified and for the remaining 7 microRNAs, in total 80 unique target genes were found. 11 target genes were not assessed with the used microarrays, 44 were not significantly changed and 25 were differentially expressed after CsA treatment. Of the 25 differentially expressed target genes, 10 were significantly up-regulated and thus showing a correlating response to the down-regulated microRNAs. The 10 correlating target genes are VCL, TIMP2, NOB1, HIF1A, NOP2, CDKN1A, BRD4, C10orf118, SHB, and IKZF5. The FXN gene showed interactions with two of the significantly down-regulated microRNAs, namely miR-559 and miR-935. However, the FXN mRNA was not differentially expressed after CsA treatment. Pathway analysis of al target genes revealed 2 significant pathways, Angiogenesis and HIF-2-alpha transcription factor network (Table 3).

16 microRNAs were differentially expressed in HepG2 cells treated with AM for 24 hours of which 7 showed interactions with 224 target genes. 31 of the target genes were not assessed and the remaining 193 were not significantly changed after treatment with AM. The PRRC $2 B$ and FASN genes were both targeted by two microRNAs. The PRRC2B gene was not significantly changed after AM treatment and was targeted by miR-324 and miR-1284 which were both significantly up-regulated. The expression of the FASN gene was not assessed and was targeted by miR-324 and miR-2110. MiR-2110 was significantly downregulated after AM exposure. Pathway analysis of all target genes resulted in 28 significant pathways (Table 3).

APAP treatment in HepG 2 cells for 24 hours revealed 4 differentially expressed microRNAs, 2 of which showed interactions with in total 200 target genes. 22 of these target genes were not assessed, 149 were not differentially expressed and 29 were significantly changed after APAP treatment. 12 target genes of the significantly up-regulated microRNA miR-183 were significantly down-regulated after APAP treatment. These correlating DEGs are TUBB $\mathrm{SLC}_{2} \mathrm{~A}_{3}, \mathrm{AUH}, \mathrm{CCNB} 1, \mathrm{PPRC} 1, \mathrm{SRSF}_{2}$, HNRNPM, SRSF10, MYBBP1A, C10orf2, TSR1, and GNL3. Pathway analysis of all target genes did not result in any significant pathways.

Interactions between significant microRNAs and their target genes after treatment for 24 hours in PMH

The overlap of differentially expressed microRNAs in PMH after treatment with CsA, AM, and
APAP for 24 hours was visualized in Figure 2. Two microRNAs were differentially expressed in the same direction in all three treatments. MiR-212 was significantly down-regulated in all three treatments and one experimentally validated target gene was identified, namely Mmpg, for which expression was not assessed with the used microarrays. MiR-3470a was significantly up-regulated in all three treatments and no experimentally validated target genes were found for this microRNA.

CsA treatment for 24 hours in PMH resulted in 41 differentially expressed microRNAs of which 15 showed interactions with 721 target genes in total. 196 of these target genes were not assessed with the used microarrays, 335 were not differentially expressed and 190 were significantly changed after CsA treatment. 103 of the 190 differentially expressed target genes were significantly up-regulated and showed a correlating response to the interacting microRNAs, which were down-regulated. The gene Peli1 was not differentially expressed after CsA treatment and was shown to interact with 3 microRNAs: miR-21a, miR-3oe and miR-425, which were all significantly down-regulated after CsA treatment. 47 genes showed interactions with two microRNAs of which 43 were shown to interact with both miR-3oe and miR-425. 12 of these target genes were differentially expressed after CsA treatment, 19 were not significantly changed and 12 were not assessed. The Ddit4 gene was significantly down-regulated and shown to interact with miR-30e and miR-221, which were both down-regulated. The gene Taok1 was not significantly changed and interacts with the down-regulated miR-425 and miR-183. The Zfp281 gene was not differentially expressed and interacts with miR-425 and miR-203, which were both down-regulated. The Camk2a gene expression was not assessed and shown to interact with the down-regulated miR-148b and miR-152. Pathway analysis of all target genes resulted in 115 significant pathways (Table 4).

40 microRNAs were differentially expressed in PMH after treatment with AM for 24 hours. In total 439 target genes were identified for 11 microRNAs, of which 126 were not assessed, 280 were not significantly changed and 33 were differentially expressed after treatment with AM. 19 of the 33 differentially expressed target genes were down-regulated and correlating to the down-regulated interacting microRNAs. These correlating target genes were Ctgf, Megf9, Arrdc3, Slc30a10, Sbk1, Fgf13, Pik3r1, Cxcl12, Atp1b1, Tbcel, Slc35e2, Tmem2, Nsmf, Mlec, Gucd1, Ank3, Dpysl3, Abhd14b, and Pdcd4. 5 genes were targeted by two microRNAs: Foxp1 by miR-128 and miR-425, Tor1aip2 by miR-140 and miR-425, Taok by miR-183 and miR-425 Pten by miR-20a and miR-21a Peli1 by miR-21a and miR-425. These 6 microRNAs were all significantly up-regulated after $A M$ treatment and the target genes were not differentially expressed. Pathway analysis of all target genes revealed 39 significant pathways (Table 4)

APAP exposure of PMH resulted in 23 differentially expressed microRNAs after 24 hours. 2 microRNAs were shown to have one target gene each. MiR-212 was significantly down regulated and shown to target $\mathrm{Mmp9}$, which was not assessed with the used microarrays. MiR-185 was significantly up-regulated after APAP treatment and shown to target Kdm6b which was not differentially expressed. Pathway analysis of these 2 target genes did not result in any significant pathways. 
in all treatments appear to be involved in the regeneration of damaged cells and inhibition of apoptosis. Therefore, microRNAs may be involved in an adaptive response to drug-induced toxicity in order to repair drug-induced damage and prevent cell death. However, since most research regarding the function of these microRNAs was conducted in cancer investigation these results may be biased. Future research should validate the function of these differentially expressed microRNAs in liver toxicity.

Apart from the microRNAs overlapping between the different treatments, several compoundspecific changes on microRNA expression are found, which seems logical since the three compounds belong to different classes of hepatotoxicants. CsA is known to induce cholestasis in human liver, AM can induce microvesicular steatosis and APAP induces hepatocellular necrosis. ${ }^{25-27}$ Pathway analysis of target genes of the differentially expressed microRNAs in HepG2 cells after CsA treatment reveals 2 significant pathways involving 6 of the 80 target genes. The significant pathways are involved in angiogenesis and the transcription factor HIF$2 \alpha$, which are important in processes involved in tumor growth. Again, these results may be biased since important microRNA research is performed in cancer research. However, HIF-2 $\alpha$ is also shown to be important in the regulation of lipid homeostasis in hepatocytes. ${ }^{28}$ In chapter 4 we show that CsA treatment of HepG2 cells did not result in bile salt accumulation but increased levels of intracellular cholesterol. The results of this study indicate that microRNAs differentially expressed after CsA treatment may be involved in lipid homeostasis, which may play an important role in CsA-induced toxicity in HepG2 cells. The 10 target genes which show correlated expression to the differential microRNAs are mostly involved in cell cycle and proliferation, which is in concordance with the analysis of the microRNAs overlapping in al three treatments and pathway analysis results of the DEGs. Pathway analysis of the target genes of microRNAs differentially expressed after AM treatment resulted in 28 significant pathways, which were mostly involved in fatty acid homeostasis, transcription and translation. Since $A M$ is known to induce steatosis in hepatocytes, these results suggest the involvement of microRNAs in fatty acid homeostasis and AM-induced toxicity. However, no target genes were differentially expressed after AM treatment. Pathway analysis of target genes of the differentially expressed microRNAs after APAP treatment did not result in significant pathways. Again, like in CsA treated cells, most correlated expressed target genes are involved in cel cycle and proliferation. In HepG2 cells, both pathway analysis of DEGs and target genes of differentially expressed microRNAs reveal changes on cell cycle processes in all treatments. Since HepG2 is a cancer cell line, these changes could be cell line-specific. Pathway analyses of target genes of the differentially expressed microRNAs in PMH after the three different treatments and investigation of correlated differential target genes did not result in a clear drug-specific response. Pathways were involved in multiple cellular processes, e.g. pathways involved in an inflammatory response and the circadian clock were significantly affected after treatment with $\mathrm{AM}$ and CsA.

Cytochrome P450 (CYP) enzymes are responsible for the metabolic activation of xenobiotics and their expression is regulated by post-transcriptional and post-translational mechanisms. MicroRNAs are believed to be involved in this post-transcriptional regulation. ${ }^{29}$ APAP CSA, AM, and APAP. No experimentally validated target genes are identified up till now and literature describing the role of miR-3470a is limited. A recent publication showed that miR$3470 a$ promotes metastasis in vivo. ${ }^{24}$ Overall, differentially expressed microRNAs overlapping 
metabolization is mainly catalyzed by CYP2E1 and Mohri et al. showed that miR-378 can repress the translation of CYP2E1 in human kidney cells. ${ }^{30}$ APAP treatment did not affect the transcription of this microRNA in our HepG2 experiments; however, miR-378a and miR-378b and the Cypze mRNA are significantly down-regulated in PMH after CsA treatment. CsA and AM are mainly metabolized by $\mathrm{CYP}_{3} \mathrm{~A} 4$, which can be regulated directly and indirectly by multiple microRNAs. MiR-148a was shown to indirectly regulate $\mathrm{CYP}_{3} \mathrm{~A}_{4}$ transcription via the post-transcriptional regulation of the Pregnane X Receptor (PXR). ${ }^{31}$ MiR-148a is significantly down-regulated after CsA and AM treatment in HepG2 cells, which could lead to increased levels of PXR and CYP3A4. However, CYP3 34 expression was not measured with the used microarrays and the levels of PXR mRNA are not changed after treatment with CsA and AM. Furthermore, CYP3 $\mathrm{A}_{4}$ expression can be directly and indirectly regulated by miR-27b and mmu-miR-298. ${ }^{32}$ These microRNAs can directly inhibit $\mathrm{CYP}_{3} \mathrm{~A}_{4}$ translation or inhibit transcription of $\mathrm{CYP}_{3} \mathrm{~A}_{4}$ via the post-transcriptional regulation of the Vitamin D Receptor (VDR). The expression of mmu-miR-298 was not measured with the used microarrays, but miR-27b is significantly down-regulated after CsA treatment in PMH. However, the expression of VDR mRNA was not assessed with the used microarrays and there is no direct homologue of $\mathrm{CYP}_{3} \mathrm{~A}_{4}$ in mice. Overall, several differentially expressed microRNAs in HepG2 cells and PMH are shown to interact with genes involved in the metabolic activation of the used compounds. However, transcriptional regulation of their target genes is not observed in our experiments. Future research should investigate the possible interaction of microRNAs and CYP enzymes in human and mice.

Apart from the regulation of $\mathrm{CYP}_{3} \mathrm{~A}_{4}$, miR-27b also targets genes involved in lipid metabolism. Vickers et al. showed the regulation of key genes in lipid metabolism, including PPARG, GPAM and ANGPTL3. PPARG is involved in fatty acid storage and glucose metabolism and the mRNA expression is changed after CsA treatment in PMH with an FDR $<0.05$, but the FC is only 1.22 The up-regulation of PPARG is in concordance with the down-regulated miR-27b. However, GPAM and ANGPTL3 are significantly down-regulated after CSA treatment (FC of -3.63 and -10.77, respectively), which suggest the presence of other regulators of these genes. Furthermore, decreased levels of miR-27b were found in plasma of rats with extrahepatic cholestasis after bile duct ligation. ${ }^{5}$ Yamaura et al. suggest that decreased levels of miR-27b in plasma, together with decreased levels of several other microRNAs, including miR-99a, miR-185, and miR-361, can be used as biomarkers for cholestasis. Expression levels of these microRNAs are significantly downregulated in PMH after treatment with CsA, which is known to induce cholestasis. MiR-9ga and miR-361 are significantly up-regulated after treatment with $A M$ and miR-185 is up-regulated in APAP exposed PMH. None of these microRNAs are differentially expressed in HepGz cells. These microRNAs could possibly be used to distinguish cholestatic compounds from other hepatotoxic compounds, since these microRNAs were not significantly expressed in the other treatments or differentially expressed in the opposite direction.

Although concordant regulations of target genes are found for overexpressed microRNAs and down-regulated microRNAs, opposite reactions are also observed. Furthermore, multiple microRNAs are shown to target the same gene, but in most cases no regulation was seen on the mRNA level. Literature search revealed the possible involvement of microRNAs in processes underlying drug-induced hepatotoxicity and many of the described targets are not yet available in the miRTarBase lists. Targeted research of these microRNAs, genes and the proteins they code for, should be performed to investigate their role in drug-induced liver injury. Differentially expressed microRNAs in PMH could be backed-up with literature, where HepG2 data shows little to no concordance with the literature, which suggests that for microRNA-based investigation of liver toxicity, PMH is preferred over HepG2 cells. However, the significantly changed microRNAs in HepG2 may provide more information once complete elucidation of all target genes of microRNAs is achieved. Future research should validate the found differentially expressed microRNAs and their ability of altering mRNA expression and translation of their target genes.

\section{Availability of supporting data}

The data sets supporting the results of this article are included within the article and its additional files. Additional files are available upon request.

Table 1. Total number of significantly expressed genes and microRNAs (False Discovery Rate $<0.05$ and absolute Fold Change >1.5) after treatment for 24 hours with the $I_{2}$ concentration of cyclosporin $A$, amiodarone and acetaminophen in HepGz cells and primary mouse hepatocytes.

$$
\text { HepG2 cells }
$$

\section{MRNA}

Up-regulated

Down-regulated

MICRORNA

p-regulated

Down-regulated

CSA AM APAP

3217

1210

2007

2273

1199

1074

\begin{tabular}{|l|l|l|}
\multicolumn{3}{|c|}{$\begin{array}{c}\text { Primary Mouse } \\
\text { Hepatocytes }\end{array}$} \\
\hline CSA & AM & APAP \\
\hline 3972 & 1458 & 1943 \\
\hline 1923 & 725 & 843 \\
\hline 2049 & 733 & 1100 \\
\hline
\end{tabular}

$41-40-23$

\begin{tabular}{l|l}
27 & 15 \\
\hline 13 & 8
\end{tabular}


Table 2.1. Differentially expressed microRNAs in HepG2 cells after treatment for 24 hours with cyclosporin A, amiodarone and acetaminophen (FDR $<0.05$ and absolute $F C>1.5$ ).

\begin{tabular}{|c|c|c|}
\hline CsA & $A M$ & APAP \\
\hline hsa-miR-148a* & hsa-miR-125b-1** & hsa-miR-2110 \\
\hline hsa-miR-202 & hsa-miR-148a* & hsa-miR-3152-3p \\
\hline hsa-miR-2110 & hsa-miR-2110 & \\
\hline hsa-miR-3152-3p & hsa-miR-3140-3p & \\
\hline hsa-miR-3159 & hsa-miR-3152-3p & \\
\hline hsa-miR-3168 & hsa-miR-368ga-5p/hsa-miR-368gb/hsa-miR-368ge & \\
\hline hsa-miR-3612 & hsa-miR-4296 & \\
\hline hsa-miR-4296 & hsa-miR-519c-3p & \\
\hline hsa-miR-519c-3p & hsa-miR-559 & \\
\hline \multicolumn{3}{|l|}{ hsa-miR-525-3p } \\
\hline \multicolumn{3}{|l|}{ hsa-miR-559 } \\
\hline \multicolumn{3}{|l|}{ hsa-miR-614 } \\
\hline \multicolumn{3}{|l|}{ hsa-miR-888 } \\
\hline \multicolumn{3}{|l|}{ hsa-miR-935 } \\
\hline \multicolumn{3}{|l|}{ hsa-miRPlus-1152* } \\
\hline \multirow{7}{*}{$\begin{array}{l}\text { hsa-miR-1284 } \\
\text { hsa-miR-3939 } \\
\text { hsa-miRPlus-C1o76 } \\
\text { hsv1-miR-H6-3p }\end{array}$} & hsa-miR-1244 & hsa-miR-1244 \\
\hline & hsa-miR-1284 & hsa-miR-183 \\
\hline & hsa-miR-3178 & \\
\hline & hsa-miR-324-3p & \\
\hline & hsa-miR-3656 & \\
\hline & hsa-miR-668 & \\
\hline & hsa-miRPlus-C1076 & \\
\hline
\end{tabular}

Table 2.2. Differentially expressed microRNAs in primary mouse hepatocytes aftertreatmentfor 24 hours with cyclosporin A amiodarone and acetaminophen ( $F D R<0.05$ and absolute $F C>1.5$ ).

\begin{tabular}{|c|c|c|}
\hline $\begin{array}{l}\text { CSA } \\
\text { mmu-miR-101c }\end{array}$ & $\begin{array}{l}A M \\
m m u-m i R-1934-3 p\end{array}$ & APAP \\
\hline mmu-miR-106b-5p & $m m u-m i R-212-3 p$ & $m m u-m i R-212-3 p$ \\
\hline mmu-miR-130a-3p & mmu-miR-2861 & mmu-miR-3057-5p \\
\hline mmu-miR-148b-3p & mmu-miR-3057-5p & mmu-miR-6368 \\
\hline mmu-miR-152-3p & mmu-miR-3098-5p & mmu-miR-68o \\
\hline mmu-miR-183-5p & mти-miR-3102-5p & mmu-miR-710 \\
\hline mmu-miR-1839-5P & mти-miR-3702-5p.2-5p & mmu-miR-711 \\
\hline mmu-miR-185-5p & mти-miR-6368 & $m m u-m i R-721$ \\
\hline mmu-miR-193a-зp & mти-тіR-6401 & \\
\hline mmu-miR-203-3p & mmu-miR-68o & \\
\hline$m m u-m i R-212-3 p$ & mmu-miR-710 & \\
\hline$m m u-m i R-21 a-5 p$ & mmu-miR-711 & \\
\hline$m m u-m i R-221-3 P$ & mmu-miR-877-5p & \\
\hline \multicolumn{3}{|l|}{$m m u-m i R-27 b-3 p$} \\
\hline \multicolumn{3}{|l|}{$m m u-m i R-30 a-3 p$} \\
\hline \multirow{2}{*}{\multicolumn{3}{|c|}{$\begin{array}{l}m m u-m i R-30 e-5 p \\
m m u-m i R-361-5 p\end{array}$}} \\
\hline & & \\
\hline \multicolumn{3}{|l|}{ mmu-miR-374c-5p } \\
\hline \multirow{2}{*}{\multicolumn{3}{|c|}{$\begin{array}{l}\text { mmu-miR-378a-3p } \\
\text { mmu-miR-378b }\end{array}$}} \\
\hline & & \\
\hline \multirow{2}{*}{\multicolumn{3}{|c|}{ mmu-miR-425-5P }} \\
\hline \multirow{2}{*}{$\begin{array}{l}m m u-m i R-5097 \\
m m u-m i R-877-5 p\end{array}$} & & \\
\hline & & \\
\hline \multicolumn{3}{|l|}{$m m u-m i R-99 a-5 p$} \\
\hline mmu-miR-1306-3p & $m m u-m i R-128-3 p$ & $m m u-m i R-151-5 P$ \\
\hline mmu-miR-1892 & $m m u-m i R-140-5 p$ & mmu-miR-1839-5p \\
\hline$m m u-m i R-3095-3 p$ & mmu-miR-151-5P & mmu-miR-185-5P \\
\hline mти-miR-3096b-3р & $m m u-m i R-183-5 p$ & mmu-miR-202-3P \\
\hline mтu-miR-347oa & mmu-miR-1839-5p & mmu-miR-21a-3p \\
\hline mmu-miR-3473a & $m m u-m i R-202-3 p$ & $m m u-m i R-22-5 p$ \\
\hline mmu-miR-3473b & mmu-miR-20a-5p & $m m u-m i R-3058-5 P$ \\
\hline$m m u-m i R-370-3 p$ & $m m u-m i R-20 b-5 p$ & mmu-miR-3096a-5p \\
\hline mmu-miR-494-3p & mmu-miR-21a-3p & $m m u-m i R-30 a-3 p$ \\
\hline mmu-miR-5105 & $m m u-m i R-21 a-5 p$ & $m m u-m i R-30 c-2-3 p$ \\
\hline mmu-miR-5119 & $m m u-m i R-25-3 p$ & mmu-miR-30e-3p \\
\hline mmu-miR-5121 & mmu-miR-28a-5p & mmu-miR-3470a \\
\hline$m m u-m i R-5622-3 p$ & mmu-miR-3058-5P & $m m u-m i R-500-3 P$ \\
\hline mmu-miR-6243 & mmu-miR-3096a-5p & $m m u-m i R-652-3 p$ \\
\hline mmu-miR-636o & $m m u-m i R-3 O c-2-3 p$ & mmu-miR-697 \\
\hline \multirow{12}{*}{$\begin{array}{l}m m u-m i R-6378 \\
m m u-m i R-712-5 p\end{array}$} & $m m u-m i R-30 e-3 p$ & \\
\hline & mmu-miR-3470a & \\
\hline & $m m u-m i R-361-5 P$ & \\
\hline & $m m u-m i R-374 c-5 p$ & \\
\hline & $m m u-m i R-378 b$ & \\
\hline & $m m u-m i R-423-5 P$ & \\
\hline & $m m u-m i R-425-5 P$ & \\
\hline & $m m u-m i R-500-3 p$ & \\
\hline & $m m u-m i R-652-3 p$ & \\
\hline & $m m u-m i R-98-5 P$ & \\
\hline & mmu-miR-99a-5p & \\
\hline & mmu-miR-99b-5p & \\
\hline
\end{tabular}


Table 3. Results of the pathway over-representation analysis of the target genes of differentially expressed microRNAs after treatment of HepC2 cells for 24 hours with cyclosporin A, amiodarone and acetaminophen.

\begin{tabular}{|c|c|c|c|c|c|c|}
\hline $\begin{array}{l}\text { Pathway } \\
\text { name }\end{array}$ & $\begin{array}{l}\text { Pathway } \\
\text { size }\end{array}$ & $\begin{array}{l}\text { Overlap } \\
\text { input genes }\end{array}$ & $\begin{array}{l}\% \\
\text { overlap }\end{array}$ & $\begin{array}{l}p \text { - } \\
\text { value }\end{array}$ & $\begin{array}{l}q- \\
\text { value }\end{array}$ & $\begin{array}{l}\text { Pathway } \\
\text { source }\end{array}$ \\
\hline \multicolumn{7}{|l|}{ Cyclosporin A } \\
\hline Angiogenesis & 19 & 3 & $15,80 \%$ & 0,00 & 0,05 & Wikipathways \\
\hline HIF-2-alpha transcription factor network & 35 & 4 & $11,40 \%$ & 0,00 & 0,03 & PID \\
\hline \multicolumn{7}{|l|}{ Amiodarone } \\
\hline Fatty Acyl-CoA Biosynthesis & 4 & 4 & $100,00 \%$ & 0,00 & 0,00 & PID \\
\hline Metabolism of polyamines & 4 & 3 & $75,00 \%$ & 0,00 & 0,00 & $P I D$ \\
\hline Spermidine and Spermine Biosynthesis & 6 & 4 & $66,70 \%$ & 0,00 & 0,00 & $S M P D B$ \\
\hline Telomere Maintenance & 10 & 3 & $30,00 \%$ & 0,00 & 0,01 & Wikipathways \\
\hline $\begin{array}{l}\text { Non-homologous end-joining - } \\
\text { Homo sapiens (human) }\end{array}$ & 13 & 3 & $23,10 \%$ & 0,00 & 0,03 & KEGG \\
\hline Metabolism of polyamines & 14 & 3 & $21,40 \%$ & 0,00 & 0,04 & Reactome \\
\hline Early Phase of HIV Life Cycle & 14 & 3 & $21,40 \%$ & 0,00 & 0,04 & Reactome \\
\hline Fatty Acyl-CoA Biosynthesis & 20 & 4 & $20,00 \%$ & 0,00 & 0,01 & Reactome \\
\hline $\begin{array}{l}\text { hypoxia and p53 in the } \\
\text { cardiovascular system }\end{array}$ & 22 & 4 & $18,20 \%$ & 0,00 & 0,01 & PID \\
\hline $\begin{array}{l}\text { hypoxia and p53 in the } \\
\text { cardiovascular system }\end{array}$ & 22 & 4 & $18,20 \%$ & 0,00 & 0,01 & BioCarta \\
\hline Extension of Telomeres & 28 & 4 & $14,30 \%$ & 0,00 & 0,03 & Reactome \\
\hline Eukaryotic Translation Initiation & 54 & 7 & $13,00 \%$ & 0,00 & 0,00 & PID \\
\hline Peptide chain elongation & 94 & 12 & $12,80 \%$ & 0,00 & 0,00 & PID \\
\hline Peptide chain elongation & 95 & 12 & $12,60 \%$ & 0,00 & 0,00 & Reactome \\
\hline $\begin{array}{l}\text { Validated targets of C-MYC } \\
\text { transcriptional activation }\end{array}$ & 87 & 11 & $12,60 \%$ & 0,00 & 0,00 & PID \\
\hline Eukaryotic Translation Elongation & 100 & 12 & $12,00 \%$ & 0,00 & 0,00 & Reactome \\
\hline $\begin{array}{l}\text { mechanism of gene regulation by } \\
\text { peroxisome proliferators via ppara }\end{array}$ & 52 & 6 & $11,50 \%$ & 0,00 & 0,01 & BioCarta \\
\hline $\begin{array}{l}\text { mechanism of gene regulation by } \\
\text { peroxisome proliferators via ppara }\end{array}$ & 52 & 6 & $11,50 \%$ & 0,00 & 0,01 & PID \\
\hline Cytoplasmic Ribosomal Proteins & 88 & 10 & $11,40 \%$ & 0,00 & 0,00 & Wikipathways \\
\hline $\begin{array}{l}\text { Transcriptional Regulation of } \\
\text { White Adipocyte Differentiation }\end{array}$ & 44 & 5 & $11,40 \%$ & 0,00 & 0,02 & Reactome \\
\hline Eukaryotic Translation Termination & 93 & 10 & $10,80 \%$ & 0,00 & 0,00 & PID \\
\hline Viral mRNA Translation & 93 & 10 & $10,80 \%$ & 0,00 & 0,00 & PID \\
\hline Eukaryotic Translation Termination & 94 & 10 & $10,60 \%$ & 0,00 & 0,00 & Reactome \\
\hline Formation of a pool of free $40 S$ subunits & 105 & 11 & $10,50 \%$ & 0,00 & 0,00 & PID \\
\hline Formation of a pool of free $40 S$ subunits & 106 & 11 & $10,40 \%$ & 0,00 & 0,00 & Reactome \\
\hline $\begin{array}{l}\text { Nonsense Mediated Decay Independent } \\
\text { of the Exon Junction Complex }\end{array}$ & 99 & 10 & $10,10 \%$ & 0,00 & 0,00 & Reactome \\
\hline $\begin{array}{l}\text { Nonsense Mediated Decay Enhanced } \\
\text { by the Exon Junction Complex }\end{array}$ & 110 & 11 & $10,00 \%$ & 0,00 & 0,00 & Reactome \\
\hline Nonsense-Mediated Decay & 110 & 11 & $10,00 \%$ & 0,00 & 0,00 & Reactome \\
\hline
\end{tabular}

Table 4. Results of the pathway over-representation analysis of the target genes of differentially expressed microRNAs after treatment of primary mouse hepatocytes for 24 hours with gyclosporin A, amiodarone and acetaminophen.

\begin{tabular}{|c|c|c|c|c|c|c|}
\hline $\begin{array}{l}\text { Pathway } \\
\text { name }\end{array}$ & $\begin{array}{l}\text { Pathway } \\
\text { size }\end{array}$ & $\begin{array}{l}\text { Overlap } \\
\text { input genes }\end{array}$ & overlap & $\begin{array}{l}p- \\
\text { value }\end{array}$ & $\begin{array}{l}q- \\
\text { value }\end{array}$ & $\begin{array}{l}\text { Pathway } \\
\text { source }\end{array}$ \\
\hline \multicolumn{7}{|l|}{ Cyclosporin A } \\
\hline Formation of editosomes by ADAR proteins & & 2 & $100,00 \%$ & 0,00 & 0,02 & Reactome \\
\hline C6 deamination of adenosine & 2 & 2 & $100,00 \%$ & 0,00 & 0,02 & Reactom \\
\hline mRNA Editing: A to I Conversion & 2 & 2 & $100,00 \%$ & 0,00 & 0,02 & Reactome \\
\hline $\begin{array}{l}\text { BH3-only proteins associate with and } \\
\text { inactivate anti-apoptotic BCL-2 members }\end{array}$ & 7 & 3 & $42,90 \%$ & 0,00 & 0,02 & Reactome \\
\hline MASTL Facilitates Mitotic Progression & 10 & 4 & $40,00 \%$ & 0,00 & 0,01 & Reactome \\
\hline Activation of $\mathrm{BH}_{3}$-only proteins & 19 & 6 & $31,60 \%$ & 0,00 & 0,00 & Reactome \\
\hline Circadian Clock & 13 & 4 & $30,80 \%$ & 0,00 & 0,01 & Reactome \\
\hline Circadian Clock & 13 & 4 & $30,80 \%$ & 0,00 & 0,01 & Reactome \\
\hline Interleukin-6 signaling & 10 & 3 & $30,00 \%$ & 0,01 & 0,04 & Reactome \\
\hline Oxidative Damage & 17 & 5 & $29,40 \%$ & 0,00 & 0,01 & Wikipathways \\
\hline SHC-related events triggered by IGFTR & 18 & 5 & $27,80 \%$ & 0,00 & 0,01 & Reactome \\
\hline ERK/MAPK targets & 20 & 5 & $25,00 \%$ & 0,00 & 0,01 & Reactome \\
\hline Signaling by $B M P$ & 21 & 5 & $23,80 \%$ & 0,00 & 0,01 & Reactome \\
\hline $\begin{array}{l}\text { Signaling of Hepatocyte Growth } \\
\text { Factor Recentor }\end{array}$ & & & & & & \\
\hline $\begin{array}{l}\text { Factor Receptor } \\
\text { Beta-catenin phosphorylation cascade }\end{array}$ & 34 & $\begin{array}{l}8 \\
4\end{array}$ & $\begin{array}{l}23,50 \% \\
23,50 \%\end{array}$ & $\begin{array}{l}0,00 \\
0,00\end{array}$ & $\begin{array}{l}0,00 \\
0,03\end{array}$ & $\begin{array}{l}\text { Wikipathway } \\
\text { Reactome }\end{array}$ \\
\hline Hedgehog Signaling Pathway & 22 & 5 & $22,70 \%$ & 0,00 & 0,01 & Wikipathways \\
\hline Trafficking of AMPA receptors & 27 & 6 & $22,20 \%$ & 0,00 & 0,01 & Reactome \\
\hline Glutamate Binding, Activation of AMPA & & & & & & \\
\hline Receptors and Synaptic Plasticity & 27 & 6 & $22,20 \%$ & 0,00 & 0,01 & Reactome \\
\hline Frs2-mediated activation & 18 & 4 & $22,20 \%$ & 0,00 & 0,03 & Reactome \\
\hline $\begin{array}{l}\text { Nuclear Events (kinase and } \\
\text { transcription factor activation) }\end{array}$ & 23 & 5 & $21,70 \%$ & 0,00 & 0,02 & Reactome \\
\hline Tiez Signaling & 19 & 4 & $21,10 \%$ & 0,00 & 0,04 & Reactome \\
\hline $\begin{array}{l}\text { MAPK targets/ Nuclear events } \\
\text { mediated by MAP kinases }\end{array}$ & 29 & 6 & $20,70 \%$ & 0,00 & 0,01 & Reactome \\
\hline Intrinsic Pathway for Apoptosis & 39 & 8 & $20,50 \%$ & 0,00 & 0,00 & Reactome \\
\hline $\begin{array}{l}\text { Degradation of beta-catenin by } \\
\text { the destruction complex }\end{array}$ & 25 & 5 & $20,00 \%$ & 0,00 & 0,02 & Reactome \\
\hline Prolonged ERK activation events & 20 & 4 & $20,00 \%$ & 0,01 & 0,04 & Reactome \\
\hline $\begin{array}{l}\text { Long-term potentiation - } \\
\text { Mus musculus (mouse) }\end{array}$ & 66 & 13 & $19,70 \%$ & 0,00 & 0,00 & KEGG \\
\hline $\begin{array}{l}\text { Endometrial cancer - } \\
\text { Mus musculus (mouse) }\end{array}$ & 52 & 10 & $19,20 \%$ & 0,00 & 0,00 & KEGG \\
\hline $\begin{array}{l}\text { Colorectal cancer - } \\
\text { Mus musculus (mouse) }\end{array}$ & 64 & 12 & $18,80 \%$ & 0,00 & 0,00 & KEGG \\
\hline $\begin{array}{l}\text { Amino acid transport across } \\
\text { the plasma membrane }\end{array}$ & 32 & 6 & $18,80 \%$ & 0,00 & 0,01 & Reactome \\
\hline $\begin{array}{l}\text { Chronic myeloid leukemia - } \\
\text { Mus musculus (mouse) }\end{array}$ & 74 & 13 & $17,60 \%$ & 0,00 & 0,00 & KEGG \\
\hline P38 MAPK Signaling Pathway & 34 & 6 & $17,60 \%$ & 0,00 & 0,02 & Wikipathways \\
\hline
\end{tabular}




\begin{tabular}{|c|c|c|c|c|c|c|}
\hline $\begin{array}{l}\text { Pathway } \\
\text { name }\end{array}$ & $\begin{array}{l}\text { Pathway } \\
\text { size }\end{array}$ & $\begin{array}{l}\text { Overlap } \\
\text { input genes }\end{array}$ & overlap & $\begin{array}{l}p- \\
\text { value }\end{array}$ & $\begin{array}{l}q- \\
\text { value }\end{array}$ & $\begin{array}{l}\text { Pathway } \\
\text { source }\end{array}$ \\
\hline \multicolumn{7}{|l|}{ Cyclosporin A } \\
\hline Signal transduction by $L 1$ & 34 & 6 & $17,60 \%$ & 0,00 & 0,02 & Reactome \\
\hline Acute myeloid leukemia - & & & & & & \\
\hline Mus musculus (mouse) & 57 & 10 & $17,50 \%$ & 0,00 & 0,00 & KEGG \\
\hline Signalling to ERKs & 35 & 6 & $17,10 \%$ & 0,00 & 0,02 & Reactome \\
\hline Apoptosis & 83 & 14 & $16,90 \%$ & 0,00 & 0,00 & Wikipathway \\
\hline $\begin{array}{l}\text { Hedgehog signaling pathway - } \\
\text { Mus musculus (mouse) }\end{array}$ & 49 & 8 & $16,30 \%$ & 0,00 & 0,01 & KEGG \\
\hline $\begin{array}{l}\text { Renal cell carcinoma - } \\
\text { Mus musculus (mouse) }\end{array}$ & 68 & 11 & $16,20 \%$ & 0,00 & 0,00 & KEGG \\
\hline $\begin{array}{l}\text { Morphine addiction - } \\
\text { Mus musculus (mouse) }\end{array}$ & 93 & 15 & $16,10 \%$ & 0,00 & 0,00 & KEGG \\
\hline $\begin{array}{l}\text { Circadian rhythm - } \\
\text { Mus musculus (mouse) }\end{array}$ & 31 & 5 & $16,10 \%$ & 0,01 & 0,04 & KEGG \\
\hline IL-7 Signaling Pathway & 44 & 7 & $15,90 \%$ & 0,00 & 0,01 & Wikipathway: \\
\hline $\begin{array}{l}\text { Amyotrophic lateral sclerosis (ALS) - } \\
\text { Mus musculus (mouse) }\end{array}$ & 52 & 8 & $15,40 \%$ & 0,00 & 0,01 & KEGG \\
\hline TGF Beta Signaling Pathway & 52 & 8 & $15,40 \%$ & 0,00 & 0,01 & Wikipathway \\
\hline Glioma - Mus musculus (mouse) & 66 & 10 & $15,20 \%$ & 0,00 & 0,00 & KEGG \\
\hline $\begin{array}{l}\text { VEGF signaling pathway - } \\
\text { Mus musculus (mouse) }\end{array}$ & 60 & 9 & $15,00 \%$ & 0,00 & 0,01 & KEGG \\
\hline $\begin{array}{l}\text { Pancreatic cancer - } \\
\text { Mus musculus (mouse) }\end{array}$ & 67 & 10 & $14,90 \%$ & 0,00 & 0,01 & KEGG \\
\hline Heart Development & 47 & 7 & $14,90 \%$ & 0,00 & 0,02 & Wikipathway: \\
\hline $\begin{array}{l}\text { Long-term depression - } \\
\text { Mus musculus (mouse) }\end{array}$ & 61 & 9 & $14,80 \%$ & 0,00 & 0,01 & KEGG \\
\hline NCAM signaling for neurite out-growth & 55 & 8 & $14,80 \%$ & 0,00 & 0,01 & Reactome \\
\hline MAP kinase activation in TLR cascade & 48 & 7 & $14,60 \%$ & 0,00 & 0,02 & Reactome \\
\hline $\begin{array}{l}\text { Splicing factor NOVA regulated } \\
\text { synpatic proteins }\end{array}$ & 41 & 6 & $14,60 \%$ & 0,00 & 0,03 & Wikipathway \\
\hline $\begin{array}{l}\text { mTOR signaling pathway - } \\
\text { Mus musculus (mouse) }\end{array}$ & 62 & 9 & $14,50 \%$ & 0,00 & 0,01 & KEGG \\
\hline $\begin{array}{l}\text { GABAergic synapse - } \\
\text { Mus musculus (mouse) }\end{array}$ & 90 & 13 & $14,40 \%$ & 0,00 & 0,00 & KEGG \\
\hline $\begin{array}{l}\text { Non-small cell lung cancer - } \\
\text { Mus musculus (mouse) }\end{array}$ & 57 & 8 & $14,00 \%$ & 0,00 & 0,01 & KEGG \\
\hline $\begin{array}{l}\text { Amino acid and oligopeptide } \\
\text { SLC transporters }\end{array}$ & 50 & 7 & $14,00 \%$ & 0,00 & 0,02 & Reactome \\
\hline $\begin{array}{l}\text { Neurotrophin signaling pathway- } \\
\text { Mus musculus (mouse) }\end{array}$ & 123 & 17 & $13,80 \%$ & 0,00 & 0,00 & KEGG \\
\hline Wnt Signaling Pathway NetPath & 109 & 15 & $13,80 \%$ & 0,00 & 0,00 & Wikipathway \\
\hline $\begin{array}{l}\text { Retrograde endocannabinoid signaling } \\
\text { Mus musculus (mouse) }\end{array}$ & 104 & 14 & $13,50 \%$ & 0,00 & 0,00 & KEGG \\
\hline
\end{tabular}

\begin{tabular}{|c|c|c|c|c|c|c|}
\hline $\begin{array}{l}\text { Pathway } \\
\text { name }\end{array}$ & $\begin{array}{l}\text { Pathway } \\
\text { size }\end{array}$ & $\begin{array}{l}\text { Overlap } \\
\text { input genes }\end{array}$ & overlap & $\begin{array}{l}p- \\
\text { value }\end{array}$ & $\begin{array}{l}q- \\
\text { value }\end{array}$ & $\begin{array}{l}\text { Pathway } \\
\text { source }\end{array}$ \\
\hline \multicolumn{7}{|l|}{ Cyclosporin A } \\
\hline Kit Receptor Signaling Pathway & 67 & 9 & $13,40 \%$ & 0,00 & 0,01 & Wikipathways \\
\hline TGF-beta Receptor Signaling Pathway & 150 & 20 & $13,30 \%$ & 0,00 & 0,00 & Wikipathways \\
\hline $\begin{array}{l}\text { Dopaminergic synapse - } \\
\text { Mus musculus (mouse) }\end{array}$ & 135 & 18 & $13,30 \%$ & 0,00 & 0,00 & KEGG \\
\hline $\begin{array}{l}\text { Glutamatergic synapse - } \\
\text { Mus musculus (mouse) }\end{array}$ & 115 & 15 & $13,00 \%$ & 0,00 & 0,00 & KEGG \\
\hline IL-3 Signaling Pathway & 100 & 13 & $13,00 \%$ & 0,00 & 0,00 & Wikipathways \\
\hline $\begin{array}{l}\text { MyD88 cascade initiated } \\
\text { on plasma membrane }\end{array}$ & 69 & 9 & $13,00 \%$ & 0,00 & 0,01 & Reactome \\
\hline Toll Like Receptor 10 (TLR10) Cascade & 69 & 9 & $13,00 \%$ & 0,00 & 0,01 & Reactome \\
\hline Toll Like Receptor 5 (TLR5) Cascade & 69 & 9 & $13,00 \%$ & 0,00 & 0,01 & Reactome \\
\hline $\begin{array}{l}\text { MyD88:Mal cascade initiated } \\
\text { on plasma membrane }\end{array}$ & 69 & 9 & $13,00 \%$ & 0,00 & 0,01 & Reactome \\
\hline Toll Like Receptor TLR1:TLR2 Cascade & 69 & 9 & $13,00 \%$ & 0,00 & 0,01 & Reactome \\
\hline MAPK signaling pathway & 158 & 20 & $12,70 \%$ & 0,00 & 0,00 & Wikipathways \\
\hline ErbB signaling pathway - & & & & & & \\
\hline $\begin{array}{l}\text { Mus musculus (mouse) } \\
\text { EGFR1 Signaling Pathway }\end{array}$ & $\begin{array}{l}87 \\
176\end{array}$ & $\begin{array}{l}11 \\
22\end{array}$ & $\begin{array}{l}12,60 \% \\
12,50 \%\end{array}$ & $\begin{array}{l}0,00 \\
0,00\end{array}$ & $\begin{array}{l}0,01 \\
0,00\end{array}$ & $\begin{array}{l}\text { KEGG } \\
\text { Wikipathways }\end{array}$ \\
\hline Prostate cancer - Mus musculus (mouse) & 89 & 11 & $12,40 \%$ & 0,00 & 0,01 & KEGG \\
\hline Toll Like Receptor TLR6:TLR2 Cascade & 73 & 9 & $12,30 \%$ & 0,00 & 0,02 & Reactome \\
\hline Toll Like Receptor 2 (TLR2) Cascade & 73 & 9 & $12,30 \%$ & 0,00 & 0,02 & Reactome \\
\hline TRAF6 mediated induction of NFkB and & & & & & & \\
\hline MAP kinases upon $T L R 7 / 8$ or 9 activation & 73 & 9 & $12,30 \%$ & 0,00 & 0,02 & Reactome \\
\hline Hepatitis B - Mus musculus (mouse) & 148 & 18 & $12,20 \%$ & 0,00 & 0,00 & KEGG \\
\hline TGF-beta signaling pathway - & & & & & & \\
\hline Mus musculus (mouse) & 82 & 10 & $12,20 \%$ & 0,00 & 0,01 & KEGG \\
\hline Apoptosis - Mus musculus (mouse) & 82 & 10 & $12,20 \%$ & 0,00 & 0,01 & KEGG \\
\hline $\begin{array}{l}\text { Circadian entrainment - } \\
\text { Mus musculus (mouse) }\end{array}$ & 99 & 12 & $12,10 \%$ & 0,00 & 0,01 & KEGG \\
\hline Estrogen signaling pathway - & & & & & & \\
\hline Mus musculus (mouse) & 99 & 12 & $12,10 \%$ & 0,00 & 0,01 & KEGG \\
\hline Adherens junction - Mus musculus (mouse) & 75 & 9 & $12,00 \%$ & 0,00 & 0,02 & KEGG \\
\hline $\begin{array}{l}\text { MyD88 dependent cascade initiated } \\
\text { on endosome }\end{array}$ & 75 & 9 & $12,00 \%$ & 0,00 & 0,02 & Reactome \\
\hline Toll Like Receptor $7 / 8$ (TLR7/8) Cascade & 75 & 9 & $12,00 \%$ & 0,00 & 0,02 & Reactome \\
\hline ESC Pluripotency Pathways & 110 & 13 & $11,80 \%$ & 0,00 & 0,01 & Wikipathways \\
\hline IL-5 Signaling Pathway & 68 & 8 & $11,80 \%$ & 0,00 & 0,03 & Wikipathways \\
\hline $\begin{array}{l}\text { Amphetamine addiction - } \\
\text { Mus musculus (mouse) }\end{array}$ & 68 & 8 & $11,80 \%$ & 0,00 & 0,03 & KEGG \\
\hline Axon guidance & 225 & 26 & $11,60 \%$ & 0,00 & 0,00 & Reactome \\
\hline Activated TLR4 signalling & 95 & 11 & $11,60 \%$ & 0,00 & 0,01 & Reactome \\
\hline Oocyte meiosis - Mus musculus (mouse) & 113 & 13 & $11,50 \%$ & 0,00 & 0,01 & KEGG \\
\hline
\end{tabular}




\begin{tabular}{|c|c|c|c|c|c|c|}
\hline $\begin{array}{l}\text { Pathway } \\
\text { name }\end{array}$ & $\begin{array}{l}\text { Pathway } \\
\text { size }\end{array}$ & $\begin{array}{l}\text { Overlap } \\
\text { input genes }\end{array}$ & overlap & $\mid p-$ & $\begin{array}{l}q- \\
\text { value }\end{array}$ & $\begin{array}{l}\text { Pathway } \\
\text { source }\end{array}$ \\
\hline \multicolumn{7}{|l|}{ Cyclosporin A } \\
\hline Chagas disease & & & & & & \\
\hline $\begin{array}{l}\text { (American trypanosomiasis) - } \\
\text { Mus musculus (mouse) }\end{array}$ & 104 & 12 & $11,50 \%$ & 0,00 & 0,01 & KEGG \\
\hline Gap junction - Mus musculus (mouse) & 88 & 10 & $11,40 \%$ & 0,00 & 0,02 & KEGG \\
\hline Toll Like Receptor 9 (TLRg) Cascade & 79 & 9 & $11,40 \%$ & 0,00 & 0,02 & Reactome \\
\hline $\begin{array}{l}\text { Progesterone-mediated oocyte } \\
\text { maturation - Mus musculus (mouse) }\end{array}$ & 89 & 10 & $11,20 \%$ & 0,00 & 0,02 & KEGG \\
\hline Wnt signaling pathway - & & & & & & \\
\hline Mus musculus (mouse) & 144 & 16 & $11,10 \%$ & 0,00 & 0,00 & KEGG \\
\hline Melanoma - Mus musculus (mouse) & 73 & 8 & $11,00 \%$ & 0,01 & 0,04 & KEGG \\
\hline $\begin{array}{l}\text { NGF signalling via TRKA } \\
\text { from the plasma membrane }\end{array}$ & 184 & 20 & $10,90 \%$ & 0,00 & 0,00 & Reactome \\
\hline Axon guidance - & & & & & & \\
\hline Mus musculus (mouse) & 129 & 14 & $10,90 \%$ & 0,00 & 0,01 & KEGG \\
\hline Apoptosis & 101 & 11 & $10,90 \%$ & 0,00 & 0,02 & Reactome \\
\hline Developmental Biology & 307 & 33 & $10,80 \%$ & 0,00 & 0,00 & Reactome \\
\hline Androgen Receptor Signaling Pathway & 111 & 12 & $10,80 \%$ & 0,00 & 0,01 & Wikipathways \\
\hline Spinal Cord Injury & 103 & 11 & $10,80 \%$ & 0,00 & 0,02 & Wikipathways \\
\hline $\begin{array}{l}\text { Gastric acid secretion - } \\
\text { Mus musculus (mouse) }\end{array}$ & 74 & 8 & $10,80 \%$ & 0,01 & 0,05 & KEGG \\
\hline $\begin{array}{l}\text { B cell receptor signaling pathway - } \\
\text { Mus musculus (mouse) }\end{array}$ & 74 & 8 & $10,80 \%$ & 0,01 & 0,05 & KEGG \\
\hline $\begin{array}{l}\text { Calcium Regulation } \\
\text { in the Cardiac Cell }\end{array}$ & 150 & 16 & $10,70 \%$ & 0,00 & 0,00 & Wikipathways \\
\hline $\begin{array}{l}\text { Neurotransmitter Receptor Binding } \\
\text { And Downstream Transmission } \\
\text { In The Postsynaptic Cell }\end{array}$ & 133 & 14 & $10,60 \%$ & 0,00 & 0,01 & Reactome \\
\hline $\begin{array}{l}\text { HIF-1 signaling pathway - } \\
\text { Mus musculus (mouse) }\end{array}$ & 113 & 12 & $10,60 \%$ & 0,00 & 0,01 & KEGG \\
\hline $\begin{array}{l}\text { Proteoglycans in cancer- } \\
\text { Mus musculus (mouse) }\end{array}$ & 229 & 24 & $10,50 \%$ & 0,00 & 0,00 & KEGG \\
\hline Toll Like Receptor 4 (TLR4) Cascade & 106 & 11 & $10,40 \%$ & 0,00 & 0,02 & Reactome \\
\hline Transmission across Chemical Synapses & 178 & 18 & $10,20 \%$ & 0,00 & 0,00 & Reactome \\
\hline Senescence and Autophagy & 98 & 10 & $10,20 \%$ & 0,00 & 0,03 & Wikipathways \\
\hline $\begin{array}{l}\text { Insulin secretion - } \\
\text { Mus musculus (mouse) }\end{array}$ & 88 & 9 & $10,20 \%$ & 0,01 & 0,04 & KEGG \\
\hline MAPK signaling pathway - & & & & & & \\
\hline Mus musculus (mouse) & 257 & 26 & $10,10 \%$ & 0,00 & 0,00 & KEGG \\
\hline IL-6 signaling Pathway & 99 & 10 & $10,10 \%$ & 0,00 & 0,03 & Wikipathways \\
\hline TRIF-mediated TLR3/TLR4 signaling & 89 & 9 & $10,10 \%$ & 0,01 & 0,04 & Reactome \\
\hline MyD88-independent cascade & 89 & 9 & $10,10 \%$ & 0,01 & 0,04 & Reactome \\
\hline Toll Like Receptor 3 (TLR3) Cascade & 89 & 9 & $10,10 \%$ & 0,01 & 0,04 & Reactome \\
\hline
\end{tabular}

\section{Pathway}

name

Amiodarone

MASTL Facilitates Mitotic Progression $10 \quad 3 \quad 30,00 \% \quad 0,00 \quad 0,02 \quad$ Reactome Interleukin-6 signaling Progession $10 \quad 30$

Signaling of Hepatocyte Growth

Factor Receptor

Oxidative Damag

Circadian Clock

Circadian Clock

Spry regulation of FGF signaling

Trafficking of GluR2-containing

AMPA receptors

GRB2:SOS provides linkage to

MAPK signaling for Intergrins

Rapi signalling

Hedgehog Signaling Pathway

Trafficking of AMPA receptors

Glutamate Binding, Activation of

AMPA Receptors and Synaptic Plasticity

EGFR downregulation

Hedgehog signaling pathway -

Mus musculus (mouse)

Signalling to ERKs

IL-7 Signaling Pathway

Renal cell carcinoma -

Mus musculus (mouse)

mTOR signaling pathway -

Mus musculus (mouse)

Intrinsic Pathway for Apoptosis

Colorectal cancer -

Mus musculus (mouse)

Nicotine addiction -

Mus musculus (mouse)

Amino acid transport across

the plasma membrane

IL-3 Signaling Pathway

Mus musculus (mouse)

VEG musculus (mouse)

Mus musculus (mouse)

Mus musculus (mouse)

Amyotrophic lateral sclerosi

Mus musculus (mouse)

Endometrial cancer -

\begin{tabular}{lllllll}
10 & 3 & $30,00 \%$ & 0,00 & 0,02 & Reactome \\
\hline & 8 & $23,50 \%$ & 0,00 & 0,00 & Wikipathways
\end{tabular}

$23,50 \% \quad 0,00 \quad 0,00 \quad$ Wikipathways

$23,50 \% \quad 0,00 \quad 0,01 \quad$ Wikipathways

$23,10 \% \quad 0,00 \quad 0,04$ Reactome

$23,10 \% \quad 0,00 \quad 0,04$ Reactome

$20,00 \% \quad 0,00 \quad 0,04$ Reactome

20,00\% 0,00 0,04 Reactome

$20,00 \% \quad 0,00 \quad 0,04$ Reactome

$20,00 \% \quad 0,00 \quad 0,04$ Reactome

$18,20 \% \quad 0,00 \quad 0,02 \quad$ Wikipathways

$14,80 \% \quad 0,00 \quad 0,04$ Reactome

$14,80 \% \quad 0,00 \quad 0,04 \quad$ Reactome

$14,80 \% \quad 0,00 \quad 0,04$ Reactome

$14,30 \% \quad 0,00 \quad 0,00 \quad$ KEGG

$14,30 \% \quad 0,00 \quad 0,02$ Reactome

$13,60 \% \quad 0,00 \quad 0,01 \quad$ Wikipathways

$13,20 \% \quad 0,00 \quad 0,00 \quad$ KEGG

$12,90 \% \quad 0,00 \quad 0,00 \quad$ KEGG

$12,80 \% \quad 0,00 \quad 0,03$ Reactome

$12,50 \% \quad 0,00 \quad 0,00 \quad$ KEGG

$12,50 \% \quad 0,00 \quad 0,03 \quad$ KEGG

$12,50 \% \quad 0,01 \quad 0,05 \quad$ Reactome

$12,00 \% \quad 0,00 \quad 0,00 \quad$ Wikipathways

$11,90 \% \quad 0,00 \quad 0,01 \quad$ KEGG

$11,70 \% \quad 0,00 \quad 0,01 \quad$ KEGG

$11,50 \% \quad 0,00 \quad 0,02 \quad$ KEGG

$11,50 \% \quad 0,00 \quad 0,02 \quad$ KEGG 
Table 4. continuation

\begin{tabular}{|c|c|c|c|c|c|c|}
\hline $\begin{array}{l}\text { Pathway } \\
\text { name }\end{array}$ & $\begin{array}{l}\text { Pathway } \\
\text { size }\end{array}$ & \begin{tabular}{|l} 
Overlap \\
input genes
\end{tabular} & overlap & $p-$ & $\begin{array}{l}q- \\
\text { value }\end{array}$ & $\begin{array}{l}\text { Pathway } \\
\text { source }\end{array}$ \\
\hline \multicolumn{7}{|l|}{ Amiodarone } \\
\hline TGF Beta Signaling Pathway & 52 & 6 & $11,50 \%$ & 0,00 & 0,02 & Wikipathways \\
\hline Endochondral Ossification & 62 & 7 & $11,30 \%$ & 0,00 & 0,01 & Wikipathways \\
\hline $\begin{array}{l}\text { GABAergic synapse - } \\
\text { Mus musculus (mouse) }\end{array}$ & 90 & 10 & $11,10 \%$ & 0,00 & 0,00 & KEGG \\
\hline $\begin{array}{l}\text { Morphine addiction - } \\
\text { Mus musculus (mouse) }\end{array}$ & 93 & 10 & $10,80 \%$ & 0,00 & 0,00 & KEGG \\
\hline $\begin{array}{l}\text { Chronic myeloid leukemia - } \\
\text { Mus musculus (mouse) }\end{array}$ & 74 & 8 & $10,80 \%$ & 0,00 & 0,01 & KEGG \\
\hline IL-2 Signaling Pathway & 76 & 8 & $10,50 \%$ & 0,00 & 0,01 & Wikipathways \\
\hline Kit Receptor Signaling Pathway & 67 & 7 & $10,40 \%$ & 0,00 & 0,02 & Wikipathways \\
\hline IL-5 Signaling Pathway & 68 & 7 & $10,30 \%$ & 0,00 & 0,02 & Wikipathways \\
\hline Wnt Signaling Pathway NetPath & 109 & 11 & $10,10 \%$ & 0,00 & 0,00 & Wikipathways \\
\hline TGF-beta Receptor Signaling Pathway & 150 & 15 & $10,00 \%$ & 0,00 & 0,00 & Wikipathways \\
\hline $\begin{array}{l}\text { Amino acid and oligopeptide } \\
\text { SLC transporters }\end{array}$ & 50 & 5 & $10,00 \%$ & 0,01 & 0,05 & Reactome \\
\hline Acetaminophen & & & & & & \\
\hline
\end{tabular}

Acetaminophen

No significant pathways were found

\section{HepG2}

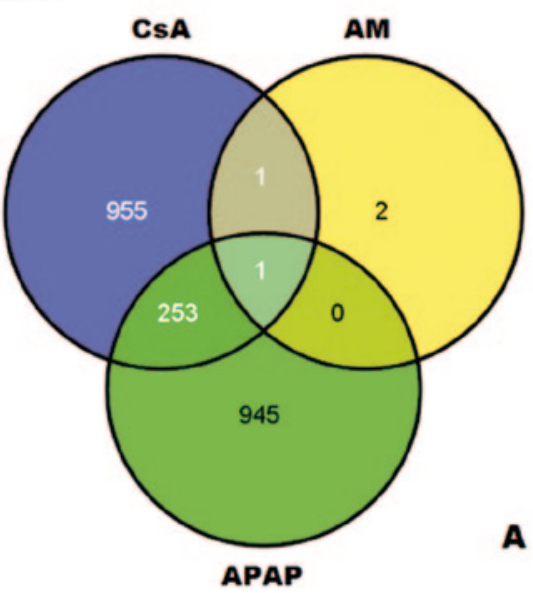

PMH

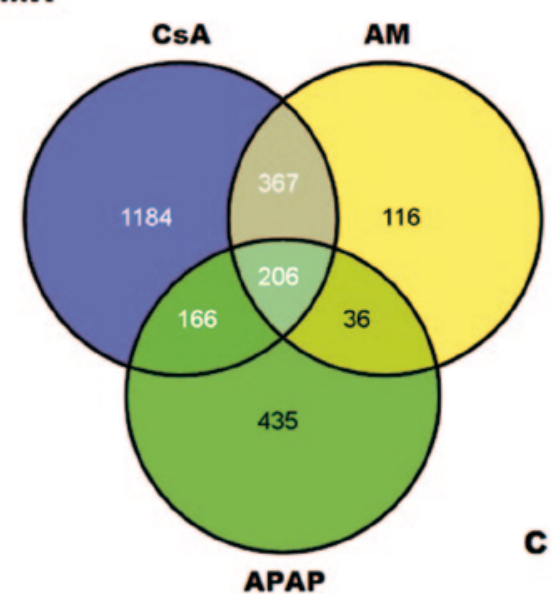

Up-regulated

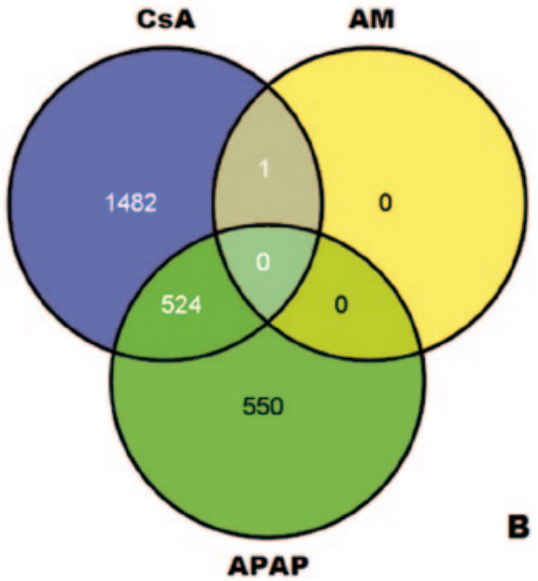

CsA

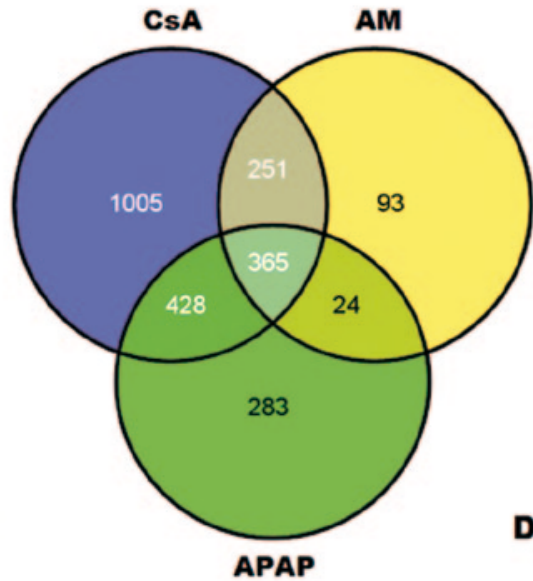

Down-regulated

Figure 1. Overlap of up-regulated and down-regulated differentially expressed genes in HepG2 cells ( $A$ and $B$, respectively) and primary mouse hepatocytes ( $C$ and $D$, respectively) after treatment with cyclosporin $A$, amiodarone and acetaminophen. 


\section{HepG2}

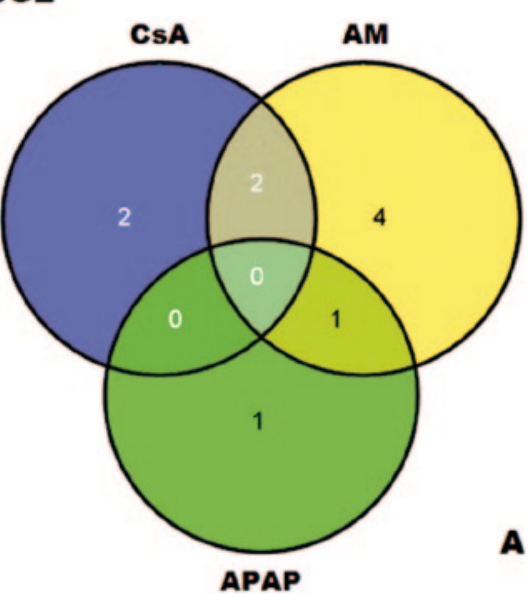

РМн

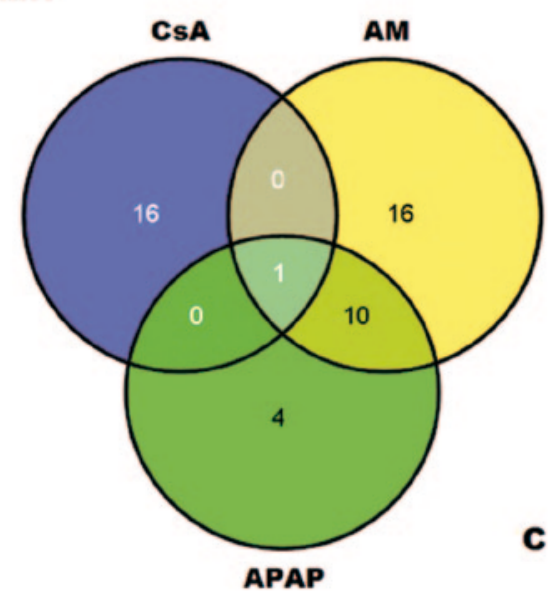

Up-regulated
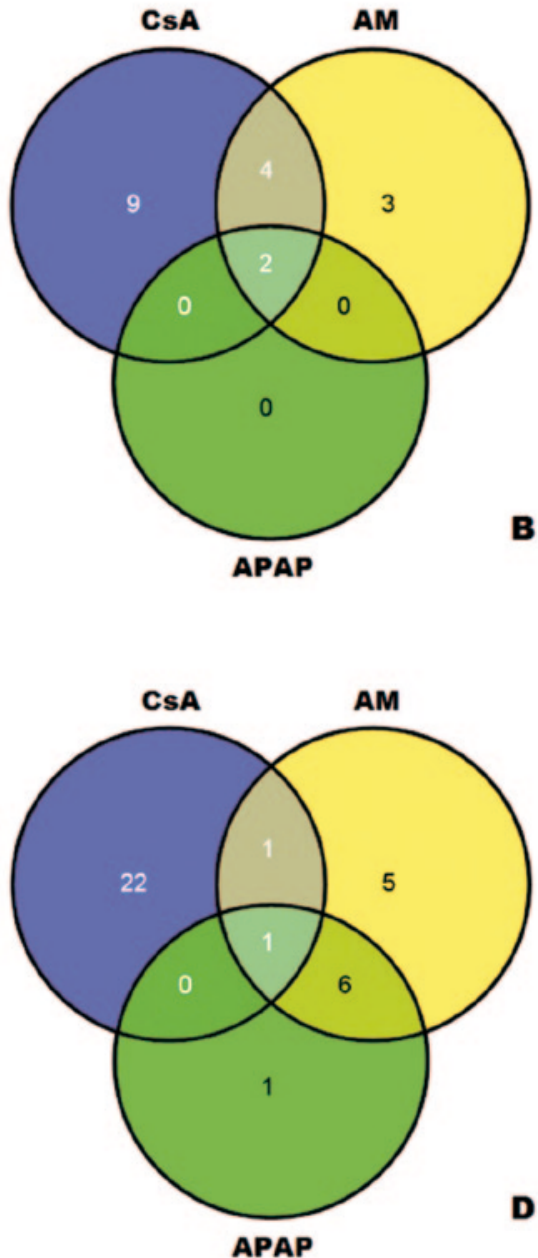

Down-regulated

Figure 2. Overlap of up-regulated and down-regulated differentially expressed microRNAs in HepG2 cells ( $A$ and $B$, respectively) and primary mouse hepatocytes ( $C$ and $D$, respectively) after treatment with cyclosporin $A$, amiodarone and acetaminophen.

Lagos-Ouintana, M., Rauhut, R., Yalcin, A., Meyer, J., Lendeckel, W., Tuschl, T. (2002) Identification of tissue-specific microRNAs from mouse. Curr Biol 12, 735-739.

2. Chang, J., Nicolas, E., Marks, D., Sander, C., Lerro, A., Buendia, M. A., Xu, C., Mason, W. S., Moloshok, T., Bort, R., Zaret, K. S. Taylor, J. M. (2004) miR-122, a mammalian liver-specific microRNA, is processed from hcr mRNA and may downregulate the high affinity cationic amino acid transporter CAT-1. RNA Biol 1, 106-113.

3. Woolbright, B. L., Antoine, D. J., Jenkins, R. E., Bajt, M. L., Park, B. K., Jaeschke, H. (2013) Plasma biomarkers of liver injury and inflammation demonstrate a lack of apoptosis during obstructive cholestasis in mice. Toxicol Appl Pharmacol 273,

4. Antoine, D. J., Dear, J. W., Lewis, P. S., Platt, V., Coyle, J., Masson, M., Thanacoody, R. H., Gray, A. J., Webb, D. J., Moggs, J. G., Bateman, D. N., Goldring, C. E., Park, B. K. (2013) Mechanistic biomarkers provide early and sensitive detection of acetaminophen-induced acute liver injury at first presentation to hospital. Hepatology $58,777-787$.

5. Yamaura, Y., Nakajima, M., Takagi, S., Fukami, T., Tsuneyama, K., Yokoi, T. (2012) Plasma microRNA profiles in rat models of hepatocellular injury, cholestasis, and steatosis. PLOS ONE 7, езо250.

6. Shifeng, H., Danni, W., Pu, C., Ping, Y., Ju, C., Liping, Z. (2013) Circulating liver-specific miR-122 as a novel potential biomarker for diagnosis of cholestatic liver injury. PLOS ONE 8, e73133.

7. Mortensen, R. D., Serra, M., Steitz, J. A., Vasudevan, S. (2011) Posttranscriptional activation of gene expression in Xenopus laevis oocytes by microRNA-protein complexes (microRNPs). Proceedings of the National Academy of Sciences 108, 82818286.

8. Vasudevan, S., Tong, Y., Steitz, J. A. (2007) Switching from Repression to Activation: MicroRNAs Can Up-Regulate Translation. Science 318, 1931-1934.

9. Selbach, M., Schwanhausser, B., Thierfelder, N., Fang, Z., Khanin, R., Rajewsky, N. (2008) Widespread changes in protei synthesis induced by microRNAs. Nature 455, 58-63.

10. Hsu, S.-D., Lin, F.-M., Wu, W.-Y., Liang, C., Huang, W.-C., Chan, W.-L., Tsai, W.-T., Chen, G.-Z., Lee, C.-J., Chiu, C.-M., Chien, C.-H., Wu, M.-C., Huang, C.-Y., Tsou, A.P., Huang, H.-D. (2011) miRTarBase: a database curates experimentally validated microRNA-target interactions. Nucleic Acids Res. 39, D163-D169.

11. Mathijs, K., Kienhuis, A. S., Brauers, K. J. J., Jennen, D. G. J., Lahoz, A., Kleinjans, J. C. S., van Delft, J. H. M. (200g) Assessing the Metabolic Competence of Sandwich-Cultured Mouse Primary Hepatocytes. Drug Metab. Dispos. 37, 1305-1311.

12. Eijssen, L. M. T., Jaillard, M., Adriaens, M. E., Gaj, S., de Groot, P. J., Müller, M., Evelo, C. T. (2013) User-friendly solutions for microarray quality control and pre-processing on ArrayAnalysis.org. Nucleic Acids Res. 41, W71-W76.

13. Dai, M. Wang, P., Boyd, A. D., Kostov, G., Athey, B., Jones, E. G., Bunney, W. E., Myers, R. M. Speed, T. P., Akil, H., Watson, S. J., Meng, F. (2005) Evolving gene/transcript definitions significantly alter the interpretation of GeneChip data. Nucleic Acids Res. 33 , $\mathrm{e} 775$

14. Irizarry, R. A., Hobbs, B., Collin, F., Beazerâ€ Barclay, Y. D., Antonellis, K. J., Scherf, U., Speed, T. P. (2003) Exploration, normalization, and summaries of high density oligonucleotide array probe level data. Biostatistics 4, 249-264.

15. Lopez-Romero, P. (2011) Pre-processing and differential expression analysis of Agilent microRNA arrays using th AgiMicroRna Bioconductor library. BMC Genomics 12, 64

16. Smyth, G. K., limma: Linear Models for Microarray Data. In Bioinformatics and Computational Biology Solutions Using R and Bioconductor, Gentleman, R.; Carey, V.; Huber, W.; Irizarry, R.; Dudoit, S., Eds. Springer New York: 2005; pp 397-420.

17. Oliveros, J. C. VENNY. An interactive tool for comparing lists with Venn Diagrams. http://bioinfogp.cnb.csic.es/tools/ venny/index.html. 
18. Kamburov, A., Wierling, C., Lehrach, H., Herwig, R. (2009) ConsensusPathDB-a database for integrating human functional interaction networks. Nucleic Acids Res. 37, D623-D628.

19. Houzelstein, D., Bullock, S. L., Lynch, D. E., Grigorieva, E. F., Wilson, V. A., Beddington, R. S. (2002) Growth and early postimplantation defects in mice deficient for the bromodomain-containing protein Brd4. Mol Cell Biol 22, 3794-3802. 20. Lardizábal, M. N., Rodriguez, R. E., Nocito, A. L., Daniele, S. M., Palatnik, J. F., Veggi, L. M. (2014) Alteration of the microRNA-122 regulatory network in rat models of hepatotoxicity. Environmental Toxicology and Pharmacology 37, 354364.

21. Li, Y., Zhang, D., Chen, C., Ruan, Z., Li, Y., Huang, Y. (2012) MicroRNA-212 displays tumor-promoting properties in non-smal cell lung cancer cells and targets the hedgehog pathway receptor PTCH. Molecular Biology of the Cell 23, 1423-1434.

22. Wada, R., Akiyama, Y., Hashimoto, Y., Fukamachi, H., Yuasa, Y. (2010) miR-212 is downregulated and suppresses methylCPG-binding protein MeCP2 in human gastric cancer. Int J Cancer 127, 1106-1114.

23. Mohammed, F. F., Pennington, C. J., Kassiri, Z., Rubin, J. S., Soloway, P. D., Ruther, U., Edwards, D. R., Khokha, R. (2005) Metalloproteinase inhibitor TIMP-1 affects hepatocyte cell cycle via HGF activation in murine liver regeneration Hepatology 41, 857-867.

24. Faraji, F., Hu, Y., Wu, G., Goldberger, N. E., Walker, R. C., Zhang, J., Hunter, K. W. (2014) An integrated systems genetics screen reveals the transcriptional structure of inherited predisposition to metastatic disease. Genome Res 24, 227-240.

25. Soresi, M., Sparacino, V., Pisciotta, G., Bonfissuto, G., Caputo, F., Carroccio, A., Calabrese, S., Montalto, G. (1995) Effects of cyclosporin A on various indices of cholestasis in kidney transplant recipients. Minerva Urol Nefrol 47, 65-69,

26. Fromenty, B., Fisch, C., Labbe, G., Degott, C., Deschamps, D., Berson, A., Letteron, P., Pessayre, D. (1990) Amiodarone inhibits the mitochondrial beta-oxidation of fatty acids and produces microvesicular steatosis of the liver in mice.J Pharmaco Exp Ther 255, $1371-1376$

27. Hinson, J. A., Roberts, D. W., James, L. P. (2010) Mechanisms of acetaminophen-induced liver necrosis. Handb Exp Pharmacol, 369-405

28. Rankin, E. B., Rha, J., Selak, M. A., Unger, T. L., Keith, B., Liu, O., Haase, V. H. (2009) Hypoxia-Inducible Factor 2 Regulates Hepatic Lipid Metabolism. Molecular and Cellular Biology 29, 4527-4538.

29. Fabian, M. R., Sonenberg, N., Filipowicz, W. (2010) Regulation of mRNA Translation and Stability by microRNAs. Annual Review of Biochemistry 79, 351-379.

3o. Mohri, T., Nakajima, M., Fukami, T., Takamiya, M., Aoki, Y., Yokoi, T. (2010) Human CYP2E1 is regulated by miR-378. Biochem. Pharmacol. 79, 1045-1052.

31. Takagi, S., Nakajima, M., Mohri, T., Yokoi, T. (2008) Post-transcriptional Regulation of Human Pregnane X Receptor by Micro-RNA Affects the Expression of Cytochrome P450 3A4. J. Biol. Chem. 283, 9674-9680.

32. Pan, Y.-Z., Gao, W., Yu, A.-M. (2009) MicroRNAs Regulate $\mathrm{CYP}_{3} \mathrm{~A}_{4}$ Expression via Direct and Indirect Targeting. Drug Metab. Dispos. 37, 2112-2117 
Chapter 7

SUMNARY

AND GENERAL DISCUSSION

Van den Hof, W.F.P.M. 
The research described in this thesis, was performed in order to investigate the feasibility of using in vitro liver models to classify hepatotoxicants and to further unravel the mechanisms underlying drug-induced liver injury. Current toxicity screening is dependent on animal experiments; however, despite being assessed as safe based on the outcome of such animal experimentation, many toxic drug-candidates still progress into clinical trials and even onto the market. ' While the liver is the most important organ in drug metabolization and excretion, it is vulnerable to drug-induced toxicity. There is a need for reliable in vitro high throughput toxicity screenings, in particular since the number of drug candidates increase every year. Different classes of hepatotoxicity are considered, including necrosis, steatosis and cholestasis. These classes have a different phenotypical profile. Necrosis is a form of premature cell death, steatosis is characterized by the accumulation of lipids inside the cell and accumulation of bile constituents, like bile salts, is characteristic for cholestasis. ${ }^{2-4}$ For most of the traditional biomarkers for liver injury, the differentiation between different classes of hepatotoxicity is difficult. Therefore, great effort is put in developing new screening methods in order to find novel and more accurate biomarkers. In the field of toxicogenomics different platforms for generating molecular information are considered. The genome-wide profiling of RNA molecules, e.g. messenger RNA and microRNA, is better known as transcriptomics and represents the most used platform in toxicogenomics research. Proteomics is used to investigate the global translation of mRNA into proteins and post-translational modifications. Metabonomics investigates the level of metabolites. All these platforms individually provide valuable information about cellular reactions to compound exposure; however, integrative analysis of all platforms has the potential of fully elucidating the mechanisms underlying drug-induced liver injury. In order to investigate drug-induced liver injury in vitro, multiple models are proposed as relevant alternative to the in vivo tests in laboratory animals. Liver slices keep a three-dimensional configuration and contain all cell types and functions of the intact liver. ${ }^{5}$ However, preparation and culturing of liver slices is laborious and long-term exposures are impossible. Primary human hepatocytes are considered to be one of the best in vitro liver models, while these cells show largely the same behavior as hepatocytes in vivo. However, human liver donors are scarce and due to interindividual variation, the comparison of multiple experiments is difficult. Stem cells may provide an unlimited supply of primary hepatocytes and therefore possibly present a valuable alternative model. Up till now, difficulties with differentiation protocols and culturing hinder the use of stem cell-derived hepatocytes in toxicity screenings. 


\section{Investigating hepatotoxicity using transcriptomics}

A different liver model worth exploring is presented by immortalized cell lines of which HepG2 and HepaRG cells are used most frequently. Both represent a human liver cell model and are easy and cheap to culture. HepGz cells show lower baseline levels of phase I and phase II enzymes than HepaRG, but the response towards hepatotoxicants is comparable. 7 In Chapter 2 we therefore aim to prove the principal that HepG2 cells can be used to classify known hepatotoxicants and non-hepatotoxicants based on their distinctive gene expression profiles. For classification we use Prediction Analysis for Microarrays. Using 36 genes, we are able to classify hepatotoxicants and non-hepatotoxicants with an accuracy of $92 \%$ for the training set and $91 \%$ for the validation set. Furthermore, a second model is set-up in an attempt to subclassify cholestatic compounds. This sub-classification of cholestatic compounds results in an accurate prediction of 8 out of 9 cholestatic compounds with an overall accuracy of $93 \%$, using 12 genes. The genes that are selected for the classification of hepatotoxicity and cholestasis, indicate the possible involvement of endoplasmic reticulum stress and the unfolded protein response in drug-induced liver injury. Although we are able to accurately classify hepatotoxicants using transcriptomic analyses of HepG2 cells, the number of compounds should be increased to improve and validate this prediction method.

Drug-induced cholestasis has a high mortality rate and is one of the most severe manifestations of drug-induced hepatotoxicity. Inhibition of transport proteins resulting in intracellular bile accumulation has been suggested as the underlying mechanism. We therefore aim to benchmark data from three in vitro liver models for the investigation of drug-induced cholestasis against data from cholestatic patients, as described in Chapter 3. Microarray data of HepG2 cells, primary mouse hepatocytes and primary human hepatocytes exposed to three cholestatic compounds, namely cyclosporin A, chlorpromazine and ethinyl estradiol, are compared to transcriptomic data of liver samples from cholestatic patients. Overlapping differentially expressed genes in all treatments are investigated to find an in vitro fingerprint of drug-induced cholestasis. Only a limited number of significantly affected genes appear to overlap in all three treatments in primary mouse and human hepatocytes, and none of these are differentially expressed in the in vivo samples. Treatment of $\mathrm{HepG}_{2}$ cells with these three compounds, though, results in 151 overlapping differentially expressed genes. 13 of these genes appear also differentially expressed in the in vivo cholestasis samples, and these point towards the involvement of the unfolded protein response in cholestasis. This is in concordance with the results presented in Chapter 2, which suggest that endoplasmic reticulum stress and the unfolded protein response may play an important role in hepatotoxicity, and especially in cholestasis. The limited overlap of differentially expressed genes after treatment with these three cholestatic compounds indicates that different mechanisms are involved in the induced toxicity. A previously published pathway for drug-induced cholestasis is then used to visualize the gene expression changes in human in vivo cholestasis. Genes involved in the uptake and synthesis of bile salts are down-regulated and the transcription of hepatocellular export proteins is up-regulated, thus indicating an adaptive response of the diseased liver in order to reduce intracellular bile salt levels and to prevent further bile salt accumulation. Indications of an adaptive response are also observed in the in vitro models after treatment with the cholestatic compounds. Furthermore, drug-specific changes on expression levels of genes in the cholestasis pathway are observed that may result in intracellular accumulation of bile salts.

\section{Multi-omics analysis in hepatotoxicity}

In order to further unravel the mechanisms underlying drug-induced toxicity, a multi-omics approach is performed in Chapter 4. HepG2 cells are treated with the cholestatic compound cyclosporin A, and mRNA, microRNA, and metabonomic profiling is performed. Treatment of HepG2 cells diminish intracellular bile salt levels and induce an intracellular accumulation of cholesterol. Pathway analysis is performed using the differentially expressed genes and significantly affected metabolites. An integrated pathway analysis results in more relevan pathways than the separate analyses of the two datasets. Integrated pathway analysis indicates the significant change of pathways involved in cell cycle and cellular metabolism. Furthermore, significant changes are found for pathways involved in protein processing of the endoplasmic reticulum, bile acid biosynthesis and cholesterol metabolism. Moreover, the pathway for drug-induced cholestasis described in Chapter 3 , is supplemented with possible interacting microRNAs. Analysis of the genes, microRNAs and metabolites of this pathway provides valuable information about cholestatic properties of compounds and upon proper validation, may therefore be used to screen new drug candidates for their possible cholestasis-inducing potential. The findings in this chapter confirm that an integrated omics approach, combining transcriptomic and metabonomic analyses of HepG2 cells, facilitates further unravelling of mechanisms underlying cyclosporin A-induced hepatotoxicity.

However, multiple important genes are minimally expressed in $\mathrm{HepG} 2$ cells, including genes involved in bile acid synthesis and important export proteins including the Bile Salt Export Pump. Up till now, toxicity screenings are mostly performed on rodents, which would sugges that primary hepatocytes from rodents present a relevant in vitro liver model. Previous research indicates that primary mouse hepatocytes are metabolically more stable than primary rat hepatocytes. ${ }^{8}$ Primary mouse hepatocytes are therefore used in the investigations described in Chapter 5, to further elucidate the mechanisms underlying cyclosporin A-induced toxicity. After treatment with cyclosporin A, expression levels of proteins, mRNAs, microRNAs and metabolites are analyzed. Integrated analyses of significantly affected proteins and differentially expressed genes reveals that protein disulfide isomerase family A, member 4 (Pdia4) is significantly up-regulated on both the protein level and mRNA level. MicroRNAs can affect the stability en translation of target mRNAs and several databases exist with experimentally validated and predicted targets of microRNAs. 9 In this study, no experimental validated microRNAs are identified that target the Pdia4 mRNA. Mmu-miR-182-5p is predicted by two separat databases to target Pdia4 and is also differentially expressed after cyclosporin A treatment. Pdia4 is involved in protein folding and secretion in the endoplasmic reticulum, confirming the results in the previous chapters that endoplasmic reticulum stress is involved in drug-induced hepatotoxicity. A network is created using the differentially expressed proteins and interacting 
regarding the induced hepatotoxicity by compounds. However, the integrated analysis of multiple omics is difficult since the available tools are not able to combine all omics data. The development of new tools that are capable of integrating all omics platforms has the potentia to further deepen our knowledge on drug-induced liver injury.

The difference in numbers of investigated genes, proteins and metabolites further challenges the integration. Microarray analysis, and even more next generation sequencing can measure the expression of thousands genes at once, which provides valuable data on the transcriptiona changes induced by hepatotoxicants. However, the field of proteomics and metabonomic fall behind. The complete human proteome and metabolome are not published yet; however, recent publications show great progress. ${ }^{16-17}$ Future research should result in high-throughput platforms for complete proteome and metabolome analyses, which would help to further unravel the mechanisms underlying drug-induced toxicity.

\section{Conclusion}

The results described in this thesis show that HepG2 cells can be used to classify hepatotoxic and non-hepatotoxic compounds and provide information on the mechanisms underlying drug-induced hepatotoxicity. The drug-induced changes in HepG2 cells and primary mouse hepatocytes indicate that endoplasmic reticulum stress and the unfolded protein response are important events in hepatotoxicity. The research in this thesis describes an integrated analysis of multiple omics techniques, which results in more relevant information on druginduced toxicity compared to the single omics analyses. Furthermore, microRNAs have been demonstrated to play an important role in drug-induced toxicity.

This thesis thus lays the foundation for the further development of integrated multi-omics analyses in in vitro toxicity screenings, which will improve the classification of hepatotoxic compounds and the knowledge on drug-induced hepatotoxicity.
Promising results are achieved for the classification of hepatotoxicants using HepG2 cells, but it should be taken into account that only a limited amount of compounds are tested. Validation efforts should thus be performed using more hepatotoxic and non-hepatotoxic compounds. Furthermore, HepG2 cells show low expression of multiple important genes, which complicates an in depth analysis of mechanisms of liver toxicity. The metabolic competence of primary mouse hepatocytes is comparable to primary human hepatocytes, which makes these more suitable for the investigation of mechanisms underlying drug-induced hepatotoxicity. However, rodent hepatocytes are not human hepatocytes, and extrapolating the results found in rodents, to the human situation has been shown to be challenging. "Furthermore, hepatocyte cultures only consist of one cell type, where in the liver multiple cell types are present, e.g. Kupffer cells and hepatic stellate cells which play important roles in inflammation and fibrosis. Since these processes are important in hepatotoxicity ${ }^{12}$, future experiments should preferably include these cells.

Three dimensional, organotypical cell cultures have recently been developed and seem to better resemble the in vivo liver. ${ }^{13}$ Furthermore, pluripotent stem cells can be used to produce metabolic competent human hepatocytes. ${ }^{14}$ Further improvement of these techniques could result in better liver models, which will result in more reliable human toxicity screening. ${ }^{15}$

Our results show that multi-omics analysis is capable of providing more relevant information 


\section{References}

1. Lee, W. M. (2003) Drug-Induced Hepatotoxicity. N Engl J Med 349, 474-485.

2. Malhi, H., Gores, G. J., Lemasters, J. J. (2006) Apoptosis and necrosis in the liver: A tale of two deaths? Hepatology 43 $S_{31-S 44 .}$

3. Labbe, G., Dominique, P., Bernard, F. (2008) Drug-induced liver injury through mitochondrial dysfunction: mechanisms and detection during preclinical safety studies. Fundamental \& Clinical Pharmacology 22, 335-353.

4. Björnsson, E., Olsson, R. (2005) Outcome and prognostic markers in severe drug-induced liver disease. Hepatology 42, $481-489$.

5. Lerche-Langrand, C., Toutain, H. J. (2000) Precision-cut liver slices: characteristics and use for in vitro pharmacotoxicology. Toxicology $153,221-253$

6. Gomez-Lechon, M. J., Donato, M. T., Castell, J. V., Jover, R. (2004) Human hepatocytes in primary culture: the choice to investigate drug metabolism in man. Curr Drug Metab 5, 443-462.

7. Gerets, H., Tilmant, K., Gerin, B., Chanteux, H., Depelchin, B., Dhalluin, S., Atienzar, F. (2012) Characterization of primary human hepatocytes, HepG2 cells, and HepaRG cells at the mRNA level and CYP activity in response to inducers and their predictivity for the detection of human hepatotoxins. Cell Biol. Toxicol. 28, 69-87.

8. Mathijs, K., Kienhuis, A. S., Brauers, K. J. J., Jennen, D. G. J., Lahoz, A., Kleinjans, J. C. S., van Delft, J. H. M. (2009) Assessing the Metabolic Competence of Sandwich-Cultured Mouse Primary Hepatocytes. Drug Metab. Dispos. 37, 1305-1311

9. Lema, C., Cunningham, M. J. (2010) MicroRNAs and their implications in toxicological research. Toxicol. Lett. 198, 100-105.

10. Shifeng, H., Danni, W., Pu, C., Ping, Y., Ju, C., Liping, Z. (2013) Circulating liver-specific miR-122 as a novel potential biomarker for diagnosis of cholestatic liver injury. PLOS ONE 8, e73133.

11. Kienhuis, A. S., van de Poll, M. C., Dejong, C. H., Gottschalk, R., van Herwijnen, M., Boorsma, A., Kleinjans, J. C., Stierum, R. H., van Delft, J. H. (2009) A toxicogenomics-based parallelogram approach to evaluate the relevance of coumarininduced responses in primary human hepatocytes in vitro for humans in vivo. Toxicol In Vitro 23, 1163-1169.

12. Kim, Y. R., Lee, N. J., Ban, J. O., Yoo, H. S., Lee, Y. M., Yoon, Y. P., Eum, S. Y., Jeong, H. S., Yoon, D. Y., Han, S. B., Hong, J. T. (2013) Curative Effects of Thiacremonone against Acetaminophen-Induced Acute Hepatic Failure via Inhibition of Proinflammatory Cytokines Production and Infiltration of Cytotoxic Immune Cells and Kupffer Cells. Evid Based Complement Alternat Med 2013, 974794

13. Gunness, P., Mueller, D., Shevchenko, V., Heinzle, E., Ingelman-Sundberg, M., Noor, F. (2013) 3D organotypic cultures of human HepaRG cells: a tool for in vitro toxicity studies. Toxicol Sci 133, 67-78.

14. Roelandt, P., Vanhove, J., Verfaillie, C., Directed Differentiation of Pluripotent Stem Cells to Functional Hepatocytes. In Pluripotent Stem Cells, Lakshmipathy, U.; Vemuri, M. C., Eds. Humana Press: 2013; Vol. 997, pp 141-147.

15. Altmann, B., Welle, A., Giselbrecht, S., Truckenmuller, R., Gottwald, E. (2009) The famous versus the inconvenient - or the dawn and the rise of $3 \mathrm{D}$-culture systems. World J Stem Cells $1,43-48$.

16. Kim, M. S., Pinto, S. M., Getnet, D., Nirujogi, R. S., Manda, S. S., Chaerkady, R., Madugundu, A. K., Kelkar, D. S., Isserlin, R., Jain, S., Thomas, J. K., Muthusamy, B., Leal-Rojas, P., Kumar, P., Sahasrabuddhe, N. A., Balakrishnan, L., Advani, J., George, B., Renuse, S., Selvan, L. D., Patil, A. H., Nanjappa, V., Radhakrishnan, A., Prasad, S., Subbannayya, T., Raju, R., Kumar, M. Sreenivasamurthy, S. K., Marimuthu, A., Sathe, G. J., Chavan, S., Datta, K. K., Subbannayya, Y., Sahu, A., Yelamanchi, S. D., Jayaram, S., Rajagopalan, P., Sharma, J., Murthy, K. R., Syed, N., Goel, R., Khan, A. A., Ahmad, S., Dey, G., Mudgal, K., Chatterjee, A., Huang, T. C., Zhong, J., Wu, X., Shaw, P. G., Freed, D., Zahari, M. S., Mukherjee, K. K., Shankar, S., Mahadevan A., Lam, H., Mitchell, C. J., Shankar, S. K., Satishchandra, P., Schroeder, J. T., Sirdeshmukh, R., Maitra, A., Leach, S. D., Drake, C. G., Halushka, M. K., Prasad, T. S., Hruban, R. H., Kerr, C. L., Bader, G. D., lacobuzio-Donahue, C. A., Gowda, H., Pandey, A.
(2014) A draft map of the human proteome. Nature 509, 575-581.

17. Wishart, D. S. Jewison, T., Guo, A. C., Wilson, M. Knox, C., Liu, Y., Djoumbou, Y, Mandal, R. Aziat, F., Dong, E., Bouatra S., Sinelnikov, I., Arndt, D., Xia, J., Liu, P., Yallou, F., Bjorndahl, T., Perez-Pineiro, R., Eisner, R., Allen, F., Neveu, V., Greiner, R. Scalbert, A. (2013) HMDB 3.0--The Human Metabolome Database in 2013. Nucleic Acids Res 41, D801-807. 


\section{NEDERLADUSE SANENYATR:HO}

Van den Hof, W.F.P.M. 
Het onderzoek dat wordt beschreven in dit proefschrift, werd uitgevoerd om te onderzoeken of in vitro levermodellen gebruikt kunnen worden voor het classificeren van schadelijke stoffen voor de lever en om de fundamentele mechanismen te ontrafelen van leverschade veroorzaakt door deze schadelijke stoffen. De huidige screening van nieuwe medicijnen is afhankelijk van dierproeven; echter, het feit dat een stof als veilig wordt beoordeeld op basis van dergelijke dierproeven, voorkomt niet dat sommige kandidaat-geneesmiddelen in klinische studies of zelfs na introductie op de markt toch giftig blijken te zijn voor de mens. ' De lever is het belangrijkste orgaan met betrekking tot het metabolisme en de uitscheiding van medicijnen, waardoo dit orgaan extra kwetsbaar is voor schade geïnduceerd door medicijnen. Er is behoefte aan betrouwbare in vitro testen voor toxiciteit met een hoge doorvoersnelheid, voornamelijk omdat het aantal kandidaat-geneesmiddelen elk jaar stijgt. Er kan onderscheid gemaakt worden tussen verschillende klassen van leverschade, waaronder necrose, steatose en cholestase, en elk van deze klassen heeft een ander fenotypische profiel. Necrose is een vorm van vroegtijdige celdood, steatose wordt gekenmerkt door de ophoping van vetten in de cel en stapeling van gal bestanddelen, zoals galzouten, is kenmerkend voor cholestase. ${ }^{2-4}$ Met behulp van traditionele biomarkers voor leverbeschadiging is de differentiatie tussen verschillende klassen van leverschade moeilijk. Daarom wordt er veel energie gestoken in het ontwikkelen van nieuwe testmethodes om nieuwe en meer accurate biomarkers te vinden. Binnen het gebied van toxicogenomics zijn er verschillende platforms voor het genereren van moleculaire informatie. Het genoom-breed profileren van RNA-moleculen, zoals messenger RNA (mRNA) en microRNA, is beter bekend als transcriptomics en vertegenwoordigt het meest gebruikte platform in toxicogenomics onderzoek. Proteomics wordt gebruikt om de vertaling van mRNA in eiwitten en post-translationele modificaties te onderzoeken. Metabonomics onderzoekt het niveau van metabolieten. Al deze platformen leveren individueel waardevolle informatie op over cellulaire reacties na blootstelling aan giftige stoffen; echter, een gecombineerde analyse van alle platformen heeft de potentie om de fundamentele mechanismen van leverschade veroorzaak door medicijnen volledig op te helderen. Om leverschade veroorzaakt door medicijnen in vitro te onderzoeken, worden meerdere modellen voorgesteld als relevant alternatief voor de in vivo situatie in laboratoriumdieren. Leverplakken houden een driedimensionale configuratie en bevatten alle celtypes en functies van de intacte lever. ${ }^{5}$ Echter, het voorbereiden en kweken van deze leverplakken is bewerkelijk en langdurige blootstellingen zijn onmogelijk. Primaire humane hepatocyten worden beschouwd als een van de beste in vitro levermodellen, omdat deze cellen grotendeels hetzelfde gedrag vertonen als hepatocyten in vivo. ${ }^{6}$ Echter humane everdonoren zijn schaars en door interindividuele variatie is de vergelijking van meerdere experimenten moeilijk. Stamcellen kunnen gebruikt worden om een onbeperkte hoeveelheid aan primaire hepatocyten te verkrijgen en zijn daarom mogelijk een waardevol alternatief model. Tot nu toe belemmeren moeilijkheden met kweken en differentiatie protocollen het gebruik van hepatocyten verkregen van stamcellen in toxiciteit screenings. 


\section{Onderzoek naar lever toxiciteit met behulp van transcriptomics}

Andere lever modellen die het onderzoeken waard zijn, zijn geïmmortaliseerde cellijnen waarvan HepG2- en HepaRG-cellen het meest gebruikt worden. Beide cellijnen zijn menselijke levercellen en zijn eenvoudig en goedkoop te kweken. HepG2 cellen vertonen lagere referentiewaarden van fase I en fase II-enzymen dan HepaRG, maar de reactie op levertoxische stoffen is vergelijkbaar 7 In Hoofdstuk $\mathbf{2}$ trachten we daarom het principe te bewijzen dat HepG2 cellen gebruikt kunnen worden om bekende levertoxische en nietlevertoxische stoffen te classificeren op hun onderscheidende genexpressie profielen. Voor de classificatie gebruiken we 'Prediction Analysis for Microarrays'. Op basis van 36 genen, zijn we in staat om levertoxische en niet-levertoxische stoffen te classificeren met een nauwkeurigheid van $92 \%$ voor de training set en $91 \%$ voor de validatie set. In een poging cholestatische verbindingen te subclassificeren, is een tweede classificatiemodel opgezet. Deze subclassificatie van cholestatische stoffen resulteert in een nauwkeurige voorspelling van 8 van de 9 cholestatische verbindingen met een totale nauwkeurigheid van $93 \%$, op basis van 12 genen. De genen die zijn geselecteerd voor de classificatie van hepatotoxiciteit en cholestase, wijzen op de mogelijke betrokkenheid van endoplasmatisch reticulum stres en een ongevouwen eiwit respons in leverschade veroorzaakt door medicijnen. Hoewel we in staat zijn om nauwkeurig levertoxische stoffen te classificeren op basis van transcriptoom analyse van HepG2-cellen, moet het aantal verbindingen verhoogd worden voor het verbeteren en valideren van deze classificatie methode.

Cholestase veroorzaakt door medicijnen heeft een hoog sterftecijfer en is een van de meest ernstige manifestaties van leverschade veroorzaakt door medicijnen. Remming van transporteiwitten waardoor intracellulaire accumulatie van gal optreedt, is voorgesteld als het onderliggende mechanisme. Wij streven dan ook naar de evaluatie van drie in vitro levermodellen voor het onderzoek naar cholestase veroorzaakt door medicijnen door deze te vergelijken met cholestatische patiënten, zoals beschreven staat in Hoofdstuk 3. Microarray data van HepG 2 cellen, primaire muis hepatocyten en primaire humane hepatocyten blootgesteld aan drie cholestatische verbindingen, cyclosporine A, chloorpromazine en ethinylestradiol, zijn vergeleken met transcriptoom data van cholestatische patiënten. Om een in vitro vingerafdruk van cholestase veroorzaakt door medicijnen te vinden zijn de differentieel tot expressie komende genen onderzocht die overlappen in alle behandelingen. Slechts een beperkt aantal significant veranderde genen lijken te overlappen in alle drie de behandelingen in primaire muis en humane hepatocyten, en geen van deze komen differentieel tot expressie in de in vivo monsters. Behandeling van HepGz cellen met deze drie verbindingen resulteert echter in 151 differentieel tot expressie komende genen die overlappen in alle drie de behandelingen. 13 van deze genen komen ook differentieel tot expressie in de in vivo cholestase monsters en deze genen zijn betrokken bij een ongevouwen eiwit respons. Dit is in overeenstemming met de resultaten van Hoofdstuk 2, die suggereren dat endoplasmatisch reticulum stress en een ongevouwen eiwit respons een belangrijke rol spelen bij hepatotoxiciteit, vooral in cholestase. De beperkte overlap van differentiee tot expressie komende genen na behandeling met deze drie cholestatische verbindingen wijst erop dat er verschillende mechanismen betrokken zijn bij de geïnduceerde toxiciteit. Een eerder gepubliceerde metabole route voor cholestase veroorzaakt door medicijnen, is vervolgens gebruikt om de genexpressie-veranderingen in humane in vivo cholestase te visualiseren. Genen die betrokken zijn bij de opname en de synthese van galzouten worden geremd en de transcriptie van hepatocellulaire export eiwitten word gestimuleerd, wat wijst op een adaptieve respons van de zieke lever om het niveau van intracellulaire galzouten te verlagen en verdere stapeling van galzouten te voorkomen. Indicaties voor een adaptieve respons worden ook waargenomen in de in vitro modellen na behandeling met de cholestatische stoffen. Bovendien worden medicijn-specifieke veranderingen in de expressie van genen in de metabole route voor cholestase waargenomen die kunnen leiden tot intracellulaire accumulatie van galzouten.

\section{Multi-omics analyse in hepatotoxiciteit}

Met het oog op het ontrafelen van de fundamentele mechanismen van toxiciteit veroorzaakt door medicijnen, is een multi-omics aanpak uitgevoerd in Hoofdstuk 4. HepG2 cellen zijn behandeld met de cholestatische verbinding cyclosporine $A$, waarna het mRNA, microRNA, en metabonoom profiel is onderzocht. Behandeling van HepG2-cellen zorgt voor een afname van de intracellulaire galzoutconcentratie en induceert een intracellulaire accumulatie van cholesterol. Analyse van metabole routes is uitgevoerd met behulp van de differentieel to expressie komende genen en significant veranderde metabolieten. Een geïntegreerde analyse resulteert in meer relevante informatie dan de afzonderlijke analyses van de twee datasets. Geïntegreerde analyse van metabole routes wijst op een significante verandering van routes betrokken bij celcyclus en cellulaire stofwisseling. Bovendien zijn significante veranderingen gevonden die betrokken zijn bij de eiwit verwerking van het endoplasmatisch reticulum de biosynthese van galzuren en het cholesterol metabolisme. Verder is de route voor cholestase veroorzaakt door medicijnen, beschreven in Hoofdstuk 3, aangevuld met mogelijk interacties tussen genen en microRNAs. Analyse van de genen, microRNAs en metabolieten van deze route levert waardevolle informatie op over de cholestatische eigenschappen van verbindingen. $\mathrm{Na}$ validatie kan deze route gebruikt worden om kandidaat-geneesmiddelen te screenen op hun cholestase-inducerende potentie. De bevindingen in dit hoofdstuk bevestigen dat een geïntegreerde omics benadering, waarbij transcriptoom en metabonoom analyses van HepG2 cellen worden gecombineerd, verdere ontrafeling van de fundamentele mechanismen van hepatotoxiciteit veroorzaakt door cyclosporine A mogelijk maakt.

Er zijn echter meerdere belangrijke genen die minimaal tot expressie komen in $\mathrm{HepG}_{2}$ cellen, waaronder genen betrokken bij galzuursynthese en belangrijke export eiwitten waaronder de galzout export pomp. Tot nu toe worden toxiciteit screenings meesta uitgevoerd op knaagdieren, wat suggereert dat de primaire hepatocyten van knaagdieren een relevant in vitro lever model vormen. Eerder onderzoek geeft aan dat de primaire muis hepatocyten metabolisch stabieler zijn dan primaire rat hepatocyten. ${ }^{8}$ Primaire muis hepatocyten zijn daarom gebruikt in het onderzoek beschreven in Hoofdstuk 5, om 


\section{Beperkingen en aanbevelingen voor de toekomst}

Veelbelovende resultaten zijn bereikt voor de classificatie van lever-toxische stoffen met behulp van $\mathrm{HepG}_{2}$ cellen, maar er moet rekening gehouden worden met het feit dat slechts een beperkte hoeveelheid verbindingen getest zijn. Verdere validatie moet dus worden uitgevoerd met meer hepatotoxische en niet-hepatotoxische verbindingen. Bovendien vertonen $\mathrm{HepG}_{2}$ cellen een lage expressie van meerdere belangrijke genen, die een diepgaande analyse van de onderliggende mechanismen van lever-toxiciteit compliceert. De metabolische competentie van primaire muis hepatocyten is vergelijkbaar met primaire humane hepatocyten, waardoor deze beter geschikt zijn voor het onderzoek naar de onderliggende mechanismen in hepatotoxiciteit veroorzaakt door medicijnen. Echter, hepatocyten van knaagdieren zijn geen humane hepatocyten en extrapolatie van de resultaten gevonden bij knaagdieren naar de humane situatie blijkt een hele uitdaging. "Verder bestaan in vitro kweken van hepatocyten slechts uit één celtype, waar in de lever verschillende celtypen aanwezig zijn, waaronder kupffercellen en stellaatcellen die een belangrijke rol spelen bij ontstekingen en fibrose. Aangezien deze processen een belangrijke rol spelen bij hepatotoxiciteit, dienen toekomstige in vitro experimenten bij voorkeur ook deze cellen te bevatten. ${ }^{12}$

Drie dimensionale, organotypische celculturen zijn recentelijk ontwikkeld en lijken beter op de in vivo lever. ${ }^{13}$ Verder zouden pluripotente stamcellen gebruikt kunnen worden om metabolisch competente menselijke hepatocyten te produceren. ${ }^{14}$ Verdere verbetering van deze technieken kan leiden tot betere levermodellen wat zal resulteren in een hogere betrouwbaarheid van humane toxiciteit screening. ${ }^{15}$

Onze resultaten tonen aan dat een geïntegreerde analyse van meerdere omics mee relevante informatie oplevert over de hepatotoxiciteit veroorzaakt door medicijnen. Echter, een geïntegreerde analyse van meerdere omics is moeilijk aangezien de beschikbare software nog niet in staat is om alle omics data te combineren. De ontwikkeling van nieuwe software die in staat is om data van alle omics platforms te integreren, heeft het potentieel om onze kennis van leverschade veroorzaakt door medicijnen verder te verdiepen.

Het verschil in aantallen tussen de onderzochte genen, eiwitten en metabolieten is een extra uitdaging bij de integratie. Microarray analyse, en in het bijzonder next generation sequencing, kan de expressie van duizenden genen tegelijkertijd meten, en levert waardevolle informatie op over transcriptionele veranderingen bij leverschade. Echter, proteomics en metabonomics lopen hierbij wat achter. Het volledige menselijk proteoom en metaboloom zijn nog niet gepubliceerd, maar recente publicaties tonen grote vooruitgang. ${ }^{16-17}$ Toekomstig onderzoe moet resulteren in een platform met een hoge doorvoercapaciteit voor complete proteoom en metaboloom analyses wat zou helpen bij het ontrafelen van de fundamentele mechanismen van hepatotoxiciteit veroorzaakt door medicijnen. functie van microRNAs in het metabolisme van deze medicijnen. Bovendien zijn differentieel tot expressie komende microRNAs wellicht betrokken bij de homeostase van vetten en bij cholestatische mechanismen. Gericht onderzoek naar de medicijn-specifieke microRNAs die differentieel tot expressie komen, de genen waarmee ze een interactie vertonen en de eiwitten waar deze genen voor coderen, zouden de rol van microRNAs in hepatotoxiciteit veroorzaakt door medicijnen verder kunnen ontrafelen. 


\section{Conclusie}

De in dit proefschrift beschreven resultaten laten zien dat HepG2 cellen gebruikt kunnen worden om hepatotoxische en niet-hepatotoxische stoffen te classificeren en informatie te verstrekken over de fundamentele mechanismen van hepatotoxiciteit veroorzaakt door medicijnen. De veranderingen in HepG2 cellen en primaire muis hepatocyten veroorzaakt door toxische medicijnen, duiden erop dat endoplasmatisch reticulum stress en een ongevouwen eiwit respons belangrijke gebeurtenissen zijn in hepatotoxiciteit. Het onderzoek in dit proefschrift beschrijft een geïntegreerde analyse van meerdere omics technieken, die resulteert in meer relevante informatie over toxiciteit veroorzaakt door medicijnen dan enkelvoudige omics analyses. Bovendien is aangetoond dat microRNAs mogelijk een belangrijke rol spelen bij toxiciteit veroorzaakt door medicijnen.

Dit proefschrift legt daarmee de basis voor de verdere ontwikkeling van geïntegreerde multi-omics analyses in in vitro toxiciteit screenings, die de classificatie van hepatotoxische stoffen en de kennis van hepatotoxiciteit veroorzaakt door medicijnen zal verbeteren.

\section{Referenties}

1. Lee, W. M. (2003) Drug-Induced Hepatotoxicity. N Engl J Med 349, 474-485.

2. Malhi, H., Gores, G. J., Lemasters, J. J. (2006) Apoptosis and necrosis in the liver: A tale of two deaths? Hepatology 43, $\mathrm{S}_{31}-\mathrm{S} 44$.

3. Labbe, G., Dominique, P., Bernard, F. (2008) Drug-induced liver injury through mitochondrial dysfunction: mechanisms and detection during preclinical safety studies. Fundamental \& Clinical Pharmacology 22, 335-353.

4. Björnsson, E., Olsson, R. (2005) Outcome and prognostic markers in severe drug-induced liver disease. Hepatology 42,481-489.

5. Lerche-Langrand, C., Toutain, H. J. (2000) Precision-cut liver slices: characteristics and use for in vitro pharmaco-toxicology. Toxicology 153, 221-253.

6. Gomez-Lechon, M. J., Donato, M. T., Castell, J. V., Jover, R. (2004) Human hepatocytes in primary culture: the choice to investigate drug metabolism in man. Curr Drug Metab 5, 443-462.

7. Gerets, H., Tilmant, K., Gerin, B., Chanteux, H., Depelchin, B., Dhalluin, S., Atienzar, F. (2012) Characterization of primary human hepatocytes, HepG2 cells, and HepaRG cells at the mRNA level and CYP activity in response to inducers and their predictivity for the detection of human hepatotoxins. Cell Biol. Toxicol. 28, 69-87.

8. Mathijs, K., Kienhuis, A. S., Brauers, K. J. J., Jennen, D. G. J., Lahoz, A., Kleinjans, J. C. S., van Delft, J. H. M. (2009) Assessing the Metabolic Competence of Sandwich-Cultured Mouse Primary Hepatocytes. Drug Metab. Dispos. 37, 1305-1311.

9. Lema, C., Cunningham, M. J. (2010) MicroRNAs and their implications in toxicological research. Toxicol. Lett. 198, 100-105.

10. Shifeng, H., Danni, W., Pu, C., Ping, Y., Ju, C., Liping, Z. (2013) Circulating liver-specific miR-122 as a novel potential biomarker for diagnosis of cholestatic liver injury. PLOS ONE 8 , e73133.

11. Kienhuis, A. S., van de Poll, M. C., Dejong, C. H., Gottschalk, R., van Herwijnen, M., Boorsma, A., Kleinjans, J. C., Stierum, R. H., van Delft, J. H. (2009) A toxicogenomics-based parallelogram approach to evaluate the relevance of coumarin-induced responses in primary human hepatocytes in vitro for humans in vivo. Toxicol In vitro 23, 1163-1169.

12. Kim, Y. R., Lee, N. J., Ban, J. O., Yoo, H. S., Lee, Y. M., Yoon, Y. P., Eum, S. Y., Jeong, H. S., Yoon, D. Y., Han, S. B., Hong, J. T. (2013) Curative Effects of Thiacremonone against Acetaminophen-Induced Acute Hepatic Failure via Inhibition of Proinflammatory Cytokines Production and Infiltration of Cytotoxic Immune Cells and Kupffer Cells. Evid Based Complement Alternat Med 2013, 974794.

13. Gunness, P., Mueller, D., Shevchenko, V., Heinzle, E., Ingelman-Sundberg, M., Noor, F. (2013) 3D organotypic cultures of human HepaRG cells: a tool for in vitro toxicity studies. Toxicol Sci 133, 67-78.

14. Roelandt, P., Vanhove, J., Verfaillie, C., Directed Differentiation of Pluripotent Stem Cells to Functional Hepatocytes. In Pluripotent Stem Cells, Lakshmipathy, U.; Vemuri, M. C., Eds. Humana Press: 2013; Vol. 997, pp 141-147.

15. Altmann, B., Welle, A., Giselbrecht, S., Truckenmuller, R., Gottwald, E. (2009) The famous versus the inconvenient - or the dawn and the rise of $3 \mathrm{D}$-culture systems. World J Stem Cells 1,43-48.

16. Kim, M. S., Pinto, S. M. Getnet, D. Nirujogi, R. S., Manda, S. S., Chaerkady, R., Madugundu, A. K., Kelkar, D. S. I Isserlin, R., Jain, S. Thomas, J. K., Muthusamy, B., Leal-Rojas, P., Kumar, P., Sahasrabuddhe, N. A., Balakrishnan, L., Advani, J., George, B., Renuse, S., Selvan, L. D., Patil, A. H., Nanjappa, V., Radhakrishnan, A., Prasad, S., Subbannayya, T., Raju, R., Kumar, M., Sreenivasamurthy, S. K. Marimuthu, A., Sathe, G. J., Chavan, S., Datta, K. K., Subbannayya, Y., Sahu, A., Yelamanchi, S. D., Jayaram, S., Rajagopalan, P., Sharma, J., Murthy, K. R., Syed, N., Goel, R., Khan, A. A., Ahmad, S., Dey, G., Mudgal, K., Chatterjee, A., Huang, T. C., Zhong, J., Wu, X., Shaw, P. C., Freed, D., Zahari, M. S., Mukherjee, K. K., Shankar, S., Mahadevan, A., Lam, H., Mitchell, C. J., Shankar, S. K., Satishchandra, P. Schroeder, J. T., Sirdeshmukh, R., Maitra, A., Leach, S. D., Drake, C. G., Halushka, M. K., Prasad, T. S., Hruban, R. H., Kerr, C. L., Bader, G. D., lacobuzio-Donahue, C. A., Gowda, H., Pandey, A. (2014) A draft map of the human proteome. Nature 509, 575-58.

17. Wishart, D. S., Jewison, T., Guo, A. C., Wilson, M., Knox, C., Liu, Y., Djoumbou, Y., Mandal, R., Aziat, F., Dong, E., Bouatra, S, Sinelnikov, I., Arndt, D., Xia, J., Liu, P., Yallou, F., Bjorndahl, T., Perez-Pineiro, R., Eisner, R., Allen, F., Neveu, V., Greiner, R., Scalbert, A. (2013) HMDB 3.0--The Human Metabolome Database in 2013. Nucleic Acids Res 41, D801-807. 


\section{VALORISATION}

CURRICULUM VITAE

LIST OF PUBLICATIONS

DANKWOORD 


\section{Valorisation}

The creation of value out of knowledge, valorisation, has two dimensions: an economic aspect and a societal aspect. The economic aspect of value-creation of our research is highlighted first. The development of a new drug may easily take several years and it may cost up to US $\$ 800$ million before approval and release onto the market, making it a time- and money-consuming business. 'Before new drugs progress into clinical trials, preclinical testing is performed, which mostly consists of long-term animal experiments. If a drug does not induce adverse effects in these animal tests, the drug will be tested in clinical trials. Approximately $20 \%$ of all new drugs which enter clinical trials, are proven successful and advance onto the market. ${ }^{2}$ However, a large number of drug candidates fail during preclinical tests or clinical trials. The most indicated reason for termination of these projects is the lack of efficacy of the new drug candidate. The second most indicated reason is drug-induced toxicity. ${ }^{3}$ Liver injury is reported in approximately $30 \%$ of all cases of drug-induced toxicity in clinical trials, which indicates that drug-induced hepatotoxicity is one of the major reasons for drug withdrawal. ${ }^{4-6}$ Since the liver is the most important organ involved in the metabolization and secretion of drugs, accumulation of drugs or toxic drug metabolites may induce adverse drug effects. Despite the fact that drug candidates are extensively tested in preclinical screenings and clinical trials, some drugs are found to be hepatotoxic after admittance onto the market. This indicates that preclinical testing needs to be improved to reduce the number of hepatotoxic drug candidates advancing into animal experiments and clinical trials.

Previous publications report an accurate classification of non-hepatotoxicants and hepatotoxic compounds, including discrimination of different classes of toxicants, based on the in vivo gene expression profiles in rat livers. 7.8 Prediction of genotoxic properties of compounds in vivo could successfully be predicted in vitro using gene expression analysis combined with the Ames mutagenicity test. 9 In chapter 2 of this thesis we describe a transcriptomic investigation of drug-induced toxicity in an in vitro liver cell line, which resulted in a selection of genes capable of classifying in vivo liver toxicants and non-toxicants. An accuracy of $91 \%$ was obtained in the classification of hepatotoxicants and non-hepatotoxicants, using the expression of 36 genes. Furthermore, using 12 selected genes in a second model, we were able to classify cholestatic properties of compounds with an accuracy of $93 \%$. These findings may result in the development of a sensitive in vitro test to screen for drug-induced toxicity, which in time may result in a reduction and replacement of laboratory animals in toxicity screening. Drug development industry could save a lot of money and time if new drug candidates could be screened in a fast and accurate in vitro test instead of in long-term toxicity testing in laboratory animals. In vitro testing allows testing of drug candidates in a high throughput way, which prevents spending too much time and money on toxic candidates in an early stage of development.

The selected genes could be used to develop an assay to detect hepatotoxicity which can 
be commercialized. The assay could consist of a microarray-based setup containing probes for the measurement of the selected classifiers. Users would expose an in vitro liver cell line to the drug candidates which they want to test, and isolate the RNA. The isolated RNA is applied to the probes and measurement of fluorescent intensity is used to quantify the expression of the selected genes relative to a negative control. For this, also automated data analysis pipelines should be put in place. Hepatotoxic properties will be reported based on the up or down-regulation of the genes as a reaction to the exposure of the drug-candidates. In order to valorize this assay, the used protocol should be patented.

However, the classification assay described in Chapter 2 was set-up and validated using a limited amount of compounds. Therefore, the selected genes should be validated using a large number of hepatotoxic and non-hepatotoxic compounds before these can be used in a new hepatotoxicity test. Personnel, money and time are needed to expose cells to all these compounds. Approximately 2-3 persons are required for a 1-2 year project for the coordination of compound recruitment, the exposure of cells, microarray analyses, data processing and the statistical analyses. Applying for dedicated grants (e.g. STW Valorisation Grant) to get money for the development of this assay would be one of the possibilities. Furthermore, collaborating with the drug development industry could be an option. Therefore, implementation of this new assay is fully dependent on the time it would take to raise enough money for the measurement of more compounds in order to validate the genes selected for classification.

Furthermore, the research described in Chapters 4, 5 and 6 emphasize the added value of integrating multiple omics in order to fully elucidate the mechanistic understanding of toxicity profiles. In these chapters, data from multiple omics techniques are combined in two in vitro liver models, HepG2 cells and primary mouse hepatocytes. In Chapter 4, HepG2 cells were treated with cyclosporin A and we show that integrating transcriptomics and metabonomics results in more information on the mechanisms underlying cyclosporin A-induced toxicity. This was confirmed in the research described in Chapter 5 , using primary mouse hepatocytes, in which transcriptomics was integrated with proteomics and metabonomics. In Chapter 6, mRNA and microRNA profiling is integrated which provides more information on the possible influence of microRNAs on the translation of drug-induced effects on mRNA level.

The transcriptomics and metabonomics data described in Chapter 4 was used for integrated pathway analysis using the available open source tool IMPaLA. ${ }^{10}$ MicroRNA data was integrated with transcriptomics data in Chapters 4, 5 and 6 using experimentally validated target genes from miRTarBase and the overlap of predicted target genes from miRanda and TargetScan. ${ }^{11-13}$ For the visualization of different omics data, PathVisio was used. ${ }^{14}$ These open source tools and databases provide valuable information on the interactions between the different omics data. However, no tools are available yet to integrate all omics data. In order to valorize the research described in these chapters, the results of the integrated analyses should be used to further improve existing tools or to set-up a new open source tool for multi-omics analysis.

Approximately 2 persons with statistical and programming skills are required for a 1-2 year project for the coordination of data recruitment and processing, statistica analysis and the set-up of the scripts needed to run such a tool. Once the tool is operational, time and money could be invested in the web-design of the open source tool. Collaboration with the research groups that developed already existing open source tools, like IMPaLA and PathVisio, could be an option. Especially the expansion of functions in PathVisio would be interesting, since separate plugins can be developed and integrated into the tool. In order to finance this project, grants applications are needed.

Apart from the economic aspect, societal value can be created from knowledge. Chemical safety is important and increasing the safety of chemicals is a task of regulatory authorities like the Organisation for Economic Co-operation and Development (OECD). The OECD launched a new program in 2012 on the generation of Adverse Outcome Pathways (AOPs). The integration of different omics data will facilitate the construction of AOPs. AOPs support the integration of different kinds of data and provide mechanistic basis for drug-induced toxicity. Therefore, AOPs can be used to support the assessment of the toxic potential of compounds. ${ }^{15}$ The results of the research described in this thesis should be used to develop new AOPs and expand existing ones. Vinken et al. published an AOP for cholestasis induced by the inhibition of the Bile Salt Export Pump (BSEP) by drugs. ${ }^{16}$ In the research described in Chapter 4 and 5 , HepG 2 cells and primary mouse hepatocytes are treated with the BSEP-inhibiting drug cyclosporin A. The results of these multi-omics approaches indicate the possible involvement of endoplasmic reticulum stress and the unfolded protein response in cholestasis. Ones validated, these mechanisms should be added to the AOP for cholestasis.

The datasets presented in this thesis, especially the data from experiments with multiple time points and doses, should be further explored in order to construct AOPs for the different adverse outcomes in drug-induced hepatotoxicity. The data presented in this thesis should be supplemented with additional datasets, including different kinds of data like e.g. physiologically based biokinetic modeling. Focusing on 1 adverse outcome will increase the feasibility of such a project. Approximately 2 persons will be required for a 1-2 year project in order to collect available data and construct the AOP. Follow-up projects for other adverse outcomes will use the developed pipeline of the first project. The developed AOPs can be used to identify key events in the induction of adverse outcomes, which will enable the use of in vitro and/or in silico tests to assess the ability of drugs to induce the adverse outcomes. These tests will reduce the amoun of laboratory animals needed for toxicity testing and decrease the number of toxic drugs advancing into clinical trials and onto the market, which highlights the societa aspect of our research. 


\section{References}

1. DiMasi, J. A., Hansen, R. W., and Grabowski, H. G. (2003) The price of innovation: new estimates of drug development costs. Journal of Health Economics, 22, 151-185.

2. Bradbard, L. (1999) From Test Tube to Patient: Improving Health Through Human Drugs. Diane Publishing Company.

3. Schuster, D., Laggner, C., and Langer, T. (2005) Why drugs fail--a study on side effects in new chemical entities. Curr. Pharm. Design, 11, 3545-3559.

4. Russmann, S., Kullak-Ublick, G. A., and Grattagliano, I. (2009) Current concepts of mechanisms in drug-induced hepatotoxicity. Curr. Med. Chem., 16, 3041-3053.

5. Lee, W. M. (2003) Drug-Induced Hepatotoxicity. N Engl J Med, 349, 474-485.

6. MacDonald, J. S., and Robertson, R. T. (2009) Toxicity Testing in the 21st Century: A View from the Pharmaceutical Industry. Toxicol. Sci, 110, 40-46.

7. Zidek, N., Hellmann, J., Kramer, P.-J, and Hewitt, P. G. (2007) Acute Hepatotoxicity: A Predictive Model Based on Focused Illumina Microarrays. Toxicol. Sci, 99, 289-302.

8. Steiner, G., Suter, L., Boess, F., Gasser, R., de Vera, M. C., Albertini, S., and Ruepp, S. (2004) Discriminating different classes of toxicants by transcript profiling. Environ. Health Persp., 112, 1236-1248.

9. Magkoufopoulou, C., Claessen, S. M. H., Tsamou, M., Jennen, D. G. J., Kleinjans, J. C. S., and van Delft, J. H. M. (2012) A transcriptomics-based in vitro assay for predicting chemical genotoxicity in vivo. Carcinogenesis, 33, 1421-1429.

o. Kamburov, A., Cavill, R., Ebbels, T. M. D., Herwig, R., and Keun, H. C. (2011) Integrated pathway-level analysis of transcriptomics and metabolomics data with IMPaLA. Bioinformatics, 27, 2917-2918.

11. Hsu, S.-D., Lin, F.-M., Wu, W.-Y., Liang, C., Huang, W.-C., Chan, W.-L., Tsai, W.-T., Chen, C.-Z., Lee, C.-J., Chiu, C.-M., Chien, C.-H. Wu, M.C., Huang, C.-Y., Tsou, A.P., and Huang, H.-D. (2011) miRTarBase: a database curates experimentally validated microRNA-target interactions. Nucleic Acids Res., 39, D163-D169.

12. Betel, D., Wilson, M., Gabow, A., Marks, D. S., and Sander, C. (2008) The microRNA.org resource: targets and expression. Nucleic Acids Res., 36, D149-D153.

3. Friedman, R. C., Farh, K. K.-H., Burge, C. B., and Bartel, D. P. (2009) Most mammalian mRNAs are conserved targets of microRNAs. Genome Res., 19, 92-105.

14. van Iersel, M., Kelder, T., Pico, A., Hanspers, K., Coort, S., Conklin, B., and Evelo, C. (2008) Presenting and exploring biological pathways with PathVisio. BMC Bioinformatics, 9,399

15. Tollefsen, K. E., Scholz, S., Cronin, M. T., Edwards, S. W., de Knecht, J., Crofton, K., Garcia-Reyero, N., Hartung, T., Worth, A. and Patlewicz, G. (2014) Applying Adverse Outcome Pathways (AOPs) to support Integrated Approaches to Testing and Assessment (IATA). Regul. Toxicol. Pharm.

16. Vinken, M., Landesmann, B., Goumenou, M., Vinken, S., Shah, I., Jaeschke, H., Willett, C., Whelan, M., and Rogiers, V. (2013) Development of an adverse outcome pathway from drug-mediated bile salt export pump inhibition to cholestatic liver injury. Toxicol. Sci., 136, 97-106. 
VALORISATION

\section{Curriculum Vitae}

LIST OF PUBLICATIONS

DANKWOORD 


\section{Curriculum Vitae}

Wilhelmus Franciscus Petrus Maria Van den Hof was born on

September 21st 1984 in Heerlen, the Netherlands. After finishing secondary school in the disciplines "Nature and Health" and "Nature and Technology" at the Jeanne d'Arc College in Maastricht, he started the bachelor study "Biology and Medical Laboratory Research" in 2001 at Zuyd University of Applied Sciences in Heerlen. He did his internship at Atrium Medical Center in Heerlen where he investigated the analytical interference of lipemia on

the analysis of patient samples. He obtained his Bachelor of Applied Sciences degree in 2006, after which he worked for 1 year as a laboratory technician at the Clinical Chemistry department at the Maastricht University Medical Center.

He continued his education in 2007, when he started with a Master's program in Biomedical Sciences with a specialization in Clinical Molecular Sciences at Maastricht University. He did his internship at the Clinical Chemistry department at the Maastricht University Medica Center, where he investigated the degradation of cardiac troponin and the influence on test harmonization. During his master he obtained licenses for working with radioactive materials (Radiation hygiene, expert level 5 b) and laboratory animals (according to art. 9 of the Dutch law on experimental animals).

In October 2009 he started as a PhD candidate at the department of Health Risk Analysis and Toxicology at Maastricht University, now the department of Toxicogenomics. Under supervision of Prof. Dr.J. Kleinjans, Dr. W. Wodzig and Dr. J. van Delft he performed the research presented in this thesis entitled: "In vitro toxicogenomics, unravelling the mechanisms underlying druginduced hepatotoxicity". From May 2014 onwards he has been working on the project "Systems toxicology supported data infrastructure for human risk assessment" at the department of Toxicogenomics at Maastricht University. This project will continue the development of the 'ASAT Knowledge Base', which is based upon the 'Assuring Safety without Animal Testing' (ASAT) principle, in which human disease data is integrated with data from non-animal in vitro models. 
VALORISATION

CURRICULUM VITAE

LIST OF PUBLICATIONS

DANKWOORD 


\section{List of publications}

Full Papers

Van den Hof, W.F.P.M., Coonen, M.L.J., van Herwijnen, M., Brauers, K., Wodzig, W.K.W.H., van Delft, J.H.M., Kleinjans, J.C.S. (2014) Classification of Hepatotoxicants Using HepG2 Cells: A Proof of Principle Study. Chem. Res. Toxicol., 27, 433-442.

Van den Hof, W.F.P.M., Van Summeren, A., Lommen, A., Coonen, M.L.J., Brauers, K., van Herwijnen, M., Wodzig, W.K.W.H., Kleinjans, J.C.S. (2014) Integrative cross-omics analysis in primary mouse hepatocytes unravels mechanisms of cyclosporin A-induced hepatotoxicity. Toxicology, 324, 18-26.

Van den Hof, W.F.P.M., Ruiz-Aracama, A., Van Summeren, A., Jennen, D.G.J., Gaj, S., Coonen, M.L.J., Brauers, K., Wodzig, W.K.W.H., van Delft, J.H.M., Kleinjans, J.C.S. Integrating multiple omics to unravel mechanisms of Cyclosporin A induced hepatotoxicity in vitro. Under review.

Van den Hof, W.F.P.M., Coonen, M.L.J., van Herwijnen, M., Brauers, K., Wodzig, W.K.W.H., Olde Damink, S.W.M., Schaap, F.G., Kleinjans, J.C.S. Validation of gene expression profiles from cholestatic hepatotoxicants in vitro against human in vivo cholestasis. In preparation.

Van den Hof, W.F.P.M., Coonen, M.L.J., Van Summeren, A., van Herwijnen, M, Brauers, K., Wodzig, W.K.W.H., Kleinjans, J.C.S. MicroRNA Involvement in Drug-Induced Hepatotoxicity: A multi-omics approach. In preparation.

\section{Abstracts}

Van den Hof, W.F.P.M., Coonen, M.L.J., van Herwijnen, M., Brauers, K., Wodzig, W.K.W.H., van Delft, J.H.M., Kleinjans, J.C.S. Classification of Hepatotoxicants Using HepG2 Cells: A Proof of Principle. Poster presentation at the GROW Science Day, November 2013, Maastricht, the Netherlands.

Van den Hof, W.F.P.M., Ruiz-Aracama, A., Van Summeren, A., Jennen, D.G.J., Gaj, S., Coonen, M.L.J, Brauers, K., Wodzig, W.K.W.H., van Delft, J.H.M., Kleinjans, J.C.S. A systems biology approach to unravel mechanisms of Cyclosporine A induced hepatotoxicity. Poster presentation at the Systems Toxicology Conference, April 2013, Ascona, Switzerland.

Van den Hof, W.F.P.M., Ruiz-Aracama, A., Van Summeren, A., Jennen, D.G.J., Gaj, S., Coonen, M.L.J., Brauers, K., Wodzig, W.K.W.H., van Delft, J.H.M., Kleinjans, J.C.S. Integrating multiple omics to unravel mechanisms of cyclosporine A induced hepatotoxicity. Oral presentation at the Annual meeting of the Netherlands Toxicogenomics Centre (NTC), January 2013 Amsterdam, The Netherlands. 
Van den Hof, W.F.P.M., Ruiz-Aracama, A., Van Summeren, A., Jennen, D.G.J., Gaj, S., Coonen, M.L.J., Brauers, K., Wodzig, W.K.W.H., van Delft, J.H.M., Kleinjans, J.C.S. A systems biology approach to unravel mechanisms of Cyclosporine A induced hepatotoxicity. Poster presentation at the First Joint German-Dutch Meeting of the Societies of Toxicology, October 2012, Düsseldorf, Germany

Van den Hof, W.F.P.M., Ruiz-Aracama, A., Van Summeren, A., Jennen, D.G.J., Gaj, S., Coonen, M.L.J, Brauers, K., Wodzig, W.K.W.H., van Delft, J.H.M., Kleinjans, J.C.S. A systems biology approach to unravel mechanisms of Cyclosporine A induced hepatotoxicity. Poster presentation at the 51st SOT Annual Meeting, March 2012, San Fransisco, USA.

Van den Hof, W.F.P.M., van Delft, J.H.M., Wodzig, W.K.W.H., Kleinjans, J.C.S. A metabolomic approach to predictive liver toxicology. Poster presentation at the Annual Meeting of the Dutch Society of Toxicology, May 2011, Zeist, the Netherlands.

Van den Hof, W.F.P.M., van Delft, J.H.M., Wodzig, W.K.W.H., Kleinjans, J.C.S. A metabolomic approach to predictive liver toxicology. Poster presentation at the $6^{\text {th }}$ Metabolomics Society Conference, June 2010, Amsterdam, the Netherlands.

\section{Achievements}

Travel grant awarded by the Netherlands Society of Toxicology for attending the $51^{\text {st }}$ SOT Annual Meeting, March 2012, San Fransisco, USA. 
VALORISATION

CURRICULUM VITAE

LIST OF PUBLICATIONS

DANKWOORD 


\section{Dankwoord}

Hier zit ik dan, 12 uur op een doordeweekse avond, is het dan waar? Is dit de laatste keer dat ik's nachts aan mijn thesis zal schrijven? Het is een eeuwenoud gezegde, maar het klopt, de laatste loodjes wegen het zwaarst. Maar nu ik begin aan mijn laatste hoofdstuk, zie ik waa ik het allemaal voor gedaan heb en ligt er gewoon een mooi boekje voor me. Natuurlijk is niet al het werk dat beschreven staat in dit boekje door mij alleen gedaan en het lijkt me dan ook vanzelfsprekend dat ik een heleboel mensen ga bedanken. 
het kweken van de primaire muis hepatocyten. Hierbij ook dank aan Karen Mathijs en Daneida voor hun advies en hulp bij de perfusies en celkweek.

Allereerst wil ik graag mijn promotor, Jos Kleinjans, bedanken. Jos, de eerste jaren van mijn promotieonderzoek hebben we slechts sporadisch overleg gehad, maar dat hebben we in de laatste maanden flink ingehaald, zeker na het vertrek van 1 van mijn copromotors. lk bewonder de manier waarop je telkens weer tijd creëerde voor het beoordelen van mijn manuscripten ondanks je drukke schema. Mede dankzij jouw doelgerichte aanpak in de laatste maanden van mijn contract is het proefschrift nu afgerond en zal ik nog in 2014 promoveren, hier ben ik je dan ook erg dankbaar voor.

Ten tweede wil ik mijn copromotor Will Wodzig bedanken. Will, ondanks het feit dat mijn project al vlak na het begin meer de richting van transcriptomics op ging in plaats van proteomics, heb je me vanuit de afdeling Klinische Chemie gedurende mijn gehele traject voorzien van waardevol advies. Ook in de toekomst hoop ik nog van je advies gebruik te kunnen maken, aangezien de klinische chemie mij blijft interesseren.

Hoewel hij officieel geen lid meer is van mijn promotieteam, wil ik ook graag Joost van Delft op deze plek bedanken. Joost, je hebt inmiddels gekozen voor een carrière buiten het onderzoek, maar zonder jouw begeleiding was dit proefschrift niet tot stand gekomen. Bedankt voor jouw kritische blik op de resultaten en ideeën voor nieuwe experimenten en analyses.

Vervolgens wil ik ook graag de beoordelingscommissie, bestaande uit voorzitter Prof. dr. E.C.M. Mariman en de leden Prof. dr. G.T.J. van der Horst, Prof. dr. H. van Loveren, Dr. S.W.M. Olde Damink en Prof. dr. B. van de Water, bedanken voor de evaluatie van mijn proefschrift en hun bereidheid om zitting te nemen in de corona bij mijn verdediging.

Buiten mijn promotieteam moet ik ook zeker al mijn collega's van GRAT en TCX bedanken. Alle collega's die de afgelopen jaren gekomen en gegaan zijn en die hebben bijgedragen aan een prettige werksfeer, heel erg bedankt. Zonder iemand tekort te doen, wil ik toch een aantal personen apart bedanken.

Op de eerste plaats al mijn kamergenoten en aangezien ik al 4 keer van bureau verhuisd ben zijn dat er heel wat. Daniëlle, Astrid, Marten, Kimberly, Marlon, Lize, Jian, Terezinha, Diana, Linda, Peter, Florian en Rachel, bedankt voor de welkome afleiding als dat nodig was en voor advies als ik daar om vroeg. Vooral de hele beschavingen en dierentuinen die ik met Marten en Kimberly opgebouwd heb, waren een prettige afwisseling van de experimenten en data-analyses.

Zonder de hulp van Sandra, Karen en Marcel was de data van de meeste hoofdstukken er nooit geweest. Bedankt voor alle hulp bij het kweken van mijn cellen, FACS analyses en het analyseren van alle microarrays. Marcel wil ik in het bijzonder bedanken voor het uitvoeren van de blootstellingen in de laatste maanden van mijn contract en voor alle gesprekken over hardlopen.

Anke, bedankt voor je gezelschap tijdens de vele reizen naar het noorden voor alle NTC-meetings en vooral voor je hulp bij het aanleren van de leverperfusie in muizen en
Nadat alle experimenten waren uitgevoerd, moest de data uiteraard geanalyseerd worden. Dit was me nooit gelukt zonder de hulp van Maarten, Daniel, Danyel, Stan en Charly. Bedankt voor jullie scripts, excel hulp en advies voor alles wat met de data-analyse te maken heeft. Maarten, jou wil ik in het bijzonder bedanken aangezien jij de meeste analyses voor mij gedaan hebt. De publicatie over de classificatie van toxische stoffen was er zonder jouw hulp niet gekomen.

Naast de wetenschappelijke collega's kan een afdeling uiteraard niet zonde administratieve hulp. René, Rob, Anneloes en Christa, bedankt voor al jullie hulp met de administratieve en financiële vragen tijdens mijn promotieonderzoek. Christa vooral bedankt voor je hulp met alle brieven in de aanloop naar mijn promotie.

Tijdens mijn periode als AIO heb ik deel uitgemaakt van een aantal 'groepen', zo is er de min of meer vaste lunch-groep, de cup-a-soup-groep, de magnum-mini-ijsjesgroep, de ga-je-mee-beneden-koffie-drinken-groep en de TCX-animatie-groep (Team Great eXpectations). Ik wil graag alle leden van deze groepen bedanken voor de fijne meetings. Vooral het maken van de laatste kerstfilm met het animatie team zal ik niet snel vergeten.

Ook de collega's van Toxicologie verderop in onze gang wil ik bedanken voor hun interesse in mijn onderzoek en de fijne gesprekken in de afgelopen jaren. In het bijzonder Roger, Els, Kristien, Hilde en Merel waarmee ik veel leuke momenten beleefd heb tijdens mijn AIO periode. Bij Merel mocht ik zelfs paranimf zijn, waardoor ik al een keer een verdediging van dichtbij heb meegemaakt, wat zeker zal helpen op 19 november.

Mijn promotieonderzoek was onderdeel van het grote NTC project, hierbij wil ik dan ook alle collega's van NTC en in het bijzonder de leden van work package 4 bedanken voor de ideeën en adviezen tijdens de verschillende meetings.

Voor de metabolomics analyses ben ik een aantal keren te gast geweest bij het RIKILT in Wageningen. Arjen, Ainhoa en Gerard, heel erg bedankt voor jullie gastvrijheid en hulp bij het meten van mijn samples.

Ainhoa, thank you very much for all your help, I really enjoyed working with you.

Voor het derde hoofdstuk kon ik gebruik maken van leversamples van patiënten met cholestase van de afdeling Algemene Heelkunde. Frank Schaap en Peter Jansen wil ik graag bedanken voor het gebruik van deze samples en de discussie van de resultaten. 
Anne-Marie, Mieke, Miep, mijn kleine zusje, misschien ben jij wel de voornaamste reden

Hoewel het soms leek alsof er geen wereld was buiten de universiteit, moet ik een hele hoop mensen buiten de academische wereld bedanken. Alle vrienden en familie hebben er voor gezorgd dat ik de afleiding vond die ik af en toe nodig had en hebben er met hun bemoedigende woorden voor gezorgd dat ik mijn promotieonderzoek met succes heb voltooid.

Naast het hardlopen, was voetbal een belangrijke uitlaatklep voor mij. Ik wil dan ook alle leden van SV Sibbe bedanken voor de fijne trainingen en goede sfeer bij de wedstrijden.

Ook ben ik al meer dan 20 jaar lid van de tafeltennisvereniging TTV Sibbe mc en sinds enige jaren ben ik hier ook secretaris. Ik wil graag de rest van het bestuur en alle leden bedanken voor hun interesse in mijn werk en hun begrip voor de beperkte hoeveelheid tijd die ik kon steken in het trainen, wedstrijd spelen en mijn secretariële taken.

Verder wil ik al mijn vrienden bedanken voor alle feestjes, uitstapjes, vakanties, mannenweekendjes, bioscoopavonden, Machiavelli-avonden en dinertjes die ervoor gezorgd hebben dat ik niet helemaal ben doorgedraaid in de afgelopen jaren. Hopelijk zullen we nog veel samen beleven

Ook mijn 'schoonfamilie' wil ik graag bedanken. Opa en Oma Theunisz, Jack, Lucie, Judith, Sjarel, Marc, Marie-Cecile en natuurlijk mijn grote vriendin Lize, bedankt voor jullie interesse in mijn onderzoek, de wekelijkse dinertjes, uitstapjes en tekeningen.

Dan mijn paranimfen, Erik en Rob. Erik, voor mij was het geen moeilijke keuze om jou als paranimf te vragen. Elkaar leren kennen op de HBO opleiding, daarna samen begonnen aan de Masteropleiding en ongeveer gelijk begonnen aan ons promotieonderzoek. Onze dagelijkse koffie-break waarin we even onze frustraties over het onderzoek konden kwijtraken is iets wat ik nu wel mis. Bedankt dat je tijdens mijn verdediging paranimf wi zijn, zodat we het promotie-hoofdstuk ook samen kunnen afsluiten. Ik ben vereerd dat ik een aantal weken later ook jouw paranimf mag zijn.

Rob, Robbie, Rupke, mijn kleine broertje, ik ben blij dat ook jij tijdens mijn verdediging naast me zal staan. Jouw aanwezigheid zal zeker in de laatste momenten voor mijn verdediging voor de nodige ontspanning zorgen. Bedankt voor alle leuke momenten de afgelopen jaren, alle fietstochtjes, hardloop wedstrijden, een gezamenlijke triatlon, optredens van 'Sjtublong' en gezellige avonden, met jou is het altijd lachen. We hebben vee steun gehad aan elkaar tijdens de ziekte van Mieke en ik ben trots op je dat je nu ook na het behalen van je MBO diploma, aan een HBO-opleiding bent begonnen. Ik heb er ook alle vertrouwen in dat je deze succesvol zal afsluiten.

Ook de rest van m'n familie wil ik uiteraard bedanken. Oma Wies, mijn petetantes Dets en Marie-Thérèse, alle ooms en tantes, al mijn neven en nichten, bedankt voor jullie interesse. Roy en Joyce, als jullie schoonbroer wil ik ook jullie bedanken voor jullie interesse in mijn onderzoek en de gezellige momenten. dat dit boekje er gekomen is. Door jouw lange ziekte ben ik geïnteresseerd geraakt in de klinische chemie en in het onderzoek. Ik dacht dat ik uiteindelijk wel een oplossin zou vinden voor jouw hersenvliesontstekingen. Uiteindelijk is mijn onderzoek een hele andere richting opgegaan, maar door jou ben ik er wel aan begonnen. Ik bewonder je voor e doorzettingsvermogen, waardoor je nu na je laatste zware operatie, een afgestudeerd pedagoge bent. Jouw doorzettingsvermogen was een inspiratie voor mij om door te blijven studeren. Ik ben trots op je.

Pieter en Margriet, pap en mam, ik ben dankbaar voor de steun die ik altijd van jullie gekregen heb. We hebben samen al behoorlijk wat meegemaakt en het was zeker niet altijd gemakkelijk, maar zeker ook dankzij jullie ben ik gekomen waar ik nu ben. Mam, jouw kracht bij de overwinning van borstkanker was een inspiratie voor me en pap, jij was altijd de rots in de branding. Ik kan niet beschrijven hoe dankbaar ik ben. Nog een extra dankjewel voor het ontwerp en de lay-out van mijn boekje, het is prachtig geworden.

Esther, moppie, eindelijk, het is af. Mijn promotieonderzoek heeft me niet alleen dit mooie boekje opgeleverd, maar dankzij mijn onderzoek op deze afdeling ben ik ook jou tegen het lijf gelopen. Toen ik begon zat ik in het 'bodemhok' en kwam er een aantal keren per dag een leuk meisje voorbij gelopen. Nu meer dan 4 jaar later, woon ik samen met dat leuke meisje. Het was af en toe niet gemakkelijk om samen te wonen met iemand die bezig was met promoveren. Ik wil je bedanken voor je steun, het aanhoren van alle frustraties en je hulp met het afmaken van mijn boekje. Vanaf nu zal er meer tijd zijn voor ons samen en kunnen we op zoek naar ons huisje, boompje en beestje. Thnx babe! 